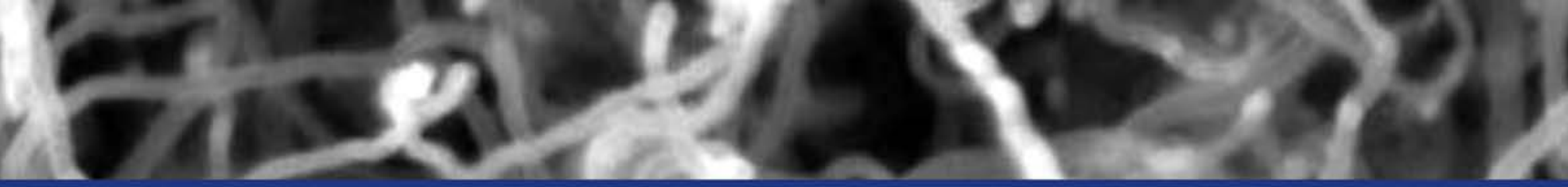

\title{
Hairy Foam: Thin Layers of Carbon nanofibers as Catalyst Support for Liquid Phase Reactions
}

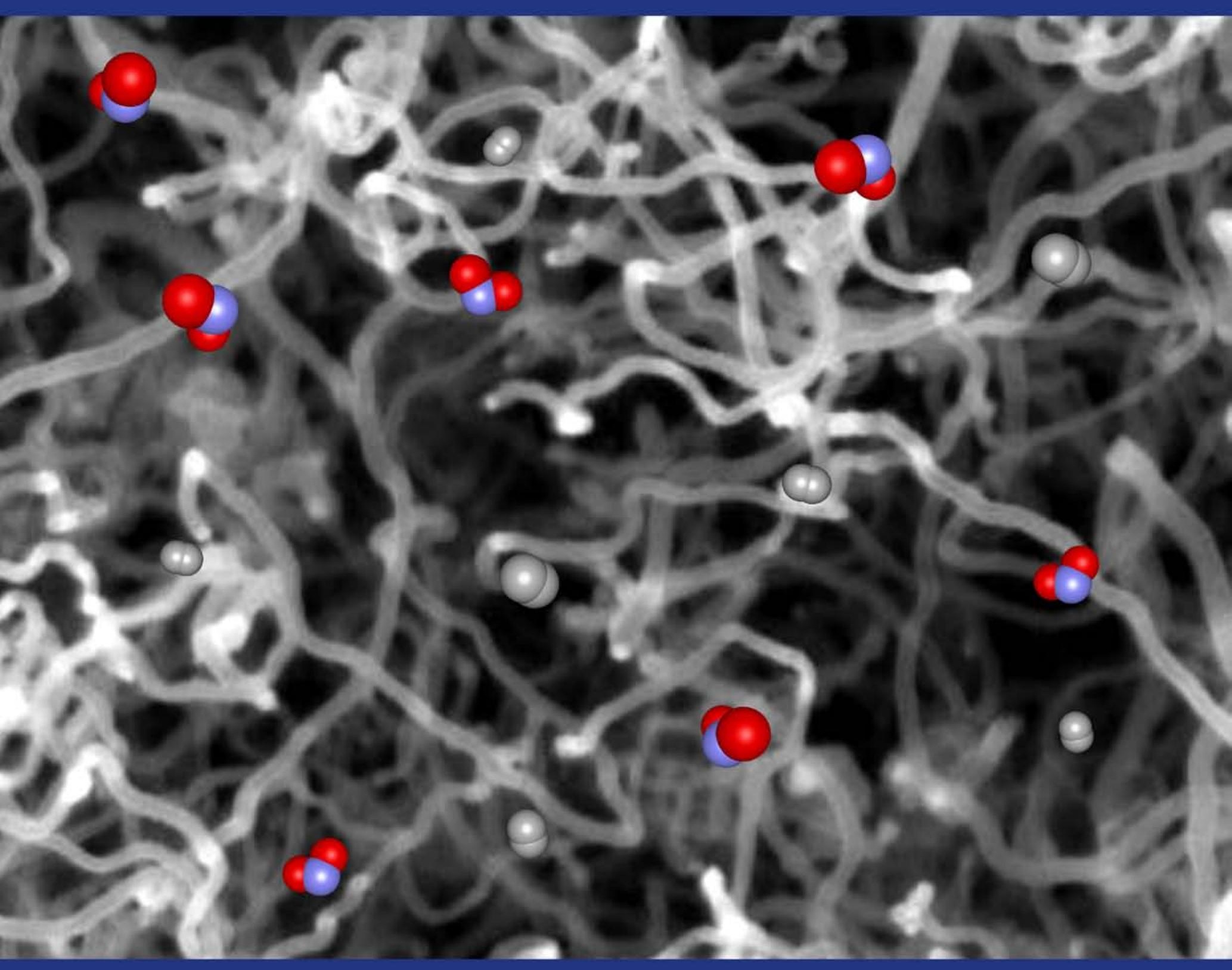

Jitendra Kumar Chinthaginjala 


\section{HAIRY FOAM: THIN LAYERS OF CARBON NANOFIBERS AS CATALYST SUPPORT FOR LIQUID PHASE REACTIONS}

Jitendra Kumar Chinthaginjala 


\section{Promotion committee}

Prof. dr. L. Lefferts, Promoter

Dr. K. Seshan

Prof. dr. M. Wessling

Prof. dr. G. Mul

Prof. dr. F. Kapteijn

Prof. dr. M. Muhler
University of Twente

University of Twente

University of Twente

University of Twente

University of Delft

Ruhr-Universität Bochum

The research described in this thesis was carried out at Catalytic Processes and Materials group at the University of Twente, The Netherlands. This project was financially supported by the Dutch Technology Foundation (STW-project number 06601).

Cover design: Ing. B. Geerdink and J.K. Chinthaginjala, Catalytic Processes and Materials group, University of Twente, Enschede, The Netherlands

Publisher: Gildeprint, Enschede, The Netherlands

ISBN: 978-90-365-3051-4

Copyright (c) 2010 by Jitendra Kumar Chinthaginjala, Enschede, The Netherlands

All rights reserved. 


\title{
HAIRY FOAM: THIN LAYERS OF CARBON NANOFIBERS AS CATALYST SUPPORT FOR LIQUID PHASE REACTIONS
}

\author{
DISSERTATION
}

to obtain

the degree of doctor at the University of Twente, on the authority of the rector magnificus, prof. dr. H. Brinksma, on account of the decision of the graduation committee, to be publicly defended on Friday, 18 June 2010 at 16:45 hrs.

by

Jitendra Kumar Chinthaginjala born on 24 November 1979

in Hyderabad, India 
This dissertation has been approved by,

Promoter: Prof. dr. L. Lefferts 
Ta my parents and Lawanya 



\section{Contents}

1 General Introduction 1

1.1 Introduction 2

1.2 Multiphase reactors 4

1.3 Carbon nanofibers as catalyst support 8

$\begin{array}{lr}1.4 \text { Nitrite hydrogenation } & 12\end{array}$

1.5 Scope and outline of this thesis 13

References 15

2 How carbon nanofibers attach to Ni foam 17

$\begin{array}{lr}2.1 \text { Introduction } & 18\end{array}$

$\begin{array}{ll}2.2 \text { Experimental } & 19\end{array}$

2.3 Results 21

2.4 Discussion $\quad 30$

2.5 Conclusions $\quad 34$

References 35

3 Influence of hydrogen on the formation of a thin layer of carbon 37 nanofibers on $\mathrm{Ni}$ foam

3.1 Introduction 38

3.2 Experimental $\quad 39$

3.3 Results 41

3.4 Discussion 49

3.5 Conclusions 53

References 54

4 Thin layer of carbon nanofibers as catalyst support for fast mass 57 transfer in hydrogenation of nitrite

4.1 Introduction $\quad 58$

4.2 Experimental $\quad 61$

4.3 Results 64

$\begin{array}{ll}4.4 \text { Discussion } & 71\end{array}$

$\begin{array}{ll}4.5 \text { Conclusions } & 78\end{array}$

References $\quad 81$

5 Support effect on selectivity of nitrite reduction in water 83

5.1 Introduction 84

5.2 Experimental $\quad 85$

$\begin{array}{ll}5.3 \text { Results } & 87\end{array}$

$\begin{array}{ll}5.4 \text { Discussion } & 91\end{array}$

5.5 Conclusions $\quad 95$

$\begin{array}{ll}\text { References } & 97\end{array}$ 
6 Nitrite reduction over Pd supported carbon nanofibers: particle size 99 effect

$\begin{array}{ll}6.1 \text { Introduction } & 100\end{array}$

6.2 Experimental 101

$\begin{array}{ll}6.3 \text { Results } & 103\end{array}$

$\begin{array}{lr}6.4 \text { Discussion } & 106\end{array}$

6.5 Conclusions 109

$\begin{array}{ll}\text { References } & 110\end{array}$

7 Rhodium catalyzed growth of carbon nanofibers 111

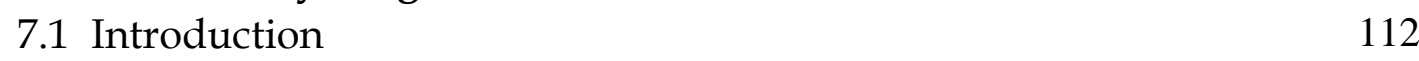

$\begin{array}{ll}7.2 \text { Experimental } & 113\end{array}$

$\begin{array}{ll}7.3 \text { Results } & 114\end{array}$

$\begin{array}{ll}7.4 \text { Discussion } & 121\end{array}$

$\begin{array}{ll}7.5 \text { Conclusions } & 124\end{array}$

$\begin{array}{ll}\text { References } & 125\end{array}$

8 Conclusions and Recommendations $\quad 127$

$\begin{array}{ll}\text { 8.1 Preparation of stable CNF layer on Ni foam } & 128\end{array}$

$\begin{array}{ll}8.2 \text { Application of CNFs as catalyst support } & 130\end{array}$

References 133

$\begin{array}{ll}\text { Summary } & 135\end{array}$

$\begin{array}{lr}\text { Samenvatting } & 139\end{array}$

$\begin{array}{ll}\text { Publications } & 143\end{array}$

$\begin{array}{ll}\text { Acknowledgements } & 145\end{array}$

$\begin{array}{lr}\text { Biography } & 149\end{array}$ 


\section{Chapter 1}

General Introduction 


\subsection{Introduction}

A three phase catalytic reactor is a system in which gas and liquid phases are contacted with a solid catalyst. The application of these reactors is of increasing importance in petrochemical, bulk and fine chemical industries as a multiphase catalytic reactor is the heart of many processes. Some of the important commercial applications of multiphase reactor technology are in the field of (1) upgrading and conversion of petroleum feed stocks and intermediates; (2) conversion of coal-derived chemicals or synthesis gas into fuels, hydrocarbons, and oxygenates; manufacturing of bulk commodity chemicals that serve as monomers and other basic building blocks for higher chemicals and polymers; (4) manufacturing of pharmaceuticals or chemicals that are used in fine and specialty chemical markets as drugs or pharmaceuticals; and (5) conversion of undesired chemical or petroleum processing by-products into environmentally acceptable or recyclable products $[1,2]$.

The reactants are often present in gas and liquid phase which are brought in contact over a metal deposited on an inert solid support to achieve the desired conversion. The rate of chemical reaction depends on parameters such as hydrodynamics (influencing the mass and heat transfer) and catalytic activity. Higher catalyst concentrations would provide maximum yield. This is typically achieved by developing catalytic sites having high intrinsic activities and by maximizing the number of active sites, e.g., by using high surface area support materials. In practice, the higher reaction rates can be taken advantage of only under the condition that transfer of mass (reactant and products) and heat can keep up with the intrinsic activity of the catalysts used. Often in industrial catalytic reactions, mass transfer limitations occur when dissolved gaseous compounds have to react because firstly, the solubility of these gases is limited and secondly, the diffusion coefficients in liquid phase is lower than that in gas phase by a factor of $10^{4}$ [3]. In case mass transfer is relatively slow, concentration gradients will occur, especially in the pore system of a heterogeneous catalyst. 
Due to the heterogeneous nature of three phase system, a number of transfer steps have to occur before a reactant can be converted to product. A typical scheme of such system is depicted in figure 1.1. The major steps are (a) mass transfer from gas

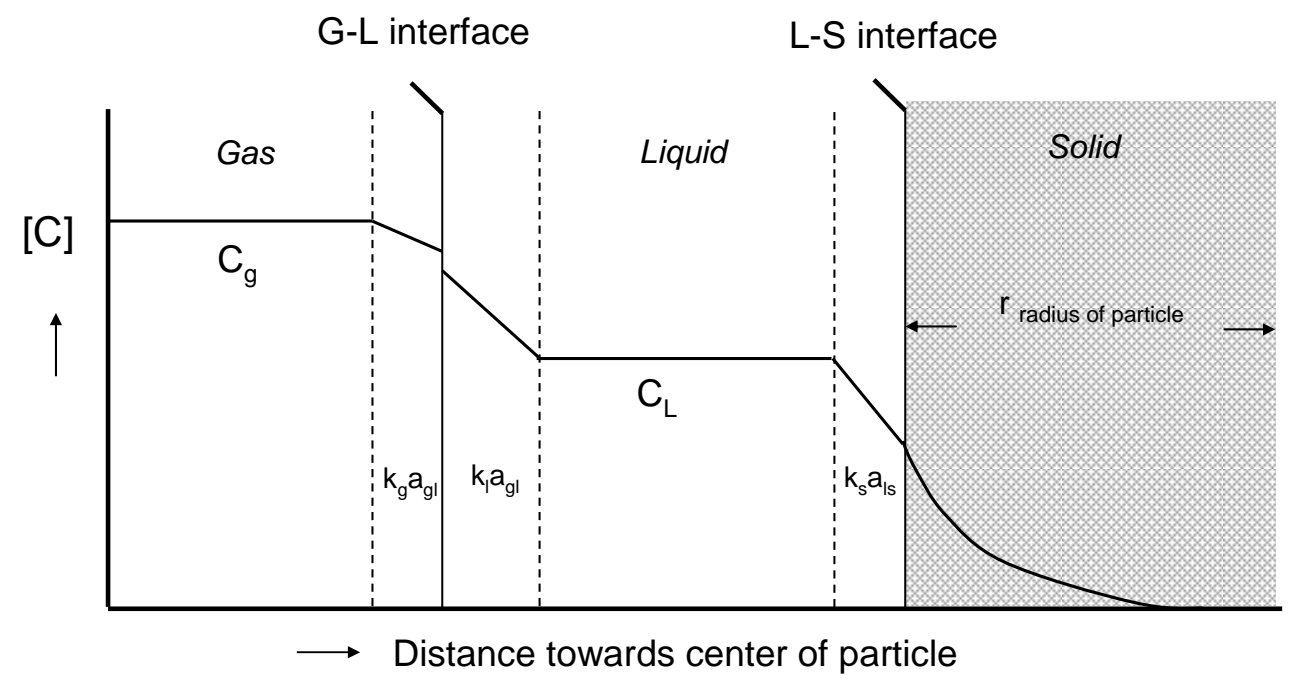

Figure 1.1 - Concentration profile for a gas liquid solid reaction.

to liquid, (b) mass transfer from bulk liquid to the catalyst surface, and (c) intraparticle diffusion within the pores of the catalyst accompanied by chemical reaction. Similarly, the products of the reaction must diffuse out of the catalyst particle into the bulk of the liquid. The overall rate of the reaction in three-phase reactors is often limited by the above factors $[1,4,5]$.

As indicated in figure 1.1, when reaction occurs simultaneously with mass transfer within a porous catalyst structure, a concentration gradient is established and interior surfaces of a catalyst particle are exposed to lower reactant concentrations than the external surface of the catalyst. The average reaction rate throughout the catalyst particle under isothermal conditions is usually lower as compared to the situation without any mass transfer limitations. This would ultimately affect activity, thereby disturbing the operation conditions in the catalytic reactor. The selectivity can also be affected due to the concentration gradients of the reactants developed along the catalyst particle. This is especially relevant in consecutive reactions, where fast diffusion of the product from the catalyst particle is necessary to avoid further conversion into undesired products.

The maximum thickness of the catalyst layer without introducing internal mass transfer limitations (pore diffusion limited) can be estimated by using the Thiele modulus, $\varphi$ (equation 1). At negligible internal mass transfer limitations, the Thiele 
modulus approaches to zero. This can be achieved via shortening the diffusion path (R) i.e. by using small catalyst particles, and increasing the porosity of the particle $(\varepsilon)$ resulting in decrease in tortuosity $(\tau)$. However, controlling these parameters of catalyst particle is rather a challenge [4-6].

The Effect of the degree of diffusion limitation in the catalyst particles on the reaction rate can be expressed as the effectiveness factor, $\eta$, defined as the ratio of the observed reaction rate and the rate in case of complete absence of any pore diffusion limitation.

$$
\varphi=R * \sqrt{\left[\left(k^{*} S_{a}^{*} \rho_{p} / D_{\text {eff }}\right)\right]}
$$

$R$ : thickness of diffusion path, $k$ : rate constant, $S_{a}$ : surface area of metal per gram of support, $\rho_{p}$ : density of the support, $\mathrm{D}_{\text {eff: }}$ effective diffusivity

\subsection{Multiphase reactors}

\subsubsection{Conventional multiphase reactors}

Different types of reactors have been used for three-phase reaction applications. Most frequently used are the stirred tank slurry reactor, the slurry bubble column reactor, and the packed-bed reactor. The choice of use of a certain reactor type is governed by its advantages and drawbacks which are briefly described below:

\subsubsection{Slurry phase reactor}

In slurry phase reactors, very small catalyst particles (typically $30 \mu \mathrm{m}$ ) are used which are suspended in liquid medium through which gas is dispersed. These small catalyst particles provide high external surface area, higher rates of liquid to solid mass transfer as well as fast intraparticle diffusion, thanks to the very short diffusion paths, leading to a more efficient utilization of catalyst particle. Thus, this reactor is widely used in oxidation and hydrogenation reactions because oxygen and hydrogen are usually diffusion limited reactants. However, there are some drawbacks of slurry reactors. The catalyst loading (amount per unit volume of the reactor) is relatively low in slurry systems. Thus, the rate of reaction per unit volume of the reactor is lower, 
while the rate per unit weight of the catalyst is likely to be higher. Separation of the catalysts poses difficulties in either batch or continuous operation of slurry reactors. Filtration of these very small catalyst particles is relatively expensive and sensitive to process disturbance. Moreover, attrition of catalyst particles may cause loss of active metal phase. Nevertheless, even slurry catalysts suffer from mass transfer limitations in the case of very active catalysts $[1,7,8]$.

\subsubsection{Fixed/trickle bed reactor}

A trickle bed reactor is a fixed bed with catalyst pellets in which gas and liquid flow along the bed either cocurrent or counter current. The catalyst particles used are relatively large $(1-10 \mathrm{~mm})$. Particle size can be reduced only to a limited extent because this would result in increased pressure drop over the reactor. Catalyst loadings can be much higher, while obviously no filtration step is required. The liquid flow patterns approach the plug flow behavior, hence fixed bed reactors are preferred to slurry reactors when high conversions are desired. They also offer higher rate of reaction per unit volume of reactor. However, the large catalyst particles lead to longer diffusion paths, easily causing intraparticle diffusion limitation. Additionally, development of liquid misdistribution and possible occurance of hotspots can hamper the conversion and selectivity $[1,8]$.
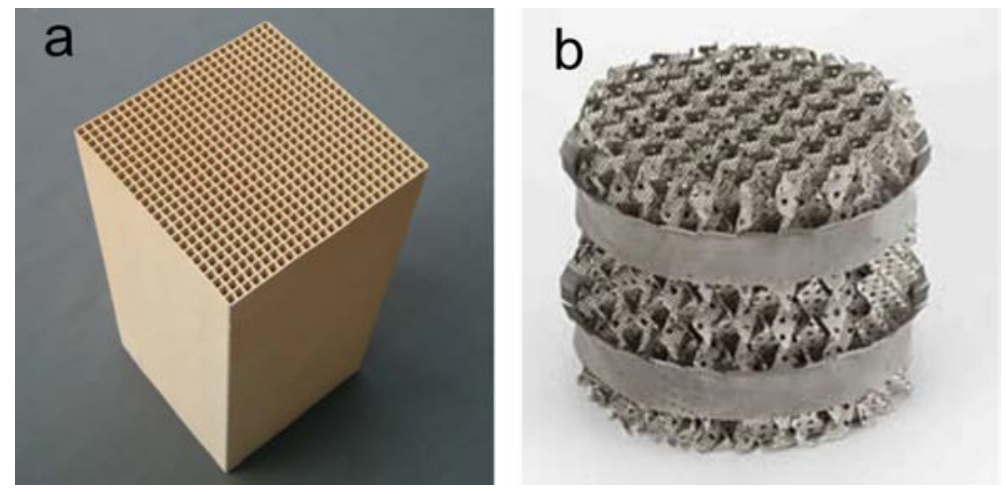

Figure 1.2 - Commercially available structured packing materials; a) monolith, b) Mellapak (Sulzer Chemtech). 


\subsubsection{Structured internals for multiphase reactors}

A structured reactor contains a structured internal which can be made out of ceramics, metals or carbon, situated inside a reactor. It can be considered as an intensified form of a randomly packed bed reactor. Structured packings have the advantage that they are made to fit the dimensions of the column in which they are placed and the exact shape and size of all column internals is determined by design rather than chance. This would avoid any liquid mal-distribution and channelling/bypassing of the solids.

The commercially available structured packings are monoliths, mellapak and katapak-s, illustrated in figure 1.2. In monoliths, the liquid and gas flow in channels created within the structured packing, whereas, in Mellapak the liquid and gas flow down corrugated sheets of gauze stacked to form open channels between these sheets. Katapak is similar to open channels Mellapak except that the channels are filled with spherical particles. These packing materials however have commonly a twodimensional structure that redirect the liquid and gas flow to planar directions. In the development of these packings the aim is to increase the rather low geometrical surface area, while maintaining a low pressure drop (high voidage) and adequate contact between the flowing phases. However, as with conventional dumped packing, the geometric surface area of these packings is difficult to increase without increasing the solids holdup. Recently, solid foam is under study as structured packings, as it maintains a high geometric surface area with low solids holdup (and hence low pressure drop) due to its cell-like structure [9].

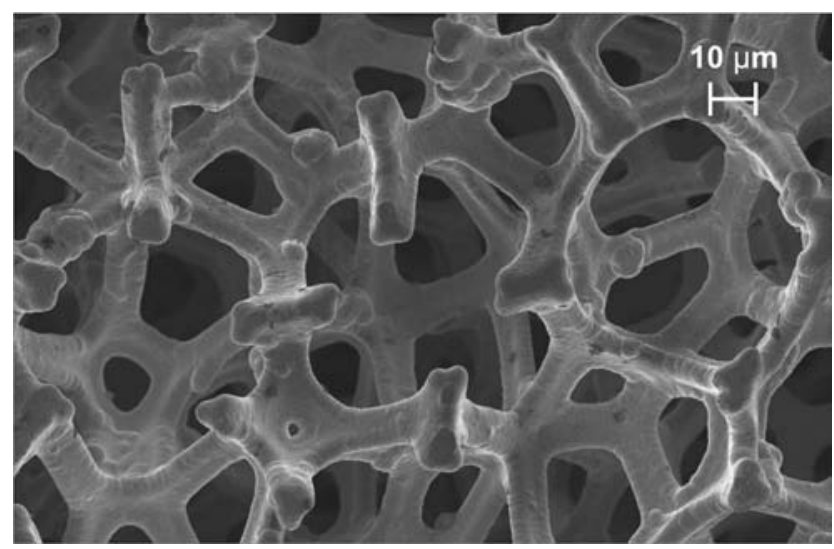

Figure 1.3 - Scanning electron micrograph of Ni foam (Recemat). 
Solid foams are highly porous materials with porosity ranging from 80-97\% (figure 1.3), which are available in a wide range of materials such as ceramics, metals, carbon and siliconcarbide. Solid foam packings have a typical specific surface area which is comparable to monoliths, but with higher voidage. Compared to conventional packed beds of spherical particles, foam packings offer higher geometric surface area [10] and lower pressure drop [9-11] per unit height. Stemmet et al. [9] have showed that solid foam packing can improve gas-liquid mass transfer coefficients and optimize hydrodynamics.

However, the geometric surface area of the structured internals (foams, monoliths etc.) is not sufficient to host catalytically active metal particles as they do not have micro pores. Therefore it is necessary to generate additional surface area. This can be achieved by depositing thin washcoat layers with high surface areas. Additionally, this thin layer should also have high pore volume to enhance internal mass transfer rate which is particularly important for heterogeneous catalytic reactions in liquid phase. Moreover, the thin layer should be mechanically stable and resistant to adverse conditions such as high pressure and temperature. Usually, these thin washcoat layers can be made by depositing an oxide layer (alumina, silica, etc) with the similar texture and porosity as compared to traditional catalyst support particles. Several authors have already shown that high surface area $\gamma$-alumina washcoats can be achieved especially on foams [11, 12-14]. These washcoat layers can be adjusted to different parameters such as, thickness of layer which governs the diffusion lengths and porosity of the layer. Such a structured reactor would effectively allow the advantage of a slurry phase operation offering short diffusion path and a fixed bed operation avoiding catalyst separation and attrition. This would allow independent optimization of intrinsic reaction kinetics, transport phenomena and hydrodynamics [15]. However, the porous washcoat layers generally suffer from relatively low pore volume $(<0.6 \mathrm{ml} / \mathrm{g})$ and high tortuosity, hampering internal mass transfer. This understanding urges the use of alternative thin layers such as entangled carbon nanofibers (CNFs) as catalyst support to satisfy the demands (high pore volume, high surface area and low tortuosity) for effective internal mass transfer. 


\subsection{Carbon nanofibers as catalyst support}

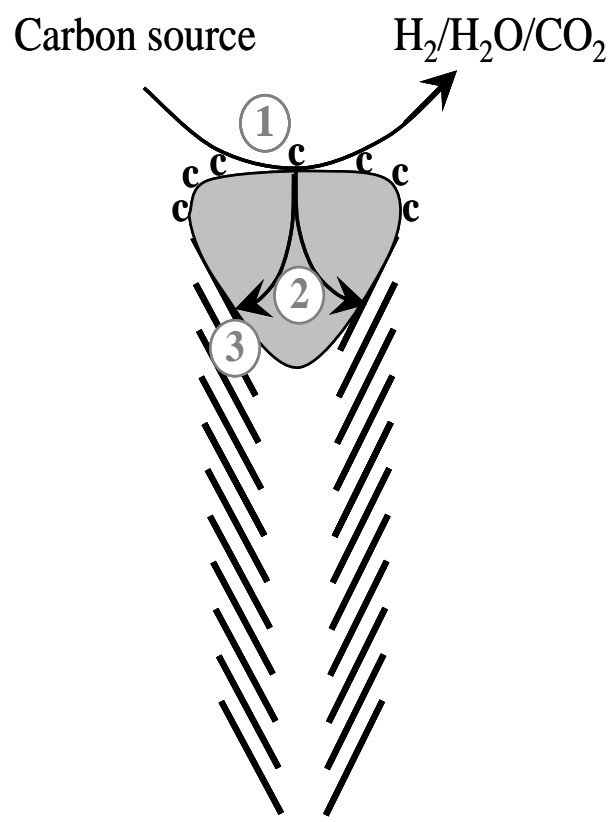

Figure 1.4 - Schematic representation of the catalytic growth of a CNF using a carbon-containing gas. Step 1, decomposition of carbon-containing gases on the metal surface. Step 2, carbon atoms dissolve in and diffuse through the bulk of the metal. Step 3, precipitation of carbon in the form of a CNF consisting of graphite [16].

Carbon filaments are formed catalytically in supported metal catalysts, particularly in $\mathrm{Ni}$, Fe, and Co containing catalysts, used for the conversion of carbon-containing gases, e.g., in steam reforming of hydrocarbons and Fischer-Tropsch synthesis [16]. In these cases, the carbon filament formation was detrimental for operation as they plugged reactors, deactivated catalysts and can even damage catalysts and reactors mechanically. This problem was turned into an opportunity in the early work of Robertson [17] and Baker et al. [18], showing that CNF materials could be prepared on demand from supported $\mathrm{Ni}$, Co, or Fe catalysts and this triggered an outburst of interest in the synthesis of carbon nanostructures. Current research on CNFs is focused on application of these structures as catalyst supports [16], polymer additives [19], electronics [20], fuel cell [16] and gas storage [16]. Carbon nanofibers can be produced by using arc discharge, laser ablation or catalytic carbon deposition. CNFs can be made in high yields at relatively low cost using the latter method.

Typically CNF formation occurs in the temperature range $425-925{ }^{\circ} \mathrm{C}$; the reactivity of the carbon source gas (typically methane, carbon monoxide, synthesis 
gas, ethylene and ethane) has a strong influence on the preferred temperature. Mechanisms proposed by various researchers for the formation of CNF agree, in general, on the sequence of the CNF formation [18, 21-23]. This involves (1) decomposition of the carbon-containing gas on the exposed surface of metal particle, (2) dissolution of carbon in the metal particle, and diffusion of the dissolved carbon through the particle and (3) precipitation/growth of CNFs at the other end of the particle. This is schematically shown in figure 1.4. Nevertheless, there have also been suggestions that only surface diffusion is involved. Further, there is still debate about the driving force for the carbon to dissolve on the one side of the metal particle and to segregate at the other side. Baker et al. [18] have proposed that a temperature gradient over the metal particle accounts for this. The temperature gradient is proposed to be caused by the differences in the thermochemistry of the hydrocarbon decomposition versus the formation of CNF, suggesting that precipitation of excess carbon will occur at the colder zone of the particle resulting in the formation of a carbon nanofiber. Hoogenraad et al. [23] postulated a specific mechanism to explain the initiation of CNF formation; diffusion of carbon into the metal particle leads to formation of metal carbide, which then decomposes to regenerate metal and precipitate graphite enveloping the metal particle. The metal particle is squeezed out of graphitic carbon due to pressure buildup during the formation of graphite layers.

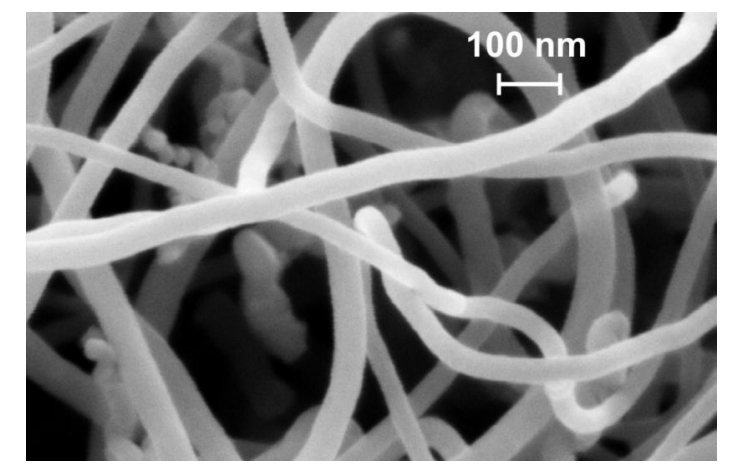

Figure 1.5 - Scanning electron micrograph of porous carbon nanofiber matrix grown on a $\mathrm{Ni}$ foam at $440^{\circ} \mathrm{C}$ using ethylene as a carbon source [26].

CNFs have a number of other characteristics that make them promising materials as catalyst supports. They are mechanically strong, chemically inert and the surface chemistry can be modified [16, 24]. Aggregates and thin layers of CNFs are potential catalyst supports because they exhibit (i) high surface area (100-200 m²/g), 
(ii) large pore volume $\left(0.5-2 \mathrm{~cm}^{3} / \mathrm{g}\right)$, and (iii) minimal or no microporosity [16, 22, 24]. The surface area depends on the diameter of carbon nanofiber formed and the pore volume depends on the entanglement/morphology of the fibers [25]. Figure 1.5 shows a typical example of a CNF matrix as observed using scanning electron microscopy (SEM), demonstrating the open structure of the aggregate. Schouten et al. suggested that the structure of CNF aggregates, as shown in figure 1.6, mimics the inverse structure of a conventional porous support material. The advantages in terms of porosity and tortuosity for the CNF aggregates can be easily recognized, which can prevent any mass transfer limitations inside the aggregates [26].

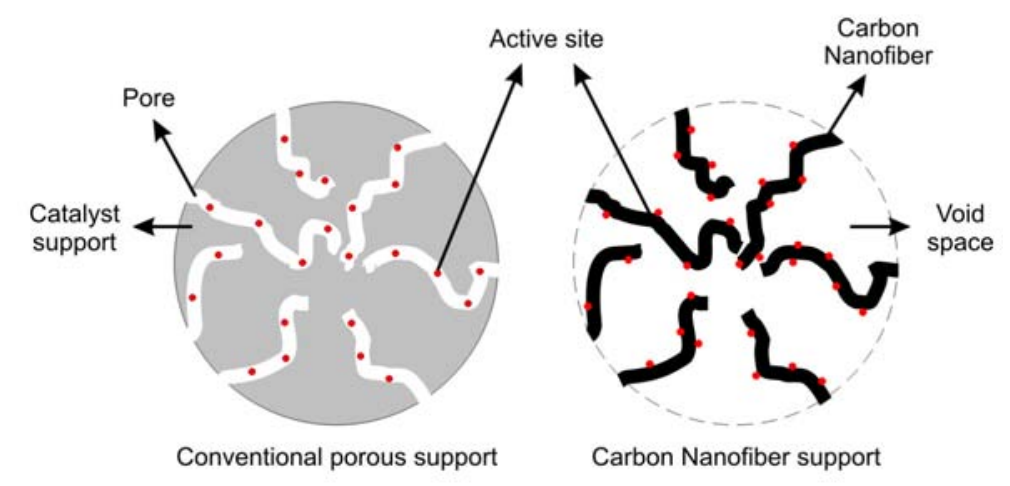

Figure 1.6 - CNFs mimicking the inverse structure of conventional porous structured material [26].

In addition, application of small CNF aggregates would suffer from agglomeration of the aggregates in the filtration unit. In trickle bed reactors, application of small CNF aggregates would result in high pressure drop. One way to overcome these difficulties is to anchor/immobilize the fibers on a structured material, especially foam. A thin layer of CNFs on foam is an interesting proposition as the combination of solid foam and fiber resembles the inverse structure of a packed bed with porous particles (figure 1.7) [26]. It can also be assumed that in the case of layers with extremely high porosity, convection flow through the porous CNF layer can occur, inducing shear forces directly on the active sites, further improving internal mass transfer (figure 1.8) [27].

Various authors have reported on immobilization of CNFs on foams [27-32], CNFs have also been immobilized on numerous other supports such as monoliths [33, 34], metal filters [35], glass fibers [36], carbon cloth [28] and activated carbon fiber 


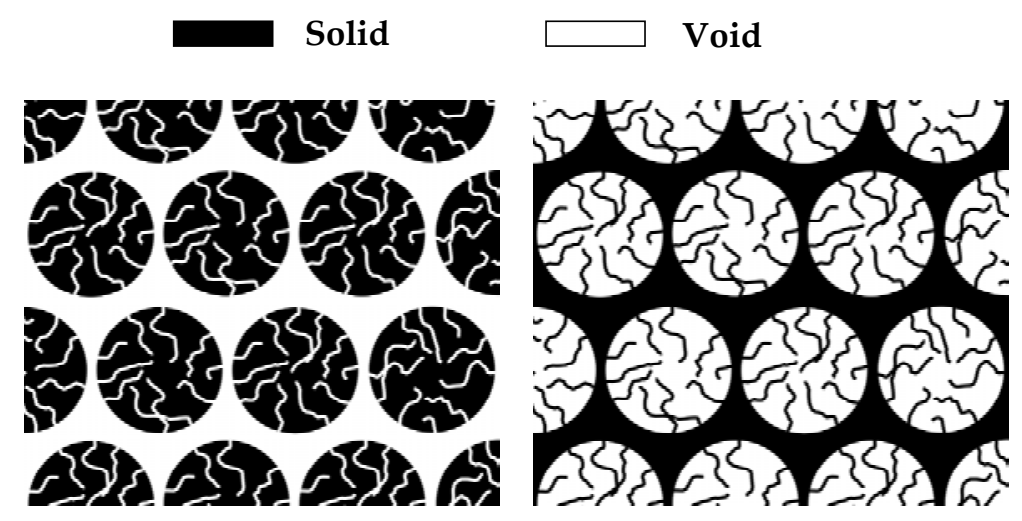

Figure 1.7 - Inverse of a porous packed bed into solid foam with a layer of CNFs [24].

[37]. Critical issues are the control of the length and diameter of the fibers and their attachment to the macroscopic support. Especially, the anchoring of the fibers is crucial for applications. It is speculated that stability to CNFs is provided due to penetration of CNFs into Ni foam/ carbon felt surface [38-40]. In this thesis, Ni foams were used as they are intrinsically active for the CNF growth. Jarrah et al. [30, 41] have carefully optimized the growth on $\mathrm{Ni}$ foam by understanding the effect of pretreatment and temperature on the CNF formation. However, the attachment of CNFs to the support is not yet clearly understood.

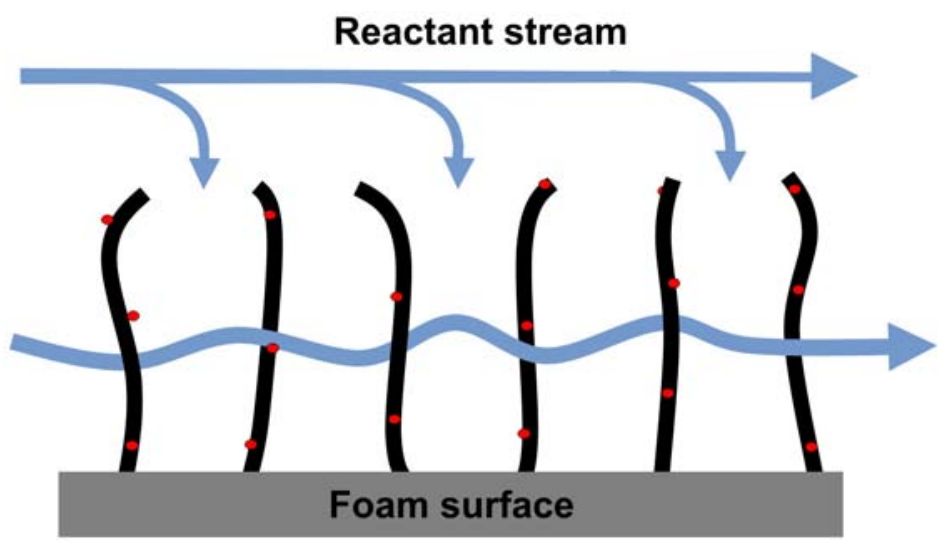

Figure 1.8 - Schematic representation of reactant stream flowing along and through the CNF layer 


\subsection{Nitrite hydrogenation}

Concentrations of harmful nitrogen-containing compounds, such as nitrate, nitrite and ammonia, have increased in the ground waters throughout the world [42]. Sources of these compounds can be attributed to fertilizers, industrial effluents and animal excretion. Although nitrate ions $\left(\mathrm{NO}_{3}{ }^{-}\right)$are not directly toxic, they are transformed to harmful nitrite ions $\left(\mathrm{NO}_{2}{ }^{-}\right)$via reduction processes in the human body. It has been reported that $\mathrm{NO}_{2}^{-}$causes blue baby syndrome, and is a precursor to the carcinogenic nitroso amine as well as to hypertension [42-44]. For these reasons, the European Community limit values for nitrate, nitrite and ammonium concentrations in drinking water are, respectively, 50, 0.5 and $0.5 \mathrm{mg} / \mathrm{L}$. However, for the discharge of wastewater the limits are 50 and $10 \mathrm{mg} / \mathrm{L}$ for nitrate and ammonium concentrations, respectively. Conventional physicochemical techniques such as ion exchange, reverse osmosis and electrodialysis allow effective removal of ions concentrating them, but do not generally convert the ions, whereas, environmentally benign method like biological process is slow and complex [44].

Catalytic de-nitrification of nitrates and nitrites from aqueous solution via hydrogenation over noble-metal solid catalysts is a promising method without the drawbacks of conventional methods. This process was first reported by Vorlop and Tacke [45]. It was reported that over a bimetallic catalyst, nitrate first reduces to nitrite, which in turn is converted to nitrogen and ammonia as a by-product, which is obviously undesired in drinking water. Thus, selectivity to $\mathrm{N}_{2}$ is of paramount importance. The reaction scheme is given below [46]:

$$
\begin{array}{lll}
2 \mathrm{NO}_{3}^{-}+2 \mathrm{H}_{2} & \stackrel{\mathrm{Pd}-\mathrm{Cu}}{\longrightarrow} 2 \mathrm{NO}_{2}^{-}+2 \mathrm{H}_{2} \mathrm{O} \\
2 \mathrm{NO}_{2}^{-}+3 \mathrm{H}_{2}+2 \mathrm{H}^{+} & \stackrel{\mathrm{Pd}}{\longrightarrow} \mathrm{N}_{2}+4 \mathrm{H}_{2} \mathrm{O} \\
\mathrm{NO}_{2}^{-}+3 \mathrm{H}_{2}+2 \mathrm{H}^{+} & \stackrel{\mathrm{Pd}}{\longrightarrow} \mathrm{NH}_{4}^{+}+2 \mathrm{H}_{2} \mathrm{O}
\end{array}
$$

It is well accepted that the first step form nitrate to nitrite is relatively slow [47] and the rest of the reaction, hydrogenation of nitrite is extremely fast, easily inducing internal concentration gradients due to diffusion limitation [48-51]. Horold et al. [48] 
and Strukul et al. [52] suggested application of small catalyst support particles to improve activity and also to reduce concentration gradients, whereas, Lecloux et al. [49] suggested use of egg shell catalysts for the same effect.

The challenge in this method is to achieve maximum selectivity towards nitrogen, since ammonia is toxic and therefore a highly undesirable product. It was reported that nitrogen selectivity depends on reaction parameters [46]. High nitrite and low hydrogen concentration, low $\mathrm{pH}$ and low temperatures favour nitrogen selectivity. It should be noted that not only hydrogen and nitrite are reacting, but also protons are consumed and it is suggested that at neutral $\mathrm{pH}$ proton diffusion may be the most limiting factor, causing a $\mathrm{pH}$ gradient in the catalyst particles, influencing the selectivity [50]. Arino et al. [50] reported use of catalyst supports with large pore volume reducing the concentration gradients and improving the selectivity towards nitrogen. However, not only the reaction parameters but also the active metal particle sizes influence the selectivity towards nitrogen $[53,54]$.

Catalytic hydrogenation of nitrite is also relevant for hydroxylamine synthesis via hydrogenation of nitrate, which is an important industrial intermediate for the synthesis of amines. The reaction occurs at much higher acidic conditions compared to the neutral $\mathrm{pH}$ conditions of nitrite hydrogenation in water. However, extremely fast nature of the reaction easily induces concentration gradients along the catalyst particle influencing the activity for nitrate reduction [47].

In this thesis, we focus on hydrogenation of nitrite as a model reaction to test the suitability of thin layers of CNFs as catalyst support. This fast reaction can easily induce concentration gradients testing the internal diffusion along the thin layers of CNFs. Moreover, during this reaction, monometallic catalysts such as Pd or Pt can be used to simplify the complexity of the reaction study.

\subsection{Scope and outline of this thesis}

The objective of the research described in this thesis is to synthesize catalyst support with properties that can avoid internal mass transfer limitations in a gasliquid-solid reaction. Furthermore, this supported catalyst was compared with 
conventional catalysts and its performance was evaluated for nitrite hydrogenation to nitrogen and/or ammonia in water.

The material was synthesized based on immobilizing a stable carbon nanofiber layer on structured support such as Ni foam, termed as 'hairy foam'. Chapter 2 and chapter 3 describe preparing a stable CNF layer on $\mathrm{Ni}$ foam. Chapter 2 describes attachment of a stable CNF layer to Ni foam. It is shown that a thin layer of highly porous open structure of CNFs is attached to Ni foam via a thin carbon layer formed at the roots of the CNFs inducing mechanical stability. Chapter 3 demonstrates tuning the properties of formed CNF layer and the carbon layer by addition of hydrogen, and its effect on the stability of CNF layer.

Chapter 4 describes the performance of CNF based catalyst over conventional catalyst for nitrite hydrogenation in water. It is shown that improved mass transfer properties of CNF based catalysts provide high activity for nitrite reduction. It is also proposed that intrinsic activity of graphite nature of the support also contributes to the high activity for nitrite reduction. Chapter 5 describes the effect of the reaction conditions and nature of the support on selectivity to ammonia. It is proposed that electric conductivity of carbon based supports significantly affect selectivity. Chapter 6 describes and explains the effect of particle size of active metal (Pd) on activity and selectivity for nitrite reduction.

Chapter 7 demonstrates development of thin layers of CNFs catalyzed by $\mathrm{Rh}$ metal on silicon wafers for the use as catalyst support in micro-channel reactor. Finally, in chapter 8 all the results are summarized and some concluding remarks are presented. 


\section{References}

[1] P.A. Ramachandran, R.V. Chaudhari, Three phase catalytic reactors, Gordon and Breach Science publishers, New york, 1983.

[2] M.P. Dudukovic, F. Larachi. P.L. Mills. Catal. Rev. 44 (2002) 123-246.

[3] W. Teunissen, A.A. Bol, J.W. Geus, Catal. Today 48 (1999) 329-336.

[4] H.S. Fogler, Elements of Chemical Reaction Engineering, Prentice-Hall, third ed., New Jersey, 2002.

[5] O. Levelspiel, Chemical Reaction Engineering, John Wiley and Sons, third ed., New York, 1999.

[6] C. N. Satterfield, Mass transfer in Heterogeneous catalysis, The Colonial Press, Massachusetts, 1970.

[7] C.N. Satterfield, J. AIChE 21 (1975) 209-228.

[8] A. Cybulski, J.A. Moulijn, Structured Catalysts and Reactors, Marcel Dekker, second ed., New York 1998.

[9] C.P. Stemmet. Gas-liquid Solid Foam Reactors: Hydrodynamics and Mass Transfer, $\mathrm{PhD}$ thesis, Eindhoven University (2008).

[10] G.I. Garrido, F.C. Patcas, S. Lang, B. Kraushaar-Czarnetzki, Chem. Eng. Sci. 63 (2008) 5202-5217.

[11] M.V. Twigg, J.T. Richardson, Ind. Eng. Chem. Res. 46 (2007) 4166-4177.

[12] A.N. Pestryakov, Catal. Today 29 (1996) 67-70.

[13] L. Giani, C. Cristiani, G. Groppi, E. Tronconi, Appl. Catal. B 62 (2006) 121-131.

[14] A. Sirijaruphan, J.G. Goodwin Jr., R.W. Rice, D. Wei, K.R. Butcher, G.W. Roberts, J.J. Spiveye, Appl. Catal. A 281 (2005) 11-18.

[15] J.A. Moulijn, M. Kreutzer, F. Kapteijn, Chem. Eng. 768 (2005) 32-34.

[16] K.P. De Jong, J. Geus, Catal. Rev. Sci. Eng. 42 (2000) 481-510.

[17] S.D. Robertson, Nature 221 (1969) 1044-1046.

[18] R.T.K. Baker, M.A. Barber, P.S. Harris, F.S. Feates, R.J.J. Waite, J. Catal. 26 (1972) 51-62.

[19] E. Hammel, X. Tnag, M. Trampert, T. Schmitt, K. Mauthner, A. Eder, P. Potschke, Carbon 42 (2004) 1153-1158.

[20] W.I. Milne, K.B.K. Teo, G.A.J. Amaratunga, P. Legagneux, L. Gangloff, J.P. Schnell, V. Semet, V. Thien Binh, O. Groening, J. Mater. Chem. 14 (2004) 933-943.

[21] R.T. Yang, J.P. Chen, J. Catal. 115 (1989) 52-64.

[22] N.M. Rodriguez, J. Mater. Res. 8 (1993) 3233-3250.

[23] M.S. Hoogenraad. Growth and utilization of carbon fibers, $\mathrm{PhD}$ Thesis, Utrecht University (1995).

[24] P. Serp, M. Corrias, P. Kalck, Appl. Catal. A 253 (2003) 337-358.

[25] M.K. van der Lee, A.J. van Dillen, J.W. Geus, K.P. de Jong, J.H. Bitter, Carbon 44 (2006) 629-637.

[26] J.K. Chinthaginjala, K. Seshan, L. Lefferts, Ind. Eng. Chem. Res. 46 (2007) 3968-3978. 
[27] P.W.A.M. Wenmakers, J. van der Schaaf, F.M. Kuster, J.C. Schouten, J. Mater. Chem. 18 (2008) 2426-2436.

[28] M. Cantoro, V.B. Golovko, S. Hofmann, D.R. Williams, C. Ducati, J. Geng, B.O. Boskovic, B. Kleinsorge, D.A. Jefferson, A.C. Ferrari, B.F.G. Johnson, J. Robertson. Diamond and Related Materials 14 (2005) 733-738.

[29] A. Cordier, E. Flahaut, C. Viazzi, C. Laurent, A. Peigney, J. Mater. Chem. 15 (2005) 4041-4050.

[30] N.A. Jarrah, F. Li, J.G. Van Ommen, L. Lefferts, J. Mater. Chem. 15 (2005) 1946-1953.

[31] M.J. Ledoux, C. Pham-Huu, Catal. Today 102-103 (2005) 2-14.

[32] P. Li, T. Li, J.H. Zhou, Z.J. Sui, Y.C. Dai, W.K. Yuan, D. Chen, Microporous and Mesoporous Materials 95 (2006) 1-7.

[33] N.A. Jarrah, J.G. van Ommen, L. Lefferts, J. Mater. Chem. 14 (2004) 1590-1597.

[34] E. García-Bordejé, I. Kvande, D. Chen, M. Rønning, Carbon 45 (2007) 1828-1838.

[35] P. Tribolet, L. Kiwi-Minsker, Catal. Today 102-103 (2005) 15-22.

[36] Z.R. Ismagilov, N.V. Shikina, V.N. Kruchinin, N.A. Rudina, V.A. Ushakov, N.T. Vasenin, H.J. Veringa, Catal. Today 102-103 (2005) 85-93.

[37] S.S. Tzeng, K.H. Hung, T.H. Ko, Carbon 44 (2006) 859-865.

[38] R. Schneider, E. Pippel, J. Wolterdorf, S. Strauss, H. Grabke, Steel Research 68 (1997) 326-332.

[39] R. Vieira, M.J. Ledoux, C. Pham-Huu, Appl. Catal. A 274 (2004) 1-8.

[40] E. Pippel, J. Woltersdorf, R. Schneider, Materials and Corrosion 49 (1998) 309-316.

[41] N.A. Jarrah, F. Li, J.G. Van Ommen, L. Lefferts, J. Catal. 239 (2006) 460-469.

[42] L.W. Canter, Nitrates in ground water, CRC Press, Boca Raton, Florida, 1996.

[43] C.S. Bruning-Fann, J.B. Kaneene, Vet. Hum. Toxicol. 35 (1993) 521-538.

[44] A. Kapoor, T. Viraraghavan, J. Environ. Eng. 123 (1997) 371-380.

[45] K.D. Vorlop, T. Tacke, Chem. Ing. Tech. 61 (1989) 836-837.

[46] S. Hörold, T. Tacke, K.D. Vorlop, Environ. Tech. 14 (1993) 931-939.

[47] C.G.M. van de Moesdijk. The catalytic reduction of nitrate and nitric oxide to hydroxylamine: kinetics and mechanism. Ph. D. Thesis, University of Eindhoven (1979).

[48] S. Hörold, K.D. Vorlop, T. Tacke, M. Sell, Catal. Today 17 (1993) 21-30.

[49] A.J. Lecloux, Catal. Today 53 (1999) 23-34.

[50] M.D’Arino, F. Pinna, G. Strukul, Appl. Catal. B, 53 (2004) 161-168.

[51] A. Pintar, G. Bercic, J. Levec, AIChE 44 (1998) 2280-2292.

[52] G. Strukul, F. Pinna, M. Marella, L. Meregalli, M. Tomaselli, Catal. Today 27 (1996) 209-214.

[53] Y. Yoshinaga, T. Akita, I. Mitkami, T. Okuhara, J. Catal. 207 (2002) 37-45.

[54] A. Miyazaki, T. Asakawa, Y. Nakano, I. Balint, Chem. Comm. (2005) 3730-3732. 


\title{
Chapter 2
}

\section{How carbon nanofibers attach to $\mathrm{Ni}$ foam}

\begin{abstract}
A stable Carbon-Nano-Fiber (CNF) layer was catalytically grown on Ni foam by decomposing ethylene. Scanning electron microscopy of the cross-section of the deposited layer on $\mathrm{Ni}$ foam revealed the presence of two distinct carbon layers; an apparently dense layer ('C-layer') at the carbon-Ni interface and a CNF layer on top of that. Variation of the growth time demonstrated that both layers develop in parallel. Characterization using temperature programmed gasification in hydrogen, Raman spectroscopy and transmission electron microscopy confirmed that both layers consists of graphene planes, which are better ordered in CNFs as compared to Clayer. The nickel surface and the attached carbon layer have similar morphological features. This may be the reason for strong adhesion of the C-layer to Ni. CNFs are strongly attached to the C-layer via roots that penetrate into the C-layer. The interconnections of the Ni surface, C-layer and CNFs induce mechanical stability. The C-layer grows continuously with time, whereas CNF growth needs typically 20 minutes initiation because of the need to form small Ni particles that allow CNF formation. The continuing formation of the C-layer, also after initiation of CNF growth, is thought to be responsible for the formation of CNF roots in the C-layer.
\end{abstract}




\subsection{Introduction}

Carbon fibers find extensive applications in a wide variety of technological fields. A new class of carbon fibers with sub micron dimensions (diameter between about 10 and $300 \mathrm{~nm}$ ) are currently of much interest, finding applications in fields such as electronic devices [1], electrochemical capacitors [2], catalyst supports [3], additives to polymers [4] and super hydrophobic coatings [5]. Fiber type carbon nanomaterials can generally be classified into two groups, namely, Carbon-Nano-Tube (CNT) and Carbon-Nano-Fiber (CNF) [6]. Both consist of polyaromatic carbon, with the graphenes running parallel to the central axis in CNTs while they are oriented at an angle to the central axis in CNFs.

CNFs can be made in high yields at relatively low cost using metal nanoparticles which assist in their formation from carbon containing gases [7]. They can be grown easily by the decomposition of hydrocarbon gases over metals such as Co, $\mathrm{Ni}$ and Fe [7-15]. Aggregates and thin layers of CNFs are potential catalyst supports because of their high surface area $\left(100-200 \mathrm{~m}^{2} / \mathrm{g}\right)$, combined with high macro-porosity and low tortuosity $[13,16]$. CNFs have exceptional physical and chemical properties, for e.g., they show excellent mechanical stability and resistance to acidic environments [3, 16-18]. The advantage in terms of porosity and tortuosity of CNF aggregates is that they can minimize mass transfer limitations within aggregates and thin layers. This is especially relevant for liquid phase reactions because of the generally sluggish diffusion of reactants and products in liquids. Preventing mass transfer limitations and thus also significant concentration gradients, induces improvement of not only catalyst activity, but in many cases also improvement of selectivity to the desired product.

However, their application as small aggregate clusters (nm range) in liquid phase reactions can be problematic due to difficulties in their separation from the reaction medium. Slurry phase operation will encounter agglomeration of fiber particles and need of filtration, while fixed bed operation results in pressure drop along the catalytic bed. One way to overcome these difficulties is to anchor the fibers on a structured material. Challenges in the growth of thin layer of CNF on various structured supports [19-22], e.g, foams (metal and carbon), filters and monoliths, has 
been reviewed earlier by us [23]. Critical issues are the control of length, diameter of the fibers and their attachment to the macroscopic support. Especially, the anchoring of the fibers is crucial for applications. It is speculated that stability to CNFs is provided due to penetration of CNFs into Ni foam/ carbon felt surface [24-26]. The attachment of CNFs to the support is not yet clearly understood.

In the current work, we studied the formation of CNF layer on nickel metal foam. Analysis of the growth of CNFs and characterization of carbon layers formed at various stages allowed us to understand the formation and attachment of the fibers.

\subsection{Experimental}

\subsubsection{Materials}

The polycrystalline $\mathrm{Ni}$ foam (99\%, RECEMAT) used in this study is a 3 dimensional network of hollow connected strands, as shown in figure 2.1. The foam was in the form of a sheet with a size of $20 * 10 \mathrm{~cm}^{2}$ and a thickness of $5 \mathrm{~mm}$. Cylindrical pieces of $\mathrm{Ni}$ foams $(4.3 \mathrm{~mm}$ in diameter) were prepared from the sheet by wire cut electrical discharge machining (AGIECUT CHALLENGE 2). The density of the foam varies by $\pm 25 \%$ within the sheet. The variation in density is caused by variation in thickness (between 11 and $15 \mu \mathrm{m}$ ) of the Ni walls of the hollow strands, the pore sizes of the foam was more or less constant. The geometric surface area per gram Ni was estimated to be less than $1 \mathrm{~m}^{2}$ [21].

High purity gases, Hydrogen (99.999\%, INDUGAS) Nitrogen (99.999\%, INDUGAS), ethylene (99.95\%, PRAXAIR) and ultra pure water (BIOSOLVE LTD) were used in the study.

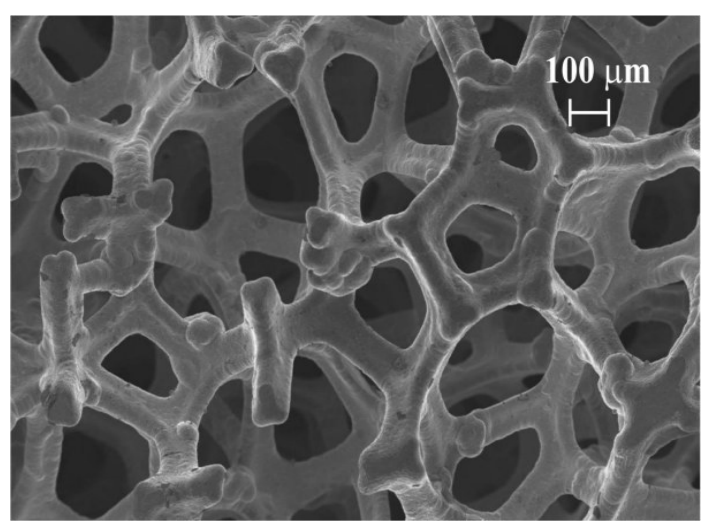

Figure 2.1 - SEM image of as received Ni foam (RECEMAT). 


\subsubsection{CNF formation}

A $\mathrm{Ni}$ foam sample of about 0.2 grams was oxidized in static air for $1 \mathrm{hr}$ increasing the temperature with $6^{\circ} \mathrm{C} / \mathrm{min}$ up to $700^{\circ} \mathrm{C}$; next, the sample was reduced in $20 \% \mathrm{H}_{2} / \mathrm{N}_{2}$ at $700^{\circ} \mathrm{C}$ for two hour with a total flow rate of $100 \mathrm{ml} / \mathrm{min}$. The temperature was then reduced to $440^{\circ} \mathrm{C}$. Carbon nanofibers were synthesized using a gas mixture containing $25 \% \mathrm{C}_{2} \mathrm{H}_{4} / \mathrm{N}_{2}$ with a total flowrate of $107 \mathrm{ml} / \mathrm{min}$. CNF synthesis was performed during 5, 10, 20, 30 and 60 minutes.

Ethylene conversion was determined with on-line chromatography (Varian GC model 3700 equipped with a $15 \mathrm{~m}$ Q-Plot column). The formation rate of carbon was calculated from the production rate of hydrogen, which was the only product in the gas phase. The maximum conversion of ethylene was kept below $5 \%$ to ensure constant ethylene concentration through out the reactor and to allow homogeneous deposition of carbon.

Finally, the sample was cooled down in $\mathrm{N}_{2}$ to room temperature. The amount of carbon formed on the foam was determined by measuring the increase in weight caused by the formation of CNFs.

\subsubsection{Characterization}

After the formation of CNFs, each sample was blown with $100 \mathrm{~L} / \mathrm{min}$ air stream for one minute, in order to remove any loose fibers from the samples before further characterization.

BET surface area of CNFs was estimated from the $\mathrm{N}_{2}$-adsorption isotherm obtained at $77 \mathrm{~K}$ (ASAP 2400 Micromeritics). Morphological features were studied by Scanning Electron Microscopy (SEM) LEO 1550 FEG-SEM equipped with in-lens detector and by Transmission electron microscopy (TEM) (Philips CM300ST-FEG). Cross-sections of carbon deposited Ni foams were obtained by cutting them with a pair of scissors.

Raman spectra were recorded at room temperature with a Kaiser RXN dispersive Raman spectrometer equipped with a $532 \mathrm{~nm}(60 \mathrm{~mW})$ laser for excitation and a Peltier element-cooled Andor CCD camera for detection. Spectra were acquired 
at a data point resolution of $2 \mathrm{~cm}^{-1}$ and 100 scans were accumulated for each spectrum.

The chemical properties of the carbon deposits on $\mathrm{Ni}$ foam were studied using temperature programmed gasification in the presence of, hydrogen, water or oxygen

Carbon gasification in hydrogen - The feed consisted of a mixture of 5vol\% hydrogen in nitrogen. About 40mg of carbon-Ni foam sample was placed in a quartz reactor tube (inner diameter of $3 \mathrm{~mm}$ ). The sample was heated at a temperature ramp of $5^{\circ} \mathrm{C} / \mathrm{min}$ upto a temperature of $750^{\circ} \mathrm{C}$ with a flowrate of $50 \mathrm{ml} / \mathrm{min}$. The hydrogen consumption during the experiment was detected with a thermal conductivity detector.

Carbon gasification by water vapor - A feed mixture of $5 \mathrm{vol} \% \mathrm{H}_{2} \mathrm{O}$ in nitrogen was used. About 40mg of carbon-Ni foam sample was placed in a quartz reactor tube (inner diameter of $3 \mathrm{~mm}$ ). The sample was heated at a temperature increase of $5^{\circ} \mathrm{C} / \mathrm{min}$ from $50^{\circ} \mathrm{C}$ to $750^{\circ} \mathrm{C}$ with a flowrate of $200 \mathrm{ml} / \mathrm{min}$. The formation of $\mathrm{CO}$ and $\mathrm{CO}_{2}$ was measured every two minutes by micro- gas chromatograph (Varian CP4900) using MS5 and PPQ column.

Carbon gasification by oxygen - A feed mixture of $1 \mathrm{vol}^{\mathrm{O}} \mathrm{O}_{2}$ in argon was used. About 15mg of carbon-Ni foam sample was placed in Thermal Gravimetric Analysis balance (METTLER TGA/SDTA851e) and the temperature was increased upto $1000^{\circ} \mathrm{C}$, ramp of $5^{\circ} \mathrm{C} / \mathrm{min}$, with a flowrate of $30 \mathrm{ml} / \mathrm{min}$.

The mechanical stability of CNFs on Ni foam to shear forces was tested by flowing water through the CNF covered foam at room temperature with a linear velocity of $1 \mathrm{~m} / \mathrm{s}$ for $4 \mathrm{hrs}$, measuring loss of CNFs based on weight loss.

\subsection{Results}

\subsubsection{CNF synthesis}

The fresh $\mathrm{Ni}$ foam was pretreated by heating in static air at $700^{\circ} \mathrm{C}$ for one hour followed by reduction at the same temperature with $20 \% \mathrm{H}_{2} / \mathrm{N}_{2}$ for two hours. The resulting morphology of $\mathrm{Ni}$ foam is shown in figure 2.2. The metal foam surface with $\mathrm{Ni}$ grains in the range of 2-10 microns can be observed. The SEM image in figure 2.3a shows the Ni-foam after exposure to $25 \%$ ethylene at $440^{\circ} \mathrm{C}$ for $1 \mathrm{hr}$ at a flowrate 
of $107 \mathrm{ml} / \mathrm{min}$. Complete coverage of the $\mathrm{Ni}$ foam by the CNF layer could be observed. Figure 2.3b shows that the coverage consists of entangled CNFs with typical fiber diameters between $20-70 \mathrm{~nm}$. Figure 2.4 a and b show SEM images of cross-sections at the Ni-carbon interface after $1 \mathrm{hr}$ of ethylene decomposition at $440^{\circ} \mathrm{C}$

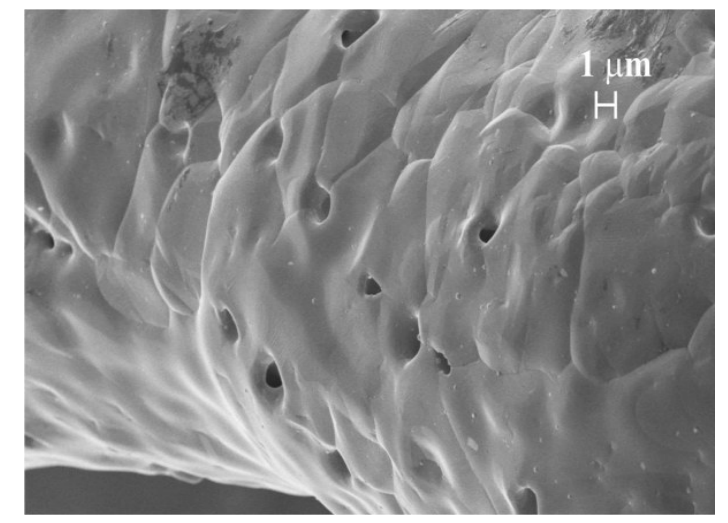

Figure 2.2 - SEM image of Ni foam after oxidation for $1 \mathrm{hr}$ and reduction for 2hrs at $700^{\circ} \mathrm{C}$.

using ethylene concentration of $25 \mathrm{vol} \%$. The presence of two distinguishable layers is clearly recognizable; directly at the $\mathrm{Ni}$ interface we observe a seemingly dense carbon layer of about $5 \mu \mathrm{m}$ (figure 2.4b). A CNF layer comprising of about $30 \mu \mathrm{m}$ is present on top of the carbon layer (figure 2.4a).

Figure 2.4c shows the results of the experiments when CNF growth was attempted with a reduced ethylene concentration of $4 \% \mathrm{C}_{2} \mathrm{H}_{4} / \mathrm{N}_{2}$ and at a flowrate of $840 \mathrm{ml} / \mathrm{min}$. Surprisingly, no CNFs were observed, instead a carbon layer was deposited similar to the C-layer shown in figure 2.4b. This carbon layer apparently looks dense as observed with SEM (figure 2.4c). Figure $2.4 \mathrm{~d}$ shows a part of the
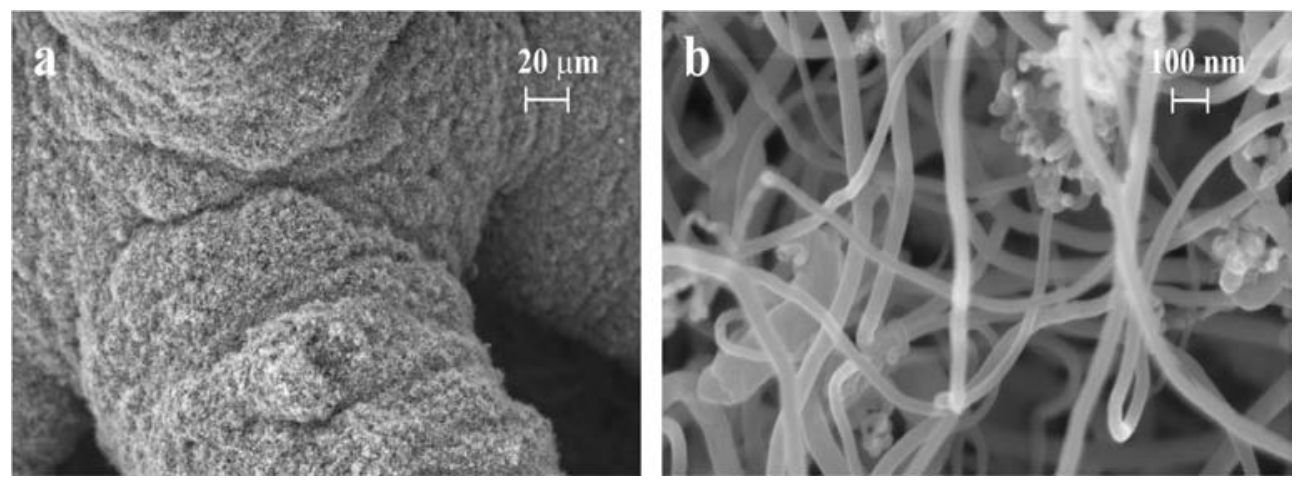

Figure 2.3 - a) CNF layer on Ni foam strand after ethylene decomposition at $440^{\circ} \mathrm{C}$ for $1 \mathrm{hr}$, b) Porous CNF matrix on Ni foam strand. 
cross-section where the carbon layer was partly separated from the Ni surface, during cutting the sample. The upper layer contains exclusively carbon whereas the bottom layer is $\mathrm{Ni}$. It can be seen from figure $2.4 \mathrm{~d}$ that the original Ni-carbon interlayer was rough, exhibiting pits in the order of typically 50nm.
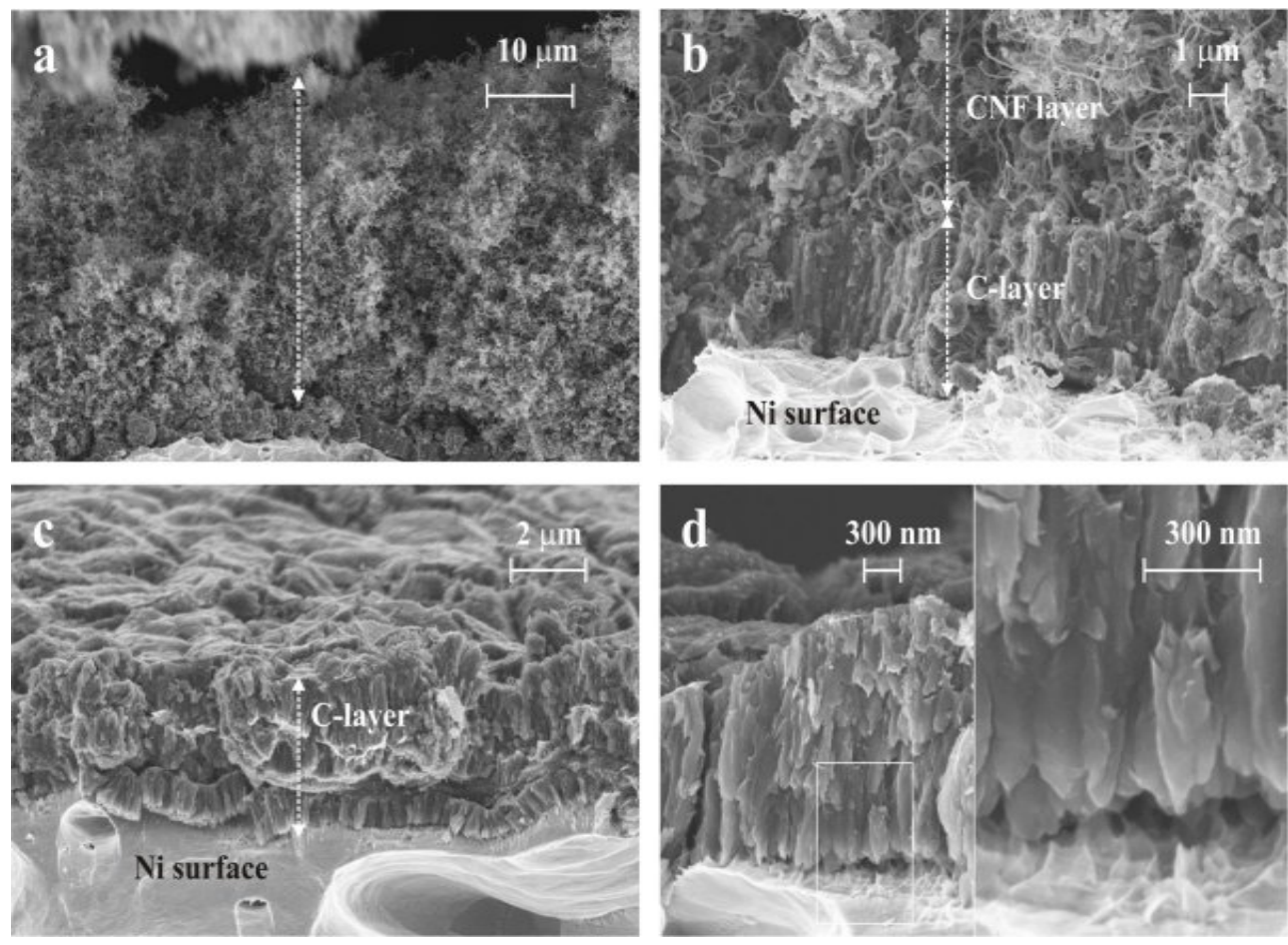

Figure 2.4 - Cross-sectional images of foam. a) CNFs on Ni foam deposited at $440{ }^{\circ} \mathrm{C}$ with $25 \% \mathrm{C}_{2} \mathrm{H}_{4} / \mathrm{N}_{2}$ for $1 \mathrm{hr}(\mathrm{CNF}-\mathrm{C} / \mathrm{Ni})$. b) C-layer and CNF layer in CNF-C/Ni sample. c) C-layer on Ni foam deposited at $440^{\circ} \mathrm{C}$ with $4 \% \mathrm{C}_{2} \mathrm{H}_{4} / \mathrm{N}_{2}$ for $1 \mathrm{hr}(\mathrm{C} / \mathrm{Ni})$. d) Left side of image shows the interface of C-layer and $\mathrm{Ni}$ surface in $\mathrm{C} / \mathrm{Ni}$ sample and the right side of the image is the zoomed in image showing the rough interface. The arrows indicate the thickness of the layer.

The sample with only the dense carbon layer is termed as $\mathrm{C} / \mathrm{Ni}$ (figure 2.4c), whereas the sample with both carbon layer and CNFs is termed as CNF-C/Ni (figure 2.4a, b).

Table 2.1 presents the synthesis conditions and BET surface areas of $\mathrm{C} / \mathrm{Ni}$ and $\mathrm{CNF}-\mathrm{C} / \mathrm{Ni}$. C/Ni sample has a surface area of $80 \mathrm{~m}^{2} / \mathrm{gm}$. This high surface area indicates that the C-layer is porous. The total surface areas per gram of carbon based on $\mathrm{N}_{2}$ adsorption are very similar for both samples. The amount of carbon deposition (table 2.1) is quite different for both samples as calculated based on the rate of hydrogen formed (figure 2.5). Initial rates of carbon deposition are roughly equal; 
however, the formation of CNFs at 25\% ethylene exhibits a clear initiation effect. The rate of formation of $\mathrm{C} / \mathrm{Ni}$ at $4 \%$ ethylene hardly increased with time.

Both conventional SEM images with in-lens detector as well as with a secondary electrons detector (SE2), highlighting the presence of metallic particles, are shown in figure 2.6. CNF-C/Ni contains smaller Ni particles ranging from 20-70nm as measured with SEM analysis (figure 2.6a). In contrast, larger Ni particles (30-300nm) were observed on $\mathrm{C} / \mathrm{Ni}$, shown in figure 2.6b. The Ni particle sizes were evaluated based on seven SEM images for each sample.

\begin{tabular}{|c|c|c|}
\hline \multicolumn{2}{|c|}{ CNF-C/Ni } & $\begin{array}{c}\text { C/Ni } \\
(\text { no CNFs) }\end{array}$ \\
\hline Flowrate & $\begin{array}{c}107 \mathrm{ml} / \mathrm{min} \\
\left(25 \% \mathrm{C}_{2} \mathrm{H}_{4} / \mathrm{N}_{2}\right)\end{array}$ & $\begin{array}{c}840 \mathrm{ml} / \mathrm{min} \\
\left(4 \% \mathrm{C}_{2} \mathrm{H}_{4} / \mathrm{N}_{2}\right)\end{array}$ \\
\hline Temperature & $440^{\circ} \mathrm{C}$ & $440^{\circ} \mathrm{C}$ \\
\hline Time & $1 \mathrm{hr}$ & $1 \mathrm{hr}$ \\
\hline Wt\% of C & $\sim 30 \%$ & $\sim 9 \%$ \\
\hline $\begin{array}{c}\text { BET surface area per } \\
\text { gram of carbon }\end{array}$ & $\sim 90 \mathrm{~m}^{2} / \mathrm{g}$ & $\sim 80 \mathrm{~m}^{2} / \mathrm{g}$ \\
\hline $\begin{array}{c}\text { Thickness of C- layer } \\
\text { Thickness of CNF layer }\end{array}$ & $\sim 5 \mu \mathrm{m}$ & $\sim 4 \mu \mathrm{m}$ \\
\hline Table $2.1-$ Exper & $\sim 30 \mu \mathrm{m}$ & 0 \\
\hline
\end{tabular}

Table 2.1 - Experimental conditions and BET surface area results.

\subsubsection{Initial growth of C-Layer and CNFs}

Initial formation of both the C-layer and CNFs in CNF-C/Ni was studied with SEM (figure 2.7a-e) after 5, 10, 20, 30 and 60 minutes exposure to 25\% ethylene. The samples were studied with SEM at the cross-sections of the Ni foam strand. After 5 minutes of exposure (figure 2.7a), some CNFs can be observed together with a less structured deposits on the Ni surface, the latter may be a precursor of C-layer. The Clayer is clearly visible after 10 minutes of exposure (figure 2.7b) and its thickness increases with time (figure 2.7c). Figures $2.7 \mathrm{~d}$ and 2.7e show extensive growth of the CNF layer after 30 and 60 minutes, respectively. Figure $2.7 \mathrm{f}$ shows a part of the crosssection where the carbon layer was partly separated from the Ni surface. The upper layer contains exclusively carbon whereas the bottom layer is Ni. The morphology at the interface of C-layer and $\mathrm{Ni}$ surface is similar to the morphology of the $\mathrm{C} / \mathrm{Ni}$ sample (figure $2.4 \mathrm{~d}$ ). It is obvious from figure $2.7 \mathrm{f}$ that the Ni-carbon interlayer is 
rough, exhibiting pits in the order of typically 50nm. Figure $2.7 \mathrm{~g}$ shows the morphology of the interface between the C-layer and the CNF layer. It appears as if CNFs are growing out of C-layer.

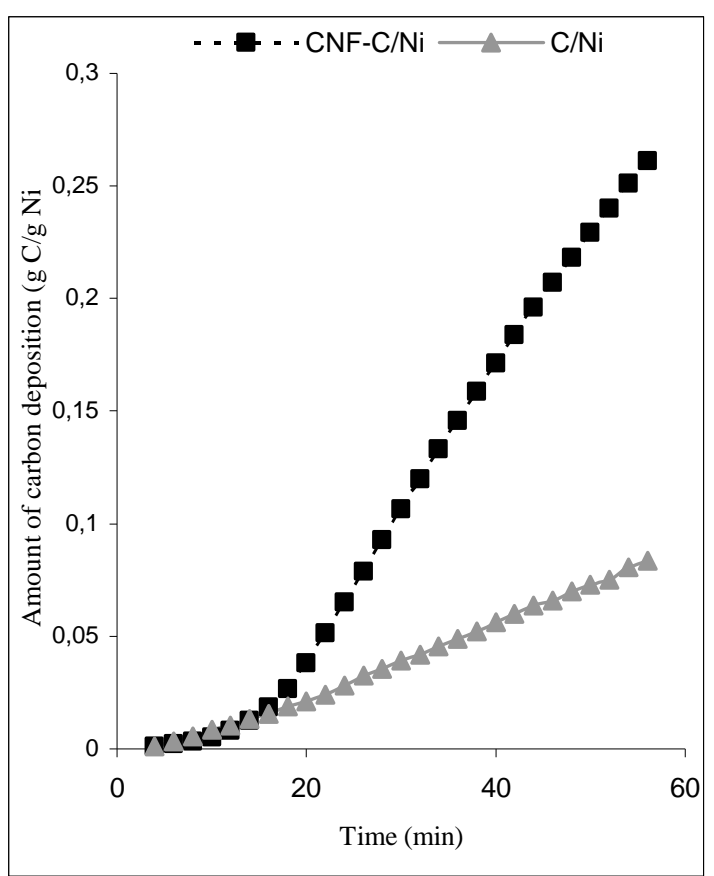

Figure 2.5 - Amount of carbon deposition on Ni foam with $25 \% \mathrm{C}_{2} \mathrm{H}_{4} / \mathrm{N}_{2}$ and $4 \% \mathrm{C}_{2} \mathrm{H}_{4} / \mathrm{N}_{2}$ at $440^{\circ} \mathrm{C}$ for $1 \mathrm{hr}$.

Figure 2.8 shows a graphical representation of the thicknesses of the CNF and C-layer as a function of growth time, based on SEM cross-sections. In the first 20 minutes, the rates of formation of C-layer and CNF layer are similar. After 20 minutes, the thickness of CNF layer increases rapidly in comparison with the increase in C-layer thickness.
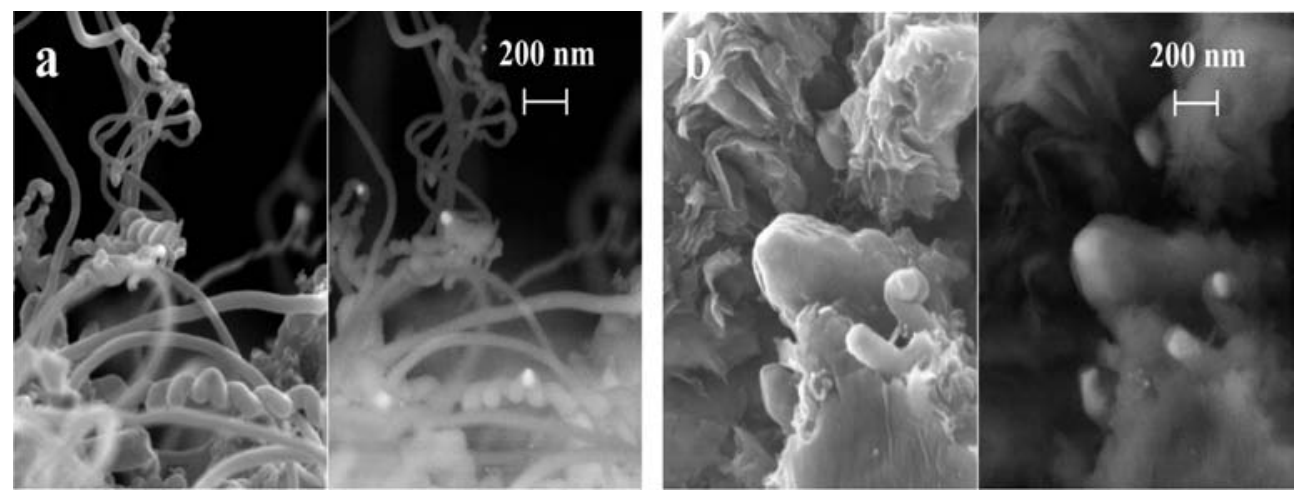

Figure 2.6 - SEM in-lens/SE2 images of (a) CNF/Ni and (b) C/Ni. Left side of the image refers to in-lens and the right side refers to SE2. 

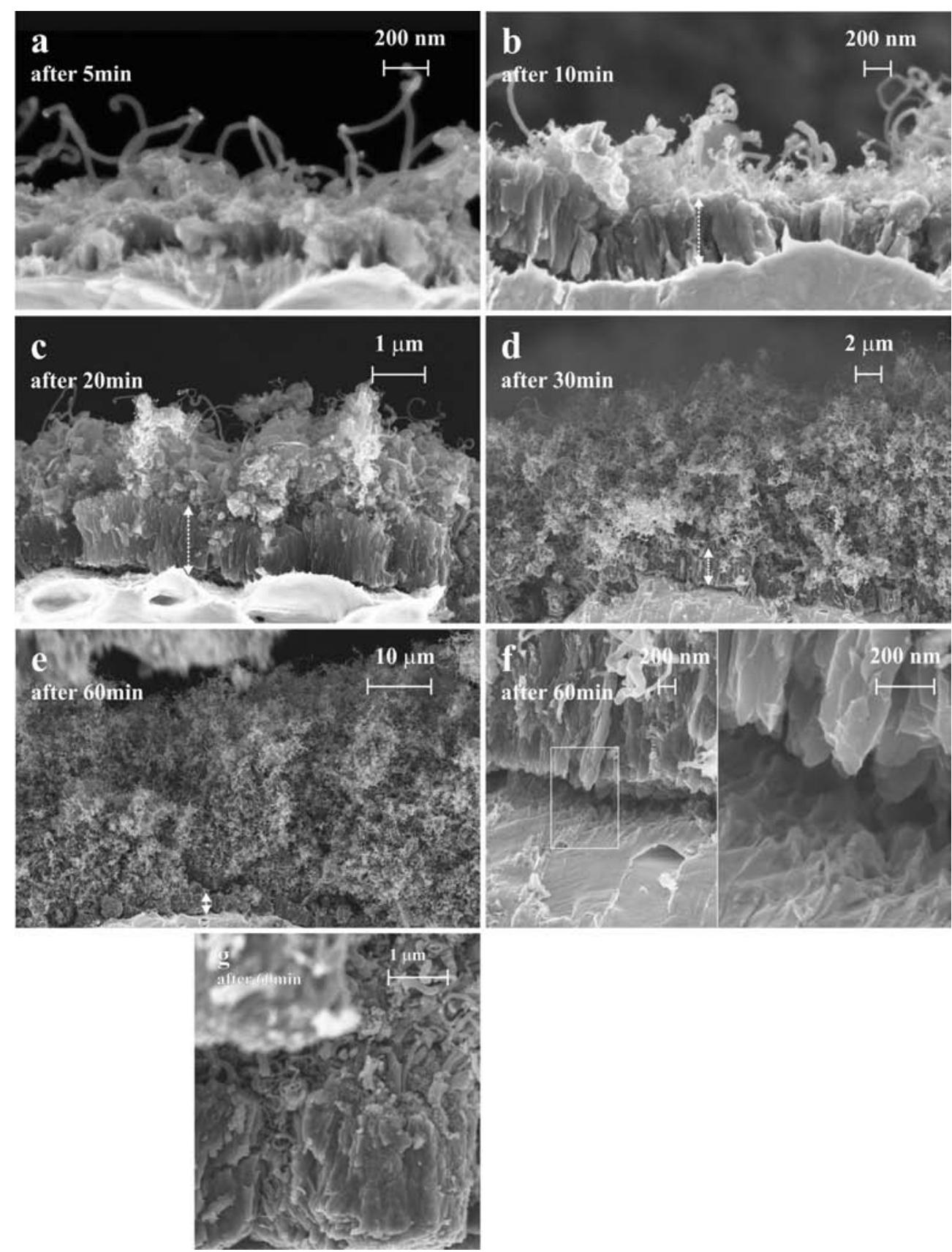

Figure 2.7a-e - Cross-sectional view of Ni foam after CNF growth at 5, 10, 20, 30 \& $60 \mathrm{mins}$ from $25 \%$ ethylene/nitrogen at $440^{\circ} \mathrm{C}$. Figure 7f: cross-sectional view of CNF-C/Ni at the interface of C-layer/Ni surface, left side of the image shows the interface of C-layer and $\mathrm{Ni}$ surface and the right side of the image is the zoomed in image showing the rough interface. Figure $\mathbf{7 g}$ : Interface of $\mathrm{CNF}$ /C-layer, showing anchored CNFs into C-layer. White arrows indicate the thickness of carbon layer on the Ni surface. 


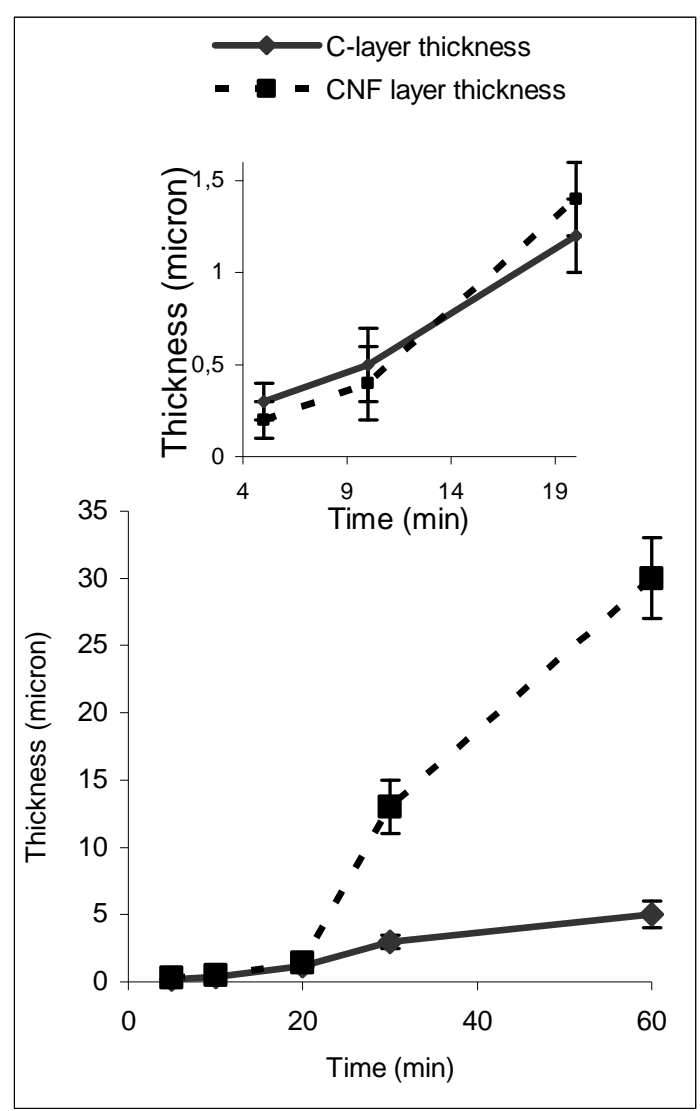

Figure 2.8 - Graphical representation of carbon layers thicknesses formed on $\mathrm{Ni}$ foam. The inset image is the magnified image between 0-20mins

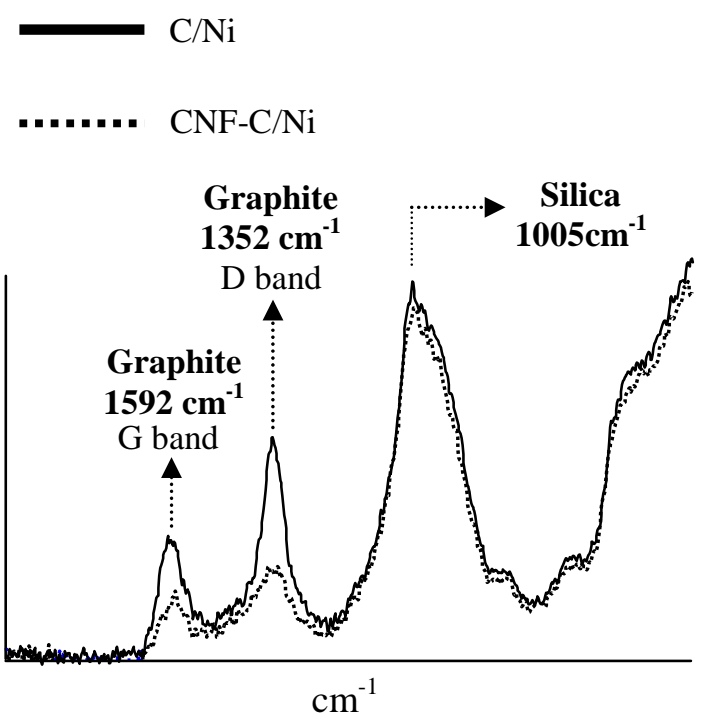

Figure 2.9 - Raman spectra of CNF-C/Ni and C/Ni samples. 


\subsubsection{Characterization}
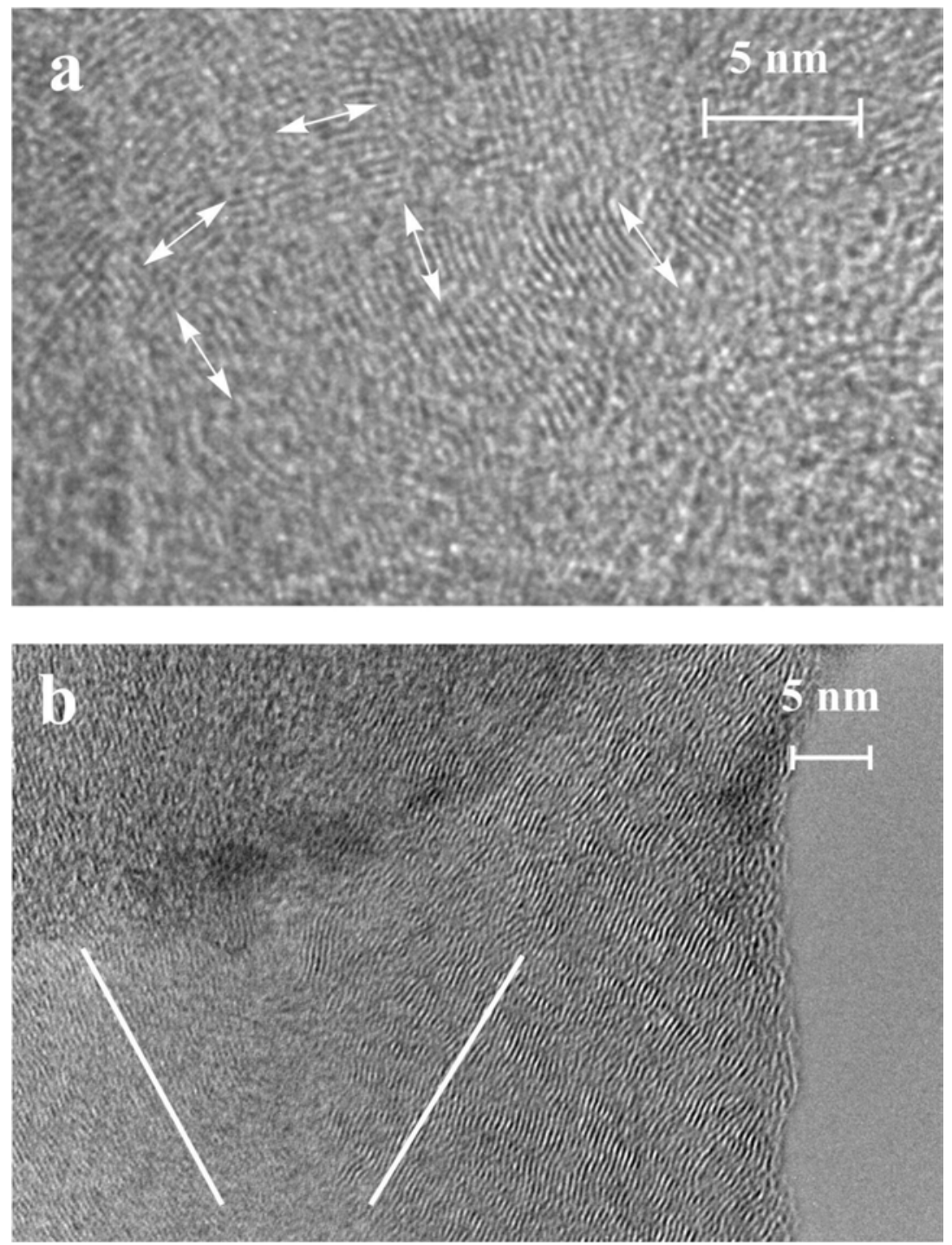

Figure 2.10 - Transmission electron microscopy images, a) carbon in $\mathrm{C} / \mathrm{Ni}$ sample and b) $\mathrm{CNF}$ in CNF-C/Ni sample. The arrows and lines indicate the graphene planes alignment.

Both types of carbon deposits were characterized with Transmission Electron Microscopy (TEM), Raman spectroscopy and temperature programmed gasification techniques. Raman spectra of $\mathrm{CNF}-\mathrm{C} / \mathrm{Ni}$ and $\mathrm{C} / \mathrm{Ni}$ samples (figure 2.9) showed three main peaks. The peaks at $1352 \mathrm{~cm}^{-1}$ and $1592 \mathrm{~cm}^{-1}$ are assigned to disordered and ordered graphite, respectively. The peak at $1005 \mathrm{~cm}^{-1}$ corresponds to the vibration of $\mathrm{O}-\mathrm{Si}-\mathrm{O}$ due to presence of silica contamination in the Ni foam, as confirmed by X-ray fluorescence spectroscopy (XRF). 
TEM micrograph of the carbon present on the C/Ni sample (Figure 2.10a) showed graphene planes with a d-spacing of $0.34 \mathrm{~nm}$, which is in good agreement with literature [27] . The graphene sheets seem poorly ordered and the domains of stacked graphene planes are in the order of a few nm. The CNFs in CNF-C/Ni also showed graphene planes with d-spacing of $0.34 \mathrm{~nm}$ (figure $2.10 \mathrm{~b}$ ). The graphene planes in $\mathrm{CNF}$ are much more ordered as compared to $\mathrm{C} / \mathrm{Ni}$, extending throughout the wall of the fishbone type CNF.

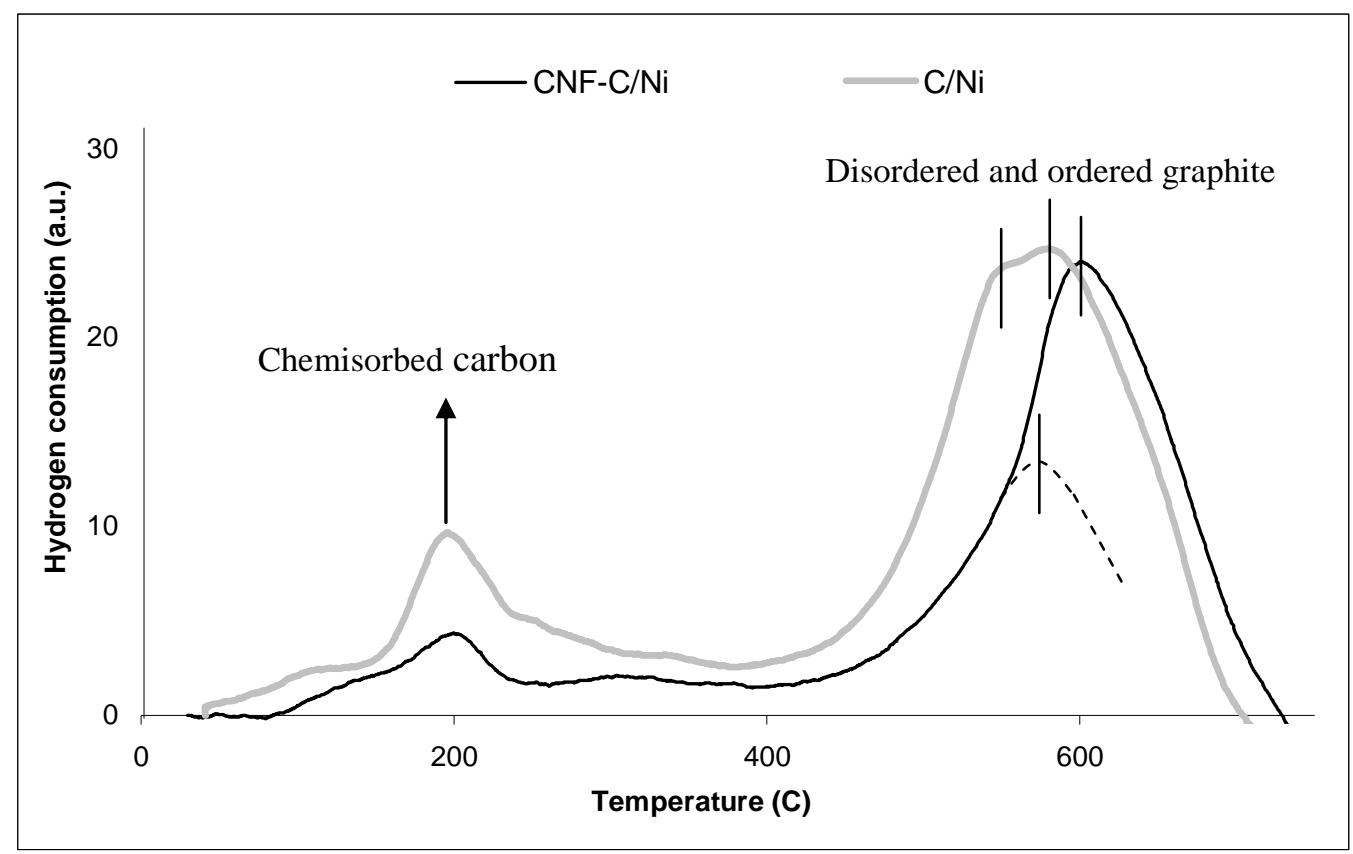

Figure 2.11: Temperature programmed gasification of carbon deposits on CNF$\mathrm{C} / \mathrm{Ni}$ and $\mathrm{C} / \mathrm{Ni}$. The peaks between $400-750^{\circ} \mathrm{C}$ consist of atleast two contributions and the positions of the peak maxima are indicated in the graph. Dotted curve represents the deconvoluted peak.

Temperature Programmed Gasification of carbon with $\mathrm{H}_{2}$ resulted in only partial removal of carbon on both the samples. The presence of remaining carbon deposits was confirmed with SEM analysis (figure not shown). Gasification of carbon with $\mathrm{H}_{2}$ on both the samples resulted in two peaks (figure 2.11). First peak is centered at $200^{\circ} \mathrm{C}$ and the second peak ranges between $450^{\circ} \mathrm{C}$ to $750^{\circ} \mathrm{C}$. Deconvolution of the second peak revealed contribution of two peaks, centered at $530^{\circ} \mathrm{C}$ and $570^{\circ} \mathrm{C}$ for $\mathrm{C} / \mathrm{Ni}$, and centered at $570^{\circ} \mathrm{C}$ and $600^{\circ} \mathrm{C}$ for $\mathrm{CNF}-\mathrm{C} / \mathrm{Ni}$, respectively. The positions of the peak maxima are indicated in the figure 2.11. Clearly, the reactivity of the carbon differs between the samples. 
No significant differences were observed when gasifying with $\mathrm{O}_{2}$ or $\mathrm{H}_{2} \mathrm{O}$. All the carbon deposits were completely removed in one step without any significant difference between both samples, the results are not shown.

Mechanical stability of the CNFs on Ni foam was confirmed by applying shear force via flowing water $(1 \mathrm{~m} / \mathrm{sec})$ through the Ni foam; no loss could be detected.

\subsection{Discussion}

First, formation and properties of both types of layers will be discussed followed by a proposition on the mechanism of formation of both layers, explaining the mechanical stability of the deposits as observed.

\subsubsection{Formation of C-layer and CNFs}

Both types of carbon deposits on CNF-C/Ni, i.e. CNF-layer and C-layer, apparently form in parallel as shown in figure 2.7. The trends in growth rate of the CNF layer and the C-layer based on the SEM observations (figure 2.8) are strikingly similar to the trends in a similar plot based on increase in weight by carbon deposition in figure 2.5. It is important to note that figure 2.5 originates from two different samples, i.e. $\mathrm{CNF}-\mathrm{C} / \mathrm{Ni}$ and $\mathrm{C} / \mathrm{Ni}$, whereas figure 2.8 is based on observations on $\mathrm{CNF}-\mathrm{C} / \mathrm{Ni}$ only. Therefore it is reasonable to assume that the properties of the Clayers formed on $\mathrm{CNF}-\mathrm{C} / \mathrm{Ni}$ and $\mathrm{C} / \mathrm{Ni}$, respectively, are very similar. This facilitates comparison of characteristics of both layers because the C-layer is now available for characterization in absence of CNFs. Additional support for this hypothesis will be discussed below.

The fact that CNFs are formed only at high ethylene concentration is in agreement with the observation in figure 2.6 that $\mathrm{CNF}-\mathrm{Ni} / \mathrm{C}$ sample contains significantly smaller Ni particles sized between $20 \mathrm{~nm}$ and $70 \mathrm{~nm}$ as compared to $\mathrm{C} / \mathrm{Ni}$; larger Ni particles apparently prevent formation of CNFs in latter case. It is well known that $\mathrm{Ni}$ particles between 10 and 100nm are very effective in catalyzing the formation of CNFs. Polycrystalline Ni surfaces do not have pre-shaped Ni nanoparticles suitable for CNF growth. Jarrah et al. [28] proposed that small Ni particles are formed via 1) decomposition of ethylene on the polycrystalline Ni surface, 2) diffusion of carbon into $\mathrm{Ni}$, eventually forming Ni-carbide $\left(\mathrm{Ni}_{3} \mathrm{C}\right)$ and 3 ) 
decomposition of $\mathrm{Ni}_{3} \mathrm{C}$ into small $\mathrm{Ni}$ particles. The absence of CNFs in $\mathrm{C} / \mathrm{Ni}$ sample may be due to the fact that most Ni particles are still too large to grow CNFs. Clearly, the process of fragmentation of the larger $\mathrm{Ni}$ crystallites to form Ni-nano-particles is affected. How, this happens exactly is not clear at the moment. It is tempting to suggest that the ethylene concentration is determining but it cannot be ruled out that the conversion level and thereby the concentration of hydrogen formed is relevant. Further work is in progress to clarify this. Remarkably, the variation in ethylene concentration did not affect the C-layer thickness, as observed from figure $2.4 \mathrm{a} / \mathrm{b}$ and c.

\subsubsection{State of the carbon deposits}

The SEM observations in figures 2.4a and 2.4c confirm that the morphologies of the C-layer in CNF-C/Ni and C/Ni are similar. The surface areas per gram of carbon of both samples are also similar (table 1.1). The surface area of the C-layer is $80 \mathrm{~m}^{2} / \mathrm{g}$. The sample containing both CNFs and the C-layer has an average surface area of $90 \mathrm{~m}^{2} / \mathrm{g}$ of carbon. Therefore the surface areas of both types of carbon deposits is in the order of $80-90 \mathrm{~m}^{2} / \mathrm{g}$. HR-TEM revealed the presence of graphene layers (d-spacing $0.34 \mathrm{~nm}$ ) in both the C-layer as well as within CNFs (figure $2.10 \mathrm{a}$ and b). The essential difference is the higher ordering of the graphene layers in CNFs as compared to the nano-domains observed in the C-layer.

Raman spectroscopy confirms that both the samples show two peaks assigned to carbon (figure 2.9). The peak centered at $1592 \mathrm{~cm}^{-1}$ ( $\mathrm{G}$ band) is assigned to crystalline graphite [29]. The peak centered at $1352 \mathrm{~cm}^{-1}$ is usually termed as the D band [30], which is a common feature of disordered $\mathrm{sp}^{2}$-based carbon and the ratio of the D-band over the G-band varies with the size of the perfect graphene stacks [30, 31]. The intensity ratio of the $D$ and $G$ bands ( $(\mathrm{D}) / \mathrm{I}(\mathrm{G})$ ) is therefore a qualitative description of the crystallinity [32, 33] . Figure 2.9 clearly shows a higher ratio of disordered graphite to ordered graphite in $\mathrm{C} / \mathrm{Ni}$ as compared to $\mathrm{CNF}-\mathrm{C} / \mathrm{Ni}$; this agrees well with the TEM results, showing nano-domains in $\mathrm{C} / \mathrm{Ni}$. The fact that the overall intensity of both the $\mathrm{D}$ and $\mathrm{G}$ band is higher for the C-layer is probably due to the higher effective density of the C-layer as compared to the CNF layer, allowing more effective light scattering. 
Gasification of the carbon deposits in the presence of $\mathrm{H}_{2}$ showed a peak at $200^{\circ} \mathrm{C}$ (figure 2.11) which is probably due to conversion (methanation) of chemisorbed carbon on the $\mathrm{Ni}$ surface. The peaks in the range of $450-750^{\circ} \mathrm{C}$ are assigned to graphene based deposits [34 - 36] . Deconvolution of the peak around $600^{\circ} \mathrm{C}$ revealed contribution of two peaks, which we tentatively assign to disordered and ordered graphite as in CNFs, inferred from Raman Spectroscopy and TEM observations. It is clear from figure 2.11 that $\mathrm{C} / \mathrm{Ni}$ is more reactive than $\mathrm{CNF}-\mathrm{C} / \mathrm{Ni}$, which seems logical because the amount of reactive edges of the graphene planes increases with decreasing crystallite size. Not all the carbon deposits were removed during gasification in the presence of $\mathrm{H}_{2}$; possibly gasification by hydrogen is catalysed by $\mathrm{Ni}$ and part of the deposits are simply too remote from $\mathrm{Ni}$ particles.

At this point it is not very clear whether nano-domains of graphite forms directly from ethylene or whether hydrogen rich coke deposits are formed as an intermediate. Graphitization of coke deposits is reported to be catalyzed by $\mathrm{Ni}$ [37, 38].

\subsubsection{Attachment of carbon deposits on Ni foam}

When both CNFs and a C-layer are formed, strong attachment of the CNFs is only possible if (i) the C-layer is well attached to the Ni foam, and (ii) the CNFs are well attached to the C-layer.

The interface between the C-layer and the Ni surface was shown in figure $2.7 \mathrm{f}$. The surface texture of the two layers seems to match closely indicating good attachment. The morphology of the interface between C-layer and Ni surface in the samples $\mathrm{C} / \mathrm{Ni}$ (figure 2.4d) and CNF-C/Ni (figure 2.7f) are very similar, both in terms of roughness and matching. The formation of CNFs apparently does not influence the C-Ni interface.

Strong attachment of CNFs on the C-layer can be directly understood based on figure 2.7g. The CNFs are anchored in the C layer, as if roots of CNFs penetrate into C-layer. It is not clear to which depth these roots penetrate in the C-layer. However, penetration till the $\mathrm{C}-\mathrm{Ni}$ interface can be excluded, based on the fact that the morphology of C-Ni interface does not depend on the presence of CNFs. 
Based on the observations in this study, we propose the following model to describe the growth and attachment of both the C-layer and CNFs on Ni foam.

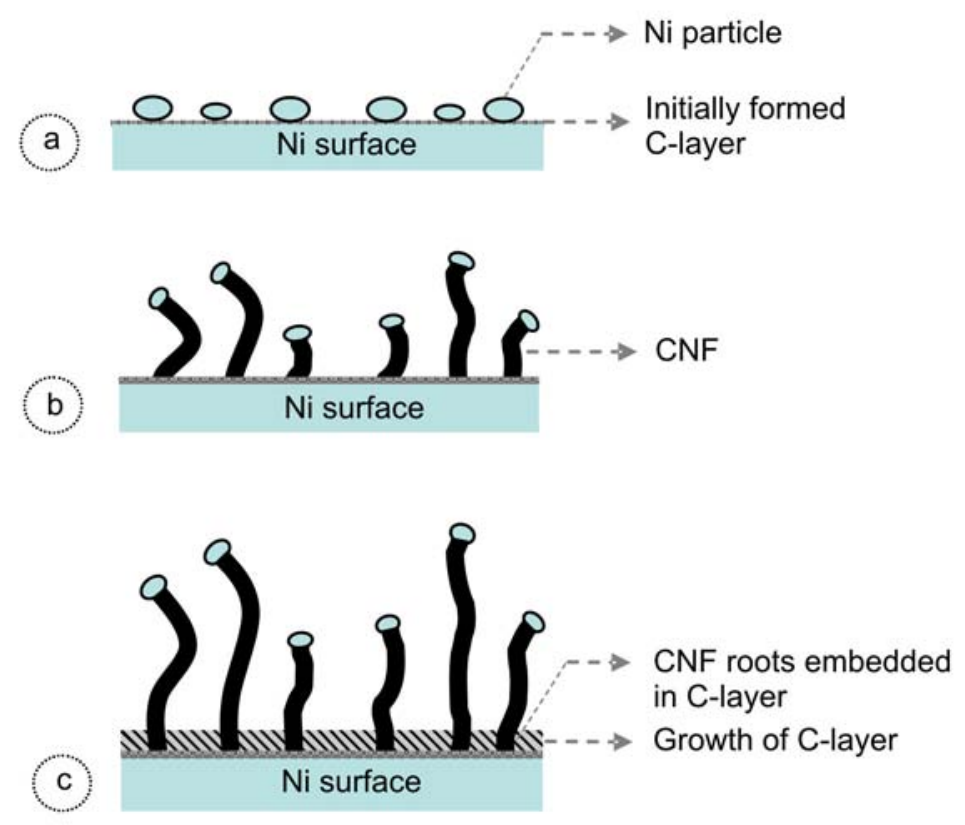

Figure 2.12 - Schematic model to explain the formation and attachment of Clayer and CNFs on Ni surface. Figure 12 a, b, c represents the schematic depiction of CNF and C-layer formation after 0-20 minutes (formation of $\mathrm{Ni}$ nanoparticles via $\mathrm{Ni}_{3} \mathrm{C}$ decomposition), 20-30 minutes (CNF growth), 30 minutes \& up (CNF growth and C-layer growth) respectively.

First, ethylene decomposes on $\mathrm{Ni}$ surface and creates small $\mathrm{Ni}$ particles via decomposition of Ni-carbide, as described by Jarrah et al. [28]. Fragmentation must occur via $\mathrm{Ni}_{3} \mathrm{C}$ decomposition because direct metal dusting of $\mathrm{Ni}$ foam would separate Ni crystals, which are still far too large to allow CNF formation. This process is relatively slow and during the first 20 minutes mostly only C-layer is formed. Most of the Ni particles formed are still not small enough to initiate rapid CNF formation. During this period the C-Ni interface is formed inducing strong attachment (figure 2.12a).

Between 20-30 minutes, fragmentation of the Ni particles has proceeded (at least in the experiment with the higher ethylene concentration) so that rapid CNF formation takes place. These fibers are initially connected to the carbon layer that was formed in the first 20 minutes and we speculate that this interaction is rather weak (figure 2.12b). However, also the C-layer continues to grow, resulting in CNFs rooted 
in the C- layer as suggested in figure 2.12c. In the next 30 minutes, both CNFs as well as the C-layer continue to grow. For simplicity, in this scheme it is assumed that all CNFs start to form at the same time. In reality the fragmentation of Ni particles to nanoparticles probably continues resulting in a distribution of depth of penetration of roots; in reality some CNFs already form in the first 20 minutes. The CNFs with the shallowest roots are probably responsible for the typical 10\% loss of CNFs when cleaning the samples with pressurized air.

Growth of the C-layer at the outer layer, which is an implicit assumption in the sequence described, is a reasonable proposition as graphene based deposits can act as catalyst for further deposition of carbon [38-41] . On the other hand, we cannot rule out that the C-layer continues to grow at the $\mathrm{C}$-Ni interface, given the fact that the Clayer is microporous.

\subsection{Conclusions}

A stable CNF layer developed when exposing Ni foam to ethylene. Two carbon layers were formed on $\mathrm{Ni}$ surface simultaneously; a micro-porous C-layer at the carbon-Ni interface and a macro-porous CNF layer on top of the C-layer. Detailed characterization of both layers revealed that both C-layer and CNFs contain graphene planes; CNFs having higher ordering. The CNFs are strongly attached to Ni foam by penetrating into the carbon layer, which itself is attached strongly to the metal surface. These roots are formed by continuous growth of the C-layer during CNF formation, embedding the first part of the CNFs in the C-layer. The interconnections between Ni surface, C-layer and CNFs result in mechanical stability. 


\section{References}

[1] W.I. Milne, K.B.K. Teo, G.A.J. Amaratunga, P. Legagneux, L. Gangloff, J.P. Schnell, V. Semet, V. Thien Binh, O. Groening, J. Mater. Chem. 14 (2004) 933943.

[2] A. Bruke, J. Power sources 91 (2000) 37-50.

[3] P. Serp, M. Corrias, P. Kalck, Appl. Catal. A 253 (2003) 337-358.

[4] E. Hammel, X. Tnag, M. Trampert, T. Schmitt, K. Mauthner, A. Eder, P. Potschke, Carbon 42 (2004) 1153-1158.

[5] K.K.S. Lau, J. Bico, K.B.K. Teo, M.G. Chhowalla, A.J. Amaratunga, W.I. Milne, G.H. McKinley, K.K. Gleason, Nano Lett. 3 (2003) 1701-1705.

[6] K.B.K. Teo, C. Singh, M. Chhowalla, W.I. Milne, Encyclopedia of Nanoscience and Nanotechnology X (2003) 1-22.

[7] D.L. Trimm, Catal. Rev. Sci. Eng. 16 (1977) 155-189.

[8] S.D. Robertson, Nature 221 (1969) 1044-1046.

[9] J.R. Rostrup-Nielsen, D.L. Trimm, J. Catal. 48 (1977) 155-165.

[10] C.H. Bartholomew, Catal. Rev. Sci. Eng. 24 (1982) 67-112.

[11] J.L. Figueiredo, Erdoel Kohle-Erdgas-Petrochem. 42 (1989) 294-297.

[12] R.T.K. Baker, M.A. Barber, P.S. Harris, F.S. Feates, R.J. Waite, J. Catal. 26 (1972) 51-62.

[13] N.M. Rodriguez, J. Mater. Res. 8 (1993) 3233-3250.

[14] R.T. Yang, J.P. Chen, J. Catal. 115 (1989) 52-64.

[15] M.S. Hoogenraad. Growth and utilization of carbon fibers, PhD Thesis, Utrecht University (1995).

[16] K.P. De Jong, J. Geus, Catal. Rev. Sci. Eng. 42 (2000) 481-510.

[17] P.M. Ajayan, Chem. Rev. 99 (1999) 1787-1800.

[18] H.J. Dai, Acc. Chem. Res. 35 (2002) 1045-1053.

[19] P. Tribolet, L. Kiwi-Minsker, Catal. Today 102-103 (2005) 15-22.

[20] N. Jarrah, J.G. van Ommen, L. Lefferts, Catal. Today 79 (2003) 29-33.

[21] N. Jarrah, F. Li, J.G. van Ommen, L. Lefferts, J. Mater. Chem. 15 (2005) 19461953.

[22] M.J. Ledoux, C. Pham-Huu, Catal. Today 102-103 (2005) 2-14.

[23] J.K. Chinthaginjala, K. Seshan, L. Lefferts, Ind. Eng. Chem. Res. 46 (2007) 3968-3978.

[24] R. Schneider, E. Pippel, J. Wolterdorf, S. Strauss, H. Grabke, Steel Research 68 (1997) 326-332.

[25] R. Vieira, M.J. Ledoux, C. Pham-Huu, Appl. Catal. A 274 (2004) 1-8.

[26] E. Pippel, J. Woltersdorf, R. Schneider, Materials and Corrosion 49 (1998) 309316. 
[27] N.M. Rodriguez, A. Chambers, R.T.K. Baker, Langmuir 11 (1995) 3862-3866.

[28] N.A. Jarrah, J.G. van Ommen, L. Lefferts, J. Catal. 239 (2006) 460-469.

[29] A.C. Ferrari, J. Robertson, Phys. Rev. B 64 (2001) $754141-7541413$.

[30] F. Tuinstra, J.L. Koenig, J. Chem. Phys. 53 (1970) 1126-1130.

[31] J. Robertson, Surface and Coatings Technology 50 (1992) 185-203.

[32] K.W.R. Gilkes, S. Prawer, K.W. Nugent, J. Robertson, H.S. Sands, Y. Lifshitz, X. Shi, J. Appl. Phys. 87 (2000) 7283-7289.

[33] H. Hiura, T.W. Ebbesen, K. Tanigaki, Chem. Phys. Lett. 202 (1993) 509-512.

[34] J.G. McCarthy, H. Wise, J. Catal. 57 (1979) 406-416.

[35] J. Van Doorn, R.C.S. Verheul, L. Singoredjo, J.A. Moulijn, Fuel 65 (1986) 1383-1387.

[36] J.G. McCarthy, P.Y. Hou, D. Sheridan, H. Wise, Am. Chem. Soc-Symp. Ser. 202 (1982) 253-282.

[37] A. Tomita, N. Sato, Y. Tamai, Carbon 12 (1973) 143-149.

[38] J. Phillips, T. Shiina, M. Nemer, K. Lester, Langmuir 22 (2006) 9694-9703.

[39] J.A. Menendez, B. Xia, J. Phillips, L.R. Radovic. Langmuir 13 (1997) 34143421.

[40] B. Xia, J. Phillips, C.K. Chen, L.R. Radovic, I.F. Silva, J.A. Menendez, Energy Fuels 13 (1999) 903-906.

[41] J. Phillips, D.J. Kelly, L.R. Radovic, D.F. Kie, J. Phys. Chem. B 104 (2000) 8170-8176. 


\title{
Chapter
}

\section{Influence of hydrogen on the formation of a thin layer of carbon nanofibers on $\mathrm{Ni}$ foam}

\begin{abstract}
Carbon nanofibers (CNFs) were catalytically grown on $\mathrm{Ni}$ foam by decomposing ethylene in the presence of hydrogen. Variation of hydrogen concentration during CNF growth resulted in significant manipulation of the properties of a thin layer of CNFs. Addition of hydrogen retards carbon deposition and increases the surface area of the CNF layer because of formation of thinner fibers. The thickness of CNF layer shows an optimum at intermediate hydrogen concentrations. These effects contribute to the competitive adsorption of hydrogen and ethylene, influencing the availability of carbon on the Ni surface, which is necessary for both the formation of small $\mathrm{Ni}$ particles by fragmentation of polycrystalline Ni, as well as for CNF-growth after formation of small particles. Furthermore, decreasing the carbon supply via adding hydrogen also delays deactivation by encapsulation of Ni particles. The thickness of the micro-porous $C$ layer between the Ni surface and the CNF layer decreases with hydrogen addition, at the expense of a slight loss in the attachment of the CNFs to the foam, supporting the proposition that CNFs are attached by roots in the C-layer. The addition of hydrogen after the initial CNF formation in ethylene only causes fragmentation of the C-layer, inducing significant loss of CNFs.
\end{abstract}




\subsection{Introduction}

Micro-structured materials such as Carbon-Nano-Tubes (CNTs) and CarbonNano-Fibers (CNFs) can be synthesized by three main processes: arc discharge [1, 2], laser ablation [3] and catalytic chemical vapor deposition (CCVD). The CCVD method uses transition metals ( $\mathrm{Ni}, \mathrm{Fe}, \mathrm{Co}$ ) to grow CNTs and CNFs by decomposing hydrocarbons at temperatures between 400 and $1000^{\circ} \mathrm{C}$ [4]. The rate of formation of these materials is influenced by carbon source, temperature, metal crystal size [5-7] and hydrogen concentration [7-24]. Presence of hydrogen has two competing effects. First, hydrogen slows down the rate of formation of CNFs/CNTs on metal nanoparticles. Second, hydrogen prevents or at least retards the deactivation of metal particles by preventing complete encapsulation, thus increasing the number of active particles and, consequently, the rate of formation.

Aggregates of entangled CNFs provide high surface area $\left(100-200 \mathrm{~m}^{2} / \mathrm{g}\right)$, combined with high macro porosity and low tortuosity [25, 26]. These properties are favorable for catalyst supports, maximizing the mass transfer rate, which is particularly important for heterogeneous catalytic reactions in liquid phase. Furthermore, these materials are mechanically strong, chemically inert and the surface chemistry can be modified. Finally, CNFs can be produced in large amounts, resulting in a novel catalyst support materials [26 - 28].

Conventional technologies for heterogeneous catalytic reactions involving both liquid and gas phases comprise slurry reactors or trickle bed reactors. Usage of small catalyst support particles can prevent mass transfer limitations in slurry phase, with the important disadvantage of the necessity of a filtration unit. In addition, application of small CNF aggregates would suffer from agglomeration of the aggregates in the filtration unit. In trickle bed reactors, application of small CNF aggregates would result in high pressure drop. Immobilization of CNFs on a structured support can overcome these problems. Thin layers of CNFs on structured materials would combine the advantages of slurry phase operation (short diffusion length) and fixed bed operation (no catalyst separation). Various authors have reported on immobilization of CNFs on structured/macroscopic supports such as foams, monoliths and filters [29-37]. 
Various authors have speculated about the mechanism of strong attachment of CNFs on monoliths [33, 36] as well as Ni- and carbon foams [22, 31]. In our research, we used Ni foam to grow and support CNFs because of two reasons. First, solid foam packing have been demonstrated to be able to increase gas-liquid mass transfer and optimize hydrodynamics [38]. Second, the application of Ni foams has the advantage, as compared to carbon foams e.g., that $\mathrm{Ni}$ is intrinsically active in formation of CNFs, without any additional step to introduce a catalyst for CNF synthesis [34, 50].

In chapter 2 [39], a stable macro-porous CNF layer was prepared on $\mathrm{Ni}$ foam along with a micro-porous C-layer between the foam surface and the CNF layer. It was observed that during CNF synthesis both the C-layer and CNF layer develop in parallel. The CNFs are strongly attached to $\mathrm{Ni}$ foam by penetrating into the carbon layer, which itself is attached strongly to the metal surface. These roots are formed by continuous growth of the C-layer during CNF formation, embedding the first part of the CNFs in the C-layer. The interconnections between Ni surface, C-layer and CNFs result in mechanical stability. In this work, we studied the effect of the hydrogen partial pressure during the CNF synthesis on the properties of both the C-layer as well as the CNFs on the foam surface. The challenge is to tune the properties of the CNF layer, i.e., increasing the surface area combined with high porosity and low tortuosity, while maintaining strong attachment to the macroscopic support.

\subsection{Experimental}

\subsubsection{Materials}

The Ni foam (RECEMAT) applied in this study is a three dimensional network of connected strands, as shown in figure 3.1. The foams were provided as sheets with a thickness of $5 \mathrm{~mm}$. The geometric surface area per gram Ni was estimated to be less than $1 \mathrm{~m}^{2} / \mathrm{g}$ [31]. Cylindrical pieces of $\mathrm{Ni}$ foams $(4.3 \mathrm{~mm}$ in diameter and $5 \mathrm{~mm}$ height) were prepared from the sheet by wire cut electrical discharge machine (AGIECUT CHALLENGE 2).

Hydrogen and nitrogen (99.999\%, INDUGAS), and ethylene (99.95\%, PRAXAIR) were used for CNFs formation without further purification. 


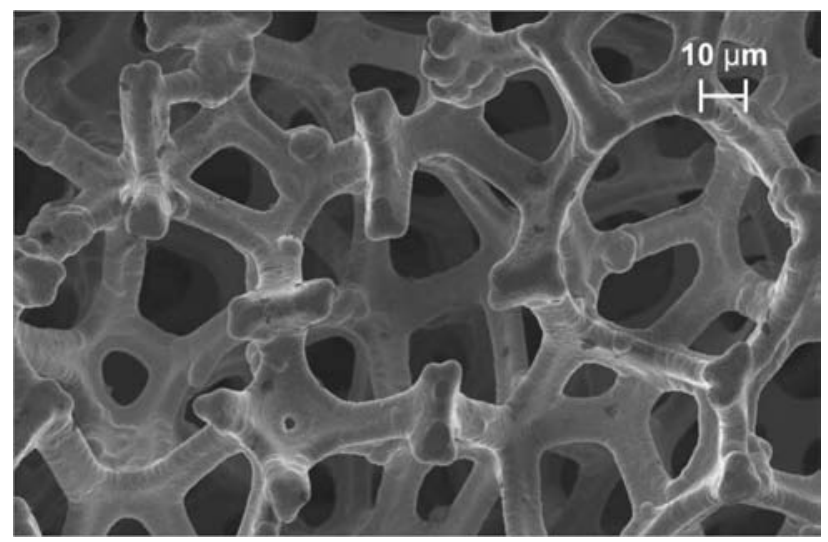

Figure 3.1 - SEM image of as received Ni foam.

\subsubsection{Carbon nanofiber formation}

CNF formation was carried out in a quartz reactor with a porous quartz plate at the bottom to support the $\mathrm{Ni}$ foam. A sample of about $0.15 \mathrm{~g}$, which is equivalent to four cylindrical pieces of $\mathrm{Ni}$ foam was used to form CNFs. The fresh $\mathrm{Ni}$ foams were pre-treated in static air for $1 \mathrm{hr}$ at $700^{\circ} \mathrm{C}$. The temperature was raised $\left(6^{\circ} \mathrm{C} / \mathrm{min}\right)$ from room temperature to $700^{\circ} \mathrm{C}$. After the oxidation the samples were flushed with nitrogen $(100 \mathrm{ml} / \mathrm{min})$ for $5 \mathrm{~min}$ before introducing hydrogen. Reduction was performed at $700^{\circ} \mathrm{C}$ in $20 \% \mathrm{H}_{2}$ in $\mathrm{N}_{2}$ with total flow rate of $100 \mathrm{ml} / \mathrm{min}$.

After the pre-treatment, the temperature was decreased to $440{ }^{\circ} \mathrm{C}$ at $5{ }^{\circ} \mathrm{C} / \mathrm{min}$ in the $\mathrm{H}_{2} / \mathrm{N}_{2}$ mixture. The CNFs were grown using a gas mixture of hydrogen and ethylene in nitrogen with a total flow rate of $107 \mathrm{ml} / \mathrm{min}$. The concentration of ethylene (25\%) in the feed was kept constant in all experiments and the nitrogen flow was adjusted whenever hydrogen concentration (0 - $14 \%)$ was modified. In all the experiments the CNF growth was performed for one hour.

On-line chromatography (Varian GC model 3700 equipped with a 15 m Q-Plot column) was used to determine the concentrations of products in the exit gas-stream. Hydrogen and traces of ethane were the only products observed with GC, next to unconverted ethylene. The concentration of ethane detected was close to the detection limit of the GC. A quadrupole mass spectrometer (Pfeiffer AG Balzers, OmniStar) equipped with Channeltron and Faraday detectors (2-200 amu) was used to qualitatively determine the formation of traces of other products. The rate of CNFformation was calculated from the production rate of hydrogen. The maximum 
conversion of ethylene was always below $10 \%$, unless a higher conversion is reported. Finally, the sample was cooled down in $\mathrm{N}_{2}$ to room temperature. The amount of carbon formed on the foam was determined by measuring the increase in the weight caused by the formation of CNFs.

\subsubsection{Characterization}

Mechanical stability of immobilized CNFs was tested by blowing compressed nitrogen at $120 \mathrm{~L} / \mathrm{min}$ for one minute through the foam, inducing removal of any loose CNFs before further characterization.

BET surface area of CNFs was calculated from the $\mathrm{N}_{2}$-adsorption isotherm obtained at $77 \mathrm{~K}$ (ASAP 2400 Micromeritics).

The morphology of the samples was studied with Scanning Electron Microscopy (SEM) LEO 1550 FEG-SEM equipped with in-lens detector. Crosssections of the layer of carbon deposited were obtained by simply cutting with a pair of scissors.

\subsection{Results}

\subsubsection{Effect of hydrogen}

The effect of hydrogen on carbon deposition was studied in two different sets of experiments; either by introducing hydrogen continuously during the 60 min period, or by introducing hydrogen after $30 \mathrm{~min}$.

The rate of carbon deposition was calculated based on the rate of hydrogen formation during the reaction. Figure 3.2 illustrates the rates of carbon deposition varying the hydrogen concentration between 0 and 14\%. All the samples clearly show an initiation effect and the extent of the initiation period increases with increasing hydrogen concentration. The slope in the rate of carbon deposition decreases with increasing hydrogen concentration. In the absence of hydrogen, carbon deposition deactivates after $20 \mathrm{~min}$, whereas deactivation seems to set in just at the end of the experiment when operating with $2.4 \%$ hydrogen concentration. 


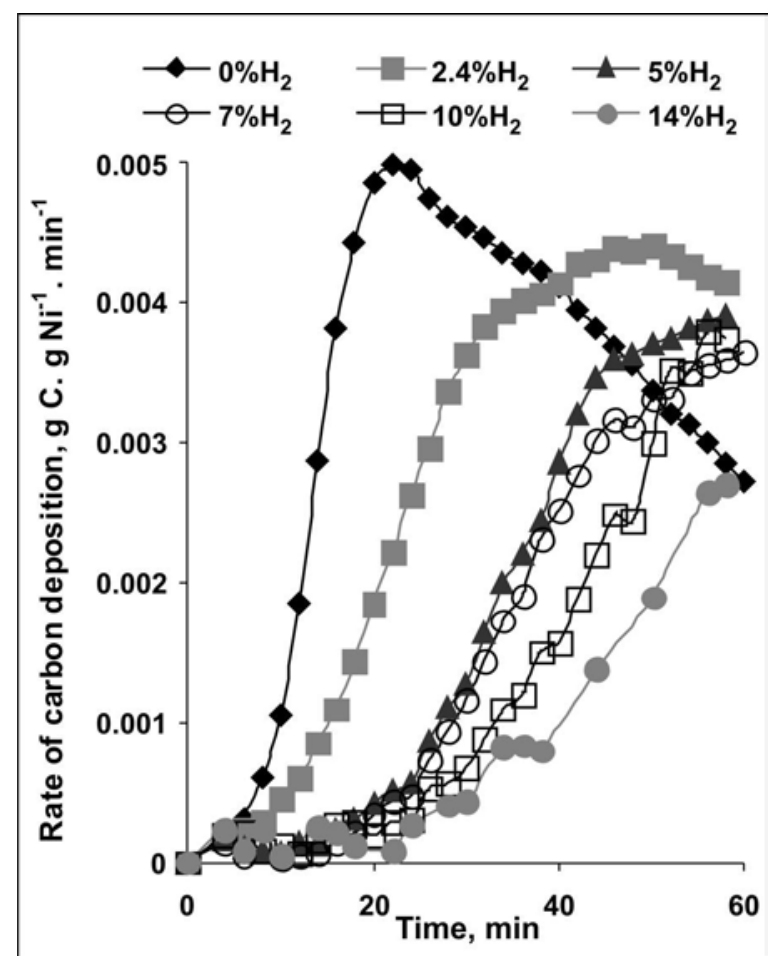

Figure 3.2 - Kinetics of carbon deposition during 0 and 60min at hydrogen concentration between $0-14 \%$.

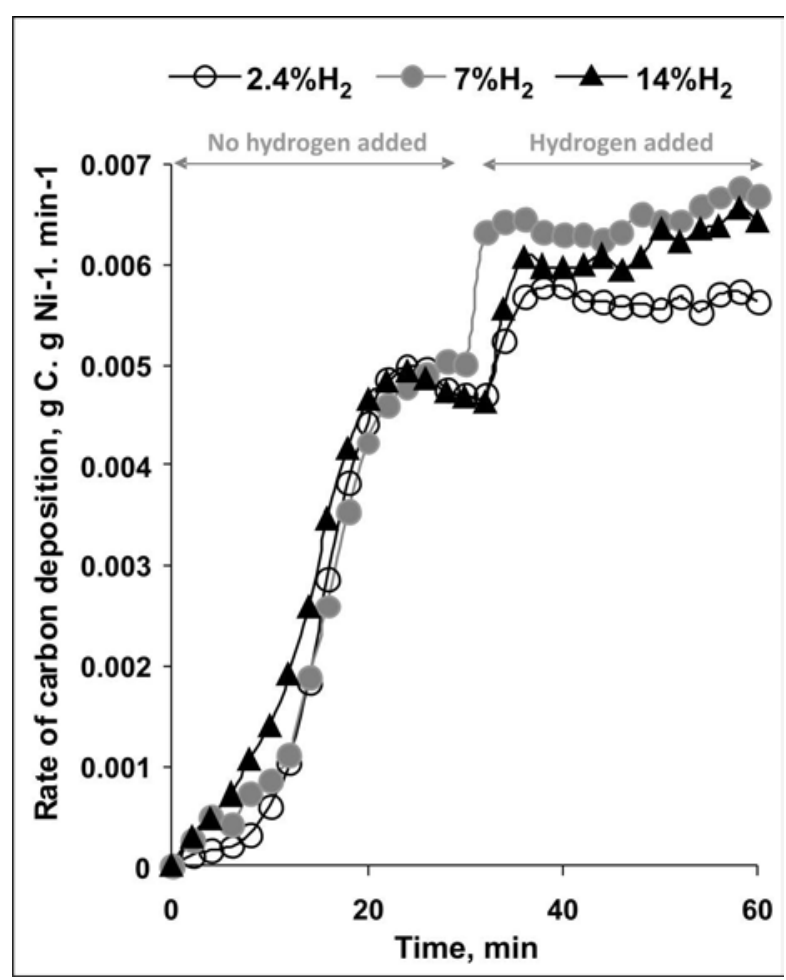

Figure 3.3 - Kinetics of carbon deposition at hydrogen concentration between $2.4-14 \%$ during 30 and $60 \mathrm{~min}$. 
Figure 3.3 presents the rates of carbon deposition when hydrogen was introduced after 30 min, with concentrations between 2.4 and 14\%. Hydrogen addition causes an immediate increase in the rate of carbon deposition. Furthermore, no deactivation is observed anymore as the rate is constant in time. Figure 3.4 shows semi-qualitatively the variation in the concentration of products in the exit by mass spectrometry, when adding $7 \%$ hydrogen after $30 \mathrm{~min}$. Next to hydrogen, also traces of methane and ethane are observed. The sharp spike observed at the moment of adding hydrogen is an artefact.

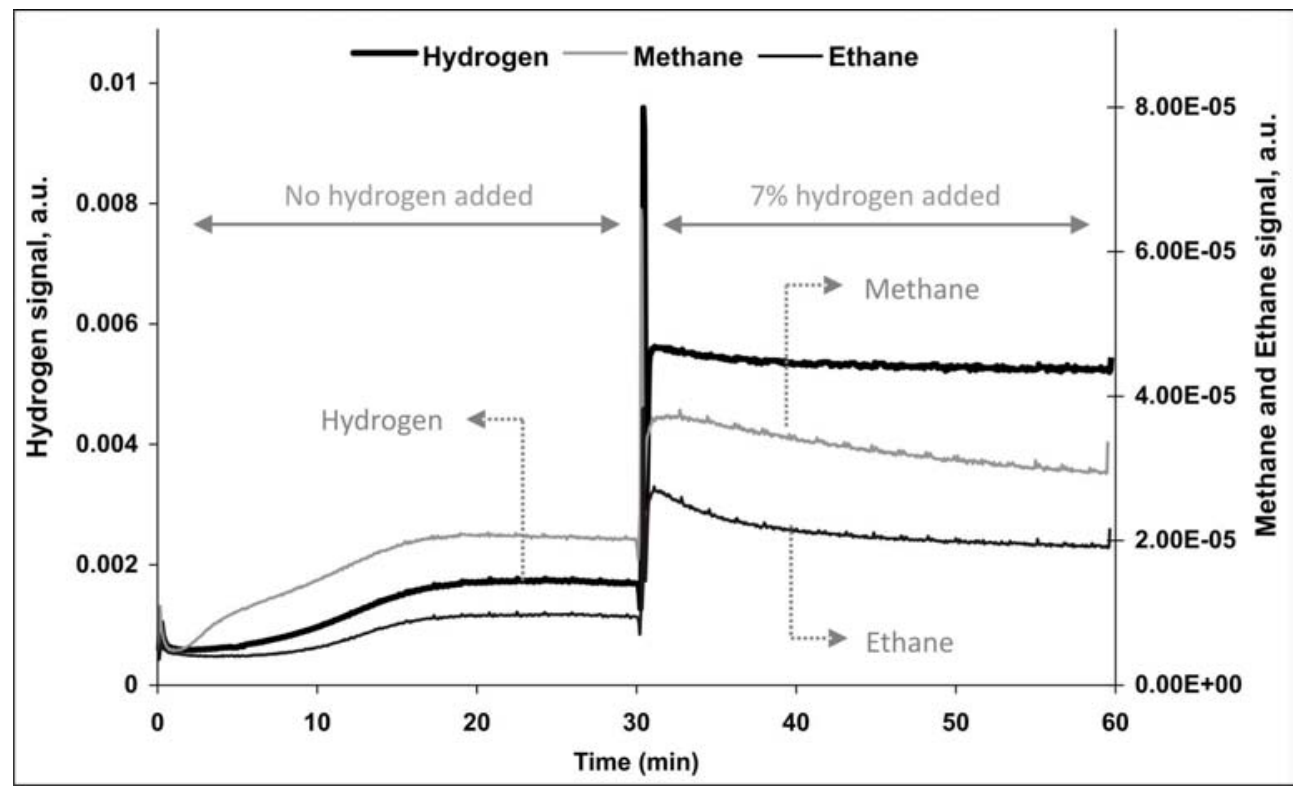

Figure 3.4 - Mass spectroscopy signals of the products formed when adding 7\% hydrogen addition after $30 \mathrm{~min}$.

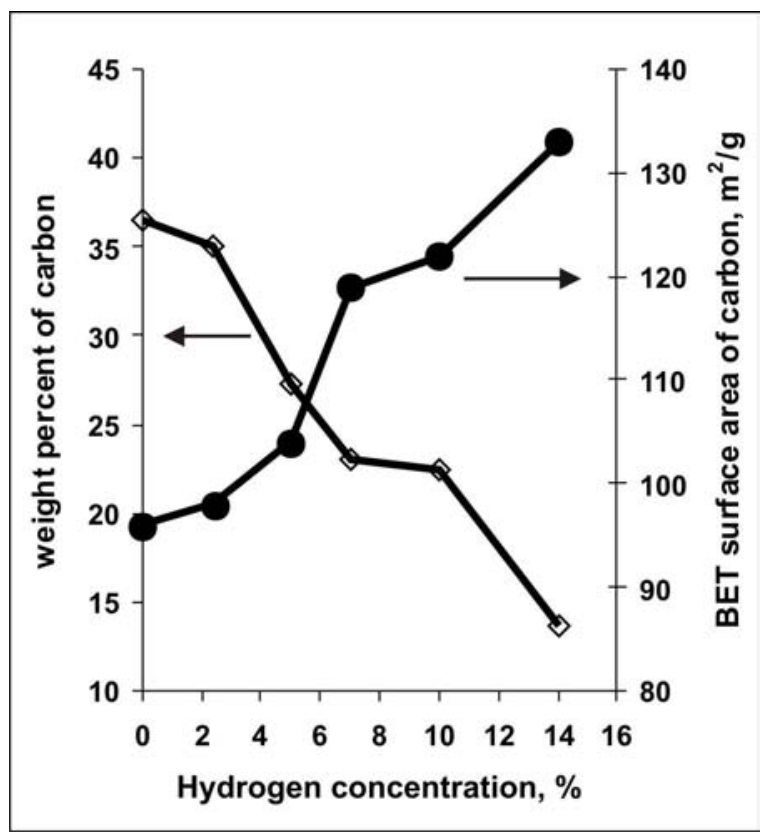

Figure 3.5 - BET surface areas of carbon formed at different $\mathrm{H}_{2}$ concentrations added continuously. 
Figure 3.5 and 3.6 presents the amounts of carbon deposited on Ni foam and the BET surface areas when adding hydrogen continuously and after 30 minutes, respectively. In the case of continuous addition of hydrogen, the carbon loading decreases with increasing hydrogen concentration, while the BET surface area per gram carbon increases. When hydrogen is added after $30 \mathrm{~min}$, both the amount of carbon deposited as well as the surface area increase with increasing hydrogen concentration.

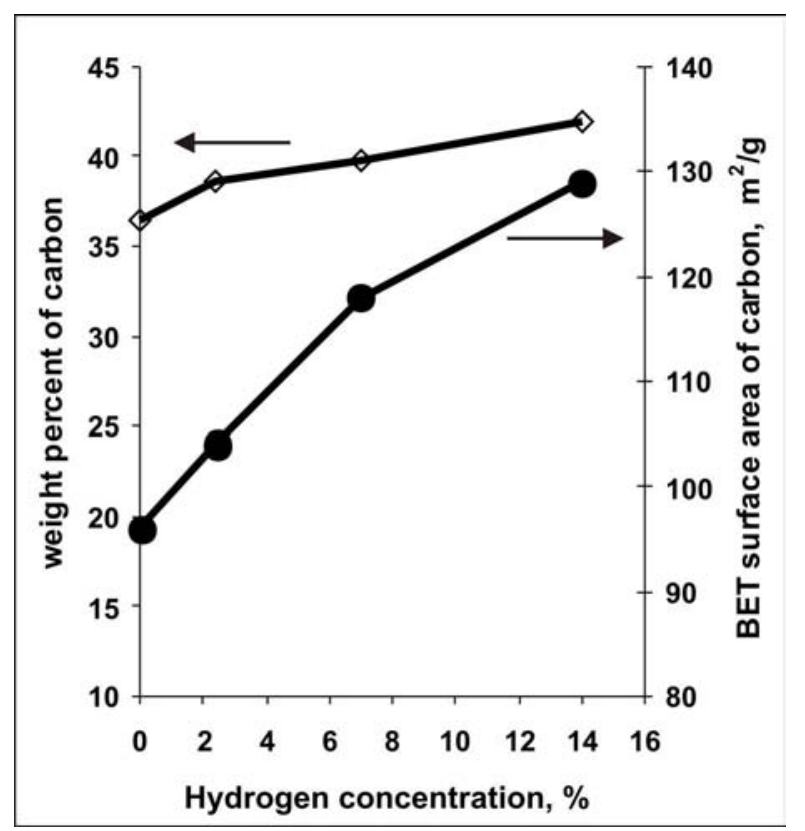

Figure 3.6 - BET surface areas of carbon formed at different $\mathrm{H}_{2}$ concentrations added between 30 and 60 minute exclusively.

Figure 3.7 presents histogram of CNF diameter distributions, when varying the hydrogen concentration in the case of continuous hydrogen addition. CNF diameters were determined based on ten SEM images (not shown) of each sample, estimating the diameters of typically 300 fibers in total. Increasing hydrogen concentration causes an increase in the fraction of CNF diameters that are smaller than $20 \mathrm{~nm}$. The average CNF diameter decreases with increasing hydrogen concentration. 


\subsubsection{Stability of CNFs}

The attachment of CNFs to the Ni foam was studied by flowing compressed nitrogen at a flowrate of $120 \mathrm{~L} / \mathrm{min}$ through the foam, as to determine the fraction of poorly bound CNFs. Figure 3.8 shows that in the absence of hydrogen only a small fraction of the CNFs can be removed, in agreement with chapter 2 [39]. Addition of hydrogen, and especially addition of hydrogen after 30 minutes, appears to affect the attachment of the fibres and the fraction that can be removed increases.

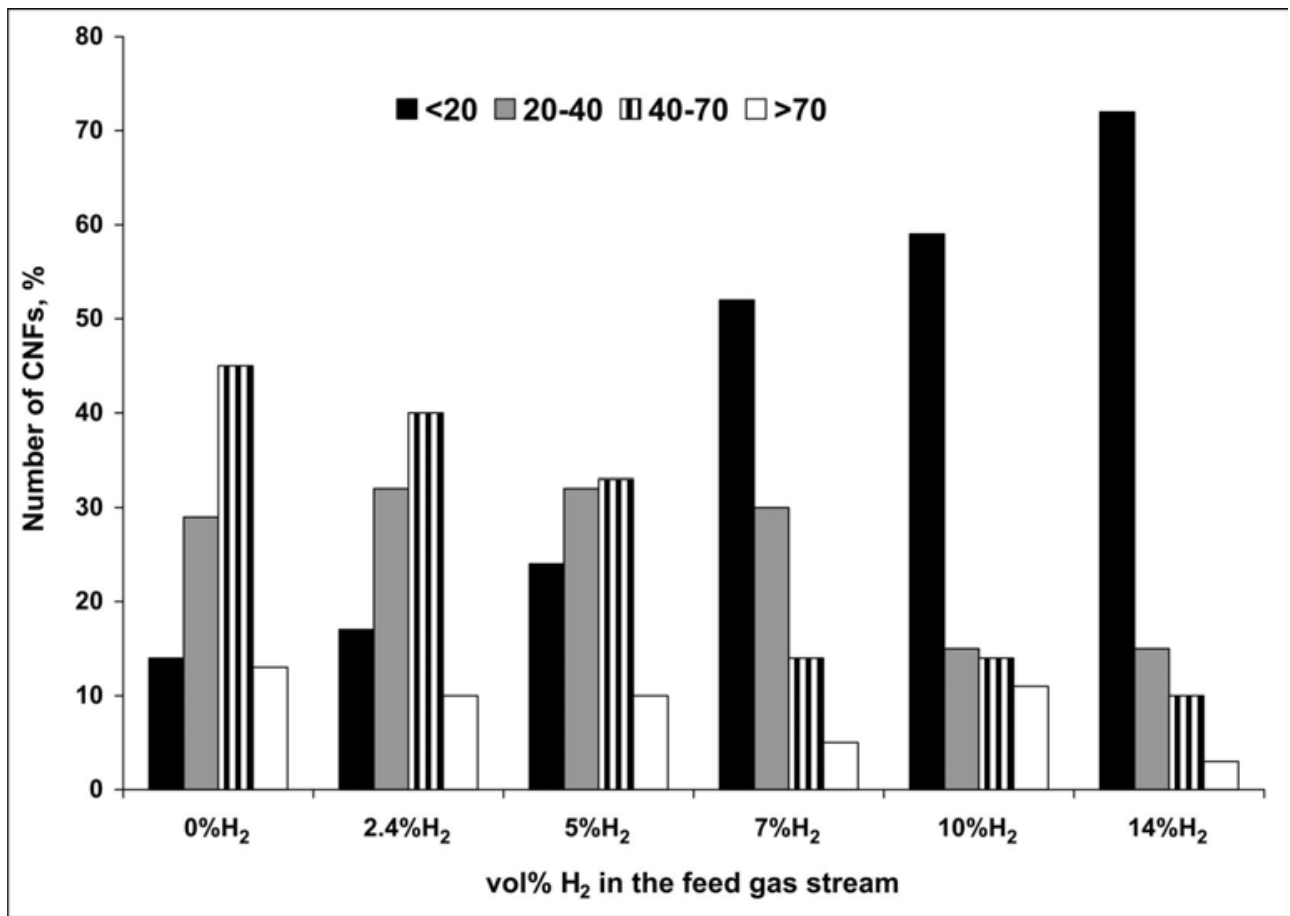

Figure 3.7 - Histogram of the diameters of CNFs formed by continuous addition hydrogen for 60 min between 0 and $14 \%$ hydrogen concentration.

After removing the loosely bound fibers, cross-sections of the samples were characterized with SEM in order to determine the thickness of CNF layer formed on Ni surface. Figure 3.9 and 3.10 show these cross-sections of carbon deposits on the $\mathrm{Ni}$ surface formed when hydrogen was continuously added at different concentrations. Figure 3.9 shows the lower magnification images in order to determine the thickness of CNF layer, whereas Figure 3.10 presents higher magnification images when adding $0 \%$ and $7 \%$ hydrogen, focusing on the presence of a C-layer between the Ni surface and the CNF layer. It was observed that all samples contain these two layers of carbon, in agreement with chapter 2 [39]. The thickness of this layer was determined for all samples with SEM but micrographs are not presented because of similarity with Figure 3.10b. The thicknesses of these two layers were determined from the 
SEM images, based on five micrographs at different positions in each sample; the averaged thicknesses are presented in figure 3.11. The C-layer thickness decreases with increasing hydrogen concentration, whereas, the thickness of the CNF layer showed a maximum at an intermediate hydrogen concentration.

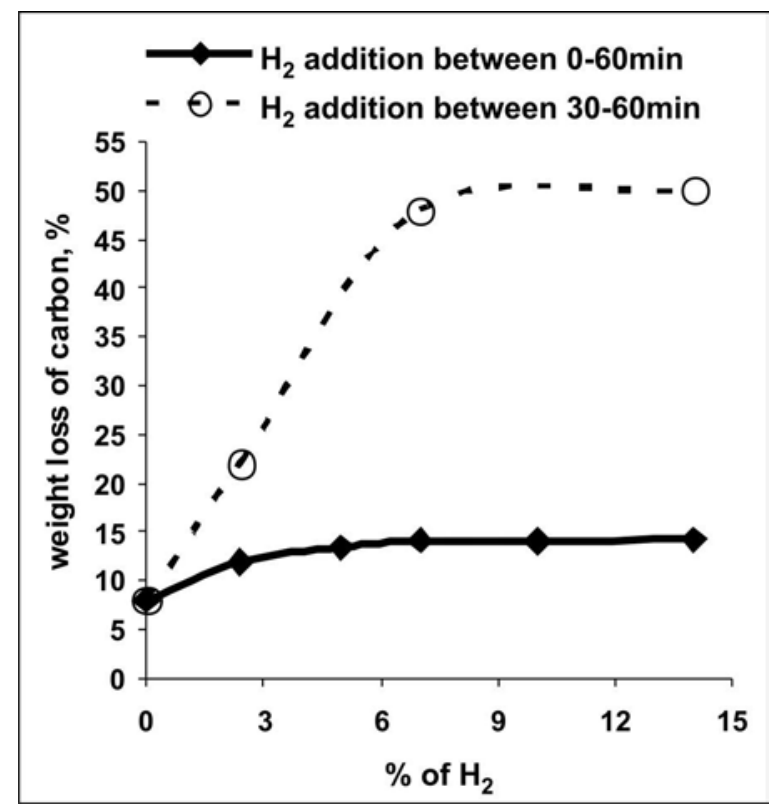

Figure 3.8 - Weight loss of carbon formed by addition of hydrogen between 060min and 30-60min.

Similar SEM analyses were done for samples prepared via adding hydrogen after 30mins (SEM images not shown), after removal of all loosely bound fibers. Figure 3.12 shows a graphical representation of the thicknesses of both the C-layer and the CNF layer as measured with SEM. The thickness of the C-layer gradually decreases with increasing hydrogen concentration, whereas the CNF layer thickness dramatically decreases from $\sim 25$ to $\sim 3$ microns at higher hydrogen concentrations. Figure 3.13 shows the top view of the sample when adding 7 and $14 \%$ hydrogen, respectively; in essence the C-layer and only few CNFs can be seen, instead of a continuous CNF layer as in Figure 3.9. Furthermore, the C-layer shows cracks containing some CNFs. 

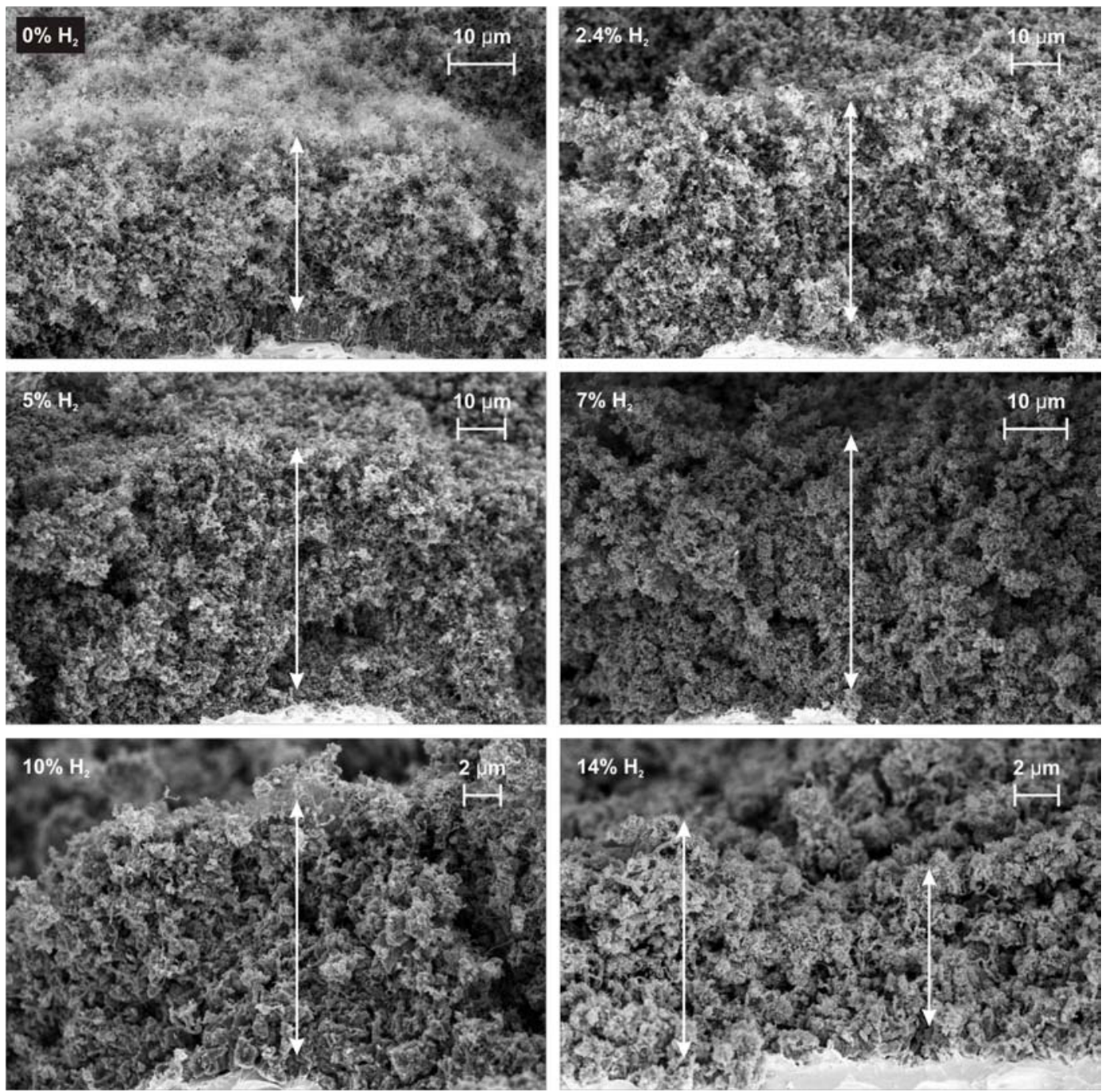

Figure 3.9 - Thicknesses of CNF layer formed by addition of hydrogen between 0 and $60 \mathrm{~min}$.
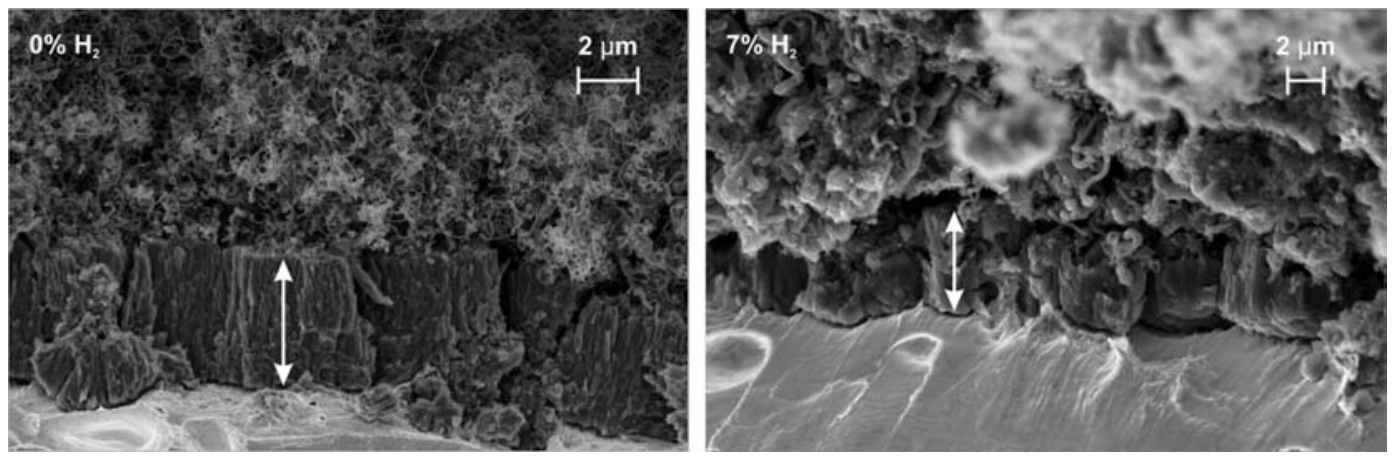

Figure 3.10 - Thicknesses of C-layer formed at 0 and 7\% concentrations of hydrogen by continuous addition of hydrogen for $60 \mathrm{~min}$. 


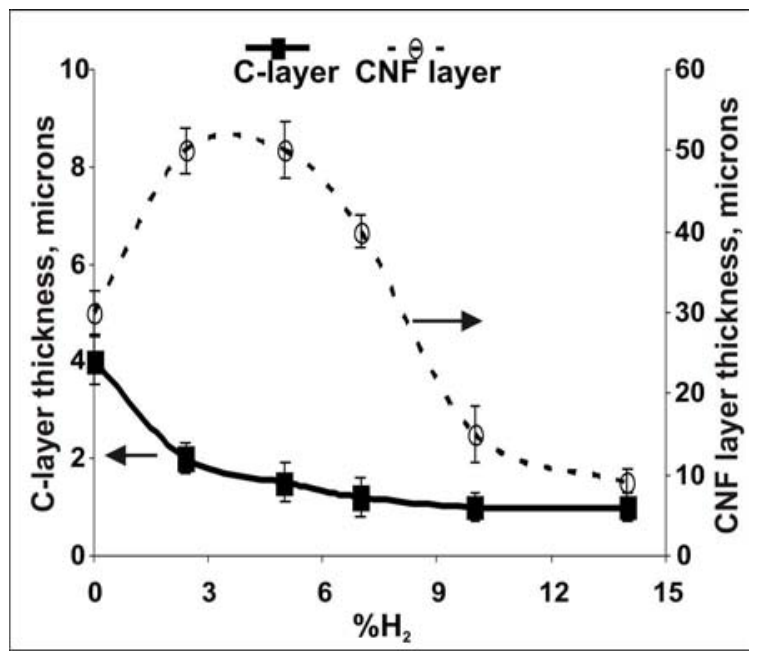

Figure 3.11 - The influence of continuous hydrogen addition (0 to $60 \mathrm{~min}$ ) on the thickness of the C-layer and the CNF layer.

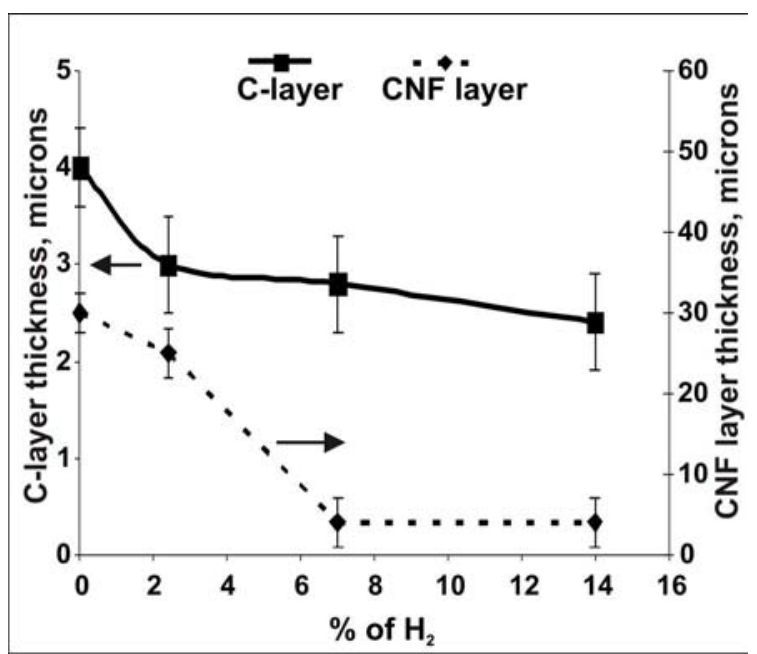

Figure 3.12 - The influence of the hydrogen concentration, added after $30 \mathrm{~min}$ till 60 min on the thickness of the C-layer and the CNF layer.
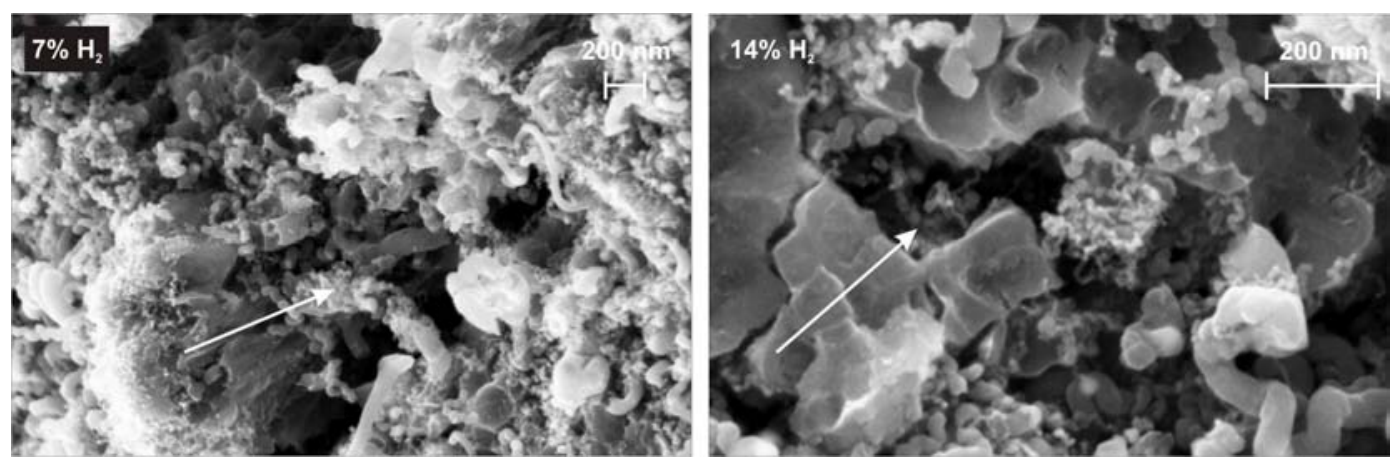

Figure 3.13 - SEM analyses performed after the shear force test on the sample where carbon was formed by the addition of $14 \%$ hydrogen between 30 and 60 min. Top view of the cracked C-layer with CNFs grown in the layer. Arrows indicate the cracks in the C-layer. 


\subsection{Discussion}

The overall rate of CNFs formation is determined by the number of Ni particles allowing CNFs formation, as well as the rate of CNF formation of each individual $\mathrm{Ni}$ particle. The number of $\mathrm{Ni}$ particles contributing to the formation of CNFs is determined by the rate of generation of small $\mathrm{Ni}$ particles via fragmentation of $\mathrm{Ni}$ grains in the surface of the $\mathrm{Ni}$ foam, as well as by the rate of deactivation of $\mathrm{Ni}$ particles due to encapsulation with carbon [31].

\subsubsection{Role of hydrogen}

In figure 3.2, the rate of carbon deposition showed an activation plateau when increasing the hydrogen concentration in the feed. This induction period is due to slow formation of small $\mathrm{Ni}$ particles via fragmentation of $\mathrm{Ni}$ grains in the surface of the $\mathrm{Ni}$ foam, which is a prerequisite for the CNF growth [31]. The presence of hydrogen changes the rates of the surface elementary reaction steps. Higher hydrogen concentrations enhance the surface coverage of adsorbed hydrogen on $\mathrm{Ni}$, consequently reducing the number of adsorption sites available for ethylene. Therefore, carbon deposition via ethylene decomposition is partly suppressed. Jarrah et al. [31] proposed that small Ni particles are formed via 1) decomposition of ethylene on the polycrystalline $\mathrm{Ni}$ surface, 2) diffusion of carbon into $\mathrm{Ni}$, eventually forming Ni-carbide $\left(\mathrm{Ni}_{3} \mathrm{C}\right)$ and 3 ) decomposition of $\mathrm{Ni}_{3} \mathrm{C}$ into small $\mathrm{Ni}$ particles. Less carbon deposition would therefore decrease the rate of formation of small Ni particles, thus delaying the CNF formation. However, an effect of hydrogen on the size of $\mathrm{Ni}$ particles formed in the induction period cannot be ruled out at this point.

Addition of hydrogen is retarding not only the initiation, but also the deactivation shown in figure 3.2, after small particles were formed as discussed above. At low hydrogen concentration, carbon encapsulation of the Ni particles is dominating, resulting in deactivation. Carbon deposition is reduced on addition of hydrogen via suppressing the encapsulation of $\mathrm{Ni}$ particles with carbon, limiting the extent of deactivation. Kim et al. [51] proposed a similar explanation for the effect of hydrogen on growing CNFs on preshaped Ni nanoparticles, inhibiting excess carbon deposition on the Ni particle thereby slowing down deactivation. 
Increasing the hydrogen concentration in the feed resulted in carbon with increasing surface area (figure 3.5). SEM analysis showed that the average diameter of CNFs decreases with increasing hydrogen concentrations (figure 3.7). Therefore the increase in the surface area can be attributed to the presence of CNFs with smaller diameters. This effect is due to the fact that small Ni particles are more prone to deactivation via encapsulation than large Ni particles, as reported by Chen et. al. [7, 40]. Chen et al. proposed that precipitation of graphene layers at the base of Ni metal is the rate determining step for Ni particles typically smaller than $30 \mathrm{~nm}$. In contrast, formation of surface carbon via decomposition of the hydrocarbon is the rate determining step for larger Ni particles. In our case, Ni particles of various sizes are continuously formed and deactivated via encapsulation. Addition of hydrogen decreases the rate of surface carbon deposition, thereby decreasing the deactivation rate. This effect is stronger for small Ni particles because of the excess of carbon on the surface in absence of hydrogen. In other words, addition of hydrogen improves the balance between graphene precipitation and carbon deposition in small Ni particles, limiting encapsulation and extending formation of thin CNFs.

SEM analysis shows the formation of two distinctive layers, independent on the presence of hydrogen (figures 3.9 and 3.10). It was reported in chapter 2 that the formation of a micro-porous nano-crystalline C-layer below the CNF layer on $\mathrm{Ni}$ foam in the absence of hydrogen [39]. The thickness of CNF layer is maximum at an intermediate hydrogen concentration, whereas the thickness of the C-layer decreased with increasing hydrogen concentration (figure 3.11) for all conditions used in this study.

Nano-crystalline carbon was proposed to form via the decomposition of hydrocarbons over the dangling bonds at the edge of graphene sheets [41-44]. Hydrogen adsorbs at these sites and the existence of free hydrogen atoms on graphite was indeed reported [45-48]. Hydrogen adsorption is therefore most likely in competition with ethylene adsorption on the surface of the growing micro-porous Clayer. Consequently, an increase in hydrogen concentration reduces ethylene adsorption, retarding the growth of the C-layer in agreement with the observation in figure 3.11 . 
The increase in the CNF layer thickness when increasing the hydrogen concentration from 0 to $2.4 \%$ can be attributed to reduced deactivation of $\mathrm{Ni}$ particles. The decrease in CNF layer thickness with increasing the hydrogen concentration from 5 to $14 \%$ is probably caused by a competing effect, i.e. competitive adsorption of ethylene and hydrogen on the surface of the active Ni particles. This competitive adsorption not only influences initiation and deactivation as discussed above, it also reduces the growth rate on active $\mathrm{Ni}$ particles, via partly suppressing ethylene decomposition.

In the discussion so far, the role of hydrogen is three fold. First, presence of hydrogen retards the fragmentation of the Ni surface into smaller Ni particles. Second, hydrogen influences formation of the C-layer via hydrogen/ethylene competition at the edges of graphene sheets. Third, the formation of the CNF layer is also influenced by hydrogen via hydrogen/ethylene competition on the Ni particles, inducing two effects when adding hydrogen: a) retarding CNF growth on active Ni particles and b) delaying deactivation which occurs due to excess deposition of carbon via decomposition of ethylene.

Effects of hydrogen on the fragmentation and formation of small $\mathrm{Ni}$ particles can be excluded by allowing first formation of these particles by feeding ethylene without hydrogen, followed by addition of hydrogen after 30 minutes. In the absence of hydrogen, there is a clear deactivation after $20 \mathrm{~min}$ of reaction time (figure 3.2). Addition of hydrogen to the feed after 30 min showed a rapid increase in the rate of carbon deposition, remaining steady without any deactivation (figure 3.3). At the moment of hydrogen addition, formation of methane and ethane is observed with mass spectrometry (figure 3.4). This observation clearly suggests that the increase in the rate of carbon deposition is due to re-activation of Ni particles via gasification of carbon encapsulating Ni particles to methane. Kim et. al., [51] and Romero et. al., [49] also reported the formation of methane and ethane over $\mathrm{Ni}$ in the presence of ethylene and hydrogen. After the initial re-activation effect, the presence of hydrogen induces competition between hydrogen and ethylene on the Ni surface. This competition is illustrated by the formation of traces of ethane. Thus, hydrogen induces a decrease in the supply of carbon in the Ni surface, avoiding deactivation via encapsulation of the Ni particles. As discussed before, small particles deactivate faster 
than large particles. Reactivation will therefore result in growth of relatively thin CNFs with high surface area, in excellent agreement with the observations in figure 3.6.

\subsubsection{Stability of CNFs}

It was proposed in chapter 2 that the C-layer provides stability by holding the CNFs together at their roots [39]. The weight losses during the shear force test $(120 \mathrm{~L} / \mathrm{min})$ are depicted in figure 3.8. In the case of continuous addition of hydrogen, we attribute the weight loss of carbon to the loss of CNFs exclusively. SEM analysis (not shown) after the shear force test revealed homogeneous coverage of the surface and no sign of complete removal of the layers locally. Nevertheless, the extent of CNF loss increases slightly, but definitively, when the thickness of the carbon layer decreases as illustrated in Figure 3.14.

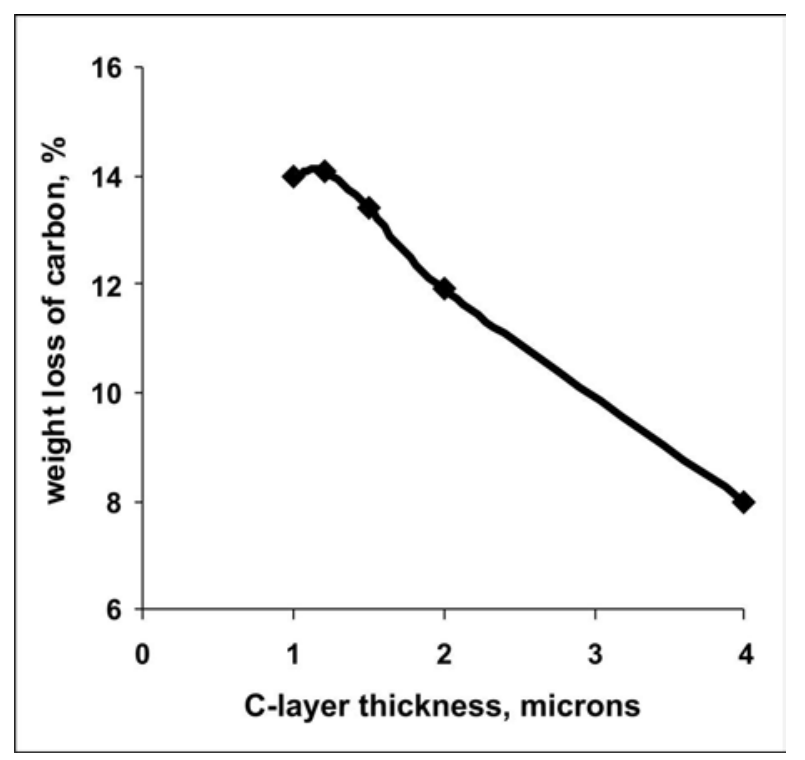

Figure 3.14 - Weight loss of carbon with respect to C-layer thickness that was formed at different partial pressures by continuous addition of hydrogen during $60 \mathrm{~min}$.

In the case of hydrogen addition after 30 minutes, a tremendous loss of carbon was observed during the shear force test, especially for $7 \% \mathrm{H}_{2}$ and higher. SEM observations after the shear force test reveal that the thickness of CNF layer was reduced significantly at higher hydrogen concentrations (figure 3.12). We attribute this to the loss of both C-layer and CNFs (figure 3.12 and 3.13) as the carbon layer appears inhomogeneous and fragmented. We speculate that this effect is caused by 
reactivation of $\mathrm{Ni}$ particles in the micro-porous C-layer, inducing CNF growth in the C-layer which would cause mechanical fragmentation of the C-layer (figure 3.13). This would seem a reasonable explanation for the fact that this phenomenon does not occur when co-feeding hydrogen continuously. Fragmentation of the C-layer would obviously destabilize the attachment of the CNFs.

These observations are in good agreement with the hypothesis formulated in chapter 2 [39] that the CNFs are strongly attached via penetration into C-layer, providing additional support for this hypothesis.

\subsection{Conclusions}

The properties of CNFs on Ni foam can be manipulated by adding hydrogen. Addition of hydrogen results in increasing surface area because of formation of thinner fibres. Remarkably, the thickness of the CNF layer shows an optimum at intermediate hydrogen concentrations. These effects are well understood in terms of hydrogen limiting the supply of carbon on the Ni surface, thereby influencing the rate of formation of small Ni-particles, the rate of formation of CNFs on active $\mathrm{Ni}$ particles as well as the rate of deactivation of Ni particles via encapsulation.

The thickness of the micro-porous C-layer between the Ni surface and the CNF layer is decreasing with hydrogen addition, at the expense of a slight loss in the attachment of the CNFs to the foam, supporting the proposition that CNFs are attached via roots in the C-layer. Remarkably, addition of hydrogen after initial CNF formation in ethylene only causes fragmentation of the C-layer, inducing significant loss of CNFs. 


\section{References}

[1] S. Iijima. Nature 354 (1991) 56-58.

[2] T.W. Ebbesen, P.M. Ajayan, Nature 358 (1992) 220-222.

[3] A Thess, R. Lee, P. Nikolaev, H.J. Dai, P. Petit, J. Robert, et al., Science 273 (1996) 483-487.

[4] S.D. Robertson, Nature 221 (1969) 1044-1046.

[5] G.G. Kuvshinov, Y.I. Mogilnykh, D.G. Kuvshinov, Catal. Today 42 (1998) 357360.

[6] M.L. Toebes, J.H. Bitter, A.J. van Dillen, K.P. de Jong, Catal. Today 76 (2002) $33-42$.

[7] D. Chen, K.O. Christensen, E. Ochoa-Fernandez, Z. Yu, B. Tøtdal, N. Latorre, et al., J. Catal. 229 (2005) 82-96.

[8] M. Endo, Chemtech. 18 (1988) 568-576.

[9] F.J. Zaera, J. Catal. 121 (1990) 318-326.

[10] P.E. Nolan, M.J. Schabel, D.C. Lynch, Carbon 33 (1995) 79-85.

[11] C. Park, N.M. Rodriguez, R.T.K. Baker, J. Catal. 169 (1997) 212-227.

[12] P.E. Nolan, D.C. Lynch, A.H. Cutler, J. Phys. Chem. B 102 (1998) 4165-4175.

[13] C. Park, R.T.K. Baker, J. Phys. Chem. B 102 (1998) 5168-5177.

[14] D. Chen, R. Lodeng, A. Holmen, Catal. Deactivation 126 (1999) 473-476.

[15] K. Bladh, L.K.L. Falk, F. Rohmund, Appl. Phys. A 70 (2000) 317-322.

[16] P. Pinheiro, M.C. Schouler, P. Gadelle, M. Mermoux, E. Dooryhee, Carbon 38 (2000) 1469-1479.

[17] L.J. Ci, J.Q. Wie, B.Q. Wie, J. Liang, C.L. Xu, D.H. Wu, Carbon 39 (2001) 329335.

[18] N.R. Franklin, Y. Li, R.J. Chen, A. Javey, H. Dai, Appl. Phys. Lett. 79 (2001) 4571-4573.

[19] C. Park, M. Keane, Langmuir 17 (2001) 8386-8396.

[20] D. Venegoni, P. Serp, R. Feurer, Y. Kihn, C. Vahlas, P. Kalck, Carbon 40 (2002) 1799-1807.

[21] C. Singh, M.S.P. Shaffer, A.H. Windle, Carbon 41 (2003) 359-368.

[22] R. Vieira, M.J. Ledoux, C. Pham-Huu, Appl. Catal. A 274 (2004) 1-8.

[23] H. Neumayer, R. Haubner, Diam. Relat. Mater. 13 (2004) 1191-1197.

[24] A. De Lucas, A. Garrido, P. Sanchez, A. Romero, J.L. Valverde, Ind. Eng. Chem. Res. 44 (2005) 8225-8236.

[25] N.M. Rodriguez, J. Mater. Res. 8 (1993) 3233-3250.

[26] K.P. De Jong, J. Geus, Catal. Rev. Sci. Eng. 42 (2000) 481-510.

[27] P. Serp, M. Corrias, P. Kalck, Appl. Catal. A 253 (2003) 337-358. 
[28] M.J. Ledoux, R. Vieira, C. Pham-Huu, N. Keller, J. Catal. 216 (2003) 333-342.

[29] N. Jarrah, J.G. van Ommen, L. Lefferts, J. Mater. Chem. 14 (2004) 1590-1597.

[30] P. Tribolet, L. Kiwi-Minsker, Catal. Today 102-103 (2005) 15-22.

[31] N. Jarrah, F. Li, J.G. van Ommen, L. Lefferts, J. Mater. Chem. 15 (2005) 19461953.

[32] M.J. Ledoux, C. Pham-Huu, Catal. Today 102-103 (2005) 2-14.

[33] K.M. De Lathouder, T.M. Flo, F. Kapteijn, J.A. Moulijn, Catal. Today 105 (2005) 443-447.

[34] J.K. Chinthaginjala, K. Seshan, L. Lefferts, Ind. Eng. Chem. Res. 46 (2007) 3968-3978.

[35] E. García-Bordejé, I. Kvande, D. Chen, M. Rønning, Carbon 45 (2007) 18281838.

[36] N. Jarrah, J.G. van Ommen, L. Lefferts, Catal. Today 79 (2003) 29-33.

[37] P.W.A.M. Wenmakers, J. van der Schaaf, F.M. Kuster, J.C. Schouten, J. Mater. Chem. 18 (2008) 2426-2436.

[38] C.P. Stemmet. Gas-liquid solid foam reactors: Hydrodynamics and mass transfer, PhD Thesis, Technical University of Eindhoven (2008).

[39] J.K. Chinthaginjala, D.B. Thakur, K. Seshan, L. Lefferts, Carbon 46 (2008) 1638-1647.

[40] Z. Yu, D. Chen, B. Tøtdal, A. Holmen, Catal. Today 100 (2007) 261-267.

[41] J.A. Menendez, B. Xia, J. Phillips, L.R. Radovic, Langmuir 13 (1997) 34143421.

[42] B. Xia, J. Phillips, C.K. Chen, L.R. Radovic, I.F. Silva, J.A. Menendez, Energy Fuels 13 (1999) 903-906.

[43] J. Phillips, D.J. Kelly, L.R. Radovic, D.F. Kie, J. Phys. Chem. B 104 (2000) 8170-8176.

[44] J. Phillips, T. Shiina, M. Nemer, K. Lester, Langmuir 22 (2006) 9694-9703.

[45] J.A. Menendez, L.R. Radovic, B. Xia, J. Phillips, J. Phys. Chem. 100 (1996) 17243-17248.

[46] H. Chang, J. Phillips, R. Heck, Langmuir 12 (1996) 2756-2761.

[47] J.C. Weigle, J. Phillips, Langmuir 20 (2004) 1189-1193.

[48] J.C. Weigle, J. Phillips, J. AIChE 50 (2004) 821-828.

[49] A. Romero, A. Garrido, A. Nieto-Márquez, A.R. de la Osa, A. de Lucas, J.L. Valverde, Appl. Catal. A 319 (2007) 246-258.

[50] N. Jeong, J. Lee, J. Catal. 260 (2008) 217-226.

[51] M.S. Kim, N.M. Rodriguez, R.T.K. Baker, J. Catal. 131 (1991) 60-73. 



\title{
Chapter 4
}

\section{Thin layer of carbon nanofibers as catalyst support for fast mass transfer in hydrogenation of nitrite}

\begin{abstract}
Carbon nanofiber-foam 'hairy foam' and carbon nanofiber (CNF) aggregates supported Pd catalysts were studied for the reduction of aqueous nitrite solution and also compared with conventional catalysts. Relatively large Pd particle size and similar Pd particle size distribution on all the catalyst supports excludes any structure sensitive effects on reaction. Intrinsic rates over hairy foam catalysts were independent of CNF layer thickness (8-28 $\mu \mathrm{m})$ and Pd loading (0.5-2 wt \%), demonstrating the absence of any mass transfer limitations. When compared to conventional catalysts at comparable diffusion layers, CNF based catalysts showed at least three times higher rates of nitrite conversion per mole of surface palladium (TOF). Increased TOF is due to the improved mass transfer provided by macroporous structure of the entangled CNFs, which offers low tortuosity, provides accessibility to all the active sites. The intrinsic activity of graphite and CNF supported Pd contributes significantly to the high activity for nitrite reduction.
\end{abstract}




\subsection{Introduction}

Multiphase reactors are commonly used in many chemical processes aiming to provide good contact between gas and/or liquid reactants with solid heterogeneous catalysts. Conventional technologies for such heterogeneous catalytic reactions comprise slurry reactors and trickle bed reactors. In slurry phase reactors, very small catalyst particles (typically $<50 \mu \mathrm{m}$ ) are used providing short diffusion path within the catalyst preventing, or limiting internal mass-transfer limitation. However, additional cost for catalyst separation and loss of active metal phase from the catalyst due to attrition are drawbacks, whereas filtration units cause relatively frequent process disturbances [1]. In trickle bed reactors, relatively large catalyst particles sizes (> $1 \mathrm{~mm}$ ) are necessary to limit the pressure drop over the fixed bed. Large catalyst particles induce long diffusion paths within the catalyst particle, thus limiting the mass transfer rate [2]. Presence of concentration gradients within the catalyst decreases overall conversion and induces loss of selectivity.

An interesting proposition is to develop a structured catalyst combining the advantages of slurry phase operation and fixed bed operation. The structured catalyst should provide a large liquid-solid surface area and short diffusion paths within the catalyst, at the same time avoiding the necessity of filtration of small catalyst particles. The application of monoliths, e.g. operated in the Taylor flow regime has been studied extensively [3, 4]. Other structural packing including foams [5-8], filters [9], fibers [10, 11] and cloths [12] have been explored as well.

Solid foam is an alternative option as a structured packing to improve gasliquid mass transfer and optimize hydrodynamics [13]. However, the external surface area is by far not sufficient for a catalyst support and a porous layer needs to be added, similar as in the case of monoliths. This layer should be mechanical stable as well as highly porous, maximizing the mass transfer rate which is particularly important for heterogeneous catalytic reactions in liquid phase. Carbon-nano-fibers (CNFs) are mechanically strong, chemically inert and the surface chemistry can be modified [15, 16, 50], well suited for catalyst support. A general introduction to CNFs relevant to the field of catalysis can be found in the reviews by De Jong et al. and Rodriguez $[15,18]$. Previous work in our group [6, 14] demonstrated that extremely 
porous layers of (CNFs) can be prepared on cylindrical pieces of polycrystalline $\mathrm{Ni}$ foam (figure 4.1), which is designated as 'Hairy foam', resulting in well attached thin layers with very high porosity and low tortuosity. The open structure of CNFs mimics the inverse structure of conventional porous support material, as suggested by Chinthaginjala et al. [17] and Wenmakers et al. [8]. Good attachment of CNFs to the host support is obviously essential for any practical application. In the case of hairy foams, CNFs are strongly attached to the Ni foam surface via a microporous carbon layer, named C-layer hereafter (figure 4.2), and the roots of the CNFs are embedded in this C-layer. Good interconnections between Ni surface, C-layer and CNFs induce mechanical stability, as described in chapter 2 [14].
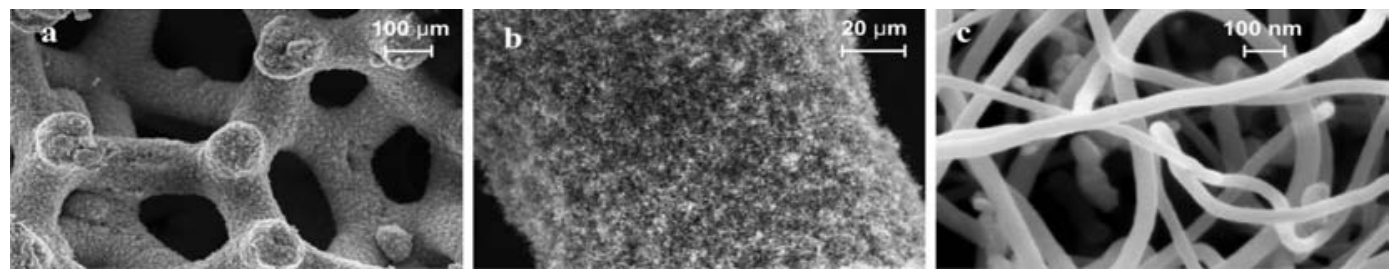

Figure 4.1 - a) Overview of the $\mathrm{Ni}$ foam after the growth of CNFs at $440^{\circ} \mathrm{C}$ in $25 \% \mathrm{C}_{2} \mathrm{H}_{4} / \mathrm{N}_{2}$ for 60 minutes b) CNF coverage on a single strand of the foam, c) CNFs grown on Ni foam showing macro-void spacing between entangled CNFs (chapter 2)[14].

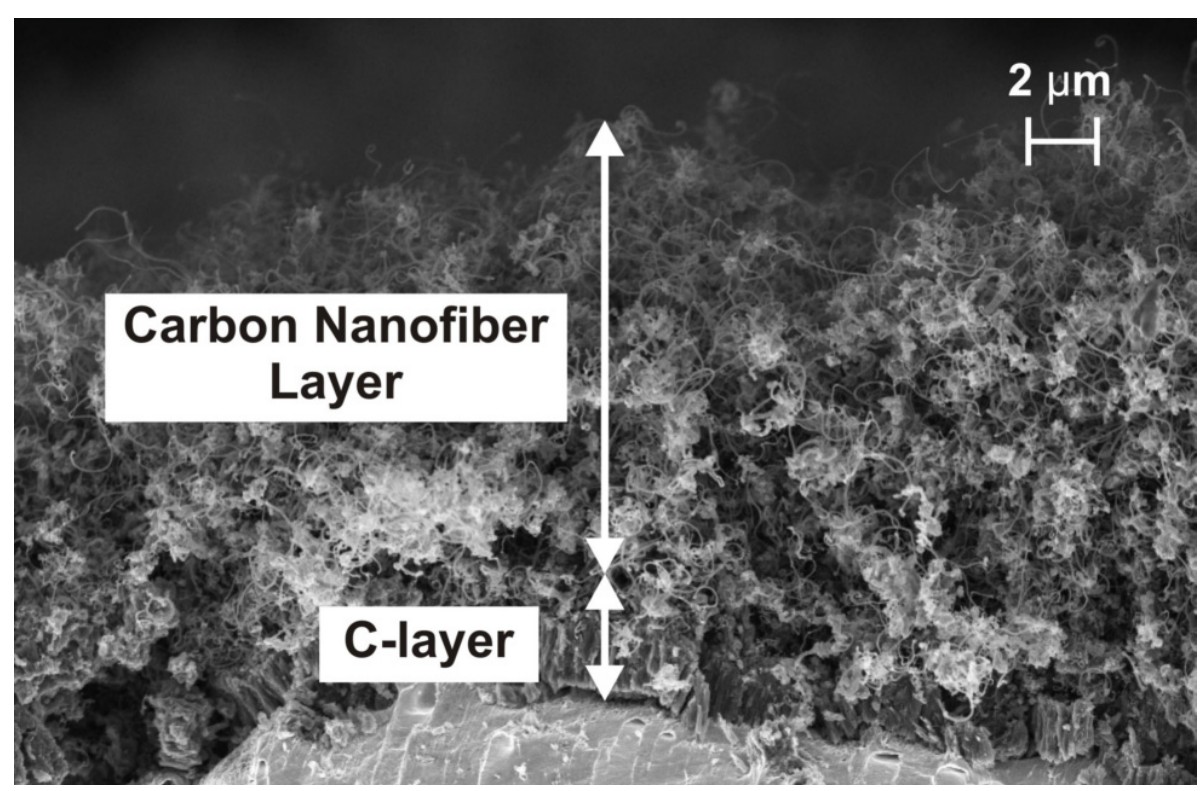

Figure 4.2 - SEM image of CNF and C-layer on the Ni surface of foam (chapter 2) [14]. 
This work aims at demonstrating the superior properties of hairy foam over traditional support materials, by using hydrogenation of nitrite in water as an extremely fast model reaction. Hörold et. al., [19, 20] reported that several noble metals (Pd, Pt, Ru, Ir, Rh) are capable of catalyzing nitrite hydrogenation, Pd being the most active metal. It is reported that hydrogenation of nitrite is extremely fast, easily inducing internal concentration gradients due to diffusion limitation [19, 2123]. Both nitrogen and ammonia are formed in nitrite hydrogenation, according equations (1) and (2) [19, 20, 24]. It should be noted that not only hydrogen and nitrite are reacting, but also protons are consumed and it is suggested that at neutral $\mathrm{pH}$ proton diffusion may be the most limiting factor, causing a $\mathrm{pH}$ gradient in the catalyst particles, influencing the selectivity [23]. Strukul et. al., [25] reported that ammonia formation is enhanced when using large catalyst particles $(>0.5 \mathrm{~mm})$. This was attributed to increased $\mathrm{pH}$ values in the centre of the catalyst particles, slowing down the formation of nitrogen more significantly and then the formation of ammonia, according kinetic data [20, 24].

$$
\begin{aligned}
& 2 \mathrm{NO}_{2}^{-}+3 \mathrm{H}_{2}+2 \mathrm{H}^{+} \longrightarrow \mathrm{N}_{2}+4 \mathrm{H}_{2} \mathrm{O} \\
& \mathrm{NO}_{2}^{-}+3 \mathrm{H}_{2}+2 \mathrm{H}^{+} \longrightarrow \mathrm{NH}_{4}^{+}+2 \mathrm{H}_{2} \mathrm{O}
\end{aligned}
$$

Catalytic hydrogenation of nitrite is relevant for nitrite and nitrate removal from drinking water [26], as well as for hydroxylamine synthesis via hydrogenation of nitrite, which is an important industrial intermediate for the synthesis of amines [27]. It is well known that hydrogenation of nitrate proceeds via nitrite as an intermediate product and that the hydrogenation of nitrite is fast as compared to nitrate.

Aim of this work is to evaluate the performance of hairy foam as catalyst support for efficient internal mass transfer in a fast liquid phase catalytic reaction. The performance of well characterized Pd catalysts on CNFs will be compared with the performance Pd catalysts supported on traditional support materials. 


\subsection{Experimental}

\subsubsection{Material}

Nitrogen (99.999\%, INDUGAS) and ethylene (99.95\%, PRAXAIR) were used for CNFs formation without further purification. Hairy foams were prepared by growing CNFs on $\mathrm{Ni}$ foam at $440^{\circ} \mathrm{C}$ by using $25 \%$ ethylene in nitrogen as described in detail in chapter 2 [14] and the CNFs were not further pre-treated. It was shown in chapter 3 [28] that the thicknesses of both the C-layer as well as the CNF-layer can be manipulated by varying feed composition and time, which was applied to vary the thickness of the CNF layer in the present study. Table 4.1 shows the properties of the materials used.

\begin{tabular}{|c|c|c|c|c|c|}
\hline $\begin{array}{l}\text { Time of } \\
\text { growth } \\
\text { (min) }\end{array}$ & $\begin{array}{c}\text { Average CNF } \\
\text { layer thickness } \\
(\mu \mathrm{m})\end{array}$ & $\begin{array}{c}\text { Average C- } \\
\text { layer thickness } \\
(\mu \mathrm{m})\end{array}$ & $\begin{array}{l}\text { Weight } \\
\text { \% carbon }\end{array}$ & $\begin{array}{c}\text { BET surface } \\
\text { area of Hairy } \\
\text { foam } \\
\left(\mathbf{m}^{2} / \mathbf{g}\right)\end{array}$ & $\begin{array}{c}\text { BET surface } \\
\text { area of } \\
\text { carbon } \\
\left(\mathrm{m}^{2} / \mathrm{g}\right)\end{array}$ \\
\hline 25 & 8 & 1.5 & 11.2 & 10.2 & 91.1 \\
\hline 35 & 13 & 3 & 18.1 & 17.4 & 96.1 \\
\hline 60 & 28 & 4 & 29.5 & 27.7 & 93.9 \\
\hline
\end{tabular}

Table 4.1 - Properties of the carbon deposits in the hairy foams used in this study.

Alumina (AKZO NOBEL), activated carbon (Norit ROX0.8), graphite (EVONIK industries) and silica (AKZO NOBEL) were used as conventional catalyst supports. Palladium acetylacetonate (Alfa Aesar) and toluene (>99.9\%, Merck) were used in the preparation of palladium catalysts. Sodium nitrite ( $>99 \%$, Merck) was used to prepare nitrite solutions for the catalytic experiments.

\subsubsection{Catalyst preparation}

Hairy foam catalysts: Organic phase wet impregnation method was used to deposit active metal on the surface of the CNFs in Hairy foams. Pd metal particles were prepared by using palladium acetylacetonate dissolved in toluene. Hairy foam supports were immersed in $40 \mathrm{ml}$ toluene, containing the proper amount of $\mathrm{Pd}$ precursor dissolved, in a round bottomed flask of a vacuum rotary evaporator. The flask was immersed in silicon oil bath maintained at a temperature of $50^{\circ} \mathrm{C}$. Toluene was completely evaporated by slowly applying vacuum and leaving behind the palladium precursor deposited on the hairy foam. The Pd loading is always expressed per gram CNF. 
Conventional catalysts: Alumina and activated carbon with two different particle sizes were used, ranging between 300-600 $\mu \mathrm{m}$ and 38-45 $\mu \mathrm{m}$ respectively. Graphite and silica catalyst supports were used with a single particle size, ranging between 100-125 $\mathrm{m}$. Palladium precursor was deposited via organic phase wet impregnation method, applying similar catalyst preparation conditions as used for preparing hairy foam supported catalysts.

\begin{tabular}{|c|c|c|c|c|c|c|}
\hline $\begin{array}{c}\text { Support type and } \\
\text { Average particle radius } \\
\left(\mathbf{\Phi}_{\mathrm{R}}\right)\end{array}$ & $\begin{array}{c}\text { Reduction } \\
\text { temperatures } \\
{ }^{\mathbf{C}}\end{array}$ & $\begin{array}{c}\text { Pd } \\
\text { weight } \\
\mathbf{\%}\end{array}$ & $\begin{array}{c}\text { Pd } \\
\text { dispersion } \\
\mathbf{\%}\end{array}$ & $\begin{array}{c}\mathbf{\Phi}_{\mathbf{p}} \\
\mathbf{n m}\end{array}$ & $\begin{array}{c}\text { Pore } \\
\text { volume } \\
\mathbf{m l} / \mathbf{g}\end{array}$ & Tortuosity \\
\hline $\begin{array}{c}\mathrm{Pd} / \mathrm{Al}_{2} \mathrm{O}_{3}, \\
\left(\Phi_{\mathrm{R}}: 225 \mu \mathrm{m}\right)\end{array}$ & 800 & 1.64 & $11.5 \pm 0.5$ & 9 & 0.6 & $3^{[48]}$ \\
\hline $\begin{array}{c}\mathrm{Pd} / \mathrm{Al}_{2} \mathrm{O}_{3}, \\
\left(\Phi_{\mathrm{R}}: 21 \mu \mathrm{m}\right)\end{array}$ & 800 & 2.23 & $11.95 \pm 0.2$ & 9 & 0.6 & $3^{[48]}$ \\
\hline $\begin{array}{c}\text { Pd-Silica, } \\
\left(\Phi_{\mathrm{R}}: 56 \mu m\right)\end{array}$ & 800 & 2.33 & $6.5 \pm 0.5$ & 17 & 1.26 & 3 \\
\hline $\begin{array}{c}\text { Pd-Activated carbon, } \\
\left(\Phi_{\mathrm{R}}: 225 \mu \mathrm{m}\right)\end{array}$ & 400 & 1.62 & $7.8 \pm 0.8$ & 14 & 0.197 & $4^{[49]}$ \\
\hline $\begin{array}{c}\text { Pd-Activated carbon, } \\
\left(\Phi_{\mathrm{R}}: 21 \mu \mathrm{m}\right)\end{array}$ & 250 & 2.33 & $8.3 \pm 0.8$ & 13 & 0.197 & $4^{[49]}$ \\
\hline $\begin{array}{c}\text { Pd-Graphite, } \\
\left(\Phi_{\mathrm{R}}: 56 \mu m\right)\end{array}$ & 430 & 2.37 & $12.4 \pm 0.3$ & 9 & 0.38 & 4 \\
\hline $\begin{array}{c}\text { Pd-unsupported CNF } \\
\text { aggregates, } \\
\left(\Phi_{\mathrm{R}}: 225 \mu \mathrm{m}\right)\end{array}$ & 250 & 1.21 & $5.3 \pm 0.1$ & 21 & - & - \\
\hline $\begin{array}{c}\text { Pd-unsupported CNF } \\
\text { aggregates, } \\
\left(\Phi_{\mathrm{R}}: 21 \mu \mathrm{m}\right)\end{array}$ & 250 & 1.48 & $5.5 \pm 0.1$ & 20 & - & - \\
\hline
\end{tabular}

Table 4.2 - Palladium dispersion and average Pd particle sizes based on CO-

chemisorption on various conventional catalysts and CNF aggregates. The pore volume was determined from desorption isotherm by applying BJH method.

Unsupported CNF aggregate catalysts: were received from Utrecht University, which were prepared as described by Van der Lee et al. [29]. Two sets of particle sizes ranging between 300-600 $\mu \mathrm{m}$ and 38-45 $\mu \mathrm{m}$ were prepared via mortaring and sieving. CNF aggregates were loaded with palladium following the same preparation methods as described above. From here on the packed bed support particle sizes are referred in average particle radius.

CNF supported catalysts were calcined at $250^{\circ} \mathrm{C}$ (ramp of $5^{\circ} \mathrm{C} / \mathrm{min}$ ) during $1 \mathrm{~h}$ and then reduced at same temperature during $2 \mathrm{~h}$. The samples were cooled down to room temperature in nitrogen at a ramp of $10^{\circ} \mathrm{C} / \mathrm{min}$. Catalysts on conventional supports were also calcined at $250^{\circ} \mathrm{C}$ (ramp of $5^{\circ} \mathrm{C} / \mathrm{min}$ ) during $1 \mathrm{~h}$, where after the reduction temperature was varied in order to obtain similar palladium dispersions for 
all the catalysts in this study; calcination temperatures applied are presented in table 4.2 .

\subsubsection{Catalytic hydrogenation of nitrite}

Catalytic hydrogenation of nitrite was performed in a fixed bed reactor placed in an oven at $298 \mathrm{~K}$. Nitrite concentration in the aqueous reactant solution was always maintained at $\sim 20 \mathrm{mg} / \mathrm{l}(435 \mu \mathrm{mol} / \mathrm{l})$ and the $\mathrm{pH}$ of the solution was maintained at 7 . The solution was pre-saturated at a hydrogen partial pressure of 0.4 bar (balance argon), resulting in a concentration of dissolved $\mathrm{H}_{2}$ equal to $312 \mu \mathrm{mol} / \mathrm{l}$, based on Henry's coefficient [30]. The reactor bed volume was varied between $0.29 \mathrm{~cm}^{3}$ and $1.74 \mathrm{~cm}^{3}$. The reactor was madeup of PEEK (polyether-ether-ketone) and the diameter was optimized in order to exactly fit with the size of the cylinder shaped pieces (diameter $4.5 \mathrm{~mm}$ ) of hairy foam catalysts. The total amount of Pd catalyst used was varied between $0.13 \mu \mathrm{mol}$ and $0.78 \mu \mathrm{mol}$ when varying bed volume or Pd loading. Liquid containing nitrite and dissolved hydrogen was pumped through the fixed bed reactor with flowrates up to $12 \mathrm{ml} / \mathrm{min}$ with an HPLC pump (DIONEX, Ultimate 3000). The pressure drop induced was less than 0.3 bar in case of hairy foam and varying between 0.8 and 4 bar for packed bed catalysts. The space velocity was calculated based on the total volume of the catalyst bed in the reactor chamber. Nitrite and ammonium concentrations in the reactants and products were measured with Ion chromatography (DIONEX, ICS 1000).

The reaction was performed under differential conditions, maintaining the nitrite conversions at $\sim 5 \%$ in most cases, increasing to maximal $12 \%$ occasionally. Therefore, concentration gradients along the axis of the reactor are not significant and turn over frequencies (activity per active site per second, TOF) can be calculated directly from the data by using the Pd dispersion of the relevant catalyst. Packed beds were reproducible for all the catalysts eliminating any tunnelling effect along the bed and measures were taken to precisely fit the hairy foams in the reactor chamber avoiding any bypassing of the liquid flow.

All Pd catalysts were used for typically $16 \mathrm{~h}$ and occasionally samples were up to $30 \mathrm{~h}$ on stream. In all experiments no significant deactivation was observed and any variation with time-on-stream is included in the error margins indicated in the results. 


\subsubsection{Characterization}

BET surface area of CNFs was calculated from the $\mathrm{N}_{2}$-adsorption isotherm obtained at $77 \mathrm{~K}$ (Micromeritics Tristar). X-ray fluorescence spectroscopy (XRF) was used to determine the palladium loading on $\gamma$-alumina, activated carbon, silica, graphite and CNF aggregates. Inductively coupled plasma (ICP) was used to determine the palladium loadings on Hairy foam. CO-chemisorption (Micromeritics, ChemiSorb 2750: Pulse Chemisorption system) at room temperature was used to determine the dispersion of palladium. The palladium particle size distribution was determined for selected catalysts with Transmission Electron Microscopy (TEM Philips CM300ST-FEG). Thirtyfive TEM images were obtained on each catalyst accounting at least $300 \mathrm{Pd}$ particles. The averaged crystal size of palladium particles was determined with line-broadening analysis in X-ray diffraction (XRD), according the Scherrer equation. XRD was performed using a PANalytical X'pert-APD powder diffractometer equipped with a position sensitive detector analyzed over the $2 \theta$-range $15-90^{\circ}$ using $\mathrm{Cu} \mathrm{K \alpha 1}(\lambda=1.78897 \AA)$ radiation. Scanning Electron Microscopy (LEO 1550 FEG-SEM) equipped with energy dispersive X-ray analysis (EDX; Thermo Noran Vantage system) was used to qualitatively study the distributions of Pd through cross-sections of the CNF and C-layers in hairy foam catalyst, as well as through cross-sections of the alumina support. Cross-sections of hairy foams were simply obtained by cutting with scissors resulting in well maintained CNF-layers, allowing analysis with EDX at discrete spots. The alumina support was embedded in a polymer before preparing a cross-section with a microtome. The polymer embedded alumina catalyst particles result in flat cross-sections after dissection, enabling SEM-EDX mapping.

\subsection{Results}

\subsubsection{Characterization}

\subsubsection{Characterization of Pd on Hairy foam}

Hairy foam samples with different CNF layer thicknesses were loaded with approximately $2 \mathrm{wt} \%$ palladium. Samples with Pd loadings between 0.5 and $2 \mathrm{wt} \%$, were prepared on hairy foam with a $13 \mu \mathrm{m}$ thick CNF layer. Table 4.3 presents the resulting Pd loadings as well as palladium dispersions, as determined with CO- 
chemisorption. In all cases the Pd dispersion is below $10 \%$ and the average Pd particle size is larger than $10 \mathrm{~nm}$. Average $\mathrm{Pd}$ particle size was estimated assuming hemispherical shaped particles.

\begin{tabular}{|c|c|c|c|}
\hline Support type & Weight \% & Dispersion & $\mathbf{\Phi}_{\mathbf{p}}, \mathbf{n m}$ \\
\hline $\begin{array}{c}\text { Hairy foam } \\
\text { CNF thickness : } 28_{\text {avg }} \mu \mathrm{m}\end{array}$ & 2.23 & $5.6 \pm 0.4$ & 20 \\
\hline \multirow{2}{*}{$\begin{array}{c}\text { Hairy foam } \\
\text { CNF thickness : } 13_{\text {avg }} \mu \mathrm{m}\end{array}$} & 1.97 & $6.7 \pm 0.3$ & 16 \\
\cline { 2 - 4 } & 1.52 & $9.6 \pm 0.2$ & 12 \\
\cline { 2 - 4 } & 1.1 & $9.6 \pm 0.3$ & 12 \\
\hline \multirow{2}{*}{$\begin{array}{c}\text { Hairy foam } \\
\text { CNF thickness : } 8_{\text {avg }} \mu m\end{array}$} & 1.95 & $6.7 \pm 0.4$ & 16 \\
\hline
\end{tabular}

Table 4.3 - Palladium metal dispersions and average Pd particle size based on COchemisorption on various hairy foam samples.

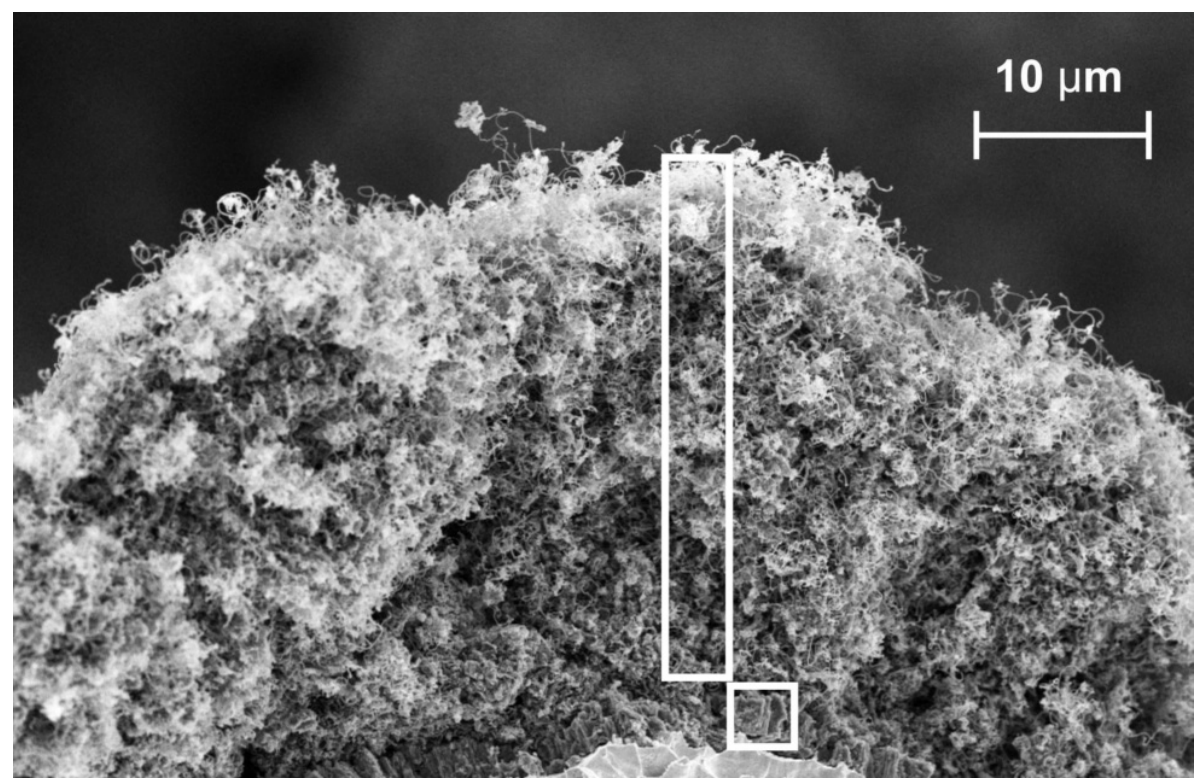

Figure 4.3 - The cross-section of the Hairy foam strand with a homogenous coverage of a $28 \mu \mathrm{m}$ CNF layer and $4 \mu \mathrm{m}$ C-layer. The SEM image is an illustration upon which areas (marked) were selected to analyze Pd concentration by SEM-EDX.

The distribution of Pd within the CNF layer and C-layer was qualitatively measured with SEM-EDX. Figure 4.3 shows a typical cross-sectional view of one of the strands, containing a C-layer on the Ni surface with the CNF layer on top. EDX was performed at five different spots ( $3 * 3$ microns) at the cross-section of the CNF layer and one spot in the C-layer. Five different strands were analyzed and the ratio of 
palladium to carbon is presented as function of the position in figure 4.4. The palladium concentration is significantly higher in the outer 10 microns of the CNF layer as compared to the deeper CNF layer as well as the C-layer.

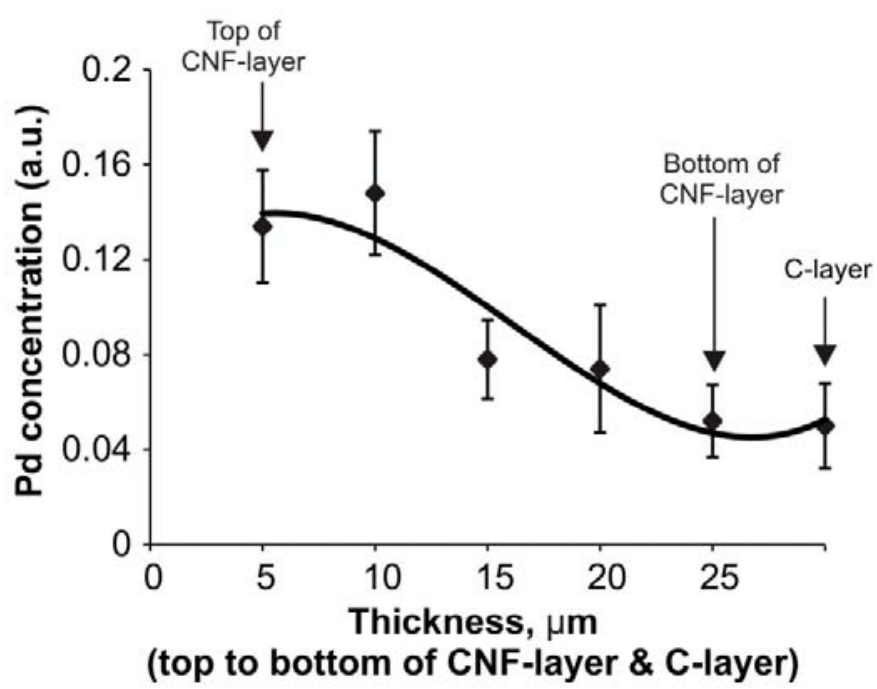

Figure 4.4 - Qualitative results of Pd distribution across a $28_{\text {avg }} \mu \mathrm{m}$ thick CNF layer of $2.23 w t \%$ Pd on hairy foam.

\subsubsection{Characterization of Pd on alumina support}

Palladium dispersions as well as estimated average particle size according to CO-chemisorption on conventional catalyst supports after reduction at indicated temperatures are presented in table 4.2. In all cases, the Pd dispersion was less than $13 \%$ and the average Pd particle size was at least $8 \mathrm{~nm}$. The distribution of palladium through $\gamma$-alumina $\left(225_{\text {avg }} \mu m\right)$ was studied by SEM-EDX mapping. Figure 4.5 a shows a typical SEM image of the cross-section of a particle of a $\gamma$-alumina supported palladium catalyst; SEM-EDX mapping in figure 4.5b reveals that $\mathrm{Pd}$ is homogeneously distributed in the alumina particle.

\begin{tabular}{|c|c|c|c|}
\hline \multirow{2}{*}{$\begin{array}{c}\text { Characterization } \\
\text { technique }\end{array}$} & \multicolumn{3}{|c|}{ Mean palladium particle size, nm } \\
\cline { 2 - 4 } & $\begin{array}{c}\boldsymbol{\gamma} \text {-Alumina } \\
(\mathbf{2 . 2 3} \mathbf{w t} \% \mathbf{P d})\end{array}$ & $\begin{array}{c}\text { Activated carbon } \\
\mathbf{( 2 . 3 3} \mathbf{w t} \% \mathbf{P d})\end{array}$ & $\begin{array}{c}\text { Hairy foam } \\
\mathbf{( 2 . 2 3} \mathbf{~ w t} \% \mathbf{P d})\end{array}$ \\
\hline * CO-chemisorption & 13 & 10 & 18 \\
\hline TEM & 6 & 5 & 8 \\
\hline XRD & 4.7 & 4.7 & 8.7 \\
\hline
\end{tabular}

Table 4.4 - Mean crystal size of palladium on alumina, activated carbon and hairy foams as characterized by CO-chemisorption, transmission electron microscopy and X-ray diffraction line broadening. * Selected chemisorption results are a repeat from table 4.2 and 4.3. 
Transmission electron microscopy was used to determine the size distribution of palladium particles on alumina, activated carbon and hairy foam catalysts, resulting in Pd particle size distributions as presented in Figure 4.6. The Pd particle size distributions are quite similar on all the supports. The averaged Pd particle size based on TEM analysis is presented in table 4.4, along with XRD-LB analysis of the same catalysts are presented in table 4.4, resulting in similar numbers. Differences with CO chemisorption data will be discussed later.
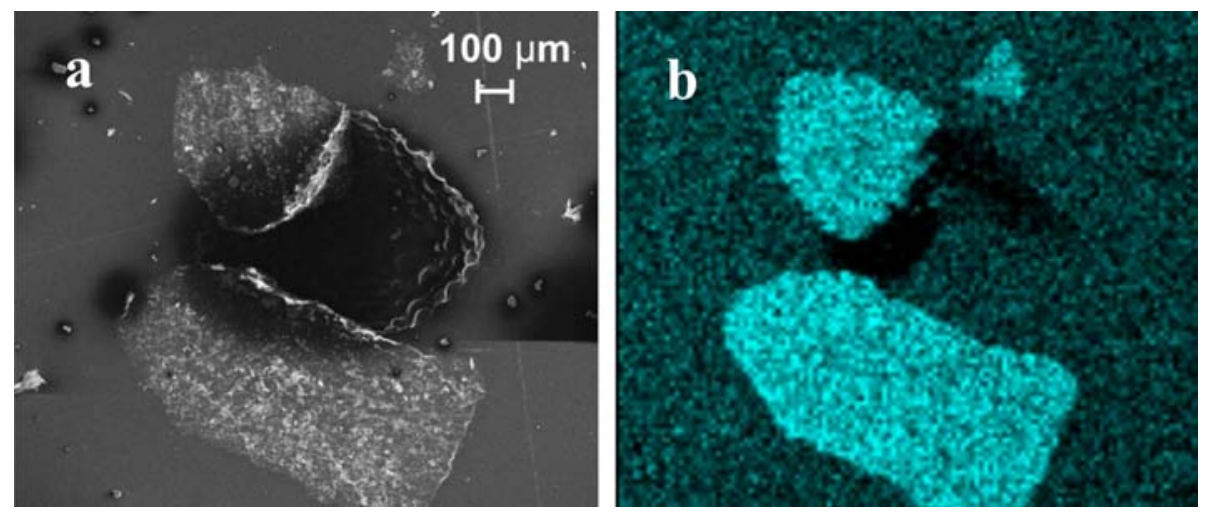

Figure 4.5 - a) SEM image of a 1.64wt\% Pd on $\gamma$-alumina catalyst of particle radius $225_{\mathrm{avg}} \mu \mathrm{m}$. b) shows the mapping images of Pd as analyzed by SEMEDX.

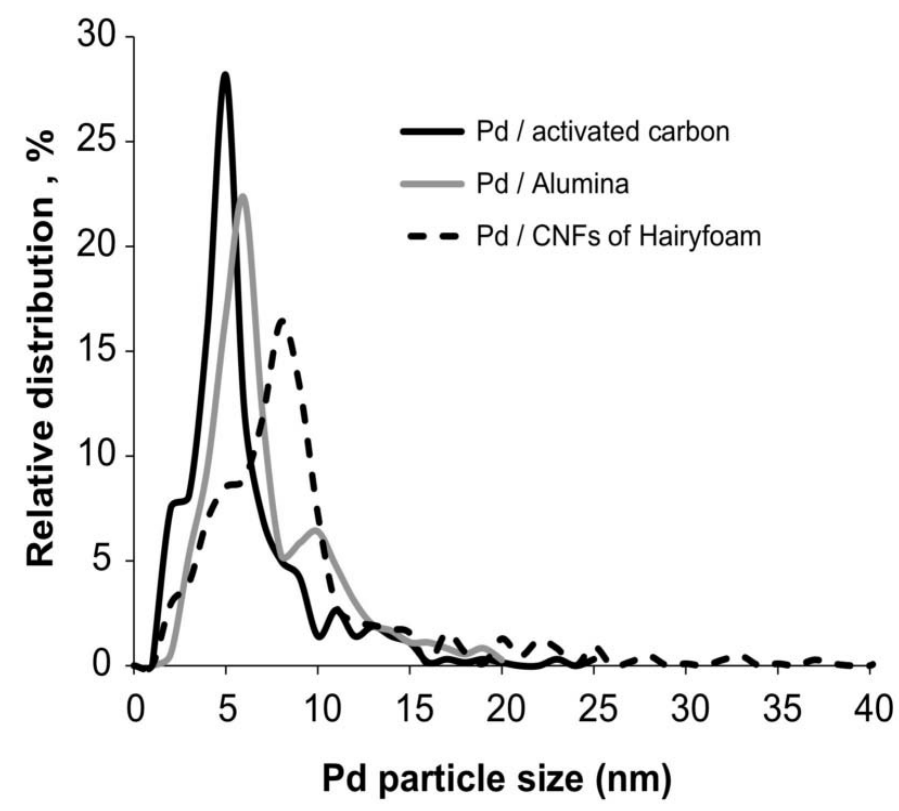

Figure 4.6 - Palladium particle size distribution on $21 \mu \mathrm{m}$ particle radius of 2.33wt\% Pd on activated carbon and 2.23wt\% Pd on $\gamma$-alumina, and $28 \mu \mathrm{m} \mathrm{CNF}$ layer of $2.23 \mathrm{wt} \% \mathrm{Pd}$ on hairy foam catalysts as characterized by TEM. 


\subsubsection{Catalytic tests}

\subsubsection{Hairy foam catalysts}

Nitrite conversion was measured at fixed space time, increasing the linear velocity (F, defined as the liquid velocity in an empty reactor) of the reactant stream and increasing the amount of catalyst (W) proportionally, maintaining a space velocity of $25.2 \mathrm{~min}^{-1}$. Figure 4.7 shows the nitrite conversion as a function of the linear velocity of the reactant. Nitrite conversion increases with linear velocity below $55 \mathrm{~cm} / \mathrm{min}$. In contrast, nitrite conversion is constant at higher velocity, indicating the absence of external mass transfer limitations for linear velocities over $55 \mathrm{~cm} / \mathrm{min}$. Therefore, further catalytic experiments with hairy foam catalysts were performed using linear velocity of $55 \mathrm{~cm} / \mathrm{min}$.

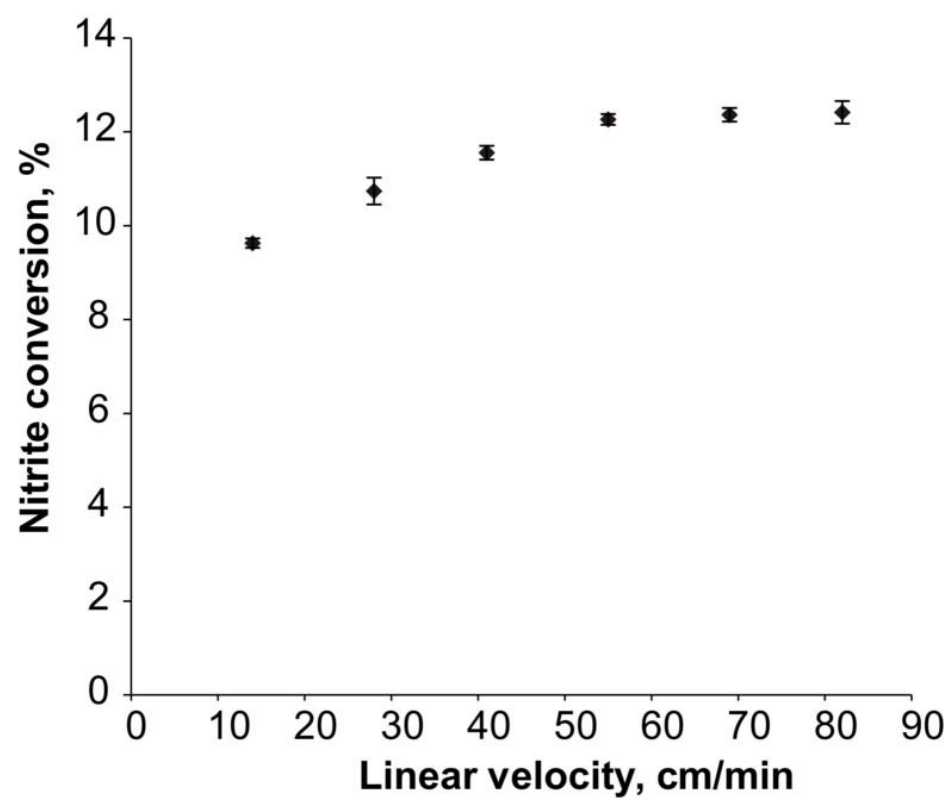

Figure 4.7 - Nitrite conversion at fixed space time on a $28 \mu \mathrm{m}$ CNF layer of $2.23 \mathrm{wt} \% \mathrm{Pd}$ on hairy foam catalyst at a space velocity of $25.2 \mathrm{~min}^{-1}$.

Figure 4.8 shows that the TOF remains constant when the thickness of CNF layer is varied. The Pd loading was kept constant in this experiment at $2 \mathrm{wt} \%$ relative to the carbon loading, implying that the total amount of Pd varies with the CNF layer thickness. This agrees well with the result in figure 4.9, showing that the TOF does not change when varying the Pd loading on hairy foam with a 13 micron thick CNF layer. These results clearly demonstrate that both external and internal mass transfer 
limitations can be excluded, resulting in a TOF equal to $0.021 \mathrm{sec}^{-1}$ under the conditions in this study.

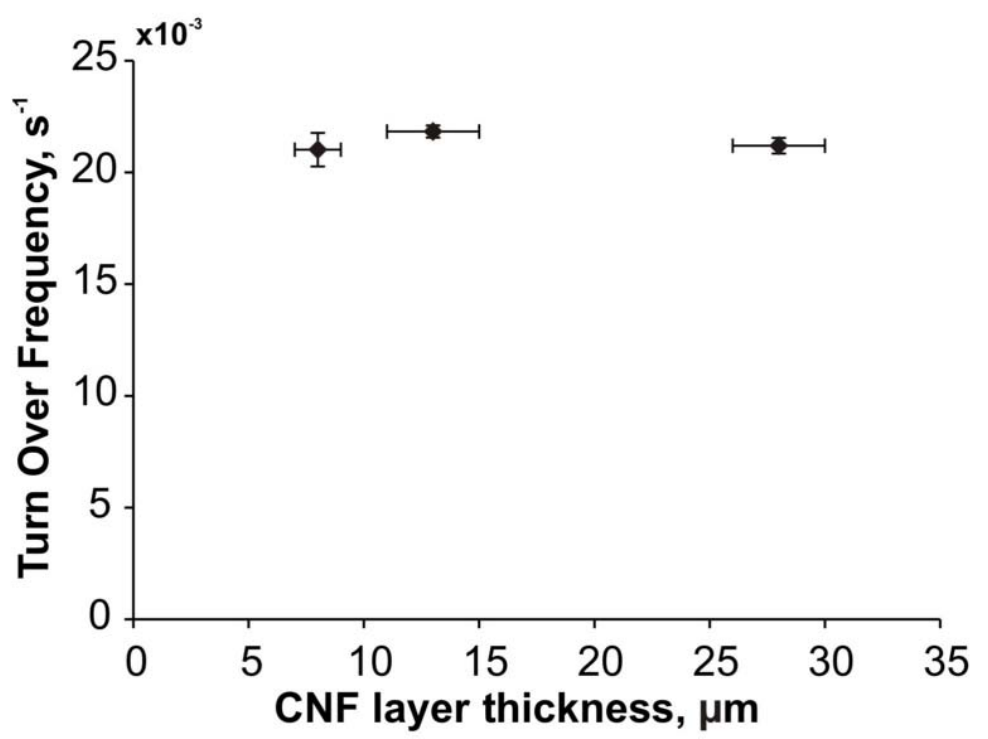

Figure 4.8 - Rate of nitrite conversion per mole of surface palladium on hairy foam catalysts with CNF layer thickness between 8 and $28 \mu \mathrm{m}$ and loading of $\sim 2 \mathrm{wt} \%$ measured at linear velocity of $55 \mathrm{~cm} / \mathrm{min}$ and space velocities of 20.2, 33.5 and $50.3 \mathrm{~min}^{-1}$ for 8,13 and $28_{\text {avg }} \mu \mathrm{m}$, respectively.

\subsubsection{Conventional catalysts}

Nitrite conversion over Pd on activated carbon $\left(\Phi_{\mathrm{R}}: 225 \mu \mathrm{m}\right)$ was measured as function of linear velocity, keeping the space velocity constant at $31.5 \mathrm{~min}^{-1}$. Figure 4.10 shows that the nitrite conversion increases with the linear velocity below 25 $\mathrm{cm} / \mathrm{min}$, remaining constant at higher linear velocity. Further experiments with conventional catalysts were therefore performed using linear velocities larger than 25 $\mathrm{cm} / \mathrm{min}$, in order to avoid external mass transfer limitation. 


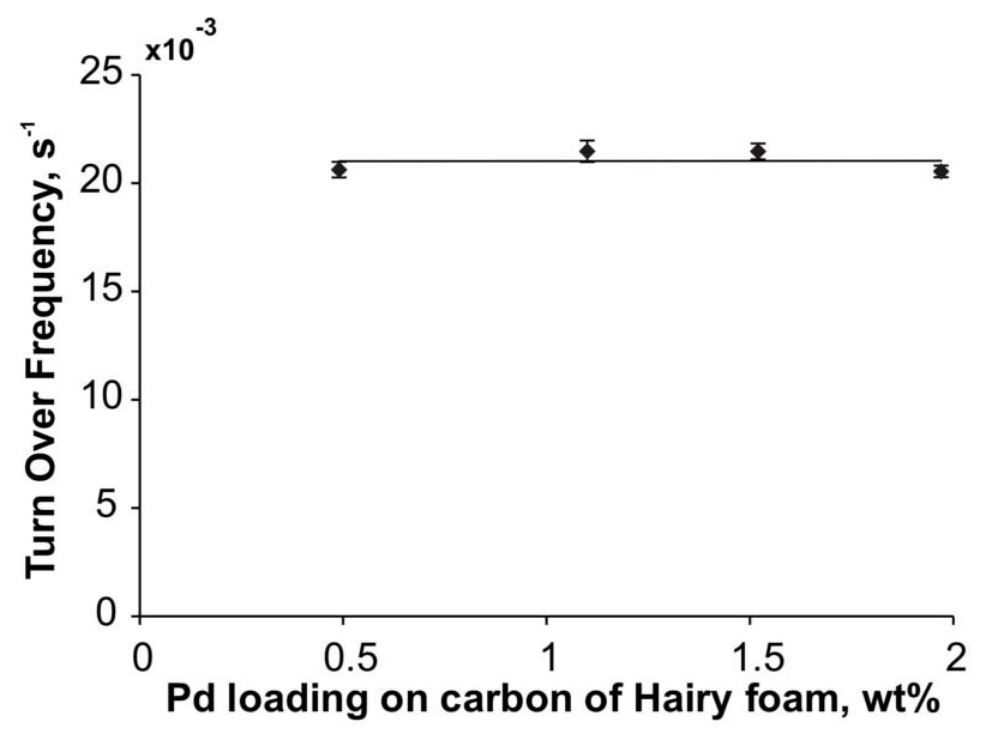

Figure 4.9 - Rate of nitrite conversion per mole of surface palladium on Hairy foam catalysts at palladium loadings between 0.5 and $2 \mathrm{wt} \%$ and a CNF layer thickness of $13 \mu \mathrm{m}$ measured at linear velocity of $55 \mathrm{~cm} / \mathrm{min}$ and space velocity of $50.3 \mathrm{~min}^{-1}$.

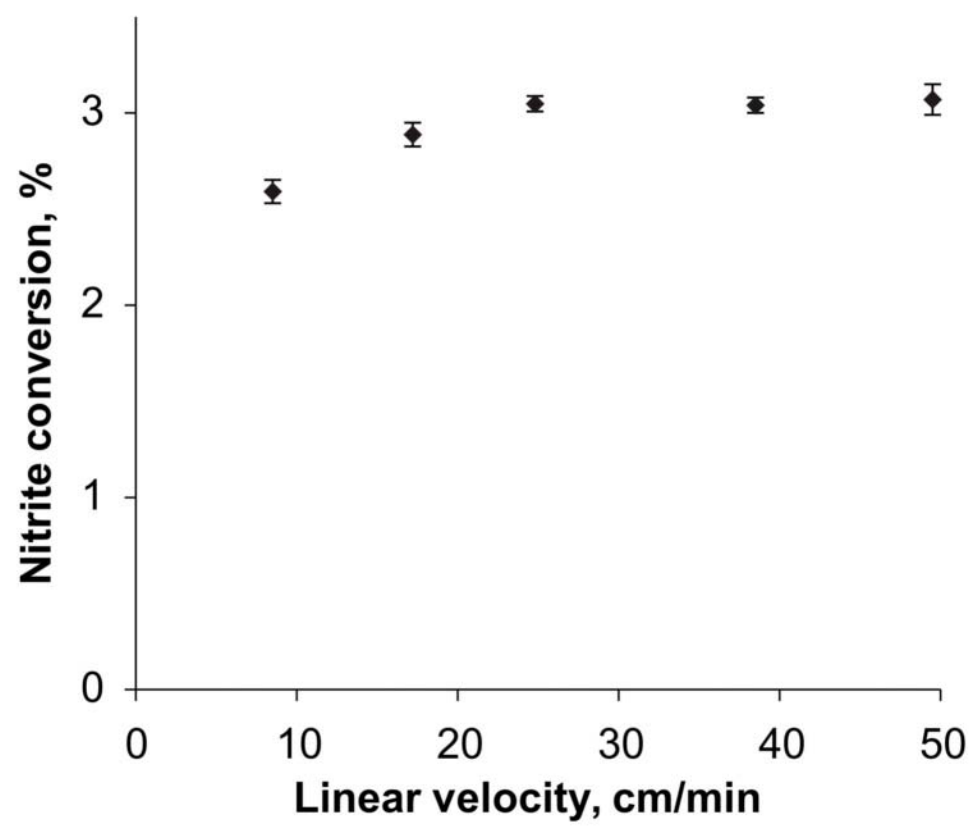

Figure 4.10 - Nitrite conversion as a function of linear velocity over 1.62wt\% Pd on activated carbon catalysts of $225_{\text {avg }} \mu m$ particle radius at a space velocity of $31.5 \mathrm{~min}^{-1}$. 
Figure 4.11 compares the TOF values as measured in fixed bed for palladium catalysts supported on alumina, activated carbon, graphite, silica as well as CNF aggregates. The properties of these catalysts are tabulated in table 4.2. Figure 4.11

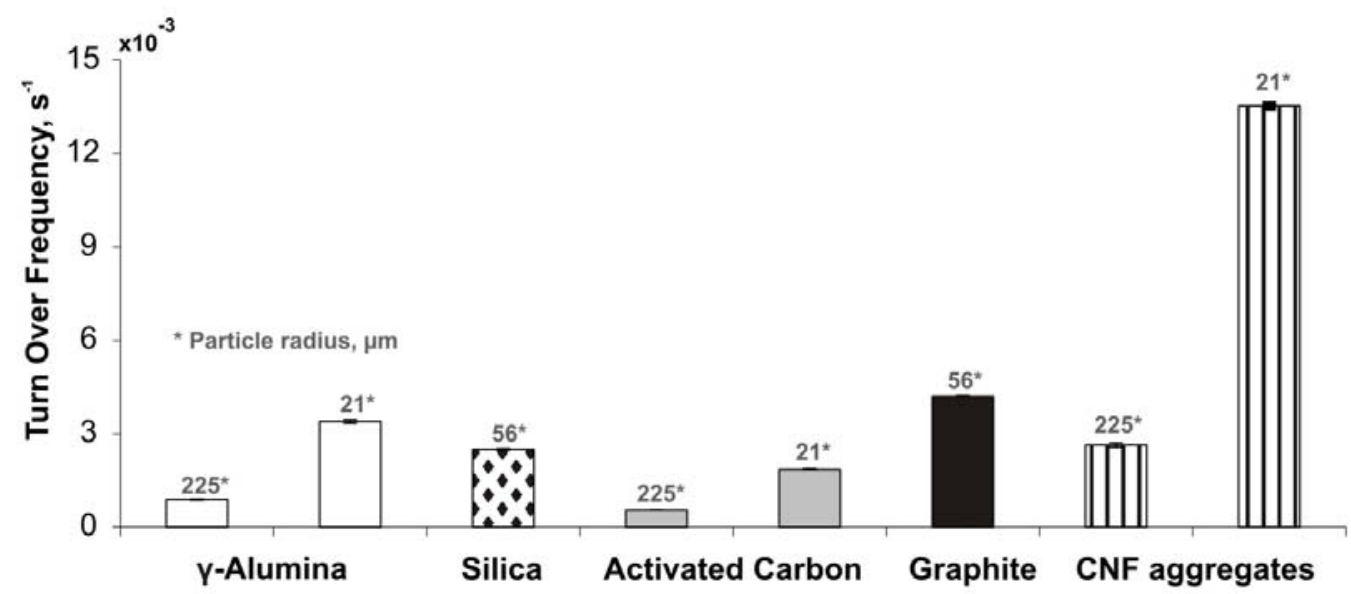

Figure 4.11 - Turn over frequency on catalysts such as, $\gamma$-alumina, activated carbon, unsupported CNF aggregates, silica and graphite at support particles radius of different radius.

demonstrates that smaller catalyst support particles are significantly more active as compared to larger catalyst particles for each specific support material. Furthermore, catalysts supported on CNF aggregates appear significantly more active than catalysts on conventional supports.

\subsection{Discussion}

\subsubsection{Catalyst characterization}

All conventional catalysts showed a reasonable homogenous distribution of Pd through the porous support (figure 4.5). The enhanced presence of Pd in the outer layer (figure 4.4) would make internal diffusion limitations less likely; however, this effect is probably compensated by the presence of Pd in the microporous carbon layer between the CNF layer and the Ni foam surface (chapter 2) [14], as Pd in the microporous layer would be less accessible. The result in figures 4.8 and 4.9 clearly demonstrates absence of any internal diffusion limitation, justifying the assumption that Pd is also homogenously distributed in hairy foam when discussing catalytic activity. 
Pd particle sizes on hairy foams are all relatively large, between 11 and $20 \mathrm{~nm}$, as reported in table 4.3. Furthermore, the Pd dispersions of all catalysts are rather low, certainly when taking into consideration the low Pd loadings (0.5 - 2wt \%) used in this study. The reason for this is the choice to prepare the hairy foam catalysts on pristine CNFs, i.e. without prior oxidation of the CNFs, in order to prevent oxidative attack of the supporting $\mathrm{Ni}$ foam. As a consequence, the interaction between Pd particles and the CNFs is rather weak, contributing to low dispersions. All other catalysts were heat treated such that very similar dispersions were achieved (table 4.3).

Mean particle sizes based on CO-chemisorption are clearly larger as compared to those based on TEM and XRD (table 4.4). This difference might be due to uncertainty in the adsorption stoichiometry of CO chemisorption on Pd [31] due to the preference to CO to bind to two or three Pd surface atoms instead of linear adsorption a single surface atom. Importantly, the large particle size according CO chemisorption allows to rule out significant presence of very small particles $(<2 \mathrm{~nm})$, which is important because such particles are difficult to detect with TEM and are not detected at all with XRD. Thus, all techniques confirm that the differences in the particles sizes are modest and that the particles are generally large, which is an advantage in this study because significant support effects are unlikely. Larger particles are less prone to significant manipulation of the geometry or electronic structure of Pd by the support [22, 32, 33].

\subsubsection{Catalyst activity}

Hairy foam catalysts require higher linear velocities to overcome external mass transfer limitations as compared to a packed bed of catalyst supported on activated carbon (figure 4.7 versus 4.10 ). This can be understood in terms of the void space in the catalyst bed. The void fraction in hairy foam is much larger as compared to a packed bed, resulting in a lower actual velocity of the liquid as well as lower pressure drop. In other words, the shear forces, determining the thickness of the stagnant liquid layer at the external surface, are significant smaller as well. Therefore, hairy foam needs higher linear liquid velocity to prevent external mass transfer limitation. 
The catalytic activity of hairy foam catalysts appears independent of the thickness of the CNF layer and the Pd loading (figures 4.8 and 4.9). This demonstrates that internal mass transfer is not limiting and that the TOFs measured are indeed intrinsic. Figure 4.12 shows that the TOFs is constant at around $0.021 \mathrm{~s}^{-1}$ for all hairyfoam supported catalysts, despite modest variation of the Pd dispersion between 5 and

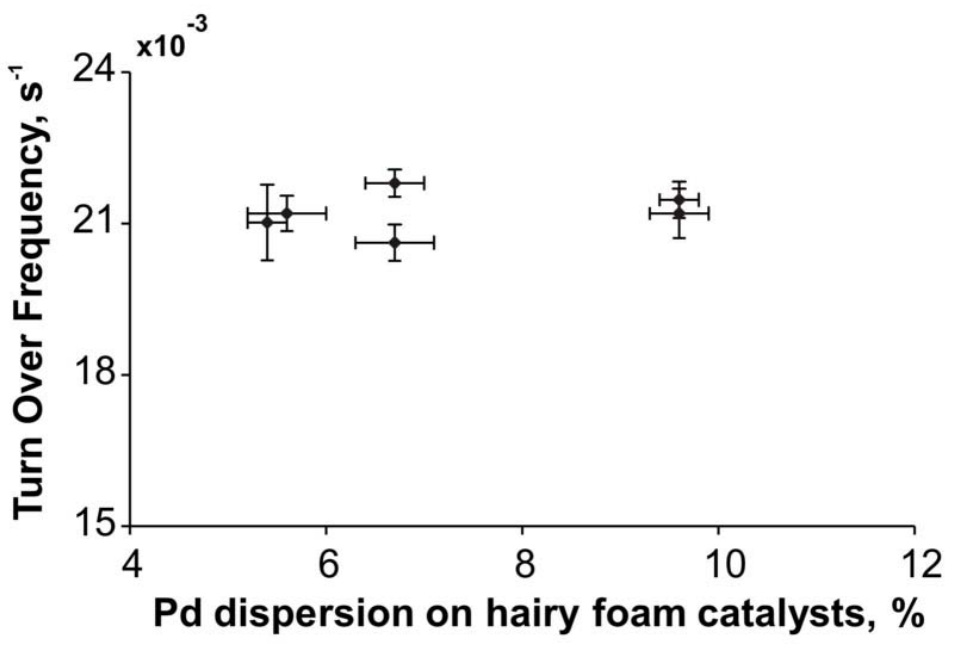

Figure 4.12 - Turn over frequency as a function of Pd dispersion for hairy foam catalysts.

$10 \%$, confirming that the activity does not depend on Pd particle size for these relatively large particles. This value of TOF seems at first sight very small, but it should be noted that the concentrations of reactants in this study are extremely small. Our observations are in good agreement with Höller et. al. [32], reporting similar TOFs for comparable Pd dispersions on $\gamma-\mathrm{Al}_{2} \mathrm{O}_{3}$ coated glass fibers. Figure 4.11 shows that packed bed catalysts with small support particles (typically $21 \mu \mathrm{m}$ ) are systematically more active as compared to large particles. This clearly suggests that large catalyst particles suffer from internal mass transfer limitations. This observation will now be further evaluated using the Weisz-Prater criterion as well as the Thiele modulus. The details of the calculations as well as the diffusion coefficients used are described in the appendix.

\subsubsection{Estimation of internal mass transfer limitations via Weisz-Prater criterion $\left(C_{W P}\right)$}

Table 4.5 shows the results of the calculation of $\mathrm{C}_{\mathrm{wp}}$ for all fixed bed catalysts, except the CNF aggregates. Unfortunately, no reliable data on the porosity of these materials are available. $\mathrm{N}_{2}$ capillary condensation results in an estimation of the pore volume of micropores and mesopores exclusively, resulting in typically $0.55 \mathrm{ml} / \mathrm{g}$ 
[29]. However, it should be noted that the morphology of entangled CNF particles and layers is very different compared to traditional porous catalyst support materials. The open volume is actually not contained in pores; in contrast the open volume is like a continuous phase and therefore adsorption- and capillary-condensation- methods fail. In any case, capillary condensation is not able to determine the volume of macropores present in entangles CNF-structures. Jarrah et al. [6] estimated the pore volume of entangled CNF-layer on $\mathrm{Ni}$ foam at $1 \mathrm{ml} / \mathrm{g}$, based on the thickness of the porous layer and its weight. In short, pore volumes based on $\mathrm{N}_{2}$ capillary condensation is resulting in significant underestimation. The $\mathrm{C}_{\mathrm{wp}}$ values were calculated [34] for nitrite and hydrogen reactants involved in the reaction using values for pore volume and tortuosity as indicated in table 4.2 . $\mathrm{C}_{\mathrm{wp}}$ values for protons were not calculated because of uncertainty about the $\mathrm{H}^{+}$or $\mathrm{OH}^{-}$concentration to be used in the equation.

\begin{tabular}{|c|c|c|c|}
\hline \multirow{2}{*}{ Support type } & $\begin{array}{c}\text { Radius of Particle } \\
\mathbf{( \mu m )}\end{array}$ & \multicolumn{2}{|c|}{$\mathbf{C}_{\mathbf{w p}}$ values of reactants } \\
\cline { 3 - 4 } & $\sim 225$ & $\mathbf{N O}_{\mathbf{2}}^{-}$ & $\mathbf{H}_{\mathbf{2}}$ \\
\hline$\gamma$-Alumina & $\sim 21$ & 0.22 & 6.56 \\
\hline$\gamma$-Alumina & $\sim 225$ & 8.18 & 0.23 \\
\hline Activated carbon & $\sim 21$ & 0.38 & 0.51 \\
\hline Activated carbon & $\sim 56$ & 0.32 & 0.37 \\
\hline Silica & $\sim 56$ & 3.48 & 5.13 \\
\hline Graphite & & \\
\hline
\end{tabular}

Table 4.5 - Values of the Weisz-Prater parameter $\left(\mathrm{C}_{\mathrm{wp}}\right)$ for different particles.

The $\mathrm{C}_{\mathrm{wp}}$ values for all reactants and large catalyst particles $(225 \mu \mathrm{m})$ is greater than 1 , indicating that internal diffusion of both reactants is limiting, agreeing well with the observation that smaller particles are significantly more active. The $\mathrm{C}_{\mathrm{wp}}$ values for small catalyst particles (21 and $56 \mu \mathrm{m}$, except for graphite) are below 1 . Nevertheless, the values for nitrite and hydrogen indicate that internal mass-transfer limitation may still influence the result to some extent. In order to estimate proton limitation and the significance of nitrite and hydrogen diffusion, efficiency factors have been estimated using the Thiele modules, using the intrinsic kinetic data obtained from hairy foam catalysts in this study.

\subsubsection{Estimation of catalyst efficiency according to Thiele modulus $\left(\varphi_{n}\right)$}

Assuming a first order reaction, maximal intrinsic rate constant ( $\left.\mathrm{k}_{\text {reactant }}\right)$ in this study was calculated from the reaction rate on hairy foam catalysts, in order to 
calculate Thiele moduli as well as effectiveness factors [34] for conventional catalysts, for each of the reactants. Table 4.6 presents the calculated Thiele moduli for alumina, activated carbon, silica and graphite catalysts with respective mean support particle radius. The large catalyst support particles $(225 \mu \mathrm{m})$ show efficiency below $30 \%$ for nitrite and hydrogen, confirming a large influence of internal diffusion limitations, in agreement with experimental observations (figure 4.11) and calculations of the Weisz-Prater criterion. Smaller catalyst support particles $(21 \mu \mathrm{m})$ as well as somewhat larger silica supported catalyst result in an efficiency of $\sim 80 \%$ to $\sim 90 \%$. The limitation in protons is clearly less severe than in nitrite and hydrogen (table 4.6). Apparently, fast diffusion of protons compensates for the low concentration at neutral $\mathrm{pH}$. D'Arino et al. [23] suggested that proton diffusion is relatively slow as compared to diffusion of nitrite; this difference is due to the relatively low concentrations of nitrite and hydrogen in the present study. Thus, the catalytic activity of these small catalyst particles is only slightly affected by internal mass transfer limitation.

\begin{tabular}{|c|c|c|c|c|c|c|c|}
\hline \multirow{2}{*}{$\begin{array}{l}\text { Support } \\
\text { type }\end{array}$} & \multirow{2}{*}{$\begin{array}{l}\text { Radius } \\
\text { of } \\
\text { Particle } \\
(\mu \mathrm{m})\end{array}$} & \multicolumn{2}{|c|}{$\begin{array}{l}\text { Based on effective } \\
\text { diffusivity of } \mathrm{NO}_{2}^{-}\end{array}$} & \multicolumn{2}{|c|}{$\begin{array}{l}\text { Based on effective } \\
\text { diffusivity of } \mathrm{H}_{2}\end{array}$} & \multicolumn{2}{|c|}{$\begin{array}{l}\text { Based on effective } \\
\text { diffusivity of } \mathbf{H}^{+}\end{array}$} \\
\hline & & $\begin{array}{c}\text { Thiele } \\
\text { modulus }\end{array}$ & $\begin{array}{l}\text { Effectiveness } \\
\text { factor }\end{array}$ & $\begin{array}{c}\text { Thiele } \\
\text { modulus }\end{array}$ & $\begin{array}{l}\text { Effectiveness } \\
\text { factor }\end{array}$ & $\begin{array}{c}\text { Thiele } \\
\text { modulus }\end{array}$ & $\begin{array}{c}\text { Effectiveness } \\
\text { factor }\end{array}$ \\
\hline$\gamma-\mathrm{Al}_{2} \mathrm{O}_{3}$ & $\sim 225$ & 10.4 & 0.26 & 10.61 & 0.26 & 5.40 & 0.45 \\
\hline$\gamma-\mathrm{Al}_{2} \mathrm{O}_{3}$ & $\sim 21$ & 1.12 & 0.92 & 1.14 & 0.93 & 0.58 & 0.96 \\
\hline $\begin{array}{l}\text { Activated } \\
\text { carbon }\end{array}$ & $\sim 225$ & 17.22 & 0.16 & 17.57 & 0.16 & 8.06 & 0.33 \\
\hline $\begin{array}{l}\text { Activated } \\
\text { carbon }\end{array}$ & $\sim 21$ & 1.86 & 0.82 & 1.93 & 0.82 & 0.89 & 0.94 \\
\hline Silica & $\sim 56$ & 1.49 & 0.88 & 1.52 & 0.87 & 0.78 & 0.97 \\
\hline Graphite & $\sim 56$ & 4.02 & 0.56 & 4.10 & 0.55 & 2.10 & 0.75 \\
\hline
\end{tabular}

Table 4.6 - Values of the Thiele modulus and effectiveness factor for different support particles

\subsubsection{Comparison of catalysts}

Figure 4.13 compares the catalytic activity of the Pd catalysts with comparable diffusion lengths, i.e. radius of particles and thickness of the active layer are similar for all catalysts. It is evident that the CNF based supports give much higher reaction rates. The advantage of CNF supports is also demonstrated in Figure 4.11, by the fact that relatively large $(225 \mu \mathrm{m}) \mathrm{CNF}$ aggregates result in much higher TOFs as compared to similar sized traditional support particles. Furthermore, the data in 
figures 4.8 and 4.9 convincingly demonstrate efficient mass transfer in CNF layers up to $28 \mu \mathrm{m}$ thick.

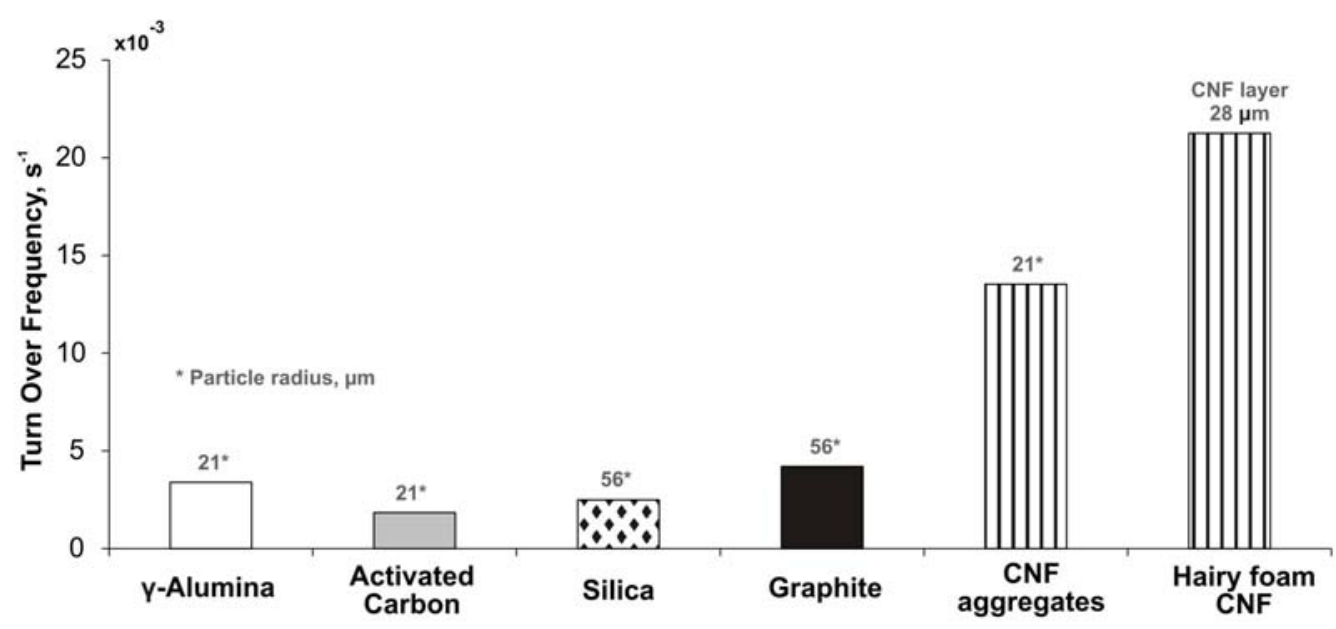

Figure 4.13 - Comparison of Turn over frequency values of conventional catalysts and CNF based catalysts at comparable particle radius and CNF layer thickness.

Enhanced mass transfer in CNF or CNT supported precious-metal catalysts in liquid phase reactions was also reported for hydrodehalogenation of bromobenzene [35], hydrogenation of trans-stilbene [36], cinnamaldehyde [37-39], citral [40] and nitrobenzene[41]. Increased activity is ascribed to better accessibility of active sites as compared traditional support materials. However, possible influences of the support material on intrinsic activities of the mean particles were never systematically ruled out as in the present study.

Hydrogenation of nitrite is extremely fast, easily inducing internal concentration gradients due to diffusion limitation. Our results agree well with results of Strukul et al. [25], reporting that small catalyst support particles (diameter : $80 \mu \mathrm{m}$ ) are more active than large catalyst support particles $(1.7 \mathrm{~mm})$. However, our results demonstrate that $80 \mu \mathrm{m}$ particles are still too large to prevent internal diffusion limitations. Lecloux [22] demonstrated that mass transfer limitations can be prevented using egg-shell catalysts with active metal located exclusively in the outer $20 \mu \mathrm{m}$ of relatively large catalyst particles. Similarly, Hörold et al [19] reported an increase in activity for nitrite reduction when increase the pore volume of alumina particles as small as $32 \mu \mathrm{m}$ suggesting the influence of diffusion limitations. 
We propose that both high porosity as well as low tortuosity of the CNF-layer contribute to the beneficial effect on activity. As discussed above, reliable experimental data on the porosity are lacking and the best information available so far is estimation from our lab $(1 \mathrm{ml} / \mathrm{g})$ based on microscopic estimation of thickness of the layer combined with weight of the carbon deposits [6]. However, Wenmakers [51] pointed out that the top layer of the CNF layer is even more porous as compared to the bottom part of the CNF layer. Given the fact that most Pd is deposited in the outer layer (figure 4.4), this might contribute to enhanced mass transfer. On the other hand, the morphology of layers of entangled CNF as observed on SEM directly hints to low tortuosity as compared to conventional catalyst supports.

Based on our observations and literature discussed above, we claim that CNF supports indeed provide better mass transfer properties; however, the high TOFs observed on CNF based supports cannot be due to mass transfer only. Based on the calculations of the WP number as well as Thiele number and the estimation of catalyst efficiency all indicate that catalysts supported on $21 \mu \mathrm{m}$ radius particles of alumina and AC suffer only slightly from diffusion limitation. Therefore, the intrinsic activity of CNF supported catalyst is significantly higher as compared to the other supports. The same effect is observed for graphite supported catalysts: despite internal diffusion limitations (tables 4.5 and 4.6, due to the low porosity of graphite), the TOFs are relatively high. Therefore, the intrinsic activity of Pd on graphite must be significantly higher as compared to alumina, silica and activated carbon. These effects are certainly not artefacts due to differences in residence time distribution as all experiments are differential, keeping conversion below 6\%. Further, Pd particle size and distributions are similar for all catalysts, whereas Figure 4.12 demonstrates that TOF are constant within the window of variation of dispersion in this study as discussed above. In short, we rule out any particle size effects. Also, the Pd particles are too large to enable support materials to influence shape or electronic structure of the metal particles. Finally, conductivity of the support material is apparently not an important factor as AC supported catalyst are not particular active, in contrast to the CNF based supports as well as graphite.

Therefore, we speculate that the adsorption of reactants on the graphite support may also contribute to the activity. Nitrite possibly adsorbs directly on the 
graphite surface, inspired from [42, 43] and/or hydrogen atoms spilled over from the Pd particles to the graphite surface $[44,45]$ may contribute to the reaction rate at the perimeter of the catalyst particles. This is not uncommon in catalysis, for example for the liquid phase hydrogenation of cinnamaldehyde over Pt/CNF catalysts it was shown that catalytic action of Pt is influenced by the amount of cinnamaldehyde adsorbed on the support in the vicinity of Pt the particles [46, 47]. Clearly, further research would be needed to clarify the underlying principle of this peculiar observation.

In short, hairy foams demonstrate advantages in terms of mass transfer, as well as intrinsic activity for nitrite hydrogenation under neutral conditions. Furthermore, hairy foams offer short diffusion paths without the disadvantage of high pressure drop in the case of a packed bed of small particles.

\subsection{Conclusions}

A series of Pd catalyst has been prepared with limited variation in Pd dispersion, containing relatively large $(\sim 10 \mathrm{~nm})$ Pd particles, in order to study the effect of the morphology of the support material on the rate of internal mass transfer. It was demonstrated that the limited variation in Pd dispersions in this study indeed resulted in identical TOFs in nitrite hydrogenation for all hairy foam supported catalysts.

It was demonstrated that CNF based catalysts are indeed highly active for nitrite hydrogenation, resulting in TOFs at least three times larger as compared to conventional catalysts. This is due to improved mass transfer thanks to high porosity as well as low tortuosity of CNF aggregates as well as thin CNF-layers in hairy foam. Surprisingly, also the intrinsic activity of graphite and CNF supported Pd contributes significantly to the high activity for nitrite reduction.

Hairy foam supports provide short diffusion pathways, combined with high porosity and low tortuosity, circumventing the disadvantage of small catalyst particles for liquid phase catalytic reactions, i.e. high pressure drop or the necessity of filtration. 


\section{Notation}

$\Phi_{\mathrm{R}} \quad$ Radius of catalyst support, $\mu \mathrm{m}$

$\Phi_{\mathrm{p}} \quad$ Pd particle size, $\mathrm{nm}$

\section{Appendix}

Weisz-Prater criterion:

Intraparticle diffusion limitation in different support particles was estimated based on the Weisz-Prater criterion (equation 3). $\mathrm{r}_{\mathrm{obs}}$ is the observed reaction rate (mol.g ${ }_{\mathrm{cat}}^{-1} \mathrm{~s}^{-1}$ ), $\rho_{\mathrm{p}}$ is the particle density $\left(\mathrm{g} \cdot \mathrm{cm}^{-3}\right), \mathrm{R}_{\mathrm{p}}$ is the particle radius $(\mathrm{cm})$, and $\mathrm{C}_{\mathrm{A}}$ is the concentration of the reactant (nitrite or hydrogen) (mol. $\mathrm{L}^{-1}$ ). The effective diffusivity $\left(D_{\text {eff }}, \mathrm{cm}^{2} . \mathrm{s}^{-1}\right.$ ) of the reactants is estimated using equation $4 . \tau$ is the tortuosity factor of the pore system and $\mathrm{D}_{\mathrm{AB}}$ is the molecular diffusivity of reactants such as nitrite, hydrogen and proton corresponding to values 1.91E-05, 5.11E-05 and $9.31 \mathrm{E}-05 \mathrm{~cm}^{2} \cdot \mathrm{s}^{-1}$, respectively [34]. $\varepsilon_{\mathrm{p}}$ is porosity of the support, calculated from the pore volume and bulk particle density of the support. The Weisz-Prater criterion value of far greater than one $\left(\mathrm{C}_{\mathrm{WP}}>>1\right)$ indicates significant limitation by diffusion in the pores in the catalyst particle, while Weisz-Prater criterion value of far less than one $\left(\mathrm{C}_{\mathrm{WP}}<<1\right)$ indicates absence of significant concentration gradients within the particle.

$$
\begin{aligned}
& C_{w p}=\left(r_{\text {obs }} * \rho_{p} * R_{p}^{2}\right) /\left(D_{\text {eff }} * C_{A}\right) \\
& D_{\text {eff }}=\left(\varepsilon_{p} * D_{A B}\right) / \tau
\end{aligned}
$$

Thiele modulus and Effectiveness factor:

Thiele modulus $(\varphi)$ can be calculated using equation $5 . R_{p}$ is the radius of the particle $(\mathrm{m}), \mathrm{k}$ is rate constant $\left(\mathrm{m}^{3} * \mathrm{~m}^{-2} * \mathrm{sec}^{-1}\right), \mathrm{S}_{\mathrm{a}}$ is the surface area of the particle $\left(\mathrm{m}^{2} * \mathrm{~g}_{\text {cat }}{ }^{-1}\right), \rho_{\mathrm{p}}$ is the density of the particle $\left(\mathrm{g}^{*} \mathrm{~m}^{-3}\right)$ and $\mathrm{D}_{\text {eff }}$ is the effective diffusivity of the reactant $\left(\mathrm{m}^{2} * \mathrm{sec}^{-1}\right)$. When the Thiele modulus is larger than typically 5 , internal diffusion usually limits the overall rate of reaction; when Thiele modulus is small $(<1)$, the kinetics is usually rate limiting. 


$$
\varphi=R_{p} * \sqrt{\left[\left(k * S_{a} * \rho_{p} / D_{\text {eff }}\right)\right]}
$$

Effectiveness factor can be estimated from the Thiele modulus according to equation 6.

$$
\eta=(3 / \varphi) *[(1 / \tanh \varphi)-(1 / \varphi)]
$$




\section{References}

[1] A. cybulski, J.A. Moulijn, Structured catalysts and reactors, second ed., Marcel Dekker, New York, 2006.

[2] T.A. Nijhuis, A.E.W. Beers, T. Vergunst, I. Hoek, F. Kapteijn, J.A. Moulijn, Catal. Rev. Sci. Eng. 43 (2001) 345-380.

[3] M.T. Kreutzer, F. Kapteijn, J.A. Moulijn, J.J. Heiszwolf, Chem. Eng. Sci. 60 (2005) 5895-5916.

[4] F. Kapteijn, J.J. Heiszwolf, T.A. Nijhuis, J.A. Moulijn, CATTECH 3 (1999) 24-41.

[5] M.J. Ledoux, C. Pham-Huu, Catal. Today 102-103 (2005) 2-14.

[6] N. Jarrah, F. Li, J.G. van Ommen, L. Lefferts, J. Mater. Chem. 15 (2005) 1946-1953.

[7] A. Cordier, E. Flahaut, C. Viazzi, C. Laurent, A. Peigney, J. Mater. Chem. 15 (2005) 4041-4050.

[8] P.W.A.M. Wenmakers, J. van der Schaaf, F.M. Kuster, J.C. Schouten, J. Mater. Chem. 18 (2008) 2426-2436.

[9] P. Tribolet, L. Kiwi-Minsker, Catal. Today 103-103 (2005) 15-22.

[10] Z.R. Ismagilov, N.V. Shikina, V.N. Kruchinin, N.A. Rudina, A. Ushakov, N.T. Vasenin, H.J. Veringa, Catal. Today 102-103 (2005) 85-93.

[11] S.S. Tzeng, K.H. Hung, T.H. Ko, Carbon 44 (2006) 859-865.

[12] M. Cantoro, V.B. Golovko, S. Hofmann, D.R. Williams, C. Ducati, J. Geng, B.O. Boskovic, B. Kleinsorge, D.A. Jefferson, A.C. Ferrari, B.F.G. Johnson, J. Robertson, Diamond Relat. Mater. 14 (2005) 733-738.

[13] C. Stemmet. Gas-liquid Solid Foam Reactors: Hydrodynamics and Mass Transfer, PhD thesis, Eindhoven University (2008).

[14] J.K. Chinthaginjala, D.B. Thakur, K. Seshan, L. Lefferts, Carbon 46 (2008) 1638-1647.

[15] K.P. De Jong, J. Geus, Catal. Rev. Sci. Eng. 42 (2000) 481-510.

[16] P. Serp, M. Corrias, P. Kalck, Appl. Catal. A 253 (2003) 337-358.

[17] J.K. Chinthaginjala, K. Seshan, L. Lefferts, Ind. Eng. Chem. Res. 46 (2007) 3968-3978.

[18] N.M. Rodriguez, J. Mater. Res. 8 (1993) 3233-3250.

[19] S. Hörold, K.D. Vorlop, T. Tacke, M. Sell, Catal. Today 17 (1993) 21-30.

[20] S. Hörold, T. Tacke, K.D. Vorlop, Environ. Tech. 14 (1993) 931-939.

[21] A. Pintar, G. Bercic, J. Levec, AIChE 44 (1998) 2280-2292.

[22] A.J. Lecloux, Catal. Today 53 (1999) 23-34.

[23] M.D’Arino, F. Pinna, G. Strukul, Appl. Catal. B, 53 (2004) 161-168.

[24] K.D. Vorlop, T. Tacke, Chem. Ing. Tech. 61(1989) 836-837.

[25] G. Strukul, F. Pinna, M. Marella, L. Meregalli, M. Tomaselli, Catal. Today 27 (1996) 209-214.

[26] B. Gabel, R. Kozicki, U. Lahl, A. Podbielski, B. Stachel, S. Struss, Chemosphere 11 (1982) 1147-1154.

[27] C.G.M. van de Moesdijk. The catalytic reduction of nitrate and nitric oxide to hydroxylamine: kinetics and mechanism. Ph. D. Thesis, University of Eindhoven (1979). 
[28] J.K. Chinthaginjala, L. Lefferts, Carbon 47 (2009) 3175-3183.

[29] M.K. van der Lee, A. J. van Dillen, J.W. Geus, K.P. de Jong, J.H. Bitter, Carbon 44 (2006) 629-637.

[30] D.R. Lide, Handbook of chemistry and physics. CRC press, $64^{\text {th }}$ edition

[31] J.J.F. Scholten, A.P. Pijpers, A.M.L. Hustings, Catal. Rev. Sci. Eng. 27 (1985) 151-206.

[32] V. Höller, K. Rådevik, I. Yuranov, L. Kiwi-Minsker, A. Renken, Appl. Catal. B 32 (2001) 143-150.

[33] Y. Matatov-Meytal, Y. Shindler, M. Sheintuch, Appl. Catal. B 45 (2003) 127-134.

[34] H.S. Fogler. Elements of chemical reaction engineering. Prentice-Hall Inc., $3^{\text {rd }}$ edition (2002).

[35] L. Chen, A.C. Cooper, G.P. Pez, H. Cheng, J. Phys. Chem. C 111 (2007) 18995-19000.

[36] T. Onoe, S. Iwamoto, M. Inoue, Catal. Comm. 8 (2007) 701-706.

[37] C. Pham-Huu, N. Keller, G. Ehret, L. Charbonniere, R. Ziessel, M.J. Ledoux, J. Mol. Catal. A 170 (2001) 155-163.

[38] J. Tessonnier, L. Pesant, G. Ehret, M.J. Ledoux, C. Pham-Huu, Appl. Catal. A 288 (2005) 203-210.

[39] H. Vu, F. Goncalves, R. Philippe, E. Lamouroux, M. Corrias, Y. Kihn, D. Plee, P. Kalck, P. Serp, J. Catal. 240 (2006) 18-22.

[40] F. Qin, W. Shen, C. Wang, H. Xu, Catal. Comm. 9 (2008) 2095-2098.

[41] C. Li, Z. Yu, K. Yao, S. Ji, J. Liang, J. Mol. Catal. A 226 (2005) 101-105.

[42] S. D. Ebbesen, B. L. Mojet, L. Lefferts, Langmuir 24 (2008) 869-879.

[43] A. Miyazaki, T. Asakawa, I. Balint, Appl. Catal. A 363 (2009) 81-85.

[44] D.J. Browning, M.L. Gerrard, J.B. Lakeman, I. M. Mellor, R. J. Mortimer, M. C. Turpin, Nano Lett. 2 (2002) 2001-2005.

[45] L. Chen, A. C. Cooper, G. P. Pez, H. Cheng, J. Phys. Chem. C 111 (2007) 18995-19000.

[46] M.L. Toebes, T.A. Nijhuis, J. Hájek, J.H. Bitter, A.J. van Dillen, D. Yu. Murzin, K.P. de Jong, Chem. Eng. Sci. 60 (2005) 5682-5695.

[47] A.J. Plomp, H. Vuori, A. O.I. Krause, K.P. de Jong, J.H. Bitter, Appl. Catal. A 351 (2008) 9-15.

[48] K.C. Metaxas, N.G. Papayannakos, Chem. Eng. Journal 140 (2008) 352-357.

[49] R. Leyva-Ramos, C.J. Geankoplis, Can. J. Chem Eng, 72 (1994) 262-271.

[50] W. Xia, C. Jin, S. Kundu, M. Muhler, Carbon, 47 (2009) 919-922.

[51] P.W.A.M. Wenmakers. Hairy Foam: Carbon nanofibers on solid foam as catalyst support, PhD thesis, Eindhoven University (2010). 


\title{
Chapter
}

\section{Support effect on selectivity of nitrite reduction in water}

\begin{abstract}
Palladium catalysts on various supports were studied for the hydrogenation of aqueous nitrite solution. The effects of reaction parameters such as nitrite and hydrogen concentration, $\mathrm{pH}$ and reaction temperature on the selectivity were discussed. Internal concentration gradients are influencing the selectivity significantly. Gradients of protons and nitrite are responsible for increasing ammonia selectivity. Carbon based catalysts were more selective towards ammonia as compared to oxidic supports. We propose that electron conductivity of carbon supports influences internal concentration gradients of both hydrogen and protons, favoring ammonia selectivity.
\end{abstract}




\subsection{Introduction}

Drinking water produced from ground water is increasingly contaminated with nitrites and nitrates in many countries, endangering public health. The toxicity of nitrates for human beings is due to the body's reduction of nitrates to nitrites, responsible for blue baby syndrome in infants and a precursor to cancer causing agents as well as to hypertension [1, 2]. In principle, these contaminants can be removed with conventional physicochemical methods (ion exchange, reverse osmosis and eletrodialysis) and biological methods [3]. The main disadvantage of physicochemical methods is the fact that nitrites or nitrates are removed by concentrating them in a secondary waste stream, which has called for new and environmental friendly systems. Biological denitrification processes are relatively slow and complex [4].

Catalytic de-nitrification of nitrates and nitrites from aqueous solution via hydrogenation over noble-metal solid catalysts is a promising method without the drawbacks of conventional methods. This process was first reported by Vorlop and Tacke [5]. It was reported that over a bimetallic catalyst, nitrate first reduces to nitrite, which in turn is converted to nitrogen and ammonia as a by-product, which is obviously undesired in drinking water. Thus, selectivity to $\mathrm{N}_{2}$ is of paramount importance. The reaction scheme is given below [6]:

$$
\begin{array}{lll}
2 \mathrm{NO}_{3}^{-}+2 \mathrm{H}_{2} & \stackrel{\mathrm{Pd}-\mathrm{Cu}}{\longrightarrow} & 2 \mathrm{NO}_{2}^{-}+2 \mathrm{H}_{2} \mathrm{O} \\
2 \mathrm{NO}_{2}^{-}+3 \mathrm{H}_{2}+2 \mathrm{H}^{+} & \mathrm{Pd} & \mathrm{N}_{2}+4 \mathrm{H}_{2} \mathrm{O} \\
\mathrm{NO}_{2}^{-}+3 \mathrm{H}_{2}+2 \mathrm{H}^{+} & \mathrm{Pd} & \mathrm{NH}_{4}^{+}+2 \mathrm{H}_{2} \mathrm{O}
\end{array}
$$

Nitrite reduction in aqueous solution can be performed over single noble metal catalysts and relatively few investigations have been published. Hörold et. al. [6] reported that several noble metals ( $\mathrm{Pd}, \mathrm{Pt}, \mathrm{Ru}, \mathrm{Ir}, \mathrm{Rh}$ ) are capable of promoting nitrite reduction, only supported Pd gives satisfactory performance in terms of activity and selectivity to nitrogen. They also reported that rate of nitrite conversion as well as the formation of ammonia, both strongly depend on the $\mathrm{pH}$ of the aqueous solution. It is reported that hydrogenation of nitrite is extremely fast, easily inducing internal 
concentration gradients due to diffusion limitation [4,7-9]. Strukul et al. [10] reported that decreasing the catalyst support particles size is resulting in increasing activity as well as selectivity to nitrogen. Gavagnin et.al. [11] proposed that sluggish counterdiffusion of formed hydroxyl ions from the catalyst pores into the bulk liquid phase, i.e. a $\mathrm{pH}$ gradient in the catalyst particle, is responsible for decreasing selectivity to nitrogen. Please note that this proposition can be likewise formulated in terms of proton diffusion.

Work in our group is focused on preparation of catalyst support materials with extreme high accessibility, by minimizing the diffusion length and tortuosity and maximizing the porosity. For that purpose we have developed methods to prepare thin layers of entangled carbon nanofibers (CNFs) supported on monoliths [12], foams $[13,14]$ and on the walls of micro-channels [15]. CNFs are mechanically strong, chemically inert and the surface chemistry can be modified, which are also favorable properties for catalyst supports [16, 17]. A thin layer of CNFs on structured supports is therefore an interesting proposition to avoid slurry phase operation including filtration, as well as to optimize hydrodynamics and gas-liquid mass transfer [18]. Other researchers have also reported on thin layers of CNFs on foams [19, 20], filters [21], fibers [22] and cloths [23] for application in gas phase, in contrast to our work.

Hydrogenation of nitrite in water is used as model reaction to demonstrate the superior properties of CNF layers on $\mathrm{Ni}$ foam (hairy foam). In chapter 4, it was showed that thin macroporous layers of CNFs indeed provide efficient mass transfer of the reactants reducing internal concentration gradients and improving reaction rates [24]. Aim of this study is to evaluate the performance of CNF based catalysts for the catalytic reduction of nitrite in terms of selectivity, in comparison to catalysts on conventional supports. The effect of reactant concentrations and temperature will also be reported.

\subsection{Experimental}

\subsubsection{Materials}

Pd supported on Alumina (AKZO NOBEL), activated carbon (NORIT ROX0.8), silica (AKZO NOBEL), graphite (Degussa), CNF aggregates and CNF/Ni 
foam ('hairy foam') were used in this study. Alumina, activated carbon and CNF aggregates with particle sizes ranging between $300-600 \mu \mathrm{m}$ as well as between 38$45 \mu \mathrm{m}$ were used. Furthermore, the particle size of graphite and silica supports was $100-125 \mu \mathrm{m}$. From here on the support particle sizes are referred in terms of the average particle radius. The thickness of the CNF layer in the hairy foam support was maintained at $28 \mu \mathrm{m}$. Preparation procedures as well as characterization of the supported Pd catalysts were reported in chapter 4 [24]. For clarity reasons some of the catalyst properties are presented again in table 5.1.

\begin{tabular}{|c|c|c|c|}
\hline $\begin{array}{c}\text { Support type and Average } \\
\text { particle radius }\left(\Phi_{R}\right)\end{array}$ & Pd weight, \% & Pd dispersion, \% & $\begin{array}{c}\text { Pd particle } \\
\text { size, } \mathbf{n m}\end{array}$ \\
\hline $\begin{array}{c}\mathrm{Pd} / \mathrm{Al}_{2} \mathrm{O}_{3}, \\
\left(\Phi_{\mathrm{R}}: 225 \mu \mathrm{m}\right) \\
\end{array}$ & 1.64 & $11.5 \pm 0.5$ & 9 \\
\hline $\begin{array}{c}\mathrm{Pd} / \mathrm{Al}_{2} \mathrm{O}_{3} \\
\left(\Phi_{\mathrm{R}}: 21 \mu \mathrm{m}\right)\end{array}$ & 2.23 & $11.95 \pm 0.2$ & 9 \\
\hline $\begin{array}{c}\text { Pd-Silica, } \\
\left(\Phi_{\mathrm{R}}: 56 \mu \mathrm{m}\right)\end{array}$ & 2.33 & $6.5 \pm 0.5$ & 17 \\
\hline $\begin{array}{l}\text { Pd-Activated carbon, } \\
\left(\Phi_{\mathrm{R}}: 225 \mu \mathrm{m}\right) \\
\end{array}$ & 1.62 & $7.8 \pm 0.8$ & 14 \\
\hline $\begin{array}{l}\text { Pd-Activated carbon, } \\
\left(\Phi_{\mathrm{R}}: 21 \mu \mathrm{m}\right)\end{array}$ & 2.33 & $8.3 \pm 0.8$ & 13 \\
\hline $\begin{array}{l}\text { Pd-Graphite, } \\
\left(\Phi_{\mathrm{R}}: 56 \mu \mathrm{m}\right)\end{array}$ & 2.37 & $12.4 \pm 0.3$ & 9 \\
\hline $\begin{array}{c}\text { Pd-unsupported CNF aggregates, } \\
\left(\Phi_{\mathrm{R}}: 225 \mu \mathrm{m}\right)\end{array}$ & 1.21 & $5.3 \pm 0.1$ & 21 \\
\hline $\begin{array}{c}\text { Pd-unsupported CNF aggregates, } \\
\left(\Phi_{\mathrm{R}}: 21 \mu \mathrm{m}\right)\end{array}$ & 1.48 & $5.5 \pm 0.1$ & 20 \\
\hline $\begin{array}{c}\text { Hairy foam } \\
\text { CNF thickness : } 28_{\text {avg }} \mu \mathrm{m} \\
\end{array}$ & 2.23 & $5.6 \pm 0.4$ & 20 \\
\hline \multirow{4}{*}{$\begin{array}{c}\text { Hairy foam } \\
\text { CNF thickness : } 13_{\text {avg }} \mu \mathrm{m}\end{array}$} & 1.97 & $6.7 \pm 0.3$ & 16 \\
\hline & 1.52 & $9.6 \pm 0.2$ & 12 \\
\hline & 1.1 & $9.6 \pm 0.3$ & 12 \\
\hline & 0.49 & $6.7 \pm 0.4$ & 16 \\
\hline $\begin{array}{c}\text { Hairy foam } \\
\text { CNF thickness }: 8_{\text {avg }} \mu \mathrm{m}\end{array}$ & 1.95 & $5.4 \pm 0.2$ & 20 \\
\hline
\end{tabular}

Table 5.1 - Palladium dispersion and average Pd particle sizes based on COchemisorption on various catalysts. The values presented in table are acquired from chapter 4 [24].

\subsubsection{Catalytic reduction of nitrite ions}

Catalytic reduction of nitrite was performed in a flow-through fixed bed reactor, operating with either a conventional fixed bed or pieces of hairy foam. Nitrite concentration in aqueous solution was varied between 10mg/l (217 $\mu \mathrm{mol} / \mathrm{l})$ and 20mg/l $(435 \mu \mathrm{mol} / \mathrm{l})$, while the solution was pre-saturated with hydrogen at a partial pressure between 0.3 bar $(210 \mu \mathrm{mol} / \mathrm{l})$ and 0.7 bar $(546 \mu \mathrm{mol} / \mathrm{l})$ with argon as inert gas. Note 
that the reaction is taking place with pre-dissolved $\mathrm{H}_{2}$ exclusively and no gas phase in present in the reactor. The reactant liquid was flown through the tubular reactor placed in a thermo stated oven and the reactant liquid temperatures (between 298K and $321 \mathrm{~K}$ ) were measured just before the catalytic bed. The $\mathrm{pH}$ of the solution (between 4.5 and 9) was adjusted by adding phosphoric acid or sodium hydroxide. HPLC (DIONEX, Ultimate 3000 pump) was used to flow liquid through the fixed bed reactor or foam reactor. Further experimental details were reported in chapter 4 [24]. Nitrite and ammonium concentrations in the reactants and products were measured with ion-chromatography (DIONEX, ICS 1000). The reaction was performed under differential conditions, maintaining the nitrite conversions around 5\% in most cases. Therefore, concentration gradients along the axis of the reactor are not significant and turn-over-frequencies (TOF) were calculated using the Pd dispersion of the relevant catalyst, resulting in a number expressing the number of nitrite ions converted per surface-Pd-atom per second. It was assumed that nitrite ions were converted to ammonium and nitrogen exclusively; the yield of nitrogen was calculated from the difference between the nitrite conversion and the ammonium yield.

\subsection{Results}

\subsubsection{Catalytic performance}

Catalytic activity and product distribution were measured for all catalysts, which will be classified in three groups: ceramic based catalysts, carbon based catalysts and CNF based catalysts.

\subsubsection{Conventional ceramic and carbon based catalysts}

In chapter 4 [24], it was reported on the activity for nitrite reduction in terms of TOF on conventional supported catalysts with different support particle sizes. Small support particles $\left(\mathrm{R}_{\mathrm{p}}=21_{\mathrm{avg}} \mu \mathrm{m}\right)$ result in high TOF, demonstrating the occurrence of internal mass transfer limitations with larger support particles [24]. For clarity reasons this result is presented again in figure 5.1, also showing that small support particle sizes generally result in high selectivity to nitrogen. In contrast, carbon based supports result in high selectivity to ammonia as compared to ceramic supports with comparable particle size. 


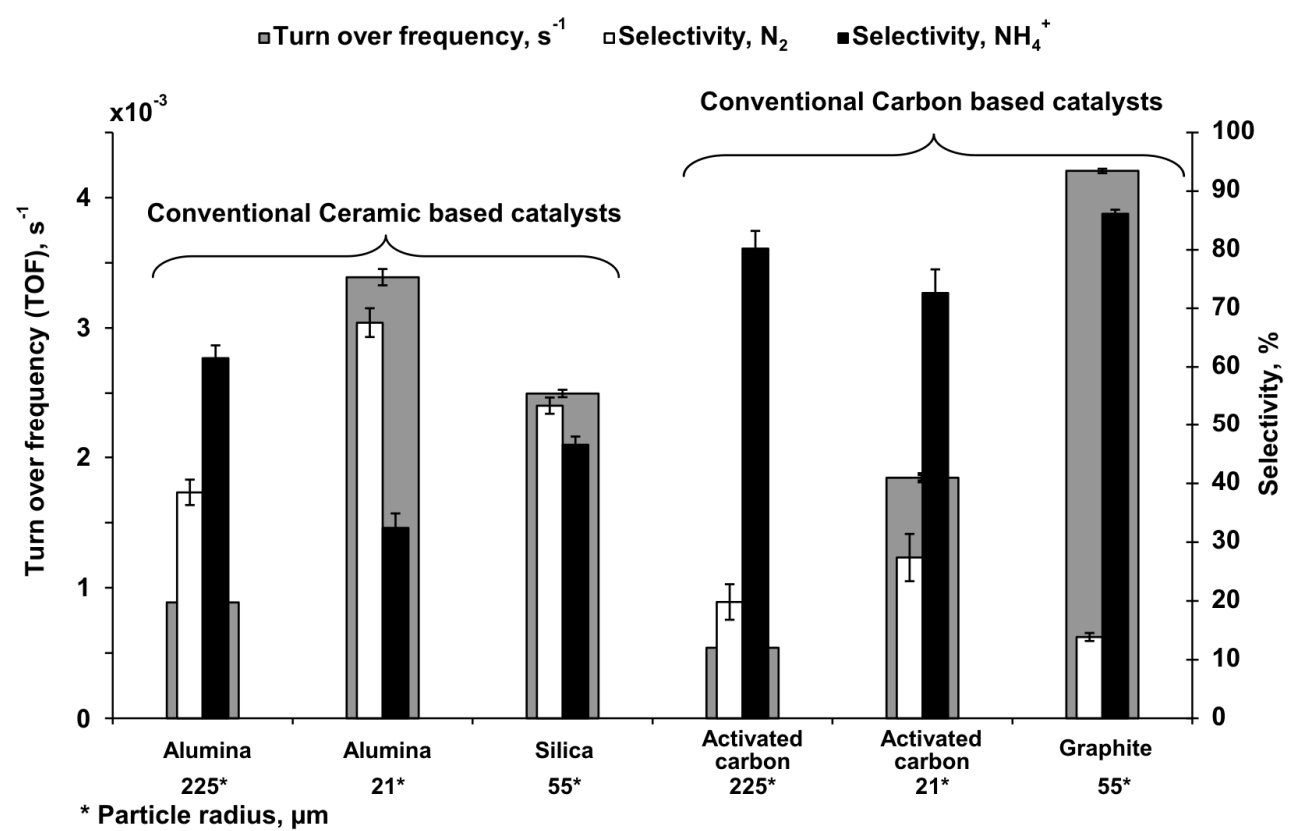

Figure 5.1 - Turn over frequency and selectivity of nitrogen and ammonia over ceramic based Pd catalysts, $\gamma$-alumina (particle radius $=225_{\text {avg }} \mu \mathrm{m} \& 21_{\text {avg }} \mu \mathrm{m}$ ) and silica (particle radius $=55_{\mathrm{avg}} \mu \mathrm{m}$ ), and carbon based Pd catalysts, activated carbon (particle radius $\left.=225_{\mathrm{avg}} \mu \mathrm{m} \& 21_{\mathrm{avg}} \mu \mathrm{m}\right)$ and graphite (particle radius $=$ $\left.55_{\text {avg }} \mu \mathrm{m}\right)$.

\subsubsection{CNF based catalysts}

As reported in chapter 4 [24], catalysts supported on hairy foam, studied at varying CNF layer thicknesses $(8-28 \mu \mathrm{m})$ and Pd loadings $(0.5-2 \mathrm{wt} \%)$, do not suffer from any internal mass transfer limitations, while, unsupported CNF-aggregates with comparable diffusion lengths resulted in quite similar TOFs. Figure 5.2 shows that the large unsupported CNF catalysts result in relatively high ammonia selectivity as compared to small unsupported CNF catalysts, however, all the CNF based catalysts exhibit ammonia selectivity of greater than $80 \%$. Hairy foam catalysts with varying CNF layer thickness and Pd loadings also exhibited ammonia selectivity higher than $80 \%$ (result not shown). 


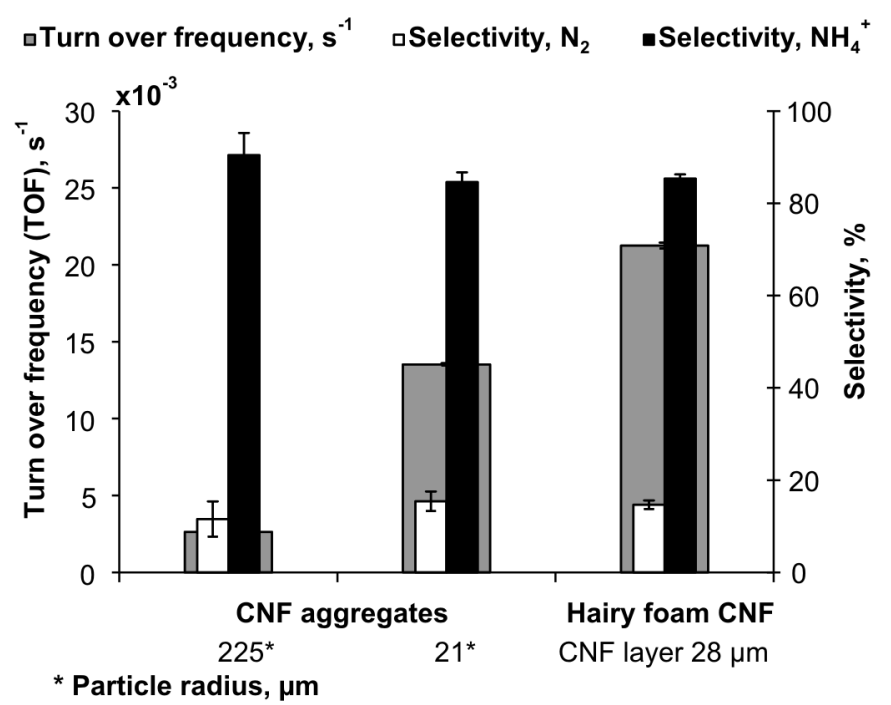

Figure 5.2 - Turn over frequency and selectivity of nitrogen and ammonia over CNF based Pd catalysts; unsupported CNF aggregate catalysts (particle radius = $225_{\text {avg }} \mu \mathrm{m} \& 21_{\text {avg }} \mu \mathrm{m}$ ) and hairy foam catalysts of $28_{\text {avg }} \mu \mathrm{m}$ thick CNF layer.

\subsubsection{Kinetics}

A kinetic study was performed with the hairy foam supported catalysts, varying the nitrite and $\mathrm{H}_{2}$ concentrations as well as temperature. The effect of hydrogen concentration and nitrite concentration on the reaction rate are presented in figure 5.3a and 5.4a, respectively. The reaction order for nitrite hydrogenation was determined to be 0.4 in hydrogen and 0.7 in nitrite. The influences of both concentrations on the selectivity to ammonia are presented in figures 5.3b and 5.4b.
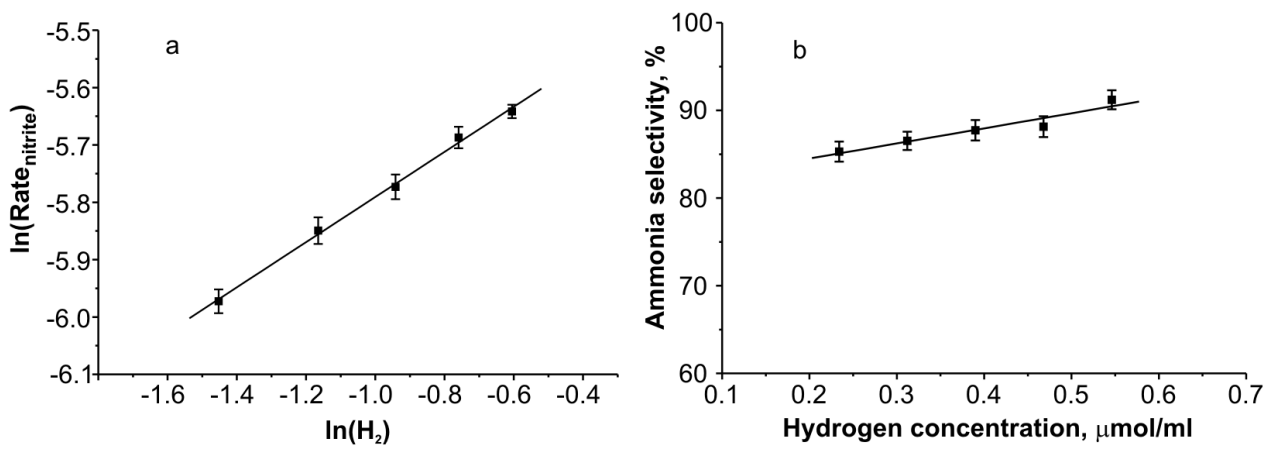

Figure 5.3 - Effect of hydrogen partial pressure on reaction rate (figure 5.3a) and selectivity to ammonia (figure 5.3b) in hydrogenation of nitrite over $2.33 \mathrm{wt} \% \mathrm{Pd} /$ Hairy foam at nitrite concentration of $0.435 \mu \mathrm{mol} / \mathrm{ml}, \mathrm{pH} 7$ and at $25^{\circ} \mathrm{C}$. 
Effect of nitrite and hydrogen concentrations on the ammonia selectivity is considerable. Increasing nitrite concentration resulted in a decrease in ammonia selectivity, whereas, increasing hydrogen concentration resulted in increasing ammonia selectivity. Figure 5.5 shows the effect of $\mathrm{pH}$ on the activity for nitrite reduction as well as the selectivity to ammonia. Increasing the $\mathrm{pH}$ resulted in a decrease in TOF while the selectivity to ammonia is observed to increase. The effect of temperature on the reaction rate constant $\left(\mathrm{k}_{\text {nitrite }}\right)$ and the selectivity to ammonia are presented in figure 5.6a,b. Reaction rate constants were calculated using the reaction orders as reported above (0.7 in nitrite and 0.4 in hydrogen). The resulting activation energy was estimated to be $22.6 \mathrm{KJmol}^{-1}$. Figure $5.6 \mathrm{~b}$ shows that higher reaction temperatures resulted in higher ammonia selectivity.
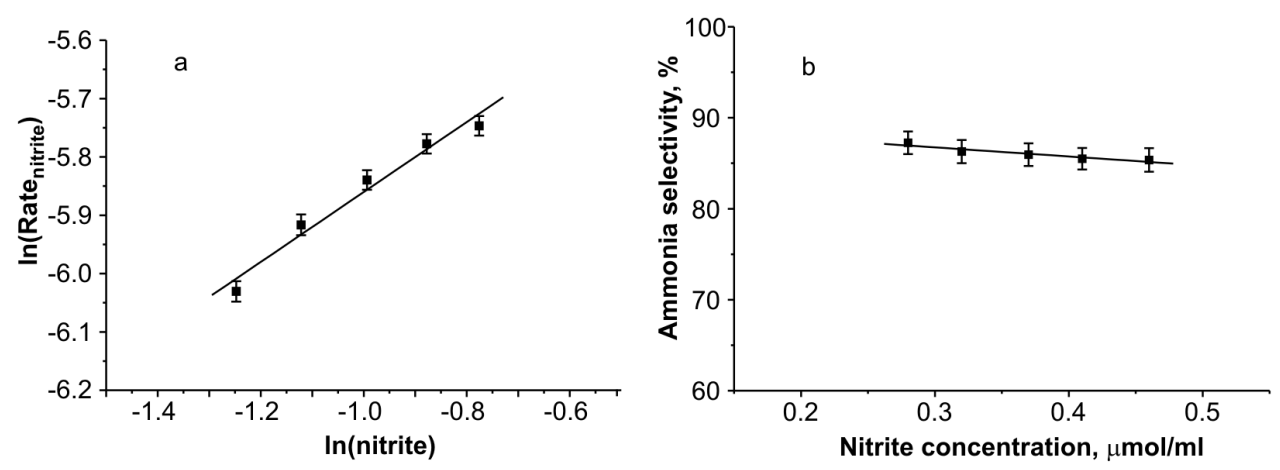

Figure 5.4 - Effect of nitrite concentration on reaction rate (figure 5.4a) and selectivity to ammonia (figure 5.4b) in hydrogenation of nitrite over $2.33 \mathrm{wt} \%$ $\mathrm{Pd} /$ Hairy foam at hydrogen partial pressure of $0.4 \mathrm{bar}, \mathrm{pH} 7$ at $25^{\circ} \mathrm{C}$.

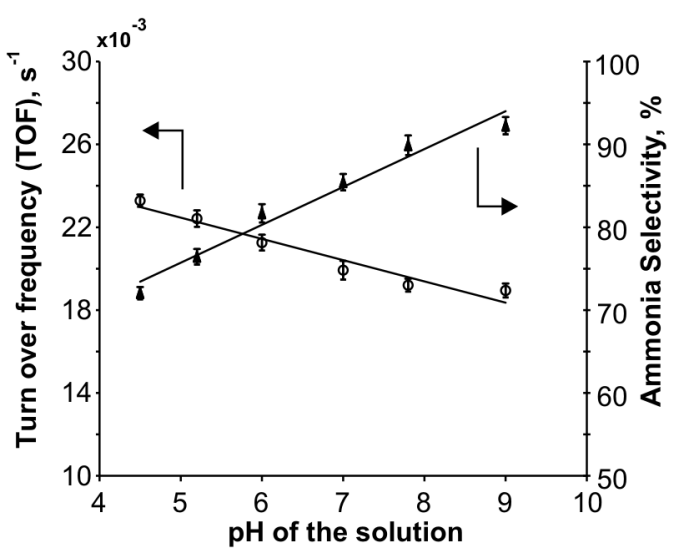

Figure 5.5 - Turn over frequency and selectivity to ammonia over Hairy foam catalysts of 28 avg $\mu m$ thick CNF layer (2.23wt\%Pd) at $\mathrm{pH}$ values between 4.5 and 9, hydrogen partial pressure of $0.4 \mathrm{bar}$ and nitrite concentration of $20 \mathrm{mg} / \mathrm{l}$. 

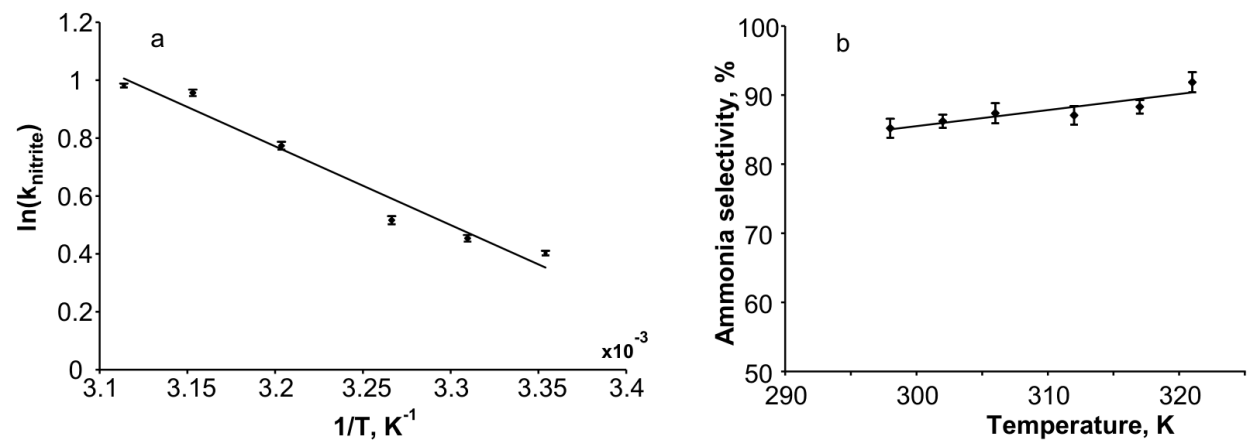

Figure 5.6 - Temperature dependence of reaction rate constant $\left(\mathrm{k}_{\text {nitrite }}\right)$ (figure $5.6 \mathrm{a}$ ) and on ammonia selectivity (figure $5.6 \mathrm{~b}$ ) over $2.23 \mathrm{wt} \% \mathrm{Pd} / \mathrm{hairy}$ foam catalyst.

\subsection{Discussion}

\subsubsection{Intrinsic Kinetics}

The experimental results on hairy foam catalysts directly lead to the following kinetic equation, as it was demonstrated in chapter 4 that mass transfer limitations do not influence nitrite reaction rates on Pd catalysts supported on hairy foam [24].

$$
\text { rate }\left(\mathrm{NO}_{2}{ }^{-}\right)=\mathrm{k}_{0} * \mathrm{e}^{-22600 / \mathrm{RT}} * \mathrm{C}_{\mathrm{NO} 2-}{ }^{0.7} \mathrm{P}_{\mathrm{H} 2}{ }^{0.4}
$$

The reaction order (0.4) in hydrogen suggests that hydrogen is dissociatively adsorbed and that the surface coverage is relatively low. The reaction order (0.7) in nitrite suggests that the surface coverage of nitrite is also relatively low under these conditions.

Matatov-Meytal et al. [25] reported reaction orders of 1 and 0 with respect to nitrite and hydrogen, respectively, for nitrite reduction on Pd supported on activated carbon cloth. Mikami et al. [26] reported orders of 1 and 0.3 with respect to nitrite and hydrogen on a bimetallic (Pd-Cu) supported on activated carbon. The differences with our results are probably due to differences in reaction conditions. The activation energy (22.6 kJ. mol${ }^{-1}$ ) is quite similar to $26 \mathrm{~kJ} \mathrm{~mol}^{-1}$ as reported in literature [6, 27]. Also, the effect of $\mathrm{pH}$ on the rate of nitrite reduction is qualitatively in agreement with literature [6]. At high $\mathrm{pH}$, more negatively charged metal particles are formed [28], which decreases the adsorption of anions by electrostatic forces. Mikami et al. [26] 
and Mojet et al. [29] have showed experimentally that adsorption of nitrite is enhanced at low $\mathrm{pH}$.

The trends in selectivity agree well with information in literature. The observation that increasing the nitrite-to-hydrogen ratio results in decreasing ammonia selectivity (figure 5.3 and 5.4) is in agreement with claims in literature that ammonia selectivity can be decreased by operating under lower surface hydrogen concentration $[6,30,31]$. Selectivity is also dependent on temperature (figure 5.6b); high temperatures favor high ammonia selectivity which is also in agreement with earlier reports [6, 27]. Additionally, selectivity is depending on $\mathrm{pH}$ : increasing $\mathrm{pH}$ result in increasing selectivity to ammonia (figure 5.5), again agreeing with literature [5, 6]. It should be emphasized that the effect of $\mathrm{pH}$ on selectivity is more pronounced as compared to effects of the concentrations of hydrogen and nitrite as well as temperature (figure $5.3-5.6$ ).

Warna et al. [32] proposed a reaction scheme including adsorbed NO as a key reaction intermediate for nitrate hydrogenation. It is well accepted that the first step form nitrate to nitrite is relatively slow [33], but it seems reasonable to assume that the rest of the scheme represents the conversion of nitrite. However, previous spectroscopic work in our group [34] suggested that ammonia and nitrogen are formed via two parallel pathways as presented in scheme 1 . The selectivity to $\mathrm{N}_{2}$ and ammonia is therefore controlled by the ratio of the rates of steps to $\mathrm{NO}_{\text {ads }}$ and $\mathrm{NH}_{2 \text {,ads }}$ from adsorbed nitrite. Obviously, when increasing the $\mathrm{H}_{2}$ pressure, the surface coverage of $\mathrm{H}$ will increase as the surface coverage is low, based on the experimental reaction order in $\mathrm{H}_{2}$ close to 0.5 , the value expected for dissociative adsorption at low coverage. Therefore, the $\mathrm{NO}_{\text {ads }}$-to- $\mathrm{NH}_{2 \text {,ads }}$ ratio will shift in favour of $\mathrm{NH}_{2 \text {,ads }}$ because

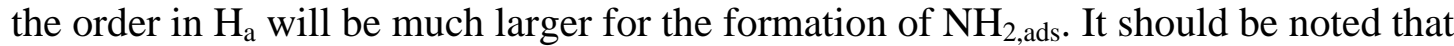
though these reaction steps are certainly not elementary, nevertheless a significant difference in order in $\mathrm{H}_{\mathrm{ads}}$ is a reasonable assumption based on the stoicheometry of the reactions. 


$$
\mathrm{NO}_{2 \text { (aq) }}^{-}+* \rightarrow \mathrm{NH}_{2 \text { (ads) }} \rightarrow \mathrm{NH}_{4}^{+}{ }_{(\text {ads) }}^{-} \rightarrow \mathrm{NH}_{4}^{+}{ }_{\text {(aq) }}
$$

Scheme 1 - Reaction scheme of the catalytic hydrogenation of nitrite over $\mathrm{Pd} / \mathrm{Al}_{2} \mathrm{O}_{3}$ as suggested by Ebbesen et al. [34] based on ATR-IR spectroscopic studies.

When increasing the nitrite concentration, the reaction rate is going to increase (order 0.7) and consequently the concentration of adsorbed hydrogen will decrease as hydrogen adsorption is far from equilibrium. Thus, the selectivity to ammonia is decreasing, as observed in figure 5.4b. The effect of temperature on selectivity (figure $5.6 \mathrm{~b})$ is probably due to differences in the activation energies for the steps leading to $\mathrm{NH}_{2}$,ads versus $\mathrm{NO}_{\text {ads }}$. The effect of $\mathrm{pH}$ on selectivity is possibly due to an increase in the surface coverage of nitrite at low $\mathrm{pH}$ due to stronger positively charged $\mathrm{Pd}$ particles. Therefore, the $\mathrm{NO}_{\mathrm{ads}}$ to $\mathrm{NH}_{2}$,ads ratio will shift towards $\mathrm{NO}_{\text {ads }}$ favouring nitrogen selectivity (figure 5.5). Nevertheless, we cannot rule out the possibility that the $\mathrm{pH}$ changes the reaction rates of the rate determining steps in the two pathways in scheme 1 directly. In short, selectivity to ammonia is decreased by lowering the hydrogen partial pressure, increasing the nitrite concentration, decreasing $\mathrm{pH}$ and as well as temperatures, which can be well explained in terms of the reaction scheme presented in scheme 1.

\subsubsection{Effect of mass transfer limitations on selectivity}

In chapter 4 it was reported that catalyst with large support particles suffer from internal mass transfer limitations [24], which is confirmed by the results in figure 5.1 and 5.2. The selectivities, as depicted in figure 5.1 and 5.2 shows that catalyst on large support particles (particle radius $225_{\text {avg }} \mu \mathrm{m}$ ) are more selective towards ammonia as compared to smaller support particles. In large support particles, hydrogen, nitrite and protons all contribute to diffusion limitation. The extent of concentration gradients increases in the order $\mathrm{H}^{+}<\mathrm{H}_{2}<\mathrm{NO}_{2}^{-}$in the case of $\mathrm{pH}$ equal to 7, although it should be noted that the differences are modest and gradients of all species probably contribute (chapter 4) [24]. The effect of support particle size on 
selectivity is in agreement with observations by Strukul et al. [10] and Lecloux et al. [7], suggesting that $\mathrm{pH}$ gradients can occur in large catalyst particles, influencing the selectivity. D’Arino et al. [8] suggested that the same effect can be achieved by varying the pore-sizes of the support. However, very large particle $(>1 \mathrm{~mm})$ combined with high nitrite concentration and low $\mathrm{pH}$ values where used in these studies which are significantly different from our experimental conditions. .

In our case, the selectivity will be influenced by concentration gradients of $\mathrm{H}^{+}$, $\mathrm{NO}_{2}{ }^{-}$as well as $\mathrm{H}_{2}$ and therefore it is not possible to predict which factor is going to dominate. The fact that ammonia selectivity increases with diffusion limitation is suggesting that $\mathrm{H}^{+}$diffusion and nitrite diffusion are responsible for the effect, because a decrease in the nitrite concentration as well as the $\mathrm{H}^{+}$concentration (increasing $\mathrm{pH}$ ) is favoring the formation of ammonia, according the intrinsic kinetic data as discussed above (figures 5.4b and 5.5). The opposite effect of hydrogen concentration gradient is apparently overruled.

\subsubsection{Effect of carbon support on selectivity}

It is striking to note that carbon based catalyst supports result in much higher selectivity to ammonia as compared to oxidic supports, independent of mass transfer effects (figure 5.1 and 5.2). This is in agreement with results of Hörold et al. [6] reporting high activity and relatively high ammonia formation on carbon based catalysts as compared to alumina based catalysts. Also Yoshinaga et al. [35] reported ammonia selectivity up to $70 \%$ for nitrite reduction over Pd supported activated carbon, in agreement with our observation. However, the reason of this remarkable difference has not been addressed yet.

We propose that the conductive nature of the support influences the product distribution. On every Pd particle the equilibrium in Eq.4 will establish, or at least try to establish, by competing with reactions converting adsorbed hydrogen (nitrite hydrogenation), determining the electrochemical potential of the Pd particle:

$$
\mathrm{H}_{2}+2 * \leftrightarrow 2 \mathrm{H}_{\mathrm{a}} \leftrightarrow 2 \mathrm{H}^{+}+2 \mathrm{e}^{-}
$$


Based on the calculations in chapter 4 [24] it is clear that diffusion of protons is less limiting than diffusion of hydrogen. Therefore, $\mathrm{H}_{2}$ internal concentration gradients, and thus lower hydrogen concentration deep in the catalyst particle, will cause higher potentials at poorly accessible Pd particles. However, in case the support is electrical conductive; electrons will start to flow from accessible Pd particles in the outer shell of the support towards poorly accessible Pd particles in the middle. These electrons will then increase the concentration of $\mathrm{H}_{\mathrm{ads}}$ according to equation 4 . In other words, molecular diffusion of $\mathrm{H}_{2}$ molecules is now assisted by diffusion of protons, increasing the hydrogen coverage of the Pd particles, therefore shifting the product distribution towards ammonia as discussed before. In other words, the hydrogen concentration gradient is relaxed whereas the proton concentration gradient increases. Both effects contribute to increasing the selectivity to ammonia.

The reasoning above implicitly assumes that the intrinsic activity and selectivity of the Pd particles in all catalyst used in this study do not vary from catalyst to catalyst. As discussed in chapter 4, [24] all catalysts used had relatively large Pd particles and similar Pd particle size distributions (table 5.1). Actually, catalyst preparation was tuned to achieve that. The relatively small variations in dispersion (table 5.1) does not introduce significant variation in performance, as can be seen from the series of hairy foam catalysts with varying both the thickness of the CNF layer as well as varying the Pd loading (table 5.1). The variation in dispersion within this series is comparable to the variation for all catalysts used in this study. Despite this variation, no difference in activity was observed, as discussed in chapter 4 [24]. More importantly, also the selectivity remained constant $(87 \% \pm 3 \%$ towards ammonia) on all hairy foam catalysts, demonstrating that the selectivity is not determined by the Pd particles size.

\subsection{Conclusions}

Palladium catalysts on various support materials were studied for nitrite hydrogenation in aqueous solution. The intrinsic selectivity to ammonia increases with decreasing nitrite concentration as well as increasing hydrogen concentration. Furthermore, high $\mathrm{pH}$ and high temperatures also result in higher ammonia selectivity. The influence of internal concentration gradients on selectivity can be explained based 
on the trends in the intrinsic selectivity. Concentration gradients cause increasing selectivity to ammonia. Remarkably, catalysts supported on carbon are more selective to ammonia as compared to oxidic supports. We propose that for activated carbon and graphite catalysts the electrical conductivity of the carbon support increases the hydrogen surface coverage of Pd particles deep in the support particles, at the same time increasing the proton internal gradient; both effects are favoring ammonia formation. 


\section{References}

[1] C.S. Bruning-Fann, J.B. Kaneene, Vet. Hum. Toxicol. 35 (1993) 521-538.

[2] L.W. Canter, Nitrates in ground water, CRC Press, Boca Raton, FL, 1996.

[3] A. Kapoor, T. Viraraghavan, J. Environ. Eng. 123 (1997) 371-380.

[4] A. Pintar, G. Bercic, J. Levec, AIChE 44 (1998) 2280-2292.

[5] K.D.Vorlop, T.Tacke, Chem. Eng. Tech. 61 (1989) 836-837.

[6] S. Hörold, T. Tacke, K. D. Vorlop, Environ. Tech. 14 (1993) 931-939.

[7] A.J. Lecloux, Catal. Today 53 (1999) 23-34.

[8] M. D’Arino, F. Pinna, G. Strukul, Appl. Catal. B 53 (2004) 161-168.

[9] S. Hörold, K.D. Vorlop, T. Tacke, M. Sell, Catal. Today 17 (1993) 21-30.

[10] G. Strukul, F. Pinna, M. Marella, L. Meregalli, M. Tomaselli, Catal. Today 27 (1996) 209-214.

[11] R. Gavagnin, L. Biasetto, F. Pinna, G. Strukul, Appl. Catal. B 38 (2002) 91-99.

[12] N. Jarrah, J.G. van Ommen, L. Lefferts, Catal. Today 79-80 (2003) 29-33.

[13] N. Jarrah, F. Li, J. G. van Ommen and L. Lefferts, J. Mater. Chem. 15 (2005) 19461953.

[14] J.K. Chinthaginjala, D.B. Thakur, K. Seshan, L. Lefferts, Carbon 46 (2008) 1638-1647.

[15] D.B. Thakur, R.M. Tiggelaar, K. Seshan, J.G.E. Gardeniers, L. Lefferts, CIMTEC, 54 (2008) 231-236.

[16] K.P. De Jong, J. Geus, Catal. Rev. Sci. Eng. 42 (2000) 481-510.

[17] P. Serp, M Corrias, P. Kalck, Appl. Catal. A 253 (2003) 337-358.

[18] J.K. Chinthaginjala, K. Seshan, L. Lefferts, Ind. Eng. Chem. Res. 46 (2007) 3968-3978.

[19] R. Vieira, M.J. Ledoux, C. Pham-Huu, Appl. Catal. A 274 (2004) 1-8.

[20] A. Cordier, E. Flahaut, C. Viazzi, C. Laurent, A. Peigney, J. Mater. Chem. 15 (2005) 4041-4050.

[21] P. Tribolet, L. Kiwi-Minsker, Catal. Today 102-103 (2005) 15-22.

[22] Z.R. Ismagilov, N.V. Shikina, V.N. Kruchinin, N.A. Rudina, A. Ushakov, N.T. Vasenin, H.J. Veringa, Catal. Today 102-103 (2005) 85-93.

[23] M. Cantoro, V.B. Golovko, S. Hofmann, D.R. Williams, C. Ducati, J. Geng, B.O. Boskovic, B. Kleinsorge, D.A. Jefferson, A.C. Ferrari, B.F.G. Johnson, J. Robertson, Diamond and Related Materials 14 (2005) 733-738.

[24] J.K. Chinthaginjala, J. H. Bitter, L.Lefferts, Appl. Catal. A (2010) (accepted).

[25] Y. Matatov-Meytal, Y. Shindler, M. Sheintuch, Appl. Catal. B 45 (2003) 127-134.

[26] I. Mikami, Y. Sakamoto, Y. Yoshinaga, T. Okuhara, Appl. Catal. B 44 (2003) 79-86.

[27] V. Höller, K. Rådevik, I. Yuranov, L. Kiwi-Minsker, A. Renken, Appl. Catal. B 32 (2001) 143-150.

[28] A. Couto, A. Rincon, M.C.Perez, C. Gutierrez, Electrochimica Acta 46 (2001) 12851296.

[29] B.L. Mojet, S.D. Ebbesen, L.Lefferts, Appl. Catal. A (2010) (submitted). 
[30] A. Pintar, J. Batista, J. Levec, Wat. Sci. Tech. 37 (1998) 177-185.

[31] Y. Matatov-Meytal, V. Barelko, I. Yuranov, M. Sheintuch, Appl. Catal. B 27 (2000) 127-135.

[32] J. Wärnå, I. Turunen, T. Salmi, T. Mannula, Chem. Eng. Sci. 49 (1994) 5763-5773.

[33] C.G.M. van de Moesdijk. The catalytic reduction of nitrate and nitric oxide to hydroxylamine: kinetics and mechanism. Ph. D. Thesis, University of Eindhoven (1979).

[34] S.D. Ebbesen, B.L. Mojet, L. Lefferts, J. Catal. 256 (2008) 15-23.

[35] Y. Yoshinaga, T. Akita, I. Mitkami, T. Okuhara, J. Catal. 207 (2002) 37-45. 


\title{
Chapter
}

\section{Nitrite reduction over $\mathrm{Pd}$ supported carbon nanofibers: Pd particle size effect}

\begin{abstract}
Pd catalysts supported on CNFs have been synthesized via Pd colloids stabilized with polyvinylalcohol (PVA). Pd catalysts with narrow particle sizes distributions and averaged sizes between $2.7 \mathrm{~nm}$ and $30 \mathrm{~nm}$ were immobilized on CNFs. Characterization with CO-chemisorption and transmission electron microscopy (TEM) revealed that a significant part of the Pd surface is blocked by the polymer layer on the Pd particles. The prepared catalysts were tested for nitrite reduction in water, resulting in nitrogen and ammonia. Nitrite reduction is structure dependent for particle sizes below $5 \mathrm{~nm}$, which is attributed to relatively low activity of low-coordination sites for nitrite activation. The selectivity towards ammonia appears structure sensitive for the complete window of particle sizes in this study, which can be attributed to enhanced activity of low coordination sites for deep hydrogenation to ammonia.
\end{abstract}




\subsection{Introduction}

Ground water pollution by nitrates and nitrites is a widespread problem all over the world and a potential risk for public health. Contaminants can be removed with conventional physicochemical methods (ion exchange, reverse osmosis and electrodialysis) and biological methods [1]. However, the existing technology removes the contaminants by concentrating, resulting in a more concentrated secondary waste stream. Therefore, conversion of nitrate is a better approach. Nitrate and nitrite removal by liquid phase hydrogenation using noble metal catalysts is one of the most promising techniques. In this process, nitrates and nitrites are converted to nitrogen in a three-phase reactor system.

The key issue in this process is finding a suitable catalyst with sufficient high selectivity to $\mathrm{N}_{2}$. As ammonia is also undesirable in drinking water, the formation of ammonia need to be suppressed almost completely. To reduce nitrates, it is necessary to activate the precious metal based catalysts by addition of second metal such as $\mathrm{Cu}$, Sn and In [2-4]. On the other hand, nitrite reduction can be performed over monometallic catalysts. The transition metal is needed to convert nitrate to nitrite; nitrate is an extremely stable ion and therefore abstraction of the first O-atom of nitrate to form nitrite needs a less noble metal than Pd or Pt. Palladium-copper catalysts are most active and selective for nitrate reduction, whereas palladium catalyst are preferred for nitrite reduction.

Over a bimetallic catalyst, nitrate first reduces to nitrite, which in turn is converted to nitrogen and/or ammonia. Catalytic conversion of nitrate to nitrite is reported to be structure insensitive [5], whereas Yoshinaga et al [6] found that nitrite reduction is structure sensitive. It is suggested that on Pd low coordination sites like edge and corner sites are particularly active for hydrogenation, resulting in deep hydrogenation to ammonia. Terrace sites, on the other hand, are suggested to be less active, forming mainly nitrogen. Miyazaki et al. [7] reported similar results for $\mathrm{Pt}$ supported on alumina based on an elegant study, varying the dominant exposed facets via the shape and morphology of the Pt particles.

In this paper, we investigate the effect of the Pd crystal size on the activity and selectivity of nitrite reduction to nitrogen and ammonia. Pd nanoparticles have been 100 
prepared using polyvinylalcohol (PVA) as stabilizer and $\mathrm{NaBH}_{4}$ as reducing agent. This preparation method allows tuning of particles sizes with narrow particle-sizedistribution by varying the concentration of protective agent and Pd salt [8,9]. It is well known that nitrite reduction is an extremely fast reaction, so that concentration gradients in the internal of catalyst particles or catalyst layers can easily occur, influencing reaction rates and selectivity. In chapter 4 [10], it was demonstrated that thin macroporous layers of entangled CNFs provide efficient mass transfer, thus resulting in intrinsic rates and selectivity. In this study we use CNF layers on Ni foam (hairy foam) as catalyst support for Pd particles, in order to ensure that intrinsic catalyst performance data are obtained.

\subsection{Experimental}

\subsubsection{Materials}

$\mathrm{Na}_{2} \mathrm{PdCl}_{4}$ (99.99\%, Aldrich), NaBH4 of purity (> 96\%, Fluka), polyvinylalcohol (PVA) of molecular weight 13000-23000 (87-89\% hydrolysed, Aldrich) were used to prepare colloids of Pd particles on carbon nanofibers.

\subsubsection{Hairy foam preparation}

Nitrogen (99.999\%, INDUGAS) and ethylene (99.95\%, PRAXAIR) were used for CNFs formation without further purification. Hairy foams were prepared by growing CNFs on $\mathrm{Ni}$ foam at $440^{\circ} \mathrm{C}$ by using $25 \%$ ethylene in nitrogen as described in detail in chapter 2 [16] and the CNFs were not further pre-treated.

\subsubsection{Catalyst preparation}

The catalysts have been prepared following the procedure reported by Villa et al. [11] aiming to achieve approximately $1 \mathrm{wt} \%$ of Pd on carbon in hairy foams. As an example the preparation of $2 \mathrm{~nm}$ Pd particles is described in detail. Solid $\mathrm{Na}_{2} \mathrm{PdCl}_{4}$ (0.043 mmol) and $880 \mu \mathrm{l} \mathrm{PVA} \mathrm{solution} \mathrm{(2} \mathrm{wt \%} \mathrm{in} \mathrm{water)} \mathrm{(Pd/PVA} \mathrm{1:1} \mathrm{wt/wt)} \mathrm{were}$ added to $130 \mathrm{ml}$ of $\mathrm{H}_{2} \mathrm{O}$. After $3 \mathrm{~min}, 860 \mu \mathrm{l}$ of $0.1 \mathrm{M} \mathrm{NaBH}$ solution was added to the yellow-brown solution under vigorous magnetic stirring resulting in $\mathrm{pH}$ around 9. The brown $\mathrm{Pd}^{\circ}$ colloids were immediately formed. Within ten minutes after their formation, the colloids were immobilized by adding the support. After 2hr excess liquid was removed by filtration whereafter the catalyst containing Pd colloid was 
washed with distilled water and finally the samples were dried at $373 \mathrm{~K}$ for $4 \mathrm{~h}$. The ratio of quantities of PVA solution and $\mathrm{Na}_{2} \mathrm{PdCl}_{4}$ solution have been varied resulting in the concentrations given table 6.1, in order to vary the colloid particle size.

\begin{tabular}{|c|c|c|}
\hline Catalyst code & Pd (II) concentration & Pd/PVA ratio (wt/wt) \\
\hline Sample 1 & $3.3 * 10^{-4} \mathrm{M}$ & $1 / 1$ \\
\hline Sample 2 & $3.3 * 10^{-4} \mathrm{M}$ & $1 / 0.5$ \\
\hline Sample 3 & $3.3 * 10^{-4} \mathrm{M}$ & $1 / 0.25$ \\
\hline Sample 4 & $3.3 * 10^{-3} \mathrm{M}$ & $1 / 0.125$ \\
\hline
\end{tabular}

Table 6.1 - Pd concentration and PVA concentration used in catalyst preparation.

\subsubsection{Characterization}

Inductively coupled plasma (Jobin Yvon JV24) was used to determine the palladium loadings on CNF-Ni foam. CO-chemisorption (Micromeritics, ChemiSorb 2750: Pulse Chemisorption system) at room temperature was used to determine the dispersion of palladium. Before introducing $\mathrm{CO}$, with the catalyst was reduced in hydrogen at room temperature. The palladium particle size distribution was determined with Transmission Electron Microscopy (TEM - Philips CM300ST-FEG).

\subsubsection{Catalytic hydrogenation of nitrite}

Catalytic hydrogenation of nitrite was performed in a fixed bed reactor placed in an oven at $298 \mathrm{~K}$. Nitrite concentration in the aqueous reactant solution was always maintained at $\sim 20 \mathrm{mg} / \mathrm{l}(435 \mu \mathrm{mol} / \mathrm{l})$ and the $\mathrm{pH}$ of the solution was maintained at 7 by adding sodium hydroxide. The solution was pre-saturated at a hydrogen partial pressure of 0.4 bar (balance argon), resulting in a concentration of dissolved $\mathrm{H}_{2}$ equal to $312 \mu \mathrm{mol} / \mathrm{l}$, based on Henry's coefficient. The reactor was made of PEEK (polyether-ether-ketone) and the diameter was optimized in order to exactly fit with the size of the cylinder shaped pieces (diameter $4.5 \mathrm{~mm}$ ) of hairy foam catalysts. Liquid containing nitrite and dissolved hydrogen was pumped through the fixed bed reactor at a flowrate of $8 \mathrm{ml} / \mathrm{min}$ with an HPLC pump (DIONEX, Ultimate 3000). Nitrite and ammonium concentrations in the reactants and products were measured with ion-chromatography (DIONEX, ICS 1000). The reaction was performed under differential conditions, varying the catalyst amount the nitrite conversions were 
maintained below 6\%; therefore, concentration gradients along the axis of the reactor are not significant. Rate of nitrite reduction was expressed in terms of activity per gram of Pd per second and also as turn-over-frequency (activity per active site per second, TOF) as calculated based on Pd dispersion according CO-chemisorption.

It was assumed that nitrite ions were converted to ammonium and nitrogen exclusively; the yield of nitrogen was calculated from the difference between the nitrite conversion and the ammonium yield.

\subsection{Results}

\subsubsection{CO-chemisorption}

Table 6.2 presents the resulting Pd loadings and dispersion, as characterized with XRF and CO-chemisorption. The Pd dispersions tend to decrease from sample 1 to 4 indicating an increase in Pd particle size. However, due to the presence of PVA on the surface of the Pd particles, a quantitative correlation with particle size cannot be made. Sample 1 was also measured after catalytic testing and it was observed that the capacity for CO chemisorption remained constant within the accuracy of the CO adsorption experiment.

\begin{tabular}{|c|c|c|}
\hline $\begin{array}{c}\text { Pd colloids on CNF- } \\
\text { Ni foam }\end{array}$ & $\begin{array}{c}\text { Pd wt\% } \\
\text { (based on weight of } \\
\text { carbon) }\end{array}$ & Pd dispersion, \% \\
\hline Sample 1 & 0.95 & $8.6 \pm 0.4$ \\
\hline Sample 2 & 0.94 & $6 \pm 0.51$ \\
\hline Sample 3 & 0.97 & $3.5 \pm 0.33$ \\
\hline Sample 4 & 0.88 & $1.96 \pm 0.24$ \\
\hline
\end{tabular}

Table 6.2 - Palladium loadings and Pd dispersion based on CO-chemisorption on various catalysts.

\subsubsection{TEM analysis}

Transmission electron microscopy was used to determine the size of palladium particles on the hairy foam samples 1-4. Figure 6.1 presents the particle size distributions and the resulting mean crystal sizes are reported in table 6.3. Between fifty and hundred Pd particles were measured for samples 1, 2 and 4, whereas, only 
ten particles were measured on sample 3, not allowing for an accurate particle size distribution. However, the estimated averaged particle size is $11 \mathrm{~nm}$. The $\mathrm{Pd}$ dispersions presented in table 6.3 were estimated based on the averaged particles size assuming hemispherical shape.
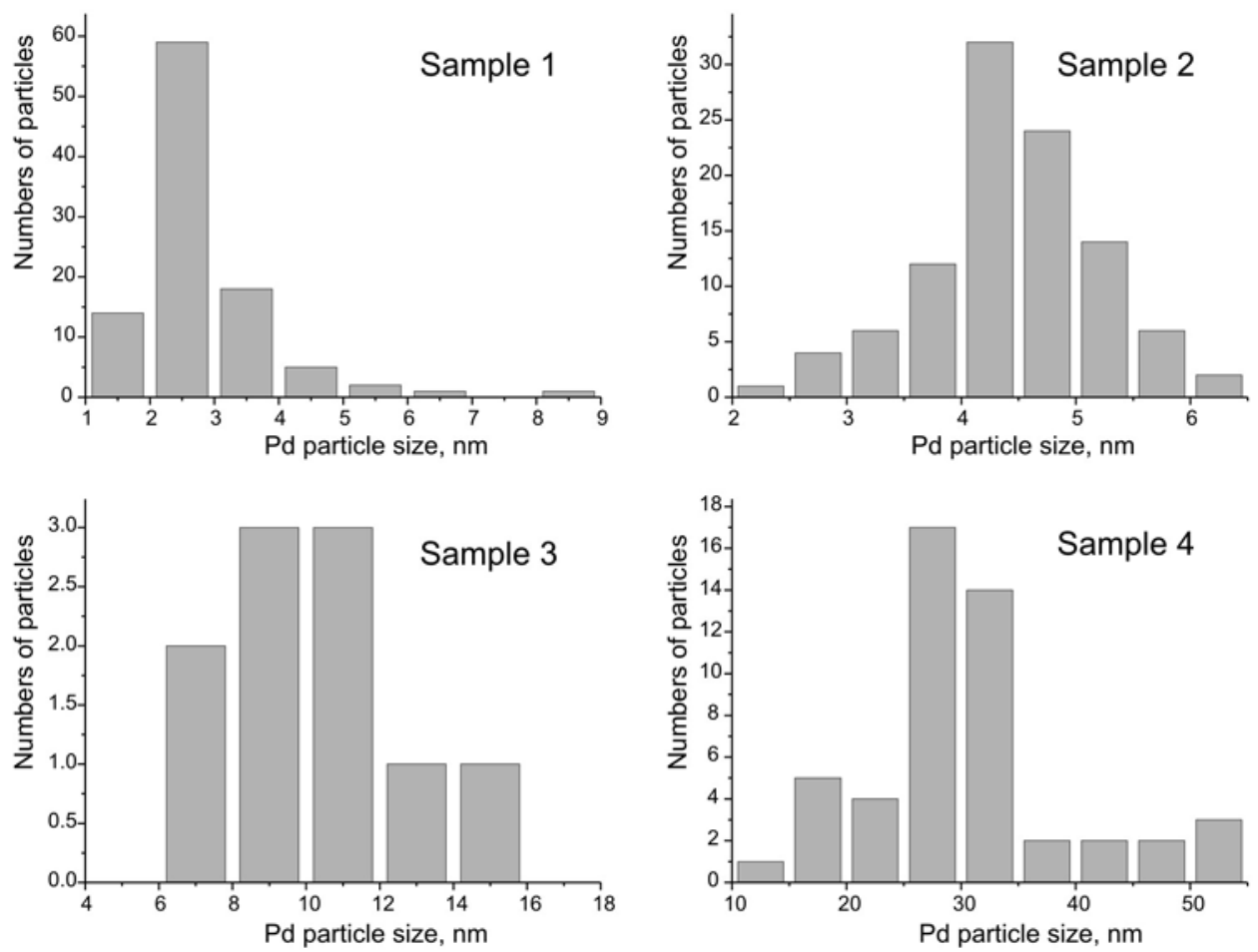

Figure 6.1 - Pd particle size distribution of Pd particles deposited on samples 14.

\begin{tabular}{|c|c|c|}
\hline $\begin{array}{c}\text { Pd colloids on CNF- } \\
\text { Ni foam }\end{array}$ & $\begin{array}{c}\text { Mean Pd particle size,nm } \\
\text { (TEM) }\end{array}$ & Pd dispersion, \% \\
\hline Sample 1 & 2.7 & 38 \\
\hline Sample 2 & 4.4 & 25 \\
\hline Sample 3 & 10.8 & 10 \\
\hline Sample 4 & 29.8 & 3.6 \\
\hline
\end{tabular}

Table 6.3 - Mean Pd particle size and Pd dispersion of samples 1-4 as measured with TEM. 


\subsubsection{Catalytic hydrogenation of nitrite}

The performance of the four catalysts in nitrite hydrogenation is shown in figure 6.2, presenting the influence of the Pd particle size on the activity and ammonia selectivity. The activity per gram Pd is almost constant for particle sizes smaller than $5 \mathrm{~nm}$, but clearly decreased when further increasing the particle size above $10 \mathrm{~nm}$. On the other hand, ammonia selectivity significantly decreased with increasing Pd

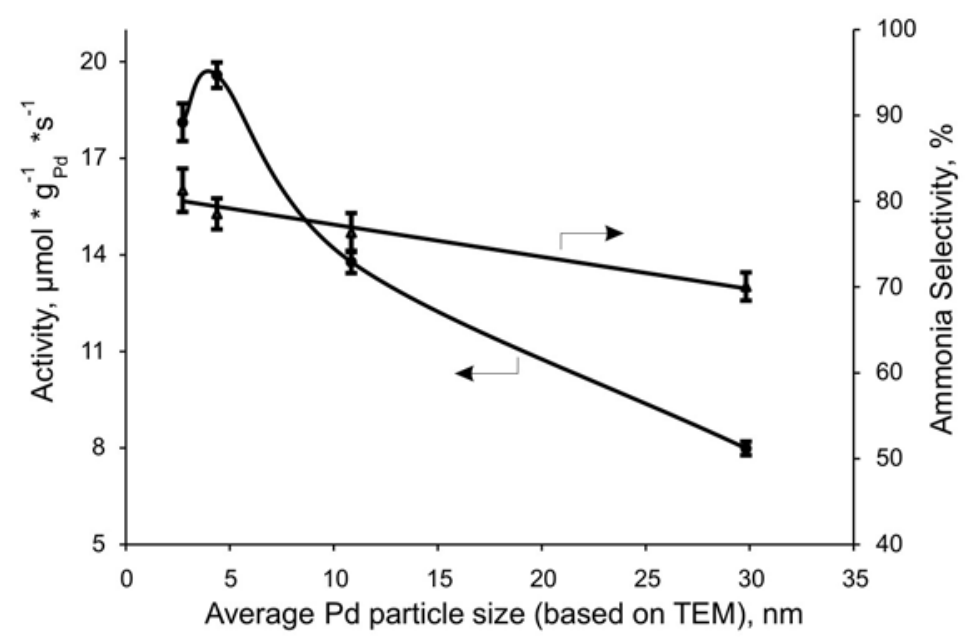

Figure 6.2 - Activity per gram of palladium and ammonia selectivity during nitrite reduction with respect to Pd particle size over Pd supported CNF-Ni foam.

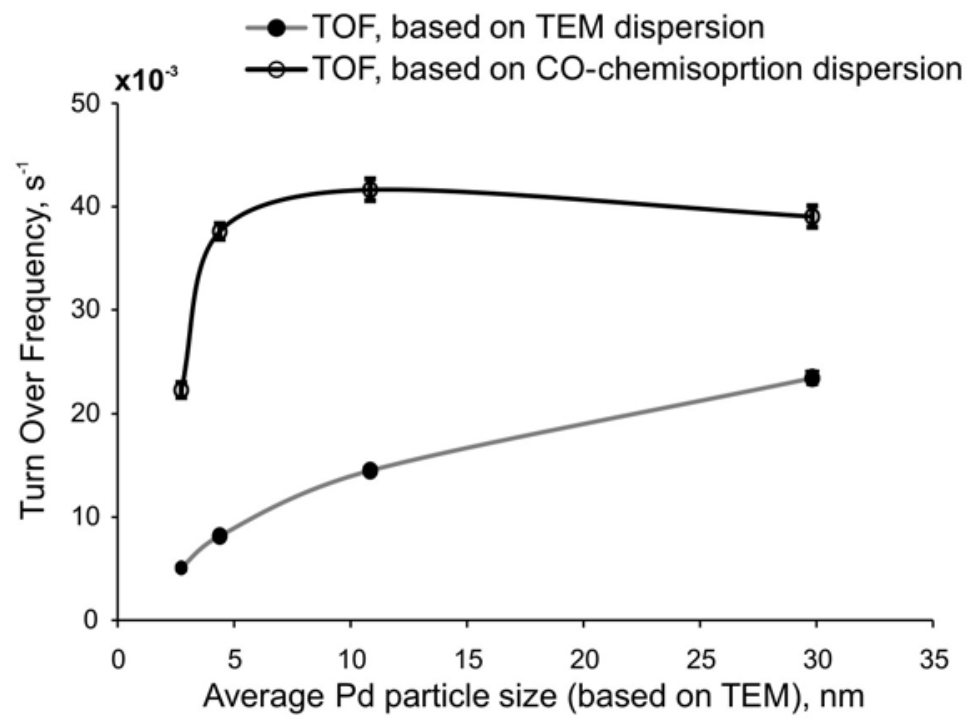

Figure 6.3 - Effect of palladium particle size on turn-over-frequency for nitrite reduction over Pd supported CNF-Ni foam estimated based on COchemisorption and TEM. 
particle size. Figure 6.3 presents the TOF for varying Pd particle sizes, based on the dispersions as estimated from both CO-chemisorption as well as TEM. The two types of TOFs change quite differently with particle size, which is obviously due to the fact that the calculation of the number of available surface Pd sites depends on the choice of method, i.e. TEM or CO chemisorption.

\subsection{Discussion}

Size of Pd particles can be tuned by varying the concentration of PVA and $\mathrm{Na}_{2} \mathrm{PdCl}_{4}$ used in the preparation procedure. This is qualitatively in agreement with data reported in literature on the preparation of gold particles [8, 9]. Similar method, though at lower $\mathrm{pH}$, were used to deposit Pd colloids [11] on oxidized carbon nanotubes, resulting in particles of 3 to $4 \mathrm{~nm}$, quite similar to $2.7 \mathrm{~nm}$ in our case.

There is a clear difference in Pd dispersions estimated with CO-chemisorption as compared to TEM. This difference is obviously due to presence of PVA on the surface of the Pd particles, blocking part of the surface Pd atoms. Similar differences were observed on PDDA covered Pd particles [13]. It appears that the difference between the two methods is relatively larger for smaller Pd particles: for sample 1, CO adsorption is about a factor 5 lower than would be expected based on the particle size based on TEM, assuming clean Pd particles. This ratio is only 2 for sample 4 . Unfortunately, we cannot conclude that the actual coverage of the Pd surface is larger for the smaller particles because of the fact that the two methods do not result in equivalent averaged values; TEM results in averaging based on number of particles whereas chemisorption provides averaged values based the surface area of particles. On carbonaceous supports, unfortunately it is not possible to verify the presence and the quantity of PVA remaining after the washing treatment. Removal of PVA coating is possible only with thermal treatment above $300^{\circ} \mathrm{C}$, which, on carbonaceous supports would result in sintering, affecting the well controlled particle sizes.

Activity per gram of catalyst decreases with increasing Pd particle size above $5 \mathrm{~nm}$ (figure 6.2). The influence of particle size on activity is, at least partly, governed by the metal surface area. However, that seems not the case for smaller particles, as similar activities were observed for particle sizes smaller than $5 \mathrm{~nm}$. TOFs can be estimated based on either CO chemisorption or TEM and the result of both type of 
calculations are presented in figure 6.3. In case of using TEM data, the blocking effect of PVA is denied, resulting in underestimation of the TOFs, as can be seen in figure 6.3. The alternative option, based on CO chemisorption data, implicetly assumes that the extent of blocking Pd sites with PVA for CO chemisorption is equivalent to the blocking catalytic activity of that site for nitrite hydrogenation. Furthermore, it is assumed that the activity of a Pd site is not influenced by blocking of a neighbouring site. The resulting curve in figure 6.3 shows more or less constant TOFs for particles larger then $5 \mathrm{~nm}$. In other words, the number of accessible Pd sites governs the activity completely and the reaction is not structure sensitive. However, the TOF decreases significantly for particles smaller then $5 \mathrm{~nm}$. It is evident that selectivity to ammonia, and thus also to $\mathrm{N}_{2}$, depends on particle size (figure 6.2). It should be noted that these effects must be due to intrinsic differences in catalytic properties, because mass transfer limitations can be excluded (chapter 4) [10] whereas experiments were performed at differential conditions. In chapter 4 and 5 [10, 12], it was reported ammonia selectivity of $87 \%$ and TOF of $0.021 \mathrm{~s}^{-1}$ were reported for Pd particles of $8 \mathrm{~nm}$ in average with a much broader distribution. The TOF is about $50 \%$ lower as compared to colloid based catalyst, whereas the ammonia selectivity is slightly above the window observed in Figure 6.3. Thus, the effect of PVA on catalyst activity is about a factor two less then one would expect based on the CO chemisorption data.

Miyazaki et al. [7] reported similar results for nitrite hydrogenation with cubic shaped Pt particles on alumina, as well as traditional Pt on alumina catalysts. TOFs were constant in the window between 10 and $40 \mathrm{~nm}$, whereas much lower values were observed for $2 \mathrm{~nm}$ particles, agreeing well with the results in figure 6.3. Also, cubic Pt particles are significantly less active than conventional alumina-supported-Pt, demonstrating similar structure dependency as observed in figure 6.3. Furthermore, the catalysts with the lower activity also showed lower selectivity to ammonia. Somewhat similar but less detailed observations have been reported by Yoshinaga et al. [6] for nitrite hydrogenation over Pd-on-carbon catalysts. The results were rationalized by assuming that low coordination sites have higher activity for hydrogenation, boosting activity as well as selectivity to ammonia, whereas terrace sites would be responsible for mild hydrogenation to $\mathrm{N}_{2}$. 
Our results partly agree with this picture: the proposition that low coordination sites would induce more deep hydrogenation is in agreement with our observations. However, it is not clear why the activity of particles smaller than $5 \mathrm{~nm}$ is low, as these would contain many low coordination sites which should result in fast conversion. This is not only in disagreement with our observations, but also with results in literature [7].

We have recently reported on an ATR-IR study on nitrite hydrogenation over Pd catalysts, observing that nitrite hydrogenation is the rate determining step [14]. This was concluded based on the fact that no surface intermediates were detected when operating with hydrogen concentration similar to what is used in this work. Surface intermediates like $\mathrm{NO}_{\text {ads }}$ and $\mathrm{NH}_{2, \text { ads }}$ were exclusively detected (besides in transient operation) when decreasing the hydrogen concentration two orders of magnitude in continuous operation, inducing a situation where nitrite activation is not rate determining anymore. Therefore, we can conclude that under the conditions used in this work, the rate of the reaction is controlled by nitrite activation. The effect of particle size on activity must therefore be attributed to a change in the rate of nitrite activation. Thus, we suggest that low coordination sites are less effective for nitrite activation as compared to terrace sites. However, it is also possible that step sites play a decisive role, as discussed by Van Santen [15].

As discussed above, the effect of particle size on the selectivity agrees with the suggestion that low coordination sites are responsible for deep hydrogenation to ammonia. Especially the observation that selectivity changes with size for particles larger than $5 \mathrm{~nm}$ (figure 6.2) whereas the TOF is constant (figure 6.3), is a clear support for the proposition that that edge-sites and corner-sites promote deep hydrogenation to ammonia. However, selectivity may also be changed via the ratio of surface coverage of $\mathrm{N}$-containing-species versus adsorbed hydrogen atoms. This is likely to occur for particles smaller then $5 \mathrm{~nm}$ as activity decrease significantly with decreasing particle size (figure 6.3), making the surface more hydrogen rich as less nitrite is available to consume adsorbed hydrogen, thus enhancing the selectivity to ammonia. 


\subsection{Conclusions}

Pd colloids stabilized with polyvinylalcohol were immobilized on CNFs. Narrow particle size distributions were achieved with averaged sizes varying between 2.7 and 30nm. Characterization with CO chemisorption and transmission electron microscopy revealed that significant part of Pd surface is blocked by the polymer layer. Pd catalysts were tested for nitrite reduction in water, resulting in formation of nitrogen and ammonia. Nitrite activation is structure dependent for particles smaller than $5 \mathrm{~nm}$ due to relatively low activity of low-coordination sites for nitrite activation compared to terrace sites. The selectivity towards ammonia is structure dependent due to enhanced activity of low coordination sites for deep hydrogenation, favoring ammonia formation. 


\section{References}

[1] A. Kapoor, T. Viraraghavan, J. Environ. Eng. 123 (1997) 371-380.

[2] S. Hörold, T. Tacke, K. D. Vorlop, Environ. Tech. 14 (1993) 931-939.

[3] S. Hörold, K.D. Vorlop, T. Tacke, M. Sell, Catal. Today 17 (1993) 21-30.

[4] U. Prüsse, M. Hähnlein, J. Daum, K.D. Vorlop, Catal. Today 55 (2000) 79-90.

[5] A. Pintar, J. Batista, J. Levec, T. Kajiuchi, Appl. Catal. B 11 (1996) 81-98.

[6] Y. Yoshinaga, T. Akita, I. Mikami, T. Okuhara, J. Catal. 207 (2002) 37-45.

[7] A. Miyazaki, T. Asakawa, Y. Nakano, I. Balint, Chem. Comm. (2005) 3730-3732.

[8] N. Dimitratos, A.Villa, L. Prati. Catal. Lett. 133 (2009) 334-340.

[9] A. Villa, D. Wang, D. Su, G.M. Veith, L. Prati, Phys. Chem. Chem. Phys. 12 (2010) 2183-2189.

[10] J.K. Chinthaginjala, J.H. Bitter, L. Lefferts, Appl. Catal. A (2010) (accepted).

[11] A. Villa, D. Wang, N. Dimitratos, D. Su, V. Trevisan, L. Prati, Catal. Today 122 (2010) 8-15.

[12] J.K. Chinthaginjala, L.Lefferts, Appl. Catal. B (2010) (submitted).

[13] A. Sarkany, A. Beck, A. Horvath, Z. Revay, L. Guczi, Appl. Catal. A 253 (2003) 283292.

[14] S.D. Ebbesen, B.L. Mojet, L. Lefferts, J. Catal. 256 (2008) 15-23.

[15] R.A. van Santen, Acc. Chem. Res. 42 (2009) 57-66.

[16] J.K. Chinthaginjala, D.B. Thakur, K. Seshan, L. Lefferts, Carbon 46 (2008) 1638-1647. 


\title{
Chapter 7
}

\section{Rhodium catalyzed growth of carbon nanofibers}

\begin{abstract}
Thin layer of carbon nanofibers (CNFs) were synthesized on thin Rh metal by decomposing ethylene in the presence of hydrogen. Interaction of $\mathrm{Rh}$ grains with carbon results in fragmentation of $R h$ grains to nano-particles facilitating CNF growth. Maximum CNF growth was achieved at intermediate hydrogen concentrations. These effects are understood in terms of competitive adsorption of hydrogen and ethylene, influencing the balance between rate of carbon deposition, rate of CNF formation and encapsulation of $R h$ with carbon. CNFs formed are catalyzed by pure Rh nano-particles demonstrating a fishbone structure. CNF growth mechanism via (sub-) surface diffusion of carbon on Rh is suggested.
\end{abstract}




\subsection{Introduction}

Carbon clusters in tubular form, commonly referred to as carbon nanotubes, fibres or filaments, have been studied since the 1950s. These materials are finding applications in fields such as electronic devices [2], electrochemical capacitors [3], catalyst support layers in microreactors [4], additives to polymers [5], super hydrophobic coatings [6], biological probes. The controlled growth of these structures is an important step in the realization of application in nanoscale devices.

A large number of studies have been published that describes the synthesis, characterization and physical properties, summarized in a number of reviews [7-12]. Typically these materials are produced by arc-discharge [13], laser ablation [14] or catalytic chemical vapor deposition (CCVD) [15]. Use of CCVD requires lower reaction temperatures than used in the arc-discharge or laser ablation methodologies and moreover, offers a high rate of carbon growth and easy control of reaction conditions. In CCVD, carbon sources such as CO, methane, alkenes, alkynes or aromatics are passed over a supported metal catalyst at elevated temperatures. Over the years, numerous metals have been used and especially Fe, Co and Ni, being the most effective for the production of carbon nanofibers/tubes. It is generally accepted that during the CNF growth over transition metals, carbon diffuses into metal particle and forms intermediate metal carbide before precipitating out with a graphitic structure at the rear end of the particle [9]. However, the presence of residual ferromagnetic catalysts particles in the CNF/Ts is an obstacle for research on the study of magnetic properties of CNF/Ts, as well as for application of CNF/T in electronic devices, electrochemical capacitors and catalysts.

Apart from $\mathrm{Fe}, \mathrm{Ni}$, Co (ferro-magnetic metals), carbon nanostructures were also grown more recently on metals like Pd [16-12, 25], Pt [20, 21, 25], Ag [25], Au [25], Ru [20 22], Re [23], Rh [20, 24], Ir [20], Os [20]. Among these catalysts, Pd is widely investigated presumably because of its high carbon yields [20]. However, the crystalline nature of graphite formed over Pd is reported to be low as compared to graphite on other metals [20].

Thin layers of CNFs may be used as catalyst supports, e.g. in micro-channel reactors [26], electrodes in fuel-cells or batteries [27] or in nanoelectronic devices [2, 112 
3]. So far only Pd was studied for the growth of CNF/Ts on thin metal films [28]. In this present work, we focus on synthesis of Rh catalyzed CNFs grown on thin film wafers by CVD process, exploring the effect of the conditions on CNF growth.

\subsection{Experimental}

\subsubsection{Materials}

A 100nm polycrystalline rhodium layer was deposited at room temperature on a single crystalline silicon wafer (standard size - Ø100mm) using DC-sputtering technique. Prior to the rhodium deposition, a 15nm thick titanium adhesion layer was sputter deposited on the silicon wafer. The titanium layer is used to enhance the adherence of rhodium onto the base wafer. The sputtering process of both the metals was carried out in argon plasma of 200W power and under 6.6E-3 mbar process pressure. Titanium was deposited at a rate of $13 \mathrm{~nm} / \mathrm{min}$ and rhodium at a rate of $20 \mathrm{~nm} / \mathrm{min}$.

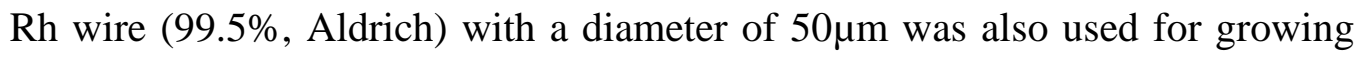
CNFs. Hydrogen (99.999\%, INDUGAS) and nitrogen (99.999\%, INDUGAS), and ethylene (99.95\%, PRAXAIR) were used for CNFs formation without further purification.

\subsubsection{Carbon nanofiber formation}

CNF formation was carried out at atmospheric pressure in a quartz reactor with a porous quartz plate at the bottom to support the wafer. The fresh wafers were heated in nitrogen $(100 \mathrm{ml} / \mathrm{min})$ at a ramp of $6^{\circ} \mathrm{C} / \mathrm{min}$ from room temperature to $600^{\circ} \mathrm{C}$. Hydrogen (5 vol\%) was introduced at flowrate $100 \mathrm{ml} / \mathrm{min}$ to reduce the samples for $15 \mathrm{~min}$. After the reduction, the reactor was flushed with nitrogen for five minutes before introducing ethylene for the growth of CNFs. The concentration of ethylene (10 vol\%) in the feed was kept constant in all experiments and the nitrogen flow was adjusted when varying the hydrogen concentration between $0-20 \mathrm{vol} \%$ keeping the flowrate at $100 \mathrm{ml} / \mathrm{min}$. The CNF growth was performed during $30 \mathrm{~min}$ in all experiments. Similarly, CNFs were grown on pretreated polycrystalline Rh wire ( $0.1 \mathrm{~g}$ ) using a mixture containing $10 \%$ ethylene and $10 \%$ hydrogen in nitrogen for 
30min. After the reaction, ethylene and hydrogen flow is turned off and the quartz reactor is cooled down to room in nitrogen at a ramp of $6^{\circ} \mathrm{C} / \mathrm{min}$.

\subsubsection{Characterization}

Surface elemental analyses of as-deposited and treated metal films were performed on a Quantera XPS system (Physical Electronics). Treated samples were exposed to ambient before performing the analysis. The morphology of the samples (top of the wafer and cross-sectional view) was studied with Scanning Electron Microscopy (SEM) (LEO 1550 FEG-SEM) equipped with energy dispersive X-ray analysis (EDX; Thermo Noran Vantage system). Cross-sections of the wafers were obtained by simply cutting with a pair of scissors. Transmission electron microscopy (Philips CM300ST-FEG) equipped with energy dispersive X-ray analysis was used to study CNFs. X-ray diffraction (XRD) was performed using a PANalytical X'pertAPD powder diffractometer system equipped with a position sensitive detector with a $2 \theta$ range of $120^{\circ}$ using $\mathrm{Cu} \mathrm{K \alpha 1}(\lambda=1.78897 \AA)$ radiation. Raman spectroscopy was used to determine the crystallinity of the carbon deposited at room temperature with a Senterra dispersive Raman microscope and a $532 \mathrm{~nm}$ laser (laser power - 2mW) with a spot size of $0.8 \mu \mathrm{m}$. The spectra presented are averaged over 10 spectra.

\subsection{Results}

\subsubsection{Characterization of fresh and pre-treated $R h$ wafers}

The morphology of an as-received wafer after $\mathrm{Ti}$ and Rh deposition is shown in figure 7.1. Figure 7.1a shows a top view of the Rh layer, showing grains in the order of $\sim 10 \mathrm{~nm}$. Figure $7.1 \mathrm{~b}$ shows the cross-section of the Rh layer, about $85 \mathrm{~nm}$ thick. As-received wafers were then heated in nitrogen at a ramp of $6^{\circ} \mathrm{C} / \mathrm{min}$ upto $600^{\circ} \mathrm{C}$. The wafer was then reduced in $5 \% \mathrm{H}_{2} / \mathrm{N}_{2}(100 \mathrm{ml} / \mathrm{min})$ at the same temperature for 15 mins. The resulting morphology of Rh surface (top view) is shown in figure 7.2a. It is apparent that significant grain growth occurred and the resulting grains are facetted, varying in size typically between 10 and 200nm. Average Rh particle size is about 90nm estimated from Rh grain size distribution (table 7.3). The cross-sectional view of the pre-treated sample is shown in figure $7.2 \mathrm{~b}$ and the thickness of the Rh layer remained constant at $\sim 85 \mathrm{~nm}$. 


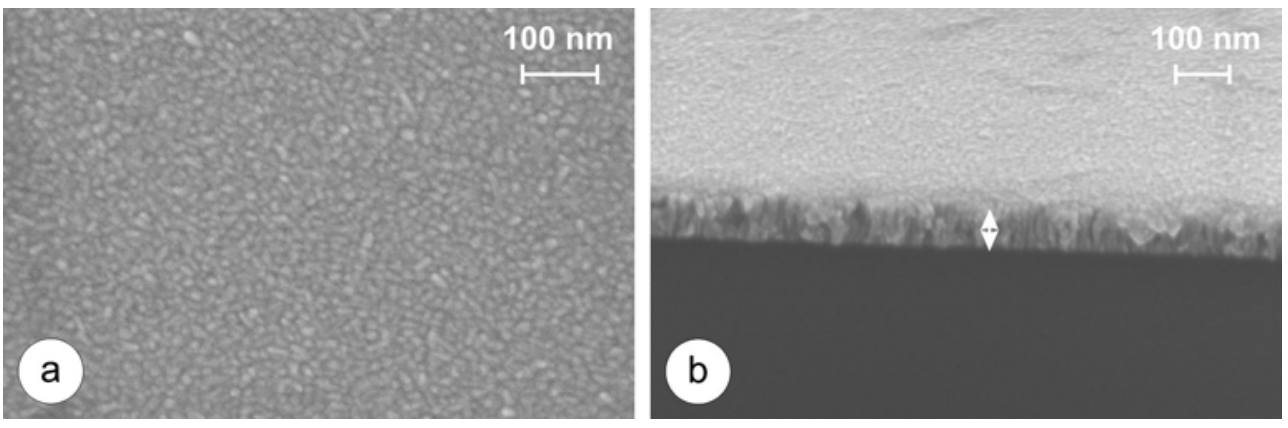

Figure 7.1 - SEM images of as-received rhodium surface. 1a) shows the top view of Rh layer and 1b) shows the cross-sectional view of Rh layer.

Table 7.1 presents atomic concentrations of Rh, Si, oxygen (O) and carbon (C) on the surface of fresh and pre-treated samples as determined with XPS. The fresh sample shows presence of $\mathrm{Rh}, \mathrm{O}$ and $\mathrm{C}$ on the $\mathrm{Rh}$ surface. The sample after pretreatment in hydrogen also showed presence of $\mathrm{Rh}, \mathrm{O}, \mathrm{C}$ and in addition traces of $\mathrm{Si}$. In both cases, Ti was not detected. The fact that traces of $\mathrm{Si}$ are detected after pretreatment in hydrogen indicates that some $\mathrm{Si}$ is able to diffuse through the $\mathrm{Rh}$ layer. The presence of oxygen is due to oxidation of the Rh layer when exposing to ambient. Carbon contamination is probably due to ambient and/or background pressure in the vacuum system, which is generally observed in XPS. Fresh and pretreated samples were also characterized with XRD. Both samples showed only two diffraction peaks which correspond to $\mathrm{Rh}(111)$ and $\mathrm{Si}(400)$, as presented in figure 7.3. The Rh diffraction peak in the pre-treated sample is much larger as compared to the fresh sample.
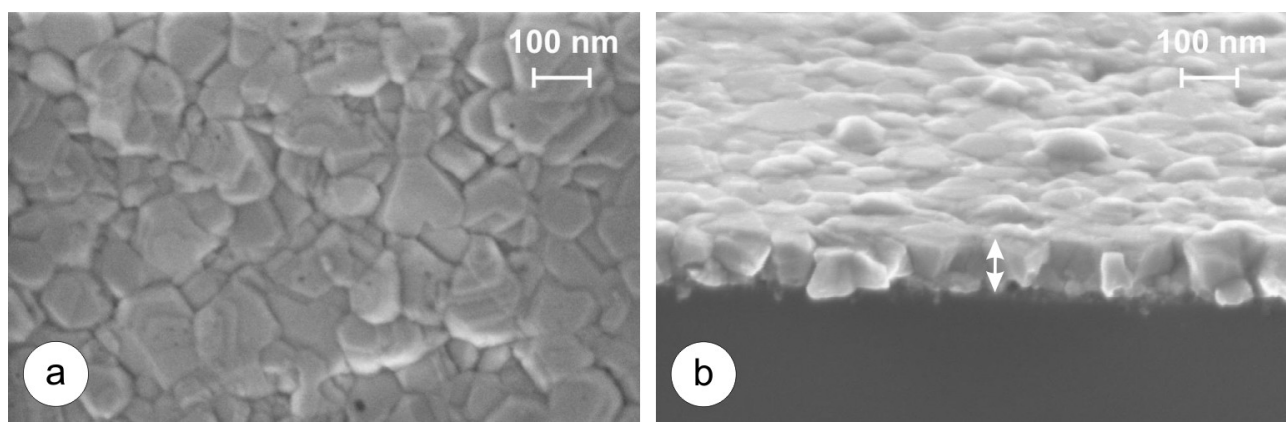

Figure 7.2 - SEM image of rhodium surface after reduction in $5 \% \mathrm{H}_{2} / \mathrm{N}_{2}$ for $15 \mathrm{~min}$. 2a) shows the top view of pre-treated Rh layer and $2 \mathrm{~b}$ ) shows the crosssectional view of pretreated $\mathrm{Rh}$ layer. 


\begin{tabular}{|c|c|c|c|c|c|}
\hline & \multicolumn{5}{|c|}{ Atomic concentration, \% } \\
\hline Elements & $\mathbf{R h}$ & $\mathbf{T i}$ & $\mathbf{S i}$ & $\mathbf{O}$ & $\mathbf{C}$ \\
\hline Fresh Sample & 37.9 & - & - & 27.9 & 33.9 \\
\hline Pretreated sample & 40.8 & - & 1.8 & 36.6 & 20.9 \\
\hline
\end{tabular}

Table 7.1 - Concentration of Rh, Ti and Si on the surface of fresh and pretreated samples.

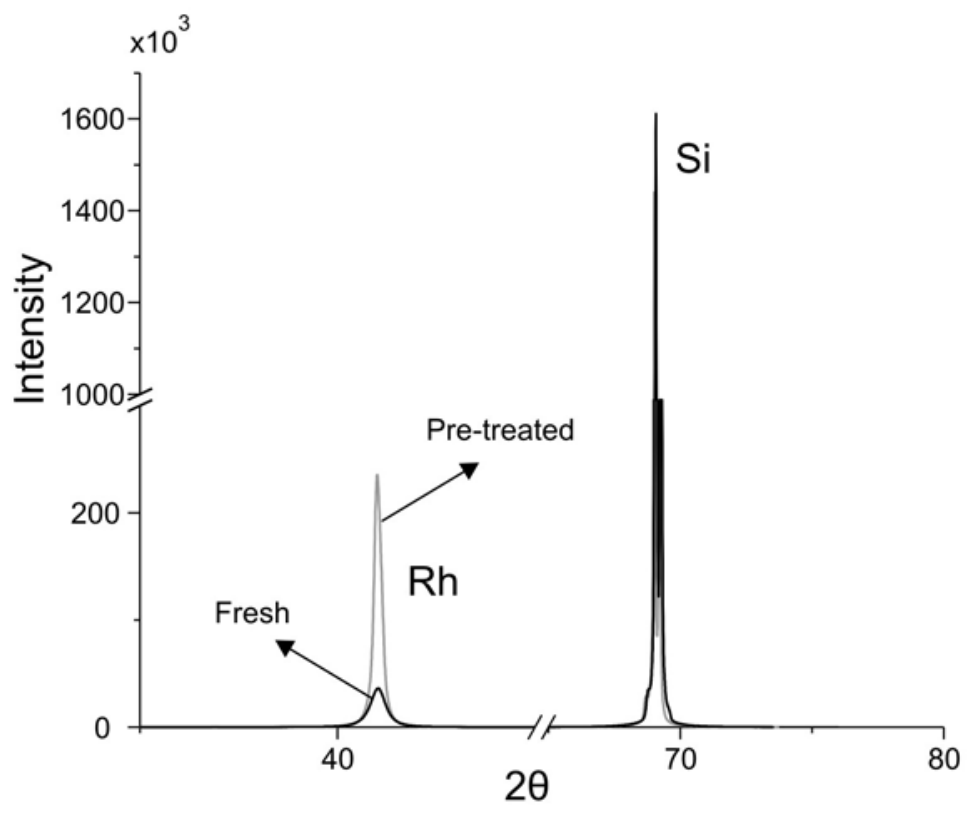

Figure 7.3 - XRD pattern on fresh and pre-treated sample.

\subsubsection{CNF synthesis and characterization}

Pre-treated wafers were exposed to $10 \%$ ethylene at various hydrogen concentrations (0-20\%) for 30mins and then characterized with SEM. Figure 7.4 shows the cross-sectional view of wafers obtained using different hydrogen concentrations. Figure 7.4a shows a thin layer of Rh without any sign of carbon nanostructures on the surface, whereas, figure $7.4 \mathrm{~b}$ shows a few randomly grown nanofibers on the Rh layer. Figure $7.4 \mathrm{c}$ and $7.4 \mathrm{~d}$ show considerable growth of fibers on the surface when increasing the hydrogen concentration to 10 and $20 \%$, respectively. The effect of hydrogen concentration on the height of CNF layer as determined from the cross-sectional SEM images is presented in figure 7.4h. 

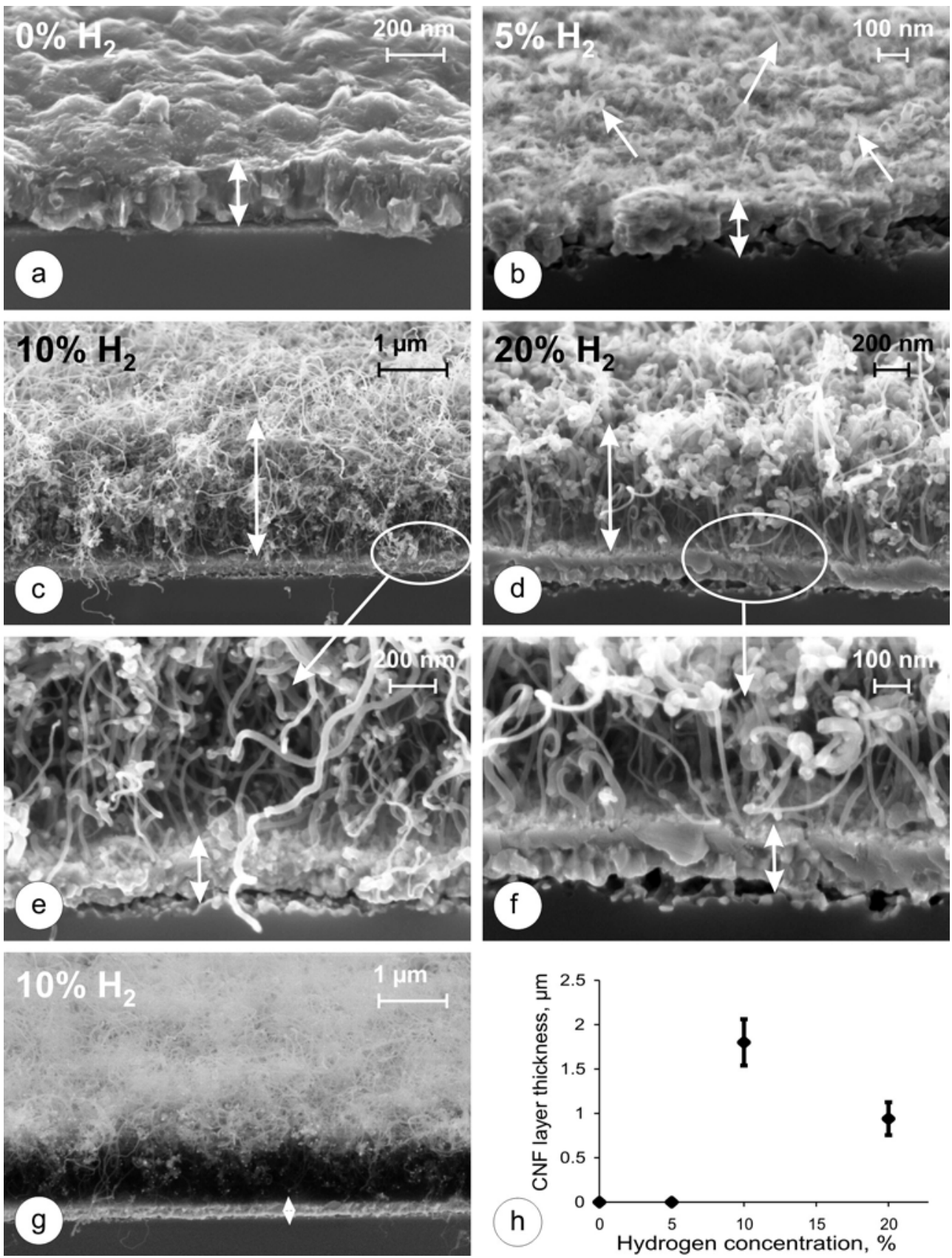

Figure 7.4a-g - SEM images at the cross-section of wafers after exposing to ethylene at different hydrogen partial pressures. The close-up image (4e and $4 \mathrm{f}$ ) shows the continuous Rh layer present under the CNF layer. Figure $4 \mathrm{~g}$ shows the secondary electron detetor image of CNFs formed at $10 \% \mathrm{H}_{2}$. Figure $4 \mathrm{~h}$ shows the thickness of CNF layer as measured by SEM. Figure 4h shows the CNF formed on Rh surface at $10 \% \mathrm{H}_{2} / 10 \mathrm{C}_{2} \mathrm{H}_{4} / \mathrm{N}_{2}$.

It is observed that $\mathrm{CNF}$ growth seems maximal at $10 \% \mathrm{H}_{2}$; addition of some hydrogen is necessary to induce CNF growth, whereas, further increasing the hydrogen concentration retards CNF formation. Figures 7.4e and 7.4f show closeup images of the interface of CNFs and the silicon surface. It is observed that CNFs are 
attached to a continuous layer, as indicated with arrows in figure 7.4a-f. The thicknesses of these continuous layers are about 120nm, 165nm, 190nm and 190nm for $0 \% \mathrm{H}_{2}, 5 \% \mathrm{H}_{2}, 10 \% \mathrm{H}_{2}$ and $20 \% \mathrm{H}_{2}$, respectively. Figure $7.4 \mathrm{~g}$ shows the SEM image as obtained with the secondary electron detector of $10 \% \mathrm{H}_{2}$ sample, which showed no contrast in the continuous under layer.
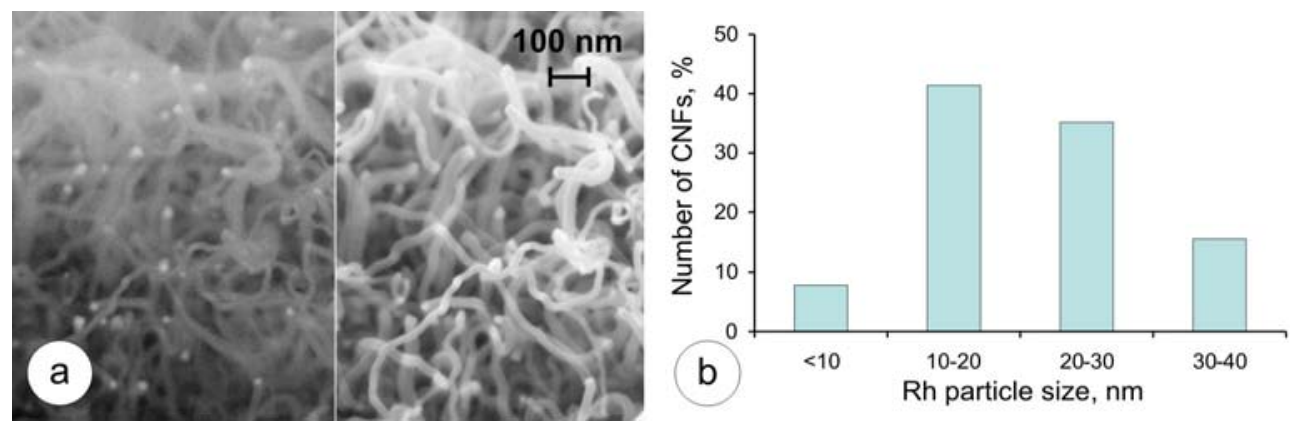

Figure 7.5 - CNFs formed at $10 \% \mathrm{H}_{2} / 10 \% \mathrm{C}_{2} \mathrm{H}_{4} / \mathrm{N}_{2}$ a) General overview by SEM-inlens detector of the CNFs grown on Rh surface. SEM-SE2 image shows metal particles at the tip of fibers b) Distribution of Rh particle sizes present at the tip of CNFs.

Figure 7.5 illustrates the morphology of CNFs formed at $10 \% \mathrm{H}_{2}$. Figure $7.5 \mathrm{a}$ shows the typical SEM image of CNFs grown on the Rh surface. The image on the left hand side was made using the secondary electrons detector, showing the metal particles at the tip of the fibers. The diameters of CNFs formed vary between 5 and 40nm, as estimated based on eight SEM images (not shown). The particle size distribution of the Rh metal particle on the tips of the CNF is presented in figure 7.5b; the sizes are rather similar to the diameters of the fibers.
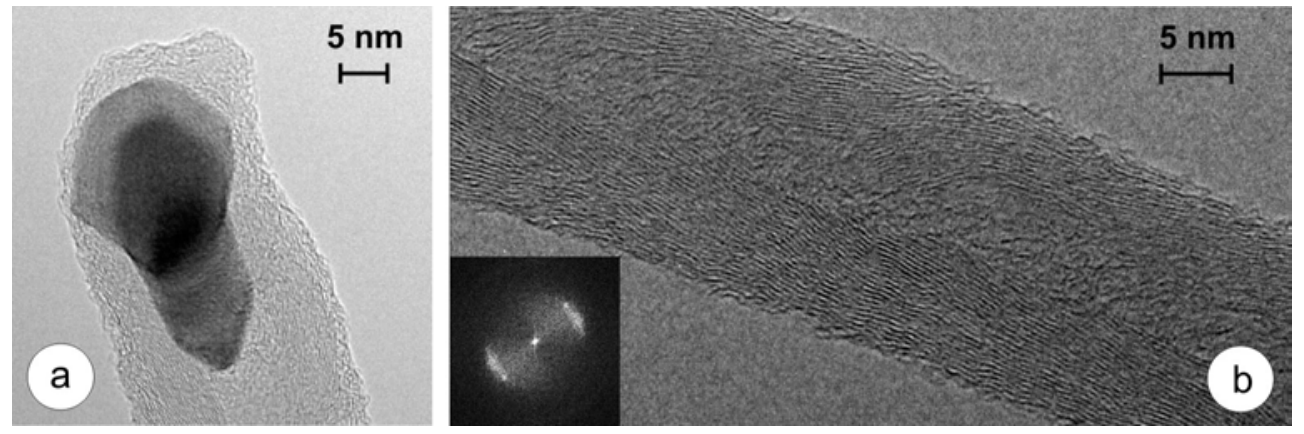

Figure 7.6 - CNFs formed at $10 \% \mathrm{H}_{2} / 10 \% \mathrm{C}_{2} \mathrm{H}_{4} / \mathrm{N}_{2}$ a) HRTEM image of CNF with a Rh metal particle at the tip. b) TEM image showing the graphene structure of CNF. Insight image in $6 \mathrm{~b}$ shows the diffraction pattern of the fiber. 
Figure 7.6a shows a typical HRTEM image of a CNF with a metal particle at the tip. Elemental analysis with TEM-EDX of the metal particles showed the presence of exclusively $\mathrm{Rh}$ and $\mathrm{C}$. Figure 7.6b presents a typical TEM image of a single fiber, containing graphene layers stacked at an angle to the central axis. The inserted image in figure 7.6b presents the electron diffraction pattern of CNF, showing 002 reflections with d-spacing estimated to be $3.42 \pm 0.03 \mathrm{~A}^{\circ}$. The $\mathrm{d}$-spacing observed is in good agreement with literature data [29].

Samples with carbon deposited using various hydrogen partial pressures were characterized with Raman spectroscopy. Figure 7.7 shows the Raman spectra presenting two distinct peaks of carbon, the so called D and G bands; it has to be noted that the intensities are normalized to $D$ band. The peak centered at $\sim 1350 \mathrm{~cm}^{-1}$ corresponds to D-band [30], which is a common feature of disordered $\mathrm{sp}^{2}$-type carbon, whereas the peak centered at $\sim 1600 \mathrm{~cm}^{-1}$ corresponds to G-band [31], assigned to crystalline graphite. It has to be noted that carbon deposited at $0 \% \mathrm{H}_{2}$ is resulting in peaks with too low intensity to determine the peak positions accurately. It is also observed that the peak positions obtained with $5 \% \mathrm{H}_{2}$ are different from those observed with $10 \%$ and $20 \% \mathrm{H}_{2}$. Table 7.2 presents the integrated ratios of the intensities of $\mathrm{D}$ and $\mathrm{G}$ band of carbon deposited at 5\%, 10\% and 20\% hydrogen concentrations. The ratio of integrated intensities of $D$ and $G$ band (I(D)/I(G)) is higher at $10 \%$ and $20 \%$ hydrogen concentrations compared to $5 \%$ hydrogen concentration.

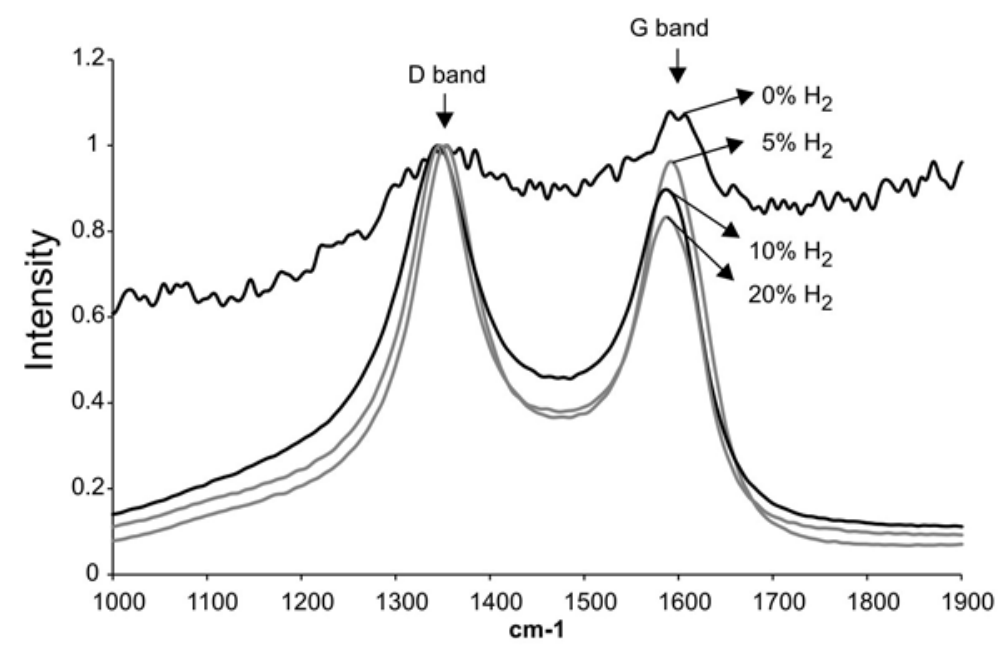

Figure 7.7 - Raman spectra of carbon deposited at various hydrogen concentrations on samples at 600C for 30min. Intensities are normalized to D band. 
Figure 7.8 presents the result of XRD analysis of the sample containing CNFs grown at $10 \% \mathrm{H}_{2}$. The main peaks at 32.8 and 41.05 are assigned to $\mathrm{Si}$ and $\mathrm{Rh}$. In addition many minor peaks were observed, which can be attributed to rhodiumsilicide $\left(\mathrm{Rh}_{5} \mathrm{Si}_{3}\right)$ and titanium-silicon-carbide $\left(\mathrm{Ti}_{3} \mathrm{SiC}_{2}\right)$. Similar peaks were also observed for the sample with carbon deposited at $0 \% \mathrm{H}_{2}$ (figure not shown). There is no significant shift in Rh peak position due to pre-treatment and carbon deposition. The averaged crystal size of Rh was estimated based on the line broadening of the Rh diffraction peak for the as prepared sample (figure 7.3), the sample after the pretreatment in hydrogen (figure 7.3) as well as after CNF growth (figure 7.8). The results are presented in table 7.3, comparing the crystal sizes according XRD line broadening with estimations based on SEM (figures 7.1, 7.2 and 7.5).

\begin{tabular}{|c|c|c|c|}
\hline $\begin{array}{c}\mathbf{H}_{\mathbf{2}} \text { concentration } \\
\text { in the feed }\end{array}$ & D band, $\mathbf{c m}^{-\mathbf{1}}$ & G band, $\mathbf{~ c m}^{-\mathbf{1}}$ & $\begin{array}{c}\text { Ratio of integrated intensities } \\
\text { of D and G band, } \\
\text { I(D)/I(G) }\end{array}$ \\
\hline $\mathbf{5 \%} \mathbf{H}_{\mathbf{2}}$ & 1353.5 & 1592 & 1.22 \\
\hline $\mathbf{1 0 \%} \mathbf{H}_{\mathbf{2}}$ & 1345 & 1587 & 1.35 \\
\hline $\mathbf{2 0 \%} \mathbf{H}_{\mathbf{2}}$ & 1347 & 1587 & 1.33 \\
\hline
\end{tabular}

Table 7.2 - Presents the peak positions of D and G band, and the ratio of integrated intensities of D and $\mathrm{G}$ band of carbon formed at 5\%, 10\% and 20\% hydrogen concentrations in the feed.

\begin{tabular}{|c|c|c|c|}
\hline Rh-Ti-Si wafer & $\begin{array}{c}\text { window particle sizes, } \\
\text { SEM, (nm) }\end{array}$ & $\begin{array}{c}\text { Average particle } \\
\text { size, SEM, (nm) }\end{array}$ & $\begin{array}{c}\text { Average particle } \\
\text { size, XRD-LB, (nm) }\end{array}$ \\
\hline Fresh & $5-20$ & 10 & 20.4 \\
\hline Pretreated & $10-200$ & 90 & 44.3 \\
\hline CNF grown & $5-40$ & 20 & 36.3 \\
\hline
\end{tabular}

Table 7.3 - Rhodium grain size on fresh, pretreated and CNF grown samples, as measured from SEM and XRD. 


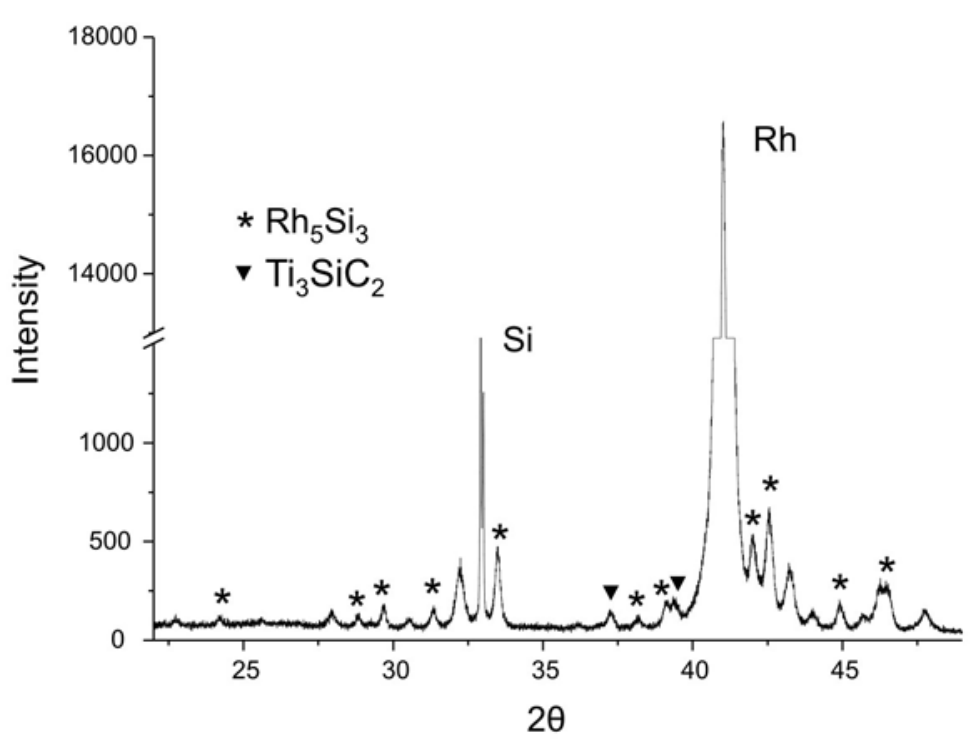

Figure 7.8 - XRD pattern of sample with CNFs grown at $10 \% \mathrm{H}_{2} / 10 \% \mathrm{C}_{2} \mathrm{H}_{4} / \mathrm{N}_{2}$ for $30 \mathrm{~min}$.

\subsection{Discussion}

Reduction of Rh-Ti-Si samples at $600^{\circ} \mathrm{C}$ resulted in increasing grain sizes as compared to fresh samples (table 7.3). XRD analysis recorded significant lower intensity of the $\mathrm{Rh}(111)$ peak on the fresh sample as compared to the pre-treated sample (figure 7.3), which is due to the formation of amorphous phase of $\mathrm{Rh}$ when sputtering at room temperature [32].The observation of trace amounts of Si in the surface of the reduced sample (table 7.1) suggests diffusion of Si into and through the Rh layer. However, no compounds containing Si and Rh could be detected with XRD (figure 7.3). Therefore, the large grains formed during the reduction apparently contain pure Rh. The dissolved Si is apparently present in such low concentrations that the XRD pattern is not influenced. Possibily, Si dissolution and diffusion is limited to the grain boundaries in the Rh layer. Carbon deposition on Rh surface resulted in traces of compounds notably attributed to titanium-silicon carbide and rhodiumsilicide (figure 7.8). A few diffraction peaks cannot be assigned at this point. Moreover, deposition of carbon resulted in the formation of CNFs with a metal particle in the tip, containing exclusively rhodium and carbon (figure 7.6). This suggests that $\mathrm{Rh}$ particles are responsible for the formation of CNFs and that the minority compounds containing Si and/or Ti are not involved in the CNF growth. 
Formation of CNFs is clearly dependent on hydrogen partial pressure (figure 7.4). In the absence of hydrogen in the feed, no CNF growth was observed, however, there is carbon deposition according to the Raman spectrum in figure 7.6, although the intensity is very low in the case of absence of $\mathrm{H}_{2}$. Increase in hydrogen concentration result in an increase in rate of CNF growth (figure 7.4a-d). This is probably due to competitive adsorption of hydrogen with ethylene, decreasing the carbon deposition rate on the $\mathrm{Rh}$ surface. Thus, encapsulation of $\mathrm{Rh}$ particles is partly suppressed, retarding deactivation and thus enhancing CNF growth. Similar effects of hydrogen on the rate of CNF growth were reported for $\mathrm{Ni}$ in chapter 3 [33, 34] and Pd [28], which was similarly explained in terms of balancing the availability of carbon on the metal surface with the ability to convert carbon to CNFs, via competitive dissociation of $\mathrm{H}_{2}$, decreasing the rate of carbon deposition. We propose that the same mechanism is operative on Rh. However, we cannot rule out at this stage that the presence of hydrogen influences the formation of Rh nanoparticles out of the Rh thin layer.

The thickness of the underlayer (as indicated by arrows in figure 7.4 a,b,e,f) after growing CNFs has almost doubled as compared to thickness of the Rh layer of fresh and pre-treated samples. This is a remarkable phenomenon that is not understood at this time. As discussed above, small amounts of titanium-silicon carbide and rhodium-silicide are observed with XRD but the low intensity of the diffraction peaks as compared to the Rh peak suggests that the amount is too limited to account for doubling the layer thickness. Also, the amount of Si diffusing through the Rh layer according XPS-data is too small, whereas significant amount of Si dissolution in the $\mathrm{Rh}$ layer can also be ruled out as the position of the Rh diffraction peak is not influenced. Furthermore, SEM using the in-lens showed a homogeneous picture of the layer with increased thickness in figure $7.4 \mathrm{~g}$, indicating that the layer is not a composite of a carbon-phase and a Rh-phase; the metal phase would appear much brighter, unless the phases would consist of nano-sized domains.

From the Raman spectra, it is evident that the ratio of integrated intensities of the $\mathrm{D}$ band and the $\mathrm{G}$ band $((\mathrm{I}(\mathrm{D}) / \mathrm{I}(\mathrm{G}))$ is higher at $10 \%$ and $20 \%$ hydrogen concentration compared to 5\% hydrogen concentration (table 7.2). The (I(D)/I(G)) is reported to vary inversely with the size of the graphene clusters [30, 35]. Therefore the the (I(D)/I(G)) ratio provides a qualitative measure of the crystallinity of carbon 
$[36,37]$. We suggest that this difference in carbon crystallinity might be due to the differences in carbon deposition mechanisms leading to graphitization. Additionally, a downshift in Raman peak positioning by $\sim 5 \mathrm{~cm}^{-1}$ was observed on CNF samples grown at $10 \%$ and $20 \%$ hydrogen concentrations. Raman shifts due to surface treatments [38] and temperature effects [39] were reported before for graphite materials. At this moment it is not very clear the exact reason behind the shifts, recommending further investigation.

\subsubsection{Mechanism of CNF growth}

The average Rh grain size after carbon deposition decreased from $\sim 44 \mathrm{~nm}$ to 36nm according to XRD-LB (table 7.3). The SEM observations in table 7.3 confirm that the average grain size from decreased from $90 \mathrm{~nm}$ to $20 \mathrm{~nm}$ when depositing carbon. Apparently, deposition of carbon causes fragmentation of Rh grains. Thus, Rh behaves similar to polycrystalline $\mathrm{Ni}$ in this respect, as it was reported that fragmentation of large $\mathrm{Ni}$ particles generates $\mathrm{Ni}$ nano-particles, facilitating $\mathrm{CNF}$ growth $[33,40]$.

The growth mechanism for the formation of CNF on Rh particle was never discussed in detail. In general, CNF formation is suggested to proceed via three steps: i) deposition of carbon on the metal via decomposition of a carbon containing compound, ii) carbon dissolution and diffusion through the bulk of the metal and iii) precipitation in the form of graphite at the other side of metal particle [9]. There is reasonable agreement that carbon diffusion through $\mathrm{Ni}$, Co and Fe particles is part of the mechanism of CNF formation, although involvement of surface diffusion can probably not be ruled out. The essential difference between $\mathrm{Ni}$, Co and Fe versus precious metals is the fact that the transition metals have a reasonable interaction with carbon, or even form stable carbides. In contrast, precious metals have a much weaker interaction with carbon, illustrated by the fact that bulk-carbides are not stable or even non-existent. However, recent studies in literature suggest that limited dissolution of carbon in Rh is possible, especially in the subsurface [41-431]. Carbon nanostructure formation on other precious metals was reported for $\mathrm{Ru}$ [22], Re [23] and Pd [28]. It was proposed that $\mathrm{CNF} / \mathrm{T}$ formation proceeds via surface diffusion of carbon instead of bulk diffusion. 
Our results show that CNFs can be grown on Rh under conditions similar to $\mathrm{Ni}$, except that Rh needs higher temperatures to form CNFs. This might be due to the fact that $\mathrm{Rh}$ is less active for ethylene decomposition as compared to $\mathrm{Ni}$, which is caused by the much stronger interaction of carbon with $\mathrm{Ni}$ as compared to Rh. Nevertheless, it is remarkable to observe that deposition of carbon results in fragmentation of the $\mathrm{Rh}$ grains in the thin layer, which is a clear indication for significant interaction between $\mathrm{Rh}$ and carbon. Also, the shape of Rh particles at the tip of the fiber (figure 7.6a) is very similar to what is usually observed for $\mathrm{Ni}$, including an elongated tail protruding in the fishbone-type fibre. Based on these arguments, we suggest that the mechanism for $\mathrm{CNF}$ formation on $\mathrm{Rh}$ is partly similar to the case of $\mathrm{Ni}$, in the sense that exposure to ethylene induces fragmentation of polycrystalline metals and in the sense that a dynamic metal particles is acting as a template for the formation of the CNF with a diameter similar to the size of the metal particle. On the other hand, CNF growth probably proceeds via (sub-)surface diffusion of carbon instead of bulk diffusion in transition metal particles.

\subsection{Conclusions}

This study reports on how to synthesize thin layers of CNFs from thin layer of Rh metal via catalytic chemical vapour deposition. Interaction of Rh grains with carbon results in fragmentation of the Rh grains to nano-particles, facilitating CNF growth. Maximum CNF growth was observed at intermediate hydrogen concentrations, which can be explained in terms of competitive adsorption of hydrogen and ethylene, influencing the balance between the rate of carbon deposition on the Rh nano-particles with the rate of CNF-formation and preventing encapsulation with carbon. Formation of CNFs is catalyzed by pure Rh nano-particles and demonstrated a fishbone structure. We suggest that CNF growth mechanism on $\mathrm{Rh}$ involves (sub-) surface diffusion of carbon. 


\section{References}

[1] W.R. Davis, R.J. Slawson, G.R. Rigby, Nature 171 (1953) 756.

[2] W.I. Milne, K.B.K. Teo, G.A.J. Amaratunga, P. Legagneux, L. Gangloff, J.P. Schnell, V. Semet, V. Thien Binh, O. Groening, J. Mater. Chem. 14 (2004) 933-943.

[3] A. Bruke, J. Power Sources 91 (2000) 37-50.

[4] P. Serp, M. Corrias, P. Kalck, Appl. Catal. A 253 (2003) 337-358.

[5] E. Hammel, X. Tnag, M. Trampert, T. Schmitt, K. Mauthner, A. Eder, P. Potschke, Carbon 42 (2004) 1153-1158.

[6] K.K.S. Lau, J. Bico, K.B.K. Teo, M.G. Chhowalla, A.J. Amaratunga, W.I. Milne, G.H. McKinley, K.K. Gleason, Nano Lett. 3 (2003) 1701-1705.

[7] M. Terrones, Ann. Rev. Mater. Res. 33 (2003) 419-501.

[8] Y. Gogosti, Nanotube and Nanofibers (Advanced Materials Vol. 2), CRC Press (2006).

[9] K.P. De Jong, J. Geus, Catal. Rev. Sci. Eng. 42 (2000) 481-510.

[10] N.M. Rodriguez, J. Mater. Res. 8 (1993) 3233-3250.

[11] K.B.K. Teo, C. Singh, M. Chhowalla, W.I. Milne, Encyclopedia of Nanoscience and Nanotechnology X (2003) 1-22.

[12] A.V. Melechko, V.I. Merkulov, T.E. McKnight, M.A. Guillorn, K.L. Klein, D.H. Lowndes, M.L. Simpson, J. Appl. Phy. 97 (2005) 041301-041339.

[13] T.W. Ebbesen, P.M. Ajayan, Nature 358 (1992) 220-222.

[14] A. Thess, R. Lee, P. Nikolaev, H.J. Dai, P. Petit, J. Robert, C. Xu, Y.H. Lee, S.G. Kim, A.G. Rinzler, D.T. Colbert, G.E. Scuseria, D. Tomanek, J.E. Fischer, R.E. Smalley, Science 273 (1996) 483-487.

[15] S.D. Robertson, Nature 221 (1969) 1044-1046.

[16] S.Y. Lee, M. Yamada, M. Miyake, (2005) Sci. Tech. Adv. Mater. 6 (2005) 420426.

[17] R. Vajtai, K. Kordás, B.Q. Wei, J. Békési, S. Leppävuori, T.F. George, P.M. Ajayan, Mater. Sci. Eng. C 19 (2002) 271-274.

[18] Y.M. Wong, S. Wei, W.P. Kang, J.L. Davidson, W. Hofmeister, J.H. Huang, Y. Cui, Diamond Relat. Mater. 13 (2004) 2105-2112.

[19] C. Lai, Q. Guo, X. Wu, D.H. Reneker, H. Hou, Nanotechnology 19 (2008) 19530311953037.

[20] H. Ichi-oka, N. Higashi, Y. Yamada, T. Miyake, T. Suzuki. Diamond Relat. Mater.16 (2007) 1121-1125.

[21] X. Wang, W. Yue, M. He, M. Liu, J. Zhang, Z. Liu, Chem. Mater. 16 (2004) 799805.

[22] M.L. Mabudafhasi, R. Bodkin, C.P. Nicolaides, X. Liu, M.J. Witcomb, N.J. Coville, Carbon 40 (2002) 2737-2742.

[23] M. Ritschel, A. Leonhardt, D. Elefant, S. Oswald, B. Buchner, J. Phys. Chem. C 111 (2007) 8414-8417.

[24] S. Inoue, T. Nakajima, Y. Kikuchi, Chem. Phys. Lett. 406 (2005) 184-187. 
[25] D. Takagi, Y. Homma, H. Hibino, S. Suzuki, Y. Kobayashi, Nano Lett. 12 (2006) 2642-2645.

[26] D.B. Thakur, R.M. Tiggelaar, J.G.E. Gardeniers, L.Lefferts, K.Seshan, J. Chem. Engg. 2010 (DOI - 10.1016/j.cej.2010.01.005)

[27] C.A. Bessel, K. Laubernds, N.M. Rodriguez, R.T.K. Baker, J. Phys. Chem. B 105 (2001) 1115-1118.

[28] T. Hashishin, J. Tamaki, Mater. Chem. Phys. 111 (2008) 54-58.

[29] N.M. Rodriguez, A. Chambers, R.T.K. Baker, Langmuir 11 (1995) 3862-3866.

[30] F. Tuinstra, J.L. Koenig, J. Chem. Phys. 53 (1970) 1126-1130.

[31] A.C. Ferrari, J. Robertson, Phys. Rev. B 64 (2001) 0754141-07541413

[32] J.D. Schafer, H. Nafe, F. Aldinger, J. Appl. Phys. 85 (1999) 8023-8031.

[33] M.S. Kim, N.M. Rodriguez, R.T.K. Baker, J. Catal. 131 (1991) 60-73.

[34] J.K. Chinthaginjala, L.Lefferts, Carbon 47 (2009) 3175-3183.

[35] J. Robertson, Surf. and Coat. Tech. 50 (1992) 185-203.

[36] K.W.R. Gilkes, S. Prawer, K.W. Nugent, J. Robertson, H.S. Sands, Y. Lifshitz, X. Shi, J. Appl. Phys. 87 (2000) 7283-7289.

[37] H. Hiura, T.W. Ebbesen, K. Tanigaki, Chem. Phys. Lett. 202 (1993) 509-512.

[38] B. Scheibe, E. Borowiak-Palen, R.J. Kalenczuk, Mater. Charact. 61 (2010) 185-191.

[39] T.V. Cuong, V.H. Pham, Q.T. Tran, J.S. Chung, E.W. Shin, J.S. Kim, E.J. Kim, Mater. Lett. 64 (2010) 765-767.

[40] N. Jarrah, F. Li, J.G. van Ommen, L. Lefferts. J. Mater. Chem. 2005, 15, 1946-1953.

[41] D.L.S. Nieskens, D. Curulla-Ferré, J.W. Niemantsverdriet, Chem. Phys. Chem. 7 (2006) 1022-1025.

[42] W.J. Arnoult, R.B. McLellan, Scripta Metall. Mater. 6 (1972) 1013-1018.

[43] Y. Saito, K. Nishikubo, K. Kawabata, T. Matsumoto, J. Appl. Phys. 80 (1996) 3062-3067. 


\section{Chapter 8}

Concluding remarks and Recommendations 
The work presented in this thesis aimed at developing a micro-structured material that can be used as catalyst support for liquid-phase catalytic reactions. The first part of the thesis is dedicated for the preparation of a stable CNF layer on nickel metal foam (termed as 'Hairy foam'), which was later used as catalyst support. The second part of the thesis is focused on evaluating the performance of Hairy foam catalyst support in comparison to classical packed bed with porous spherical particles.

\subsection{Preparation of a stable CNF layer on Ni foam}

Carbon-Nano-Fiber (CNF) layer was catalytically grown on $\mathrm{Ni}$ foam by decomposing ethylene at $440^{\circ} \mathrm{C}$ for $1 \mathrm{hr}$. Two distinct carbon layers were formed on Ni surface; a micro-porous C-layer at the carbon-Ni interface of $\sim 4 \mu \mathrm{m}$ thickness and a macro-porous CNF layer of $\sim 30 \mu \mathrm{m}$ on top of the C-layer. Monitoring the formation of these two layers for a period of 60mins suggests they develop in parallel. Characterization using temperature programmed gasification in H2, Raman spectroscopy and transmission electron microscopy confirmed that both layers consists of graphite carbon consisting graphene planes, which are better ordered in CNFs as compared to C-layer.

Addition of hydrogen during the CNF growth resulted in carbon with manipulated properties. Increasing hydrogen concentration resulted in carbon with increasing surface area because of the formation of thinner CNFs. At lower hydrogen concentrations between $2.4 \%$ and $5 \%$, the thickness of CNF layer increased to $50 \mu \mathrm{m}$, more than 50\% higher compared to CNF layer formed in the absence of additional hydrogen. These effects are well understood in terms of competitive adsorption of hydrogen and ethylene, influencing the availability of carbon on the Ni surface, which is necessary for both the formation of small $\mathrm{Ni}$ particles by fragmentation of polycrystalline $\mathrm{Ni}$, as well as for CNF-growth after formation of small particles. Furthermore, decreasing the carbon supply via adding hydrogen also delays deactivation by encapsulation of Ni particles. The thickness of the micro-porous Clayer between the Ni surface and the CNF layer decreased with hydrogen addition.

Considering the carbon limiting effect of hydrogen, it is recommended to study the effect of hydrocarbon source containing higher elemental proportions of hydrogen, 
such as ethane instead of ethylene. This would avoid an additional step of adding excess hydrogen.

The CNFs showed good stability against compressed nitrogen flow of 120L/min through the foam showing only $8 \%$ initial loss of carbon in the case of no hydrogen addition. The nickel surface and the attached carbon layer have similar morphological features. This may be the reason for strong adhesion of the C-layer to Ni. CNFs are strongly attached to the C-layer via roots that penetrate into the C-layer. The interconnections of the Ni surface, C-layer and CNFs induce mechanical stability. The C-layer grows continuously with time, whereas CNF growth needs typically 20 minutes initiation because of the need to form small Ni particles that allow CNF formation. The continuing formation of the C-layer, also after initiation of CNF growth, is thought to be responsible for the formation of CNF roots in the C-layer. Increasing weight loss of CNFs was observed at decreasing C-layer thicknesses, supporting the proposition that CNFs are attached via roots in the C-layer.

The CNFs in the $\mathrm{Ni}$ foam have been synthesized in the nanoscopic form $(<100 \mathrm{~nm})$ with a tip growth mechanism. The attachment of CNF layer is stable which is attached via penetration into the support. However, it is recommended to explore alternative methods to ensure much stronger attachment of CNFs to the support. In this study, CNFs were grown via a tip growth mechanism; CNFs via base growth mechanism [1] can be promising because of strong chemical interaction of metal and support. For this purpose, the support the support should be inactive for CNF growth. While, additional metal particles that are active for CNF growth needs to be added. However, we compromise here with additional step of depositing active metal phase for an improved attachment of CNF layer.

The advantage of chemical inertness of CNFs cannot be exploited using $\mathrm{Ni}$ foam based hairy foam limiting its applicability only to neutral or basic environments. So, it is recommended to explore other foam supports alongside of available graphite and siliconcarbide foams. 


\subsection{Application of CNFs as catalyst support}

The second part of the thesis is focused on demonstrating the superior properties of hairy foam catalysts over conventional catalysts. Hydrogenation of nitrite in water is considered as a model reaction; as it is extremely fast reaction inducing concentration gradients within the catalyst particle.

Pd was deposited on CNF based catalysts such as hairy foams and unsupported CNF aggregates, and conventional catalysts such as $\gamma$-alumina, silica, activated carbon and graphite. All the catalysts were prepared with limited variation in Pd dispersion containing relatively large Pd particles $(\sim 10 \mathrm{~nm})$. Therefore, any structure sensitive effects on the reaction can be eliminated.

It was demonstrated that rates of nitrite conversion per mole of surface palladium (TOF) for all hairy foam supported catalysts with a CNF layer thickness of $<30 \mu \mathrm{m}$ is similar excluding any effect of internal mass transfer limitations. CNF based catalysts are indeed highly active for nitrite hydrogenation, resulting in TOFs at least three times larger as compared to conventional catalysts. This is due to improved mass transfer, thanks to high porosity as well as low tortuosity of CNF aggregates as well as thin CNF-layers in hairy foam. Surprisingly, also the intrinsic activity of graphite and CNF supported Pd contributes significantly to the high activity for nitrite reduction. We suggested direct adsorption of nitrite on graphite support and/or hydrogen atoms spilled over from Pd onto the graphite support also contribute to the reaction at the periphery of the Pd particle. Hairy foam supports provide short diffusion pathways, combined with high porosity and low tortuosity. This will overcome the disadvantage of using small catalyst particles which lead to high pressure drop in fixed bed reactor for liquid phase catalytic reactions.

Intrinsic activity of graphite based support is significantly contributing to nitrite activity. It is recommended to study the intrinsic activity of graphite support by tuning the surface properties. Surface treatment/modification of CNF could result in manipulation of adsorbed nitrite ultimately affecting activity. Such effects on activity due to surface modification are reported for some reactions [2, 3]. It is also recommended to explore possible methods to measure real pore volume of the CNF based supports, which is relevant in estimating weisz-prater criterion or Thiele modulus for a better comparison in terms of mass transfer with conventional catalyst 
supports. Additionally, it is recommended to consider consecutive reaction as a case study for the estimation of mass transfer properties of CNF supports.

The reaction conditions significantly affect the selectivity to nitrogen or ammonia. The intrinsic selectivity to ammonia increases with decreasing nitrite concentration as well as increasing hydrogen concentration. Furthermore, high $\mathrm{pH}$ and high temperatures also result in higher ammonia selectivity. Selectivity is also influenced by internal concentration gradients along the catalyst particle. Concentration gradients cause increasing selectivity to ammonia. Remarkably, catalysts supported on carbon are more selective to ammonia as compared to oxidic supports. We propose that for diffusion limited graphite and activated carbon catalysts, the electrical conductivity of the carbon support increases the hydrogen surface coverage of $\mathrm{Pd}$ particles deep in the support particles, at the same time increasing the proton internal gradient; both effects are favoring ammonia formation.

Pd particle size effect on nitrite activity and selectivity towards ammonia or nitrogen was studied by immobilizing Pd colloids stabilized with polyvinylalcohol over CNFs. A narrow particle size distribution and averaged sizes of 2.7, 4.4, 10.8 and $29.8 \mathrm{~nm}$ were achieved. Characterization with CO chemisorption and transmission electron microscopy revealed that significant part of Pd surface is blocked by a polymer layer. Pd catalysts were tested for nitrite reduction in water resulting in nitrogen and ammonia. The rate of nitrite reduction per active site is relatively low at Pd particles size less than $5 \mathrm{~nm}$. We suggest that low coordination sites in small particles are less effective for nitrite activation as compared to terrace sites. The selectivity towards ammonia decrease with increasing Pd particles size, suggesting selectivity towards ammonia is structure dependent. We suggest this is due to increased activity of low coordination sites for deep hydrogenation favor ammonia formation

It is recommended to estimate the precise dispersion of Pd colloids to evaluate the real dispersion effect on TOFs and selectivity. Additionally, careful removal of polymer layer is necessary preserving the narrow particle size distribution.

The final part of the thesis is focused on developing thin layers of CNFs on silicon wafers for the use as catalyst support in micro-channel reactor. Thin layer of CNFs has been synthesized on Rh based thin films by decomposing ethylene in the 
presence of hydrogen at $600^{\circ} \mathrm{C}$. Pretreatment of Rh layer at $600^{\circ} \mathrm{C}$ resulted in sintering of grains. Deposition of carbon on Rh grains resulted in fragmentation of grains to smaller particles favoring the CNF growth. Maximum CNF growth was achieved at intermediate hydrogen concentrations. Effect of hydrogen is well understood in terms of competitive adsorption of hydrogen and ethylene affecting the availability of carbon to the Rh surface. Rh catalyzed CNFs demonstrated a fishbone structure and (sub-) surface diffusion of carbon is suggested as the CNF growth mechanism over Rh metals.

The rate of CNF growth over Rh metal (chapter 7) is very low compared to $\mathrm{Ni}$ metal particles (chapter 3). For this reason it is recommended to explore alternative metals which provide maximum CNF growth. It is recommended to select sufficient thickness of active metal layer on wafer for the growth of CNF. Lower loadings of active metal can lead to less CNF growth lowering the specific surface area per volume of reactor, whereas, higher loading of active metal can lead to excess growth of CNFs lowering the macro pore volume. Excess amount of active metal can also lead to incomplete use of active metal as observed in chapter 7. 


\section{References}

[1] K.B.K. Teo, C. Singh, M. Chhowalla, W.I. Milne, Encyclopedia of Nanoscience and Nanotechnology X (2003) 1-22.

[2] M.L. Toebes, T.A. Nijhuis, J. Hájek, J.H. Bitter, A.J. van Dillen, D. Yu. Murzin, K.P. de Jong, Chem. Eng. Sci. 60 (2005) 5682-5695.

[3] A.J. Plomp, H. Vuori, A. O.I. Krause, K.P. de Jong, J.H. Bitter, Appl. Catal. A 351 (2008) 9-15. 



\section{Summary}

Catalytic multiphase reactors are at the heart of many chemical industries. They allow efficient contact between gas and/or liquid reactant phases with solid catalysts increasing reaction rates. In practice, the higher reaction rates can be taken advantage of only under the condition that the transfer of mass (reactant and products) can keep up with the intrinsic activity of the catalysts used. In the case where mass transfer is relatively slow, concentration gradients will occur, especially in the pore system of a heterogeneous catalyst. Concentration gradients will also induce loss in selectivity and byproducts are usually formed via reaction networks that often contain parallel and consecutive reactions. Concentration gradients may thus prevent optimal operation because the active catalytic sites experience different concentrations and at least a part of the active sites operates under nonoptimal conditions. This problem is most relevant when gases (e.g., hydrogen or oxygen) have to be dissolved in a liquid (e.g., water) resulting in low concentrations. This coupled with the low diffusivity of gases in liquids cause concentration gradients to occur even more easily. Conventional multiphase reactors such as slurry phase reactor offers efficient mass transfer but the rate per unit volume of the reactor is low and the cost for catalyst separation is high. Whereas, trickle bed reactor pose mass transfer limitations, pressure drop and fluid maldistribution. Structured reactors, especially foam type internals exhibit low pressure drop and reduce fluid maldistribution. However, structured internals have low specific surface area and this can be improved by developing thin layer of carbon nanofibers (CNFs) on the surface of the support. Thin layer of CNFs offers high surface, high porosity and low tortuosity, maximizing the mass transfer rate which is particularly important for heterogeneous catalytic reactions in liquid phase. The research described in this thesis is focused on preparing a CNF layer on a structured foam support (termed as 'Hairy foam') and then evaluating the performance of hairy foam catalyst in comparison to conventional porous catalysts.

First part of the thesis is focused on preparing a stable CNF layer on structured foam support. Ni foam, which is intrinsically active for the growth of CNF was used in this study. A stable CNF layer was developed on Ni foam by decomposing ethylene at $440^{\circ} \mathrm{C}$ for $1 \mathrm{~h}$ and the surface area of the carbon deposited was $\sim 90 \mathrm{~m}^{2} \mathrm{~g}^{-1}$. Chapter 2 
describes attachment of a stable CNF layer to Ni foam. Microscopic study revealed the formation of two layers, a $\sim 4 \mu \mathrm{m}$ microporous carbon layer (C-layer) and a $\sim 30 \mu \mathrm{m}$ CNF layer on top of C-layer. Monitoring the formation of these two layers for a period of 60mins suggests they develop in parallel. Characterization of these carbon deposits suggest that both the layers are graphite in nature and the CNFs are well crystalline compared to C-layer. The CNFs are strongly attached to $\mathrm{Ni}$ foam by penetrating into the carbon layer, which itself is attached strongly to the metal surface. The interconnections between Ni surface, C-layer and CNFs result in mechanical stability.

Chapter 3 describes the effect of hydrogen on the properties of CNFs formed on Ni foam. Increasing hydrogen concentration (upto 14\%) resulted in carbon with increasing surface area. At lower hydrogen concentration the thickness of CNF layer is more than 1.5 times higher compared to CNF layer formed in the absence of hydrogen. These effects were understood in terms of competitive adsorption of hydrogen and ethylene, influencing the availability of carbon on the Ni surface, which is necessary for both the formation of small $\mathrm{Ni}$ particles by fragmentation of polycrystalline $\mathrm{Ni}$, as well as for CNF-growth after formation of small particles. Furthermore, decreasing the carbon supply limits the deactivation of Ni particle. The thickness of the micro-porous C-layer between the Ni surface and the CNF layer decreases with hydrogen addition, at the expense of a slight loss in the attachment of the CNFs to the foam, supporting the proposition suggested in chapter 2 that CNFs are attached by roots in the C-layer.

The performance of hairy foam catalyst over conventional porous catalysts for hydrogenation of nitrite to nitrogen and ammonia is described in chapter 4. Palladium active metal was deposited on CNF based catalysts such as hairy foams and CNF aggregates, and on conventional catalysts such as alumina, silica, activated carbon and graphite. All the catalysts were prepared with similar Pd particle size and similar particle size distribution to exclude any geometric and/or electron effects on the reaction. Intrinsic rates over hairy foam catalysts were independent of CNF layer thickness (8-28 $\mu \mathrm{m})$ and Pd loading, demonstrating the absence of any mass transfer limitations. At comparable diffusion lengths, CNF based catalysts show three times higher rates of nitrite conversion per mole of surface palladium (TOF). Increased TOF 
is due to the improved mass transfer provided by macroporous structure of the entangled CNFs, which offers low tortuosity, provides accessibility to all the active sites. The intrinsic activity of graphite and CNF supported Pd contributes significantly to the high activity for nitrite reduction.

The effect of reaction conditions and nature of the support on the selectivity during nitrite reduction is described in chapter 5 . The intrinsic selectivity to ammonia increases with decreasing nitrite concentration as well as increasing hydrogen concentration. Furthermore, high $\mathrm{pH}$ and high temperatures also result in higher ammonia selectivity. Internal concentration gradients influence the selectivity significantly. Gradients of protons and nitrite are responsible for increasing ammonia selectivity. Carbon based catalysts were more selective towards ammonia as compared to oxidic supports. It is proposed that for diffusion limited graphite and activated carbon catalysts, the electrical conductivity of the carbon support increases the hydrogen surface coverage of Pd particles deep in the support particles, at the same time increasing the proton internal gradient; both effects are favoring ammonia formation.

Effect of Pd particle size on activity for nitrite reduction and selectivity to ammonia or nitrogen is described in chapter 6. Pd colloids stabilized with polyvinylalcohol were immobilized over CNFs. Averaged Pd sizes of 2.7, 4.4, 10.8 and $29.8 \mathrm{~nm}$ with a narrow particle size were achieved. Characteristic studies with CO-chemisorption and transmission electron microscopy (TEM) revealed that a significant part of the Pd surface is blocked by the polymer layer on the Pd particles. The rate of nitrite reduction per active site is relatively low at Pd particles size less than $5 \mathrm{~nm}$. It is suggested that low coordination sites in small particles are less effective for nitrite activation as compared to terrace sites. The selectivity towards ammonia appears structure sensitive for the complete window of particle sizes in this study. We suggest this is due to increased activity of low coordination sites for deep hydrogenation favoring ammonia formation.

Chapter 7 describes preparation of thin layer of CNFs on silicon wafers for the use as catalyst support in micro-channel reactor. Thin layer of CNFs has been synthesized on Rh based thin films by decomposing ethylene in the presence of 
hydrogen at $600^{\circ} \mathrm{C}$. Deposition of carbon on Rh grains resulted in fragmentation of grains to smaller particles favoring the CNF growth. Maximum CNF growth can be was achieved at intermediate hydrogen concentrations. Effect of hydrogen is well understood in terms of competitive adsorption of hydrogen and ethylene affecting the availability of carbon to the Rh surface. Rh catalyzed CNFs demonstrated a fishbone structure and (sub-) surface diffusion of carbon is suggested as the CNF growth mechanism over Rh metals.

The findings and understandings in this study namely the stability of CNF layer and the superior performance of CNF based catalyst in terms of efficient mass transfer provides scope to use CNFs as catalyst support for fast three phase catalytic reaction. 


\section{Samenvatting}

Katalytische meerfase reactoren vormen het hart van een groot aantal chemische processen. In dit type reactoren is een efficiënt contact mogelijk tussen reactanten in de gas en/of vloeistof fase waarbij vaste fase katalysatoren de reactie versnellen. In de praktijk kunnen deze hogere reactie snelheden alleen behaald worden als de massa overdracht van de reactanten en producten minstens gelijk is aan de intrinsieke activiteit van de gebruikte katalysator. Concentratie gradiënten ontstaan wanneer de massa overdracht relatief langzaam is en dit geldt in het bijzonder in de poriën van heterogene katalysatoren. Concentratie gradiënten zorgen er ook voor dat de selectiviteit daalt door de vorming van bijproducten die gewoonlijk gevormd worden via reactie netwerken die vaak bestaan uit parallelle of opeenvolgende reacties. Concentratie gradiënten kunnen dus een optimale reactie in de weg staan omdat de actieve katalytische sites de reacties katalyseren bij verschillende concentraties. Dit heeft tot gevolg dat er reacties plaats vinden op katalytische sites onder niet ideale omstandigheden. Dit probleem is vooral relevant wanneer gassen (bijv. waterstof of zuurstof) opgelost dienen te worden in een vloeistof (bijv. water). Het oplossen van deze gassen zorgt voor lage concentraties van deze stoffen in de vloeistof. Dit gekoppeld met de lage diffusie snelheden van gassen in vloeistoffen zorgt ervoor dat concentratie gradiënten nog makkelijker ontstaan. Conventionele meerfase reactoren, zoals een slurry fase reactor, bieden efficiënte massa overdracht eigenschappen maar de snelheid per reactor volume eenheid is laag en de kosten van het terugwinnen/scheiden van de katalysator zijn hoog. Trickle bed reactoren staan bekend om de massa overdracht limiteringen, drukval en slechte vloeistof distributie in deze reactoren. Gestructureerde reactoren (en vooral schuim type vullingen) hebben de voordelen van een lagere drukval en hebben minder last van slechte vloeistof distributie maar deze gestructureerde vullingen hebben echter een laag specifiek oppervlak. Dit specifieke oppervlak kan verbeterd worden door het ontwikkelen van een dunne laag van koolstofnanodraden (CNF's) op het oppervlak van de drager. Dunne laag CNF's hebben een groot oppervlak, zijn erg poreus en hebben een lage tortuositeit. Hierdoor wordt de massa overdracht gemaximaliseerd en dit is vooral belangrijk voor heterogene gekatalyseerde reacties in de vloeibare fase. Het onderzoek gepresenteerd in dit proefschrift is voornamelijk gericht op het maken van 
de CNF laag op een gestructureerde schuim drager (wordt aangeduid met de term "Harig schuim”). Verder worden de katalytische eigenschappen van deze harige schuim katalysatoren vergeleken met conventionele poreuze katalysatoren.

Het eerste deel van het proefschrift richt zich op het bereiden van een stabiele CNF laag op een gestructureerde schuim drager. In dit onderzoek is nikkel schuim gebruikt omdat het intrinsiek actief is voor het groeien van CNF's. Een stabiele CNF laag op Nikkel schuim is verkregen door het ontleden van ethyleen bij $440^{\circ} \mathrm{C}$ gedurende 1 uur. Met gedeposeerde koolstof had een oppervlak van rond de $90 \mathrm{~m}^{2} / \mathrm{g}$. Hoofdstuk 2 beschrijft hoe deze stabiele CNF laag gebonden is aan het Nikkel schuim. Microscopisch onderzoek toonde aan dat er twee lagen gevormd waren, een $\sim 4 \mu \mathrm{m}$ microporeuze koolstof laag (C-laag) waarop een $\sim 30 \mu \mathrm{m}$ CNF laag was gevormd. De vorming van deze twee lagen is bestudeerd gedurende 60 minuten en de resultaten wijzen erop dat beide lagen gelijktijdig gevormd worden. Karakterisatie van de koolstof deposities wijzen erop dat beide lagen bestaan uit grafiet waarbij de CNF's een hoge kristalliniteit hebben vergeleken bij de C-laag. De CNF's zijn zeer sterk gebonden aan het Nikkel schuim doordat ze de koolstof laag penetreren (de koolstof laag is weer sterk gebonden aan het metaal oppervlak). De verbindingen tussen het Nikkel oppervlak, C-laag en de CNF's zorgen voor een hoge mechanische stabiliteit.

Hoofdstuk 3 beschrijft het effect van waterstof op de eigenschappen van de gevormde CNF's op het Nikkel schuim. Het gebruik van hogere waterstof concentraties (tot aan 14\%) resulteerde in koolstof met grotere oppervlakten. Bij lage waterstof concentraties werd er een CNF laag gevormd die meer dan 1.5 keer zo dik was vergeleken bij de CNF laag die gevormd werd zonder waterstof. Deze effecten zijn verklaard in termen van competitieve waterstof en ethyleen adsorptie die de toegankelijkheid van met koolstof op het Nikkel oppervlak beïnvloeden. Het controleren van de toegankelijkheid van met koolstof op het Nikkel is noodzakelijk voor zowel de vorming van kleine Nikkel deeltjes door de fragmentatie van polykristallijn Nikkel als ook voor het groeien van CNF's op deze kleinere Nikkel deeltjes. Verder is aangetoond dat het verminderen van de toevoer van de koolstof een limiterend effect heeft op de deactivatie van de Nikkel deeltjes. De dikte van de micro poreuze C-laag tussen het Nikkel oppervlak en de CNF laag wordt kleiner in de 
aanwezigheid van waterstof maar dit heeft een gering verlies aan bindingssterkte van de CNF's aan het schuim tot gevolg. Deze bevindingen steunen het voorstel gedaan in hoofdstuk 2 dat CNF's vastzitten aan de C-laag via CNF wortels.

De prestaties van de harige schuim katalysator worden vergeleken met de conventionele poreuze katalysatoren voor de hydrogenatie van nitriet naar stikstof en ammonia en deze worden beschreven in hoofdstuk 4. Palladium actief metaal is aangebracht op de CNF gebaseerde katalysatoren zoals harig schuim en CNF aggregaten en ook op conventionele katalysatoren zoals alumina, silica, geactiveerd koolstof en grafiet. Al deze katalysatoren zijn bereid met vergelijkbare $\mathrm{Pd}$ deeltjesgrootte en deeltjesgrootteverdeling zodat geometrische en/of elektronische effecten voorkomen worden. Intrinsieke snelheden van harige schuim katalysatoren bleken onafhankelijk te zijn van de CNF laag dikte $(8-28 \mu \mathrm{m})$ en Pd belading. Dit toont aan dat er geen massa overdracht limiteringen aanwezig waren. Bij vergelijkbare diffusie lengten toonden CNF gebaseerde katalysatoren een drie maal hogere snelheid voor de omzetting van nitriet per mol of oppervlakte Palladium (TOF). Deze verhoogde TOF is veroorzaakt door de verbeterde massa overdracht in de macroporeuze vervlochten structuur van de CNF's. Hierdoor wordt een lage tortuositeit verkregen en zijn alle actieve sites toegankelijk. De intrinsieke activiteit van grafiet en Pd/CNF draagt significant bij aan de hoge activiteit voor de reductie van nitriet.

Het effect van de reactie condities en het dragermateriaal op de selectiviteit van nitriet reductie is beschreven in hoofdstuk 5. De intrinsieke selectiviteit naar ammonia neemt toe met zowel afnemende nitriet concentraties als toenemende waterstof concentraties. Een hogere $\mathrm{pH}$ en hogere temperaturen zorgen ook voor een toenemende selectiviteit naar ammonia. Interne concentratie gradiënten beïnvloeden de selectiviteit aanmerkelijk. Gradiënten van protonen en nitriet zijn verantwoordelijk voor een hogere ammonia selectiviteit. Koolstof gebaseerde katalysatoren waren selectiever naar ammonia vergeleken met oxide dragers. De elektrische conductiviteit van het diffusie gelimiteerd grafiet en geactiveerd koolstof kan er gelijktijdig voor zorgen dat zowel de waterstof bezetting op het oppervlak van Pd deeltjes, die zich diep in de drager bevinden, als de interne proton gradiënt toenemen; beide effecten begunstigen de vorming van ammonia. 
Het effect van de Pd deeltjesgrootte op de activiteit voor nitriet reductie en selectiviteit naar ammonia en stikstof is beschreven in hoofdstuk 6. Polyvinylalcohol gestabiliseerde Pd colloïden werden geïmmobiliseerd op CNF's. Pd deeltjes van gemiddeld 2.7, 4.4, 10.8 en 29.8nm met een smalle deeltjesgrootteverdeling werden op deze manier verkregen. Karakterisering met TEM en CO-chemiesorptie toonden aan dat een overgroot deel van het Pd oppervlak geblokkeerd is door de polymeer laag op de Pd deeltjes. De snelheid van de nitriet reductie per actieve site is relatief laag voor Pd deeltjes beneden de 5nm. Er wordt aangedragen dat de lage coördinatie sites in de kleine Pd deeltjes minder effectief zijn voor nitriet reductie vergeleken met de plateau sites. De selectiviteit naar ammonia blijkt voor alle bestudeerde Pd deeltjesgrootte in deze studie structuur afhankelijk te zijn. We denken dat dit veroorzaakt wordt door de verhoogde activiteit van lage coördinatie sites voor diepe hydrogenatie waarbij de vorming van ammonia gunstig is.

Hoofdstuk 7 beschrijft de bereiding van een dunne CNF laag op silicon wafers en zullen gebruikt worden als katalytisch drager materiaal in micro-channel reactoren. Dunne laag CNF's zijn gesynthetiseerd op Rh gebaseerde dunne films door het ontleden van ethyleen in de aanwezigheid van waterstof bij $600^{\circ} \mathrm{C}$. Koolstof depositie op $\mathrm{Rh}$ korrels resulteerde in fragmentatie van deze korrels in kleinere deeltjes welke gunstig bleken te zijn voor de groei van CNF's. Maximale CNF groei was bereikt bij tussenliggende waterstof concentraties. Het effect van de waterstof concentratie wordt uitgelegd in termen van competitieve adsorptie van waterstof en ethyleen en dit beïnvloedt de beschikbaarheid van koolstof op het Rh oppervlak. Rh gekatalyseerde CNF's hadden een visgraat structuur en (sub) oppervlakte diffusie van koolstof wordt voorgesteld als mechanisme voor CNF groei van Rh metaal.

De resultaten en kennis verkregen tijdens dit onderzoek bieden met name op het gebied van de stabiliteit van de CNF laag en de superieure prestaties van de CNF gebaseerde katalysator (in termen van efficiënte massa overdracht) interessante perspectieven voor het gebruik van CNF's als katalytisch drager materiaal voor snelle drie fase gekatalyseerde reacties. 


\section{Publications}

\section{Journal Papers}

- J.K. Chinthaginjala, K. Seshan and L. Lefferts. Preparation and application of CarbonNanoFiber based microstructured materials as catalyst supports, Industrial \& Engineering Chemistry Research 2007, 46, 3968.

- J.K. Chinthaginjala, D.B. Thakur, K. Seshan and L. Lefferts. How Carbon Nano-fibers attach to Ni foam, Carbon 2008, 46, 1638.

- Agiral, A.W. Groenland, J.K. Chinthaginjala, K. Seshan, L. Lefferts and J.G.E.H. Gardeniers. On-chip microplasma reactors with Carbon Nano-fibers and $\mathrm{W}_{18} \mathrm{O}_{19}$ Nanowires as electrodes, Journal of Physics D: Applied Physics 2008, 41, 194009.

- J.K. Chinthaginjala, L. Lefferts. Influence of hydrogen on the formation of a thin layer of carbon nanofibers on Ni foam, Carbon 2009, 47, 3175.

- J.K. Chinthaginjala, H. Bitter and L. Lefferts. Thin layer of carbon nanofibers as catalyst support for fast mass transfer in hydrogenation of nitrite, Applied Catalysis A 2010 (accepted).

- J.K. Chinthaginjala and L. Lefferts. Support effect on selectivity of nitrite reduction in water, Applied Catalysis B (submitted).

- J.K. Chinthaginjala, A. Villa, D. Su and L. Lefferts. Nitrite reduction over Pd supported carbon nanofibers: particle size effect (in preparation).

- J.K. Chinthaginjala, S. Unnikrishnan and L. Lefferts. Rhodium catalyzed growth of carbon nanofibers (in preparation).

- H.C. Aran, J.K. Chinthaginjala, R. Groote, T. Roelofs, L. Lefferts, M. Wessling and R.G.H. Lammertink. Porous ceramic mesoreactors: A new approach for gas-liquid contacting in multiphase microreaction technology (in preparation). 


\section{Oral Presentations}

- J.K. Chinthaginjala, D.B. Thakur, K. Seshan and L. Lefferts. How Carbon-NanoFibers attach on Ni foam, $9^{\text {th }}$ Netherlands Catalysis \& Chemistry Conference 2008, The Netherlands.

- J.K. Chinthaginjala, K. Seshan and L. Lefferts. Hairy foam catalyst: A new structured catalyst support, $3^{\text {rd }}$ International Symposium on Carbon for Catalysis 2008, Germany.

- J.K. Chinthaginjala and L.Lefferts. Hairy foam: Novel catalyst support for fast mass transfer in liquid phase catalytic reactions, $10^{\text {th }}$ Netherlands Catalysis \& Chemistry Conference 2009, The Netherlands.

- J.K. Chinthaginjala and L. Lefferts. Carbon nanofibers as catalyst support for efficient mass transfer in liquid phase catalytic reactions, North American Catalysis Society Meeting 2009, USA.

- J.K. Chinthaginjala and L. Lefferts. Hairy foam catalysts for fast mass transfer in liquid phase catalytic reactions, $3^{\text {rd }}$ International Conference on Structured Catalysts and Reactors 2009, Italy.

- H.C. Aran, J.K. Chinthaginjala, D. Salamon, R.G.H. Lammertink, L. Lefferts and M. Wessling. Porous ceramic microreactors for multiphase reaction systems, IMRET 2010 Japan. 


\section{Acknowledgements}

The time has come to look back and acknowledge each and everyone who was associated with me professionally and socially during this memorable $\mathrm{PhD}$ journey.

At first, I would like to express my sincerest gratitude to my professor, Leon Lefferts, for giving me the opportunity to pursue research in his group. Leon, thank you for your guidance and patience. It would have been very difficult without your support. Special thanks for teaching me the 'critical approach' which assisted me in making my research valuable and relevant.

Seshan and Jayanthi, your support and care in the last years mean a lot to me. Seshan, apart from your supervision during the first years of my $\mathrm{PhD}$ you have been a great friend to me. Your cool character, willingness to discuss anything anytime and your valuable suggestions helped me professionally and personally. I really enjoyed your company at the conference in Seoul, the Friday borrels and watching cricket. Jayanthi, thanks for your hospitality and for many dinner invitations which made me feel at home.

Barbara, you are like a spark. Though your work time is limited, your presence always gives me a flash of cheerful mood and positive feeling. I was also very much impressed with your novel scientific ideas.

Igor and (Abu-) Bert; I really enjoyed your company throughout my $\mathrm{PhD}$ journey. Crazy Friday borrels and private coffee breaks are memorable. Igor, special thanks for your scientific advice whenever needed. Abu Bert, special appreciation for your technical support, image editing and Dutch translations; without your help many things would have been difficult in Enschede.

Arie; thanks for your amicable nature and at times, your big laugh, which acted like a brief laughing therapy during the stressful moments of my $\mathrm{PhD}$. Jan, thanks for the stories of your diving experiences, always a treat to hear. Karin, I appreciate your kind support in the lab and special thanks for your warm nature, nice chats and organizing CPM group dinners. Louise; I acknowledge your cordial nature and quick measurements whenever required. Lianne, I appreciate your charming spirit and understanding nature. Sabine, thanks for sharing interesting topics during lunch time. 
My special thanks to Mark for being supportive and friendly during SEM analysis, which was a major characterization tool in my thesis. I also acknowledge Rico and Gerard for TEM and XPS characterizations.

The stay in Netherlands would have been incomplete without my CPM and foreign friends at UT. Cri and Dav, we share fabulous friendship and wonderful memories starting from science, dinner, parties, trips, crazy discussions and many more. Thanks for getting me acquainted with European culture, especially Italian cuisine. Dejan, 'the fighter'; you have been an excellent example for me in many ways. I have really enjoyed your company, thanks for being a wonderful friend. Gacia, we shared the same office and also many ideas. I acknowledge your support during the stressful moments in my $\mathrm{PhD}$ and your good friendship. Hrudya, my little Indian friend, I always enjoyed listening to your stories and many more conversations. Marijana, the laughing bee; thanks for your friendship and interesting conversations, both personally and professionally. I wouldn't forget the trips we planned, which never accomplished $(-)$. Dennis, you are a special Dutch friend for me, always enjoyed our talks about Dutch and Indian cultural and cuisine differences. Digvijay, you have been an Indian companion to me in our group; sharing the same room either in the conference or during the group trips. Thanks for sharing your ideas all these years. Berta, we started at the same time as master's project students in this group and spent five years enjoying social life and exchanged many viewpoints. Thanks for the wonderful experience. Sune, I am grateful for the international dinners at your place, which has given me opportunity to get acquainted to European culture. Iris, thanks for being an excellent officemate and your Brazilian spirit. Kazu, you have inspired me with your Japanese professionalism and a friendly attitude. Your inspiration during the first years of my $\mathrm{PhD}$ is appreciated greatly. Vitto, my fitness partner in Enschede. I had great times with you during our dinners, salsa and late night parties. Thanks for your Italian spirit and your friendship. Can, a cheerful person and faithful friend. I am always amazed with your laidback approach and your Turkish spirit. I am glad that we worked together, which has given me opportunity to develop our friendship. Son, I always enjoyed your presence in the group and your sense of humor. Chris, your witty jokes and cutting British humor has always given me cheerful mood. Željko, I have been amazed with the knowledge your have during our conversations and also appreciate your helping nature whenever needed. Sergio, always enjoyed your black humor and your presence in the group. Inga, your ideas and point of view were impressive; I enjoyed your company in the group. Tom, I always cherish your pleasant humor and proactive nature in the group. Thanks for nice conversations during the coffee breaks and borrels. Ruben, you are a guy who is always there to help in any given situation, thanks for your cheery company. Martine, truly a pleasant 
person to talk to, though your stay was short we had nice conversations during the social breaks. Roman and Liza, our short Sunday conversations in the corridor are always interesting. I would also like to thank some of my ex-colleagues Anil, Khalid, Hans, Patrick, Xiang and Joreon who also made my PhD period memorable. Chau, Masoud, Arturo, Koteswara, Shilpa, Yingnan and Joline, though we know each other for a very short time, I enjoyed your company during our social breaks. I would like to thank Alberto for his contribution in my thesis and my students Noelia and Wouter for their contribution in my research.

The Indian community in The Netherlands has bought me lots of happiness and relaxation. My wholehearted thanks to my good friends and my housemates Sandeep and Srivatsa, you guys have been my family for the last four years. Many wonderful memories and jolly experiences to remember, special thanks for your constant support. Jalaja, thanks for your afternoon tea on Saturdays and dinners during the last months of my $\mathrm{PhD}$, you have been like a 'sister' to me in The Netherlands.

I would like to thank my good friends and cricket buddies Shankar, Raghav, Andy and Balaji for our excellent cricketing experience and joyful conversations, especially Shankar-you have been a role model to me in many ways and Raghav-our private coffee corners are always enjoyable. I would like to thank my good friend and squash partner Ashok for his company. Raghu, you have been an excellent friend, thanks for our nice conversations via phone, which have become more interesting with the introduction of Teja.

I would like to acknowledge Ambati (for our big Indian dinners)-Sangeetha, Pramod-Vishaka, Chandu-Meenakshi for your support and care. I extend my gratitude to many other Indians Giri, Kishore, Anand (Chaaki), Vishnu, Srinath, Mayur, Jigar, Dhaval, Ganesh, Anand (Torti) and Mustafa who made my stay in Enschede memorable.

My friends in India- Jaggu, Malla and Vijju; you guys are my good friends for more than 12years, inbetween many awesome memories. Thanks for your support through out my bachelor life and now in my married life. Gupta, an excellent friend and my cooking guru, your support throughout the masters program and now in $\mathrm{PhD}$ was immense. Bobby, you are always there for me when I come to India on holiday. I always remember our crazy parties. Thanks for your support and friendship when it mattered the most. Gayatri, my very old school friend; thanks for our funny and long distance conversations. 
I would like to thank all those people, whom I have not mentioned but perhaps should have; for making my PhD journey unforgettable.

I would like to thank my family, whom I have missed so much in these years for every festival, birthday and glorious occasion. My dear parents for all their love, encouragement, trust and sacrifices for me. Whatever I am on this day is just a reflection of their hardships and care all these years. My little brother, for our nice conversations over phone and for taking responsibility back home in my absence. My cousin Rakesh, for our long friendship and your availability whenever I am in India. My special gratitude to my wife Lavanya for being so loving, understanding and supportive, especially during the final and stressful moments of my $\mathrm{PhD}$.

Thank you all.

Jitendra Kumar Chinthaginjala June, 2010 


\section{Biography}

Jitendra Kumar Chinthaginjala was born on November $24^{\text {th }} 1979$ in Hyderabad, India. In 2001 he graduated in Chemical Engineering at Jawaharlal Nehru Technological University, Hyderabad. In 2002 he joined masters in Process Technology in Fachhochschule Münster Univeristy of Applied Sciences, Germany. His master's thesis was on 'A new type of structured catalyst for liquid phase application' under the supervision of Prof. L.Lefferts and Prof. K.R.Körff in the group of Catalytic Processes and Materials (CPM) in University of Twente and graduated in November 2004. His quest for knowledge continued when he started his Ph.D. in the group of Prof. L.Lefferts on the title 'Hairy foam: thin layers of carbon nanofibers as catalyst support for liquid phase reactions' at University of Twente in February 2005. From October 2009, he is working as a post doctorate in Thermo-Chemical Conversion of Biomass group at University of Twente on the topic 'Catalytic hydrothermal generation of hydrogen from aqueous biomass streams: Integration with a crude oil refinery’. 


\section{$4 y^{3}$}

$-2.23 x^{2}$
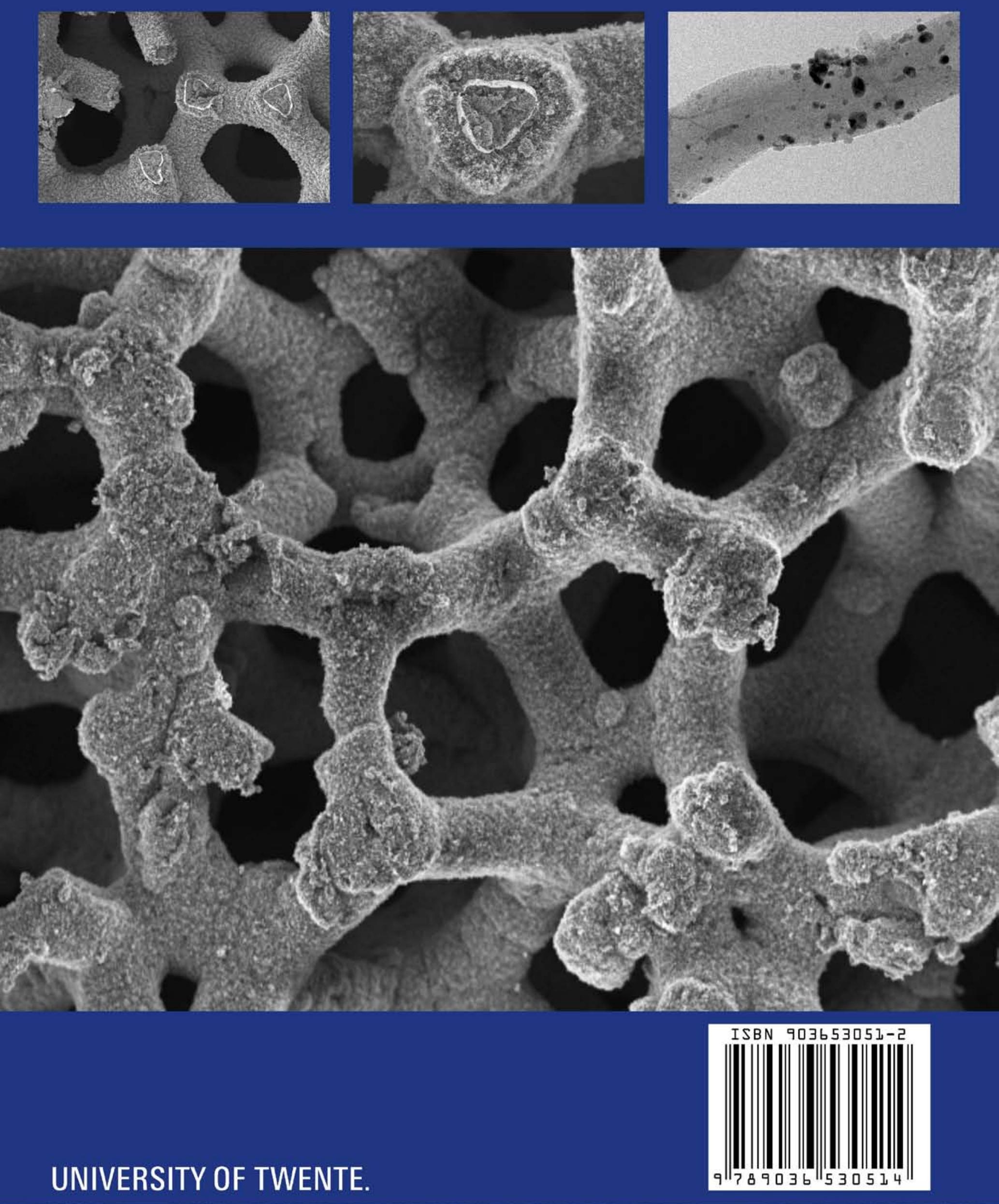

UNIVERSITY OF TWENTE. 